LUCIANO RIBEIRO PINTO CONSOLI

ANÁLISE DO COMPORTAMENTO DINÂMICO LATERAL DE UM VEÍCULO FERROVIÁRIO 
LUCIANO RIBEIRO PINTO CONSOLI

\section{ANÁLISE DO COMPORTAMENTO DINÂMICO LATERAL DE UM VEÍCULO FERROVIÁRIO}


LUCIANO RIBEIRO PINTO CONSOLI

\title{
ANÁLISE DO COMPORTAMENTO DINÂMICO LATERAL DE UM VEÍCULO FERROVIÁRIO
}

\author{
Dissertação apresentada à Escola \\ Politécnica da Universidade de São \\ Paulo para obtenção do título de Mestre \\ em Engenharia Mecânica. \\ Área de concentração: Dinâmica e \\ Controle \\ Orientador: Prof. Dr. Roberto Spinola \\ Barbosa
}




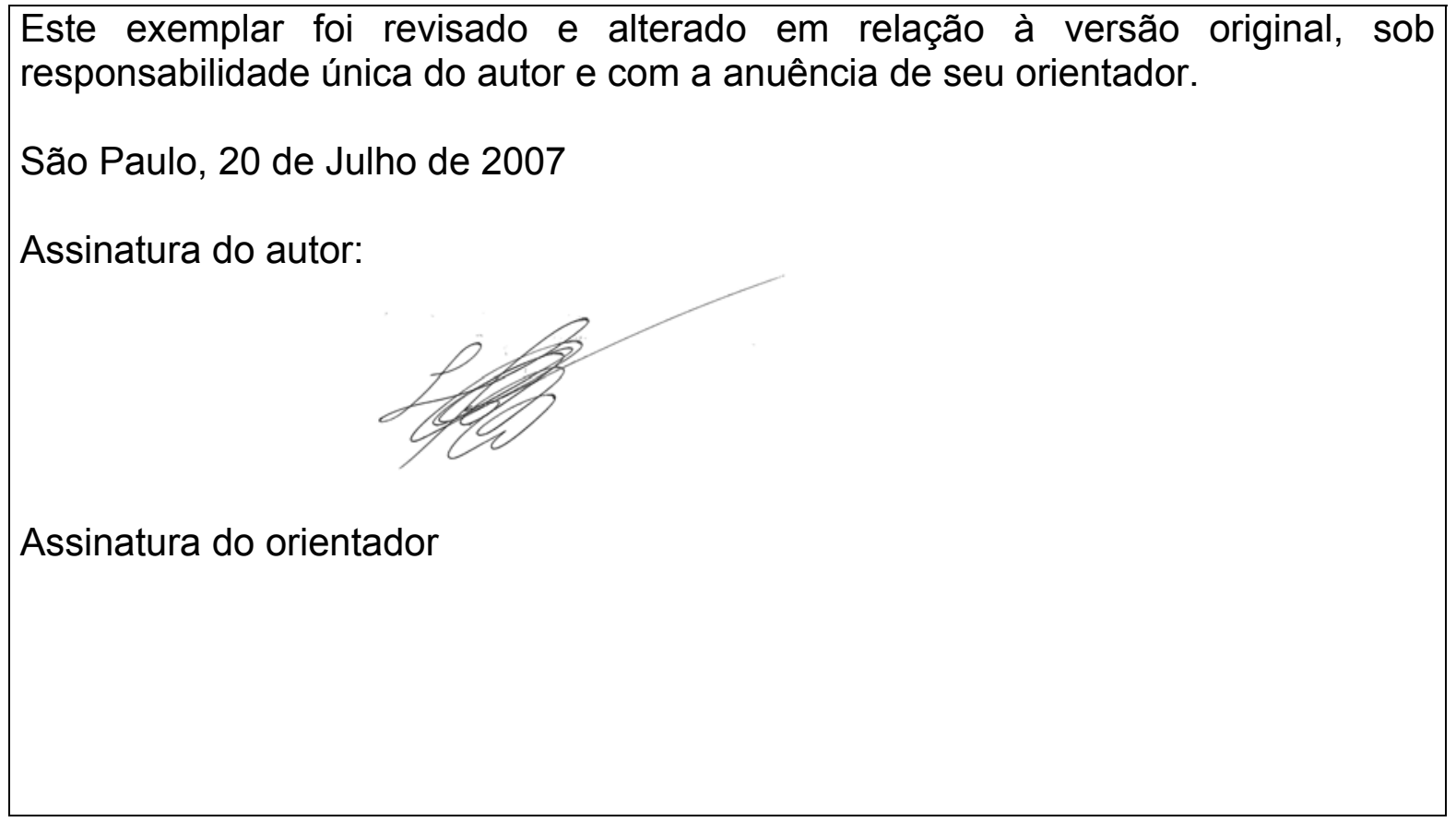

Ficha Catalográfica

Consoli, Luciano Ribeiro Pinto

Análise do comportamento dinâmico lateral de um veículo ferroviário / L.R.P. Consoli. -- São Paulo, 2007. $158 \mathrm{p}$.

Dissertação (Mestrado) - Escola Politécnica da Universidade de São Paulo. Departamento de Engenharia Mecânica.

1.Dinâmica veicular 2.Ferrovias 3.Suspensão mecânica (Si-mulação) 4.Conforto veicular I.Universidade de São Paulo. Escola Politécnica. Departamento de Engenharia Mecânica II.t. 


\section{Dedicatória}

A Charlotte, minha esposa,

à minha filha que está a caminho,

ao meu irmão Marco Antônio,

e a Nossa Senhora de Kazan (Казанской Божией Матери). 


\section{Agradecimentos}

Gostaria de agradecer ao Professor Dr. Roberto Barbosa Spinola, orientador desta dissertação, pelo suporte técnico-científico, apoio e profissionalismo oferecidos durante todo o desenvolvimento deste trabalho.

Agradeço também à Escola Politécnica da USP pela oportunidade que me proporcionou e manifesto a satisfação de me tornar um de seus ex-alunos.

Não poderia me esquecer da Regina Freitas e de toda sua equipe que me ajudaram nos percalços administrativos que muitas vezes tiveram de ser resolvidos a distância.

Aos meus pais, pela ajuda mesmo havendo um oceano entre nós.

Finalmente, à minha esposa Charlotte pelos inúmeros finais de semana em que ela deixou de viajar, sair, ver os amigos e a familia para que eu pudesse me dedicar à realização desta obra. 
"I have fought the good fight,

I have kept the faith,

I have finished my curse"

2 Timóteo 4: 7 


\section{Resumo}

O propósito desta dissertação consiste em realizar um estudo do comportamento dinâmico lateral da caixa de um veículo ferroviário. Inicialmente fez-se uma abordagem do estado da arte referente à utilização de suspensões pneumáticas, sobre o funcionamento de sistemas de nivelamento, flexibilidade de caixas em análise dinâmica e irregularidades de vias férreas. Em seguida, definiu-se um modelo físico de um veículo ferroviário e, após determinadas simplificações, chegou-se a um sistema de nove graus de liberdade composto de uma caixa e dois truques de um rodeiro cada. Uma vez deduzidas as equações diferenciais de movimento, desenvolveram-se duas soluções capazes de fornecer resultados temporais e no domínio da freqüência. Através da primeira delas, a solução analítica, obtêm-se as respostas em freqüência e temporal dos movimentos lateral, roll e yaw da caixa para excitações de rotação longitudinal dos rodeiros. $\mathrm{O}$ segundo tipo de solução, por integração numérica, possui como excitações de entrada os deslocamentos verticais e rotacionais dos rodeiros e, como saídas, os movimentos nos nove graus de liberdade definidos para o sistema. Outra propriedade da solução por integração numérica é sua capacidade de simular suspensões secundárias lineares e não lineares. $O$ artigo "Manchester Benchmarks for rail vehicle simulation" (IWNICKI, 1999) forneceu os parâmetros que definem o veículo e os princípios de irregularidades da via. Três tipos de comparações foram conduzidas, na primeira delas os resultados da análise modal deste trabalho foram confrontados com os resultados publicados pelos participantes do Benchmark e a proximidade entre eles permite fazer sua validação. O segundo tipo de comparação foi feito entre os resultados temporais das soluções analítica e por integração numérica e, o terceiro, entre simulações por integração numérica utilizando suspensões secundárias lineares e não lineares. Neste último caso, os resultados mostram que a linearização das suspensões secundárias podem ser feitas sem que haja diferenças significativas uma vez que os deslocamentos e ângulos são pequenos. Finalmente, elaborou-se uma análise para verificar a influência da variação da rigidez vertical das suspensões secundárias nas amplitudes, acelerações e no valor médio quadrático da aceleração (rms) dos movimentos laterais da caixa no domínio da freqüência. 
Os resultados obtidos permitem dizer que para a faixa de freqüência de maior sensibilidade do ser humano às vibrações laterais, entre $0,5 \mathrm{~Hz}$ e $2 \mathrm{~Hz}$ segundo a norma ISO 2631, há uma redução das vibrações dos movimentos lateral e roll da caixa, quando tais rijezas são reduzidas. Porém, as conseqüências da variação deste parâmetro nos demais modos de vibrar e na estabilidade do veículo constituem um estudo que pode ser realizado em um trabalho futuro.

Palavras-chave: Dinâmica veicular. Ferrovias. Suspensão mecânica (Simulação). Conforto veicular. 


\begin{abstract}
This master's thesis aims at studying the lateral dynamic behavior of a railway vehicle's bodyshell. First is examined the state of the art related to the use of pneumatic suspensions, to leveling systems' operation, to carbody flexibility's dynamic analysis and to railway's irregularities. The definition of the physical modeling of rail vehicle is carried out, followed by a number of simplifications, from which is defined a system with nine degrees of freedom, made up of a carbody and two bogies with one wheelset each. Once the motion's differential equations are defined, two solutions are carried out, capable of producing results in both time and frequency domains. The first one enables to display time and frequency responses of the carbody lateral displacement, roll and yaw for longitudinal rotation excitations of the wheelsets. The second type of solution that is obtained through numerical integration, deals with rolling and vertical displacement of the wheelsets as input data, and outputs the movements of the nine degrees of freedom defined for the system. The numerical integration solution also has the advantage of being capable of simulating linear as well as non linear secondary suspensions. The article "Manchester Benchmarks for rail simulation" (IWNICKI, 1999) provides the parameters that define the vehicle and the irregularities' principles of the railway. Three types of comparisons were carried out. In the first, the results of this work's modal analysis were confronted to the results published by the participants of the benchmark, and the proximity of them was worth validation. The second type of comparison was made between the time domain results of both analytic and numerical integration solutions, and the third between numerical integration simulations using linear and non linear secondary suspensions. This last comparison show that the linearization of secondary suspensions can be done without afecting the results for small displacements and angles. Finally, an analysis is made up so as to verify how the vertical stiffness of secondary suspension affects the lateral displacement, acceleration and the rootmean-square (rms) accelerations of the carbody in frequency domain. The result of this work allows concluding that in the frequency range of maximal sensibility to the human being to lateral vibrations, that is between $0.5 \mathrm{~Hz}$ and $2 \mathrm{~Hz}$ according to ISO263-1, a decrease of the lateral and roll vibrations of the carbody occurs when
\end{abstract}


this stifness is reduced. However this parameter's variations consequences on other vibration modes and on the vehicle stability could be analyzed in greater depth in a future study.

Key-words: Vehicle dynamics. Railway. Mechanical suspension (Modeling). Vehicle comfort. 


\section{Resumé}

L'objet de ce mémoire de maîtrise est de réaliser l'étude du comportement dynamique latéral de la caisse d'un véhicule ferroviaire. En premier lieu est donné l'état de l'art relatif à l'utilisation de suspensions pneumatiques, au fonctionnement de systèmes de nivellement, à la flexibilité de caisses en analyse dynamique ainsi qu'aux irrégularités des voies ferrées. Ensuite, on définit le modèle physique d'un véhicule ferroviaire et après certaines simplifications, il se dégage un système de neuf degrés de liberté composé d'une caisse et de deux bogies comportant un ensemble de roue chacun. Une fois les équations différentielles du mouvement réduites, deux solutions sont développées, capables de fournir des résultats dans les domaines du temps et de la fréquence. Grâce à la première, la solution analytique, sont obtenues les réponses en fréquence et en temps des mouvements latéraux, roll et yaw de la caisse pour les excitations de rotation longitudinale des ensembles de roues. Le second type de solution, par intégration numérique, a pour excitations d'entrée les déplacements verticaux et de rotation des ensembles de roues, et pour sortie les mouvements des neufs degrés de liberté définis pour le système. Une autre propriété de la solution par intégration numérique est sa capacité à simuler les suspensions secondaires linéaires et non linéaires. L'article "Manchester Benchmarks for rail vehicle simulation" (IWNICKI, 1999) fournit les paramètres qui définissent le véhicule et les principes d'irrégularités de la voie. Trois types de comparaisons ont été conduits. Avec le premier, les résultats de l'analyse modale de ce travail ont été confrontés avec les résultats publiés par les participants du Benchmark, et la proximité de ces résultats permet de valider l'analyse. Le deuxième type de comparaison s'est fait entre les résultats en fonction du temps des solutions analytiques et par intégration numérique, et le troisième entre des simulations par intégration numérique utilisant des suspensions secondaires linéaires et non linéaires. Dans ce dernier cas, les résultats montrent que la linéarisation des suspensions secondaires peut être faite sans qu'il y ait de différences significatives par rapport à un système non linéaire, étant donné que les déplacements et les angles sont petits. Enfin, on construit une analyse pour vérifier l'influence de la variation de la rigidité verticale des suspensions secondaires en amplitudes, des accélérations, 
et, à la valeur moyenne quadratique de l'accélération (rms), des mouvements latéraux de la caisse dans le domaine de la fréquence. Les résultats obtenus permettent de dire que pour la bande de fréquence de plus grande sensibilité pour l'être humain aux vibrations latérales, entre $0,5 \mathrm{~Hz}$ et $2 \mathrm{~Hz}$ selon la norme ISO 2631, il se produit une réduction des vibrations des mouvements latéral et roll de la caisse quand cette rigidité est réduite. Cependant, les conséquences de la variation de ce paramètre sur les autres modes de vibration et sur la stabilité du véhicule restent le sujet d'un travail qui pourra être réalisé dans le futur.

Mots-clés : Dynamique véhicule. Voies ferrées. Suspension mécanique (Simulation). Confort véhicule. 


\section{Sumário}

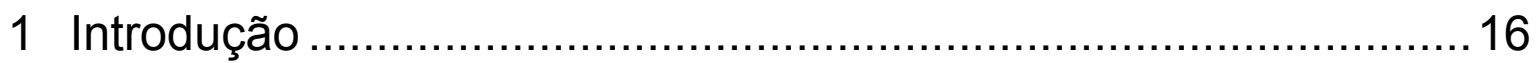

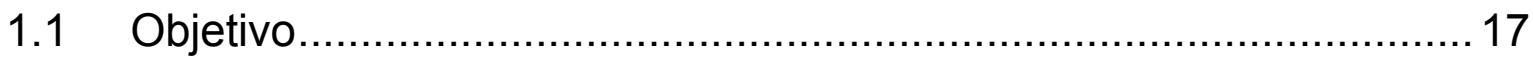

2 Estado da arte ....................................................................... 19

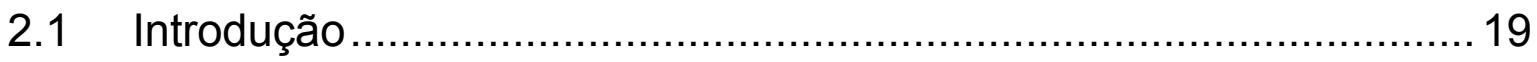

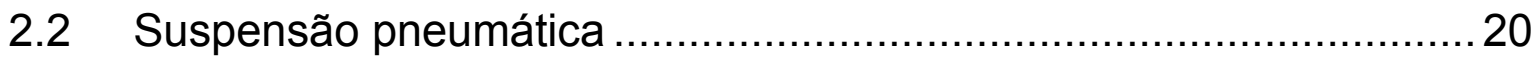

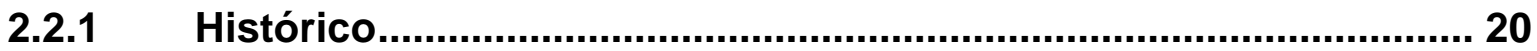

2.2.2 Tipos de suspensões...................................................................... 21

2.2.3 Vantagens e desvantagens das suspensões pneumáticas............. 24

2.2.4 Modelamento de suspensões pneumáticas ................................... 26

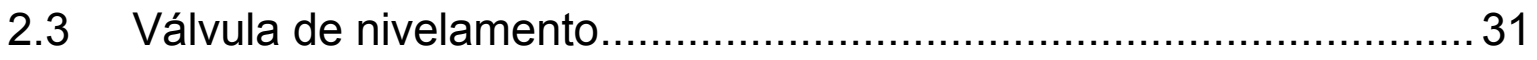

2.4 Flexibilidade da caixa em modelos dinâmicos ................................. 37

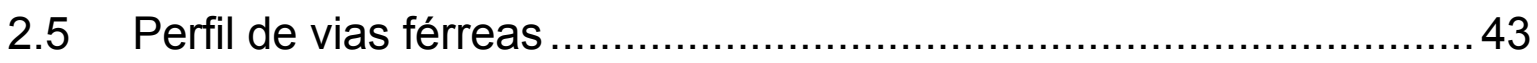

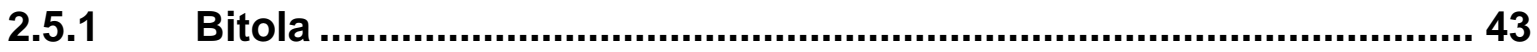

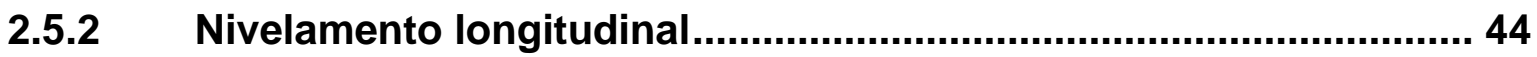

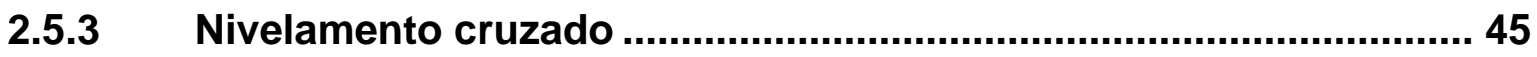

2.5.4 Alinhamento longitudinal ...............................................................4 46

3 Modelagem do veículo ......................................................... 50

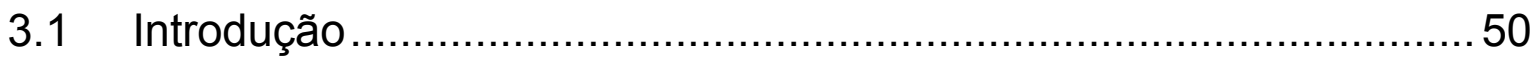

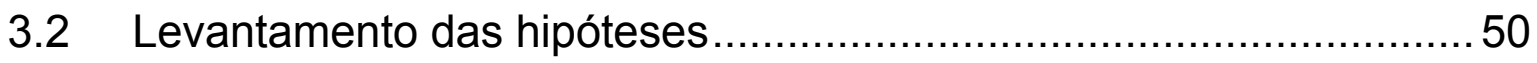

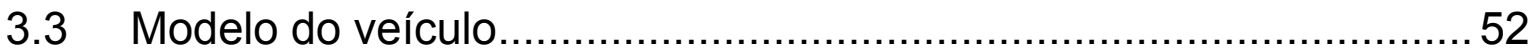

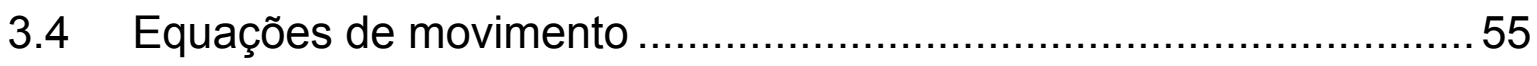

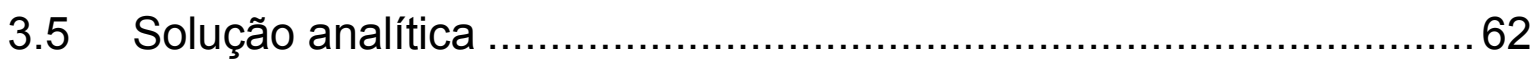

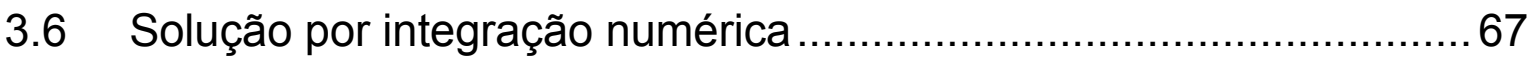

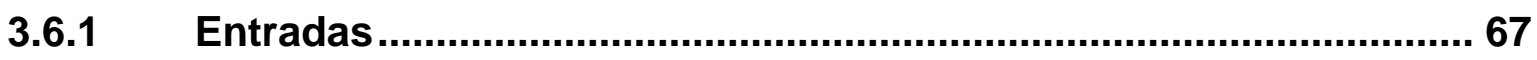

3.6.2 Processamento e saídas ............................................................... 70

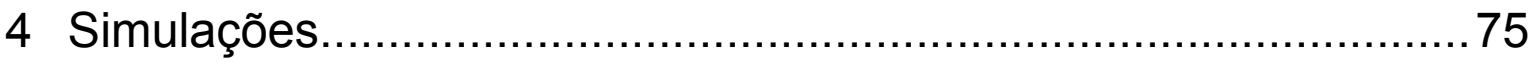

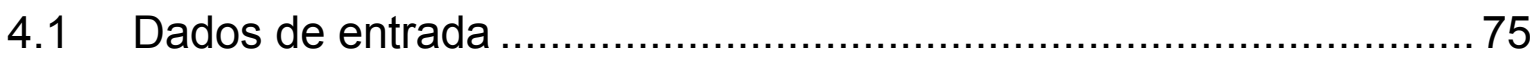

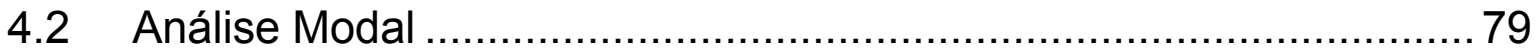

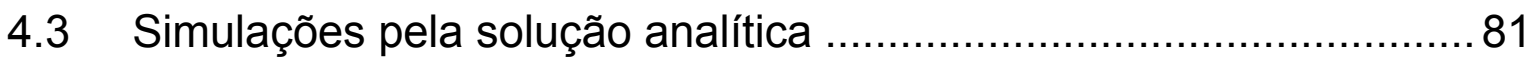

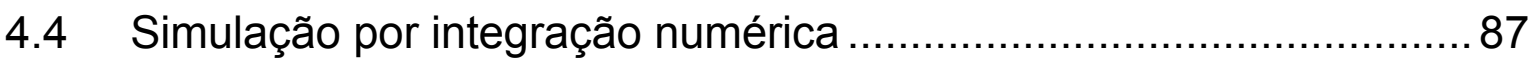




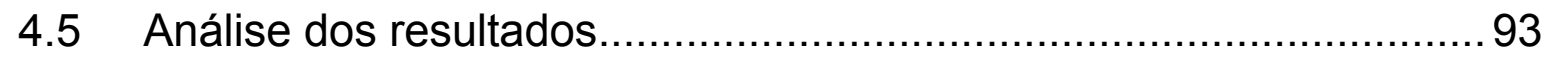

4.6 Considerações sobre o conforto de passageiros .............................. 98

5 Conclusões e Recomendações ............................................. 103

5.1 Sumário das principais conclusões ............................................. 103

5.2 Recomendações para trabalhos futuros ...................................... 105

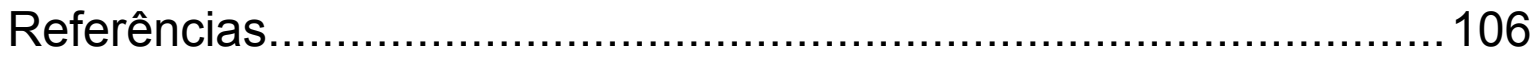

Apêndice A - Suspensões secundárias não lineares .......................111

Apêndice B - Matrizes de massa, rigidez e amortecimento..............116

Apêndice C - Programa de cálculo dos autovetores e autovalores .. 118 Apêndice D - Solução Analítica ................................................. 120

Apêndice E - Resultados da solução analítica ................................125

Apêndice F - Apresentação gráfica da solução analítica .................128

Apêndice G - Apresentação gráfica da solução por integração

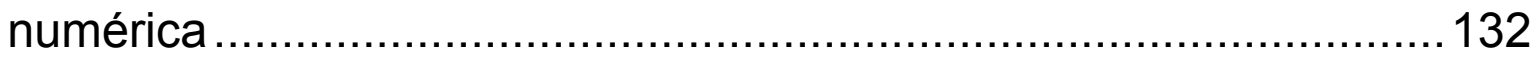

Apêndice $\mathrm{H}$ - Resultados do solução por integração numérica ....... 143

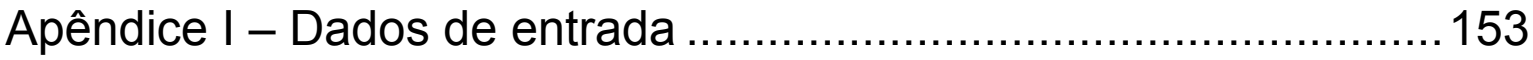

Apêndice $\mathrm{J}$ - Cálculo das curvas de suspensão não linear .............. 155 


\section{Introdução}

Durante a fase de pesquisa bibliográfica desta dissertação, constatou-se que atualmente o foco principal dos trabalhos desenvolvidos com relação aos sistemas de transporte terrestre está no setor automotivo, porém, muito do que é estudado pode também ser aplicado ao transporte ferroviário. Dessa maneira, percebe-se que para ambos os meios de transporte dois assuntos são bastante estudados, sendo eles o comportamento de estabilidade e o conforto de passageiros.

Normalmente os veículos são estáveis a baixas velocidades, à medida que elas aumentam existe um ponto em que eles passam a ser instáveis o que normalmente ocorre em altas freqüências. Tais instabilidades são originadas pelos contatos rodatrilho provenientes das irregularidades da via. Este problema torna-se mais grave nos trens de alta velocidade como o TGV (Train à Grand Vitesse) francês que chega atingir 513 km/h (BARBOSA, 1999). Segundo (RAGHU; KIM; SETOGUCHI, 2002), para percorrer distâncias entre $60 \mathrm{~km}$ e $600 \mathrm{~km}$ o meio de transporte mais rápido são os trens de alta velocidade. Teoricamente a partir de $600 \mathrm{~km}$ os aviões deveriam ser mais rápidos, mas se for levado em consideração o deslocamento até os aeroportos e o tempo de embarque e desembarque, esta distância aumenta significativamente. Considerando igualmente os deslocamentos em centros urbanos feitos por metrô e trens, as distâncias de operação nas quais o transporte ferroviário se torna vantajoso estende-se enormemente. Assim, devido a importância de se aumentar as velocidades e conseqüentemente reduzir o tempo de transporte, muitos trabalhos têm sido publicados a respeito de controle ativo e passivo de suspensões de veículos ferroviários. O sistema passivo é aquele que responde às excitações da via ou outras formas de distúrbio sem atuar diretamente em parâmetros como: inércia, rigidez ou amortecimento. O conceito de sistema ativo consiste em utilizar sensores, controladores e atuadores integrados ao veículo passando por um algoritmo de controle (YAGIZ; GURSEL, 2005).

Com relação ao conforto de passageiros, existem duas faixas de freqüência de vibração nas quais os seres humanos são mais sensíveis. Até a freqüência de 0,5 $\mathrm{Hz}$ ocorrem os problemas de mal-estar onde são ocasionados enjôos e ânsia. De maneira geral, essas vibrações de baixa frequência são encontradas nos mais 
diversos meios de transporte como marítimo (barco e submarino), aéreo (avião e helicóptero), terrestre (automóvel e trem) e animal (elefante e camelo) (FÖRSTBERG, 1990). Na segunda faixa de freqüência, entre $0,5 \mathrm{~Hz}$ e $80 \mathrm{~Hz}$, são ocasionados os problemas de saúde e conforto. Nesse sentido, dois tipos de trabalho relacionado aos veículos ferroviários e rodoviários são publicados atualmente. $\mathrm{O}$ primeiro consiste na melhoria do conforto através do controle ativo e semi-ativo e o segundo na redução das vibrações de forma passiva atuando no sistema de suspensão ou mesmo nos assentos, uma vez que eles são os últimos filtros de atenuação do ponto de vista do usuário.

Nesta dissertação, inicialmente é feito um estudo do estado da arte sobre as suspensões secundárias, as válvulas de nivelamento, a influência de caixas flexíveis nas análises de conforto e as irregularidades da via. Esta análise serve de suporte teórico ao modelamento de veículo ferroviário e a via utilizada nas simulações. Em seguida são propostas duas soluções, uma analítica que faz a análise no domínio da freqüência e outra por integração numérica que fornece os resultados temporais para elementos de suspensão lineares e não lineares. Finalmente é feita uma análise dos resultados obtidos e um sumário das conclusões.

\subsection{Objetivo}

O presente trabalho possui como objetivo o estudo do comportamento dinâmico lateral do compartimento de passageiros de um veículo ferroviário.

Segundo (NARAYANASWAMY, 1998), a melhora do conforto dos passageiros se faz atuando nas suspensões secundárias, e a melhora da estabilidade e comportamento em curvas nas suspensões primárias. Dessa forma, foi desenvolvido um modelo físico e através de duas soluções, uma analítica e outra por integração numérica é conduzida uma análise da influência das suspensões secundárias no movimento lateral da caixa e sua influência nos parâmetros de conforto.

Existem determinados parâmetros na definição de um veículo ferroviário que não concernem diretamente aos usuários e que passam despercebidos durante a 
utilização como a tensão de alimentação, bitola ou consumo. Por outro lado quando se trata de conforto térmico, acústico e vibratório, os passageiros são mais exigentes e como conseqüência os operadores também, o que obriga os construtores de veículos e fornecedores de equipamentos desenvolverem produtos sempre de melhor desempenho. Outro setor que segue a mesma tendência, são os órgãos governamentais e de normalização.

Portanto a importância do estudo de conforto possui dois lados. O primeiro deles se trata do usuário final que utiliza o metrô ou trem cotidianamente. O segundo são os fabricantes que devem respeitar as normas exigidas pelos operadores e que muitas vezes, sua aceitação ou não, podem decidir o vencedor de uma concorrência. $A$ otimização de sistemas complexos implica na escolha de determinados critérios e desempenho em detrimento de outros, logo as escolhas tomadas além de respeitarem as prescrições técnicas, devem também ter um custo baixo para que não inviabilize comercialmente o produto. Portanto, a primeira motivação deste trabalho é de desenvolver um método que melhore o conforto dos passageiros atuando nos parâmetros que definem o veículo. A segunda motivação reside no fato que através de um modelamento virtual pode-se prever, modificar e otimizar um sistema antes mesmo que ele seja construído, reduzindo custos que poderiam ser gerados pelas modificações, atraso de entrega ou penalidades. 


\section{Estado da arte}

\subsection{Introdução}

O setor ferroviário está dividido em diversos ramos de atividade que variam em função do tipo de utilização e operação. A norma EN 12663 classifica os veículos ferroviários em função do tipo de construção e do uso em que os dois principais grupos são os vagões de transporte de carga e os veículos de transporte de passageiros, incluindo locomotivas. Cada um desses dois grupos é dividido em categorias de acordo com o dimensionamento estrutural dos veículos, conforme mostrado a seguir.

- Categoria P-I:

- Pendolino: graças a um sistema de controle da inclinação da caixa, é possível atingir velocidade em curva até $30 \%$ superior a dos trens convencionais, podendo obter uma redução de $20 \%$ do tempo de trajeto (BARNETT, 1992);

- Trem de alta velocidade: possui uma velocidade de operação em média na faixa de $300 \mathrm{~km} / \mathrm{h}$. Existem versões de um ou dois andares e as composições variam de 8 a 18 vagões movidos por duas locomotivas;

- Categoria P-II, trem intermunicipal: tracionado por locomotiva elétrica ou diesel. Este tipo de veículo circula em uma região específica. Os vagões possuem 20 metros de comprimento ou mais e a velocidade de circulação pode atingir até $200 \mathrm{~km} / \mathrm{h}$;

- Categoria P-III, trem de subúrbio: esse tipo de transporte de massa percorre uma distância entre estações bem mais significativa que os metrôs. Os veículos são maiores possuindo uma capacidade de carga bem mais importante e a captação é feita por catenária;

- Categoria P-IV, metrô: a principal característica de um metrô consiste na circulação em zona urbana, linhas subterrâneas ou suspensas e captação de energia elétrica por terceiro trilho. As primeiras linhas de metrô datam do final do século XIX e início do século XX. A partir da década de 50 foram desenvolvidos os primeiros sistemas a pneu e vinte anos mais tarde teve-se o início das 
operações das primeiras linhas automáticas em que não há necessidade de piloto. Um conceito muito difundido atualmente consiste no chamado "people mover" que atende pequenas linhas como em cidades de médio porte (Torino, Lyon, Lille, Toulouse e Rennes) e em aeroportos (Chicago, Dallas, Charles de Gaulle, Orly e Incheon);

- Categoria P-V, tramway: neste caso as linhas são integradas aos centros urbanos com travessia de pedestres e automóveis. A captação de energia é feita por catenária e a circulação é exclusivamente exterior.

\subsection{Suspensão pneumática}

\subsubsection{Histórico}

A história das suspensões pneumáticas, segundo (PRESTHUS, 2002), teve seu início em 1847 quando John Lewis patenteou o primeiro sistema de molas pneumáticas para veículos ferroviários, apenas três anos após a certificação da patente de vulcanização obtida pelo norte americano Charles Goodyear. $O$ invento de John Lewis, embora fosse inovador, exigia determinadas características do material que impediram sua utilização prática. Foi somente a partir dos anos 40 (durante a Segunda Guerra Mundial) que Paul Monges (1908-1999), funcionário de André Citroën, desenvolveu secretamente o conceito de suspensão hidropneumática utilizada comercialmente pela primeira vez no modelo DS em 1955. Em 1964, o grupo Mercedes-Benz introduziu o modelo 600 com suspensão a ar projetado especialmente para contornar a patente de André Citroën. Atualmente a grande maioria dos ônibus em circulação na Europa bem como os trens de transporte urbano utilizam o sistema de suspensão pneumática. A seguir, é mostrado o desenho encontrado na primeira patente de suspensão pneumática ferroviária (LEWIS, 1847) cujo autor alega o uso em viaturas de reboque, amortecedor e prensa hidráulica. 

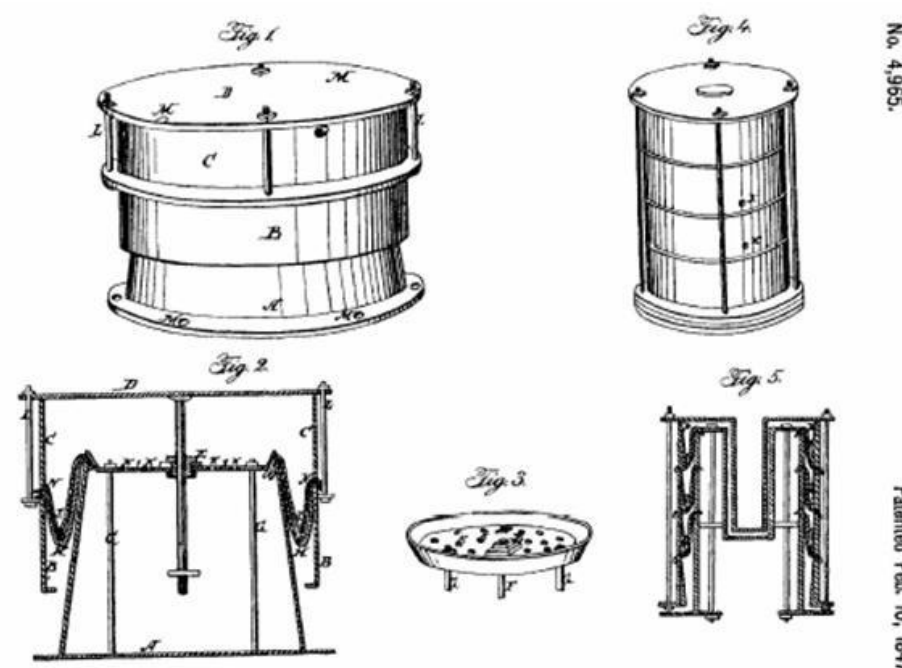

Sag. 5

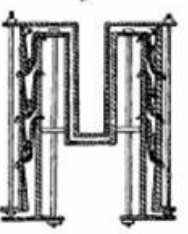

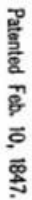

Figura 2.1 - John Lewis US Patent 4,965, - "Pneumatic Spring"

\subsubsection{Tipos de suspensões}

De maneira geral, tanto os veículos automotivos quanto os ferroviários possuem dois tipos de suspensão sendo elas: a primária e a secundária. A suspensão primária é o primeiro filtro de vibração. No caso dos veículos automotivos esta função é realizada pelo pneu e nos veículos ferroviários é feita por molas que isolam as vibrações provenientes do contato roda-trilho e que são transmitidas à armação do truque. Em ambos os casos ela funciona como um filtro para as altas freqüências. A figura abaixo mostra dois exemplos de suspensão primária utilizada no transporte ferroviário.

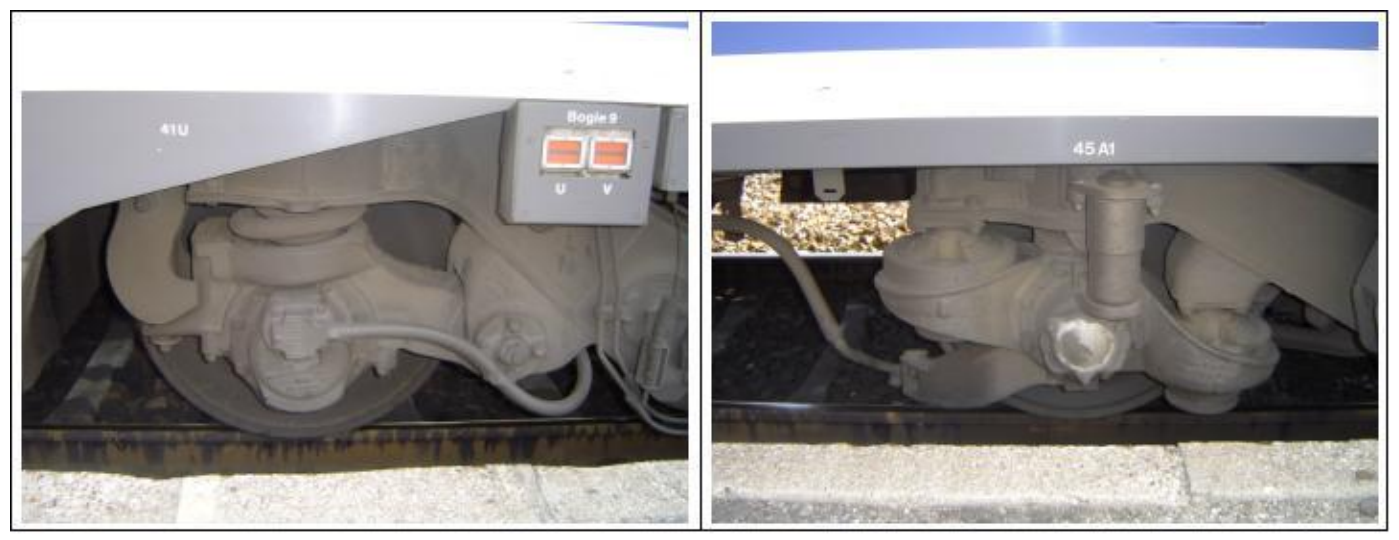

Figura 2.2 - Suspensões Primárias de Mola Helicoidal e Elastomérica (foto do autor) 
A suspensão secundária nos veículos ferroviários de transporte de passageiros geralmente é feita com a utilização de molas pneumáticas. Sua função é isolar as vibrações de baixa freqüência provenientes da armação do truque, garantindo a estabilidade do veículo e o conforto dos passageiros. Além de filtrarem as vibrações geradas durante a circulação, as suspensões primária e secundária também reduzem as forças de interação entre o trilho e o rodeiro.

Existem dois tipos de suspensões secundárias: as que utilizam molas pneumáticas e as que utilizam molas helicoidais. As suspensões à mola helicoidal são utilizadas principalmente nos trens de frete por terem um custo menos elevado e por serem mais simples que os sistemas pneumáticos ou hidropneumático. Porém, em alguns casos, este tipo de suspensão é utilizado em trens de passageiro como, por exemplo, no EUROSTAR que faz a ligação Paris-Londres como mostrado na figura a seguir.

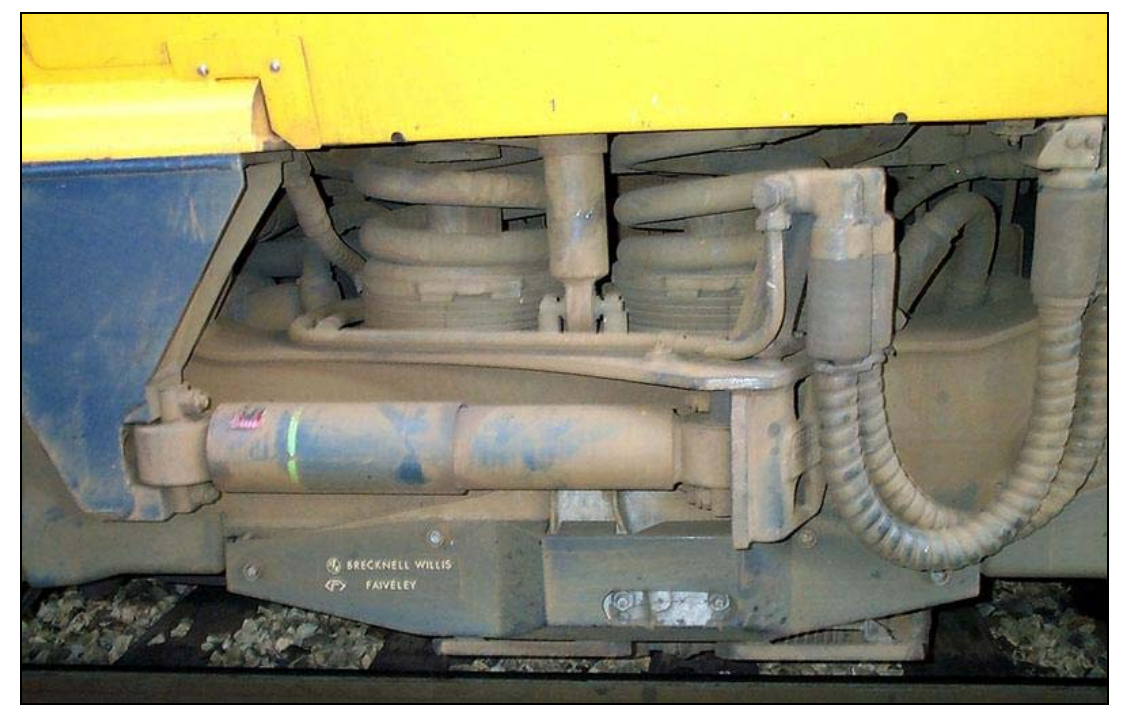

Figura 2.3 - Suspensão Secundária à Mola Helicoidal do Trem EUROSTAR (foto do autor)

Em função das características físicas como rigidez, amortecimento, dimensão e tipo de aplicação, diferentes modelos de suspensões foram desenvolvidos. A seguir, são mostrados quatro tipos de molas pneumáticas, também conhecidas como bolsas de ar, encontradas no catálogo (CONTINENTAL, 2007). 


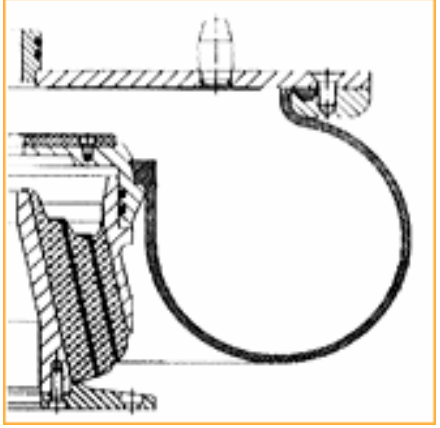

Figura 2.4a

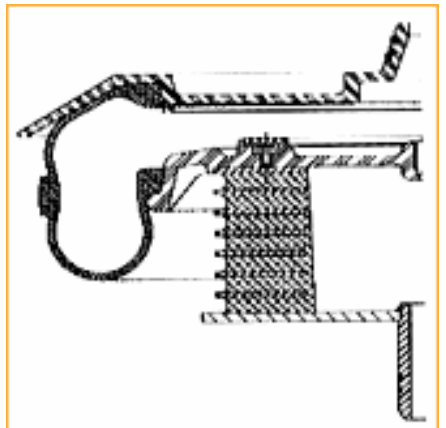

Figura 2.4b

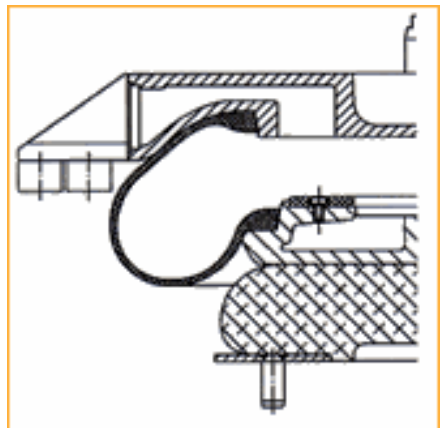

Figura 2.4c

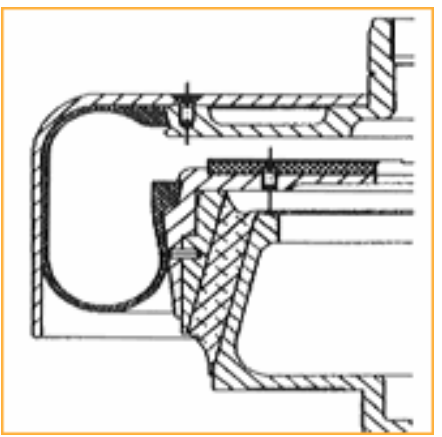

Figura 2.4d
Suspensão pneumática com mola cônica: devido à grande espessura e resistência da câmara de ar é possível realizar todos os movimentos relativos entre a caixa e o truque sem a necessidade do uso de travessas, fazendo assim a união direta entre a caixa e o truque. Este tipo de suspensão é muito utilizado nos trens de alta velocidade, trens de subúrbio e metrôs. Quando a suspensão é desinflada, a caixa repousa sobre molas de borracha cônica.

Suspensão pneumática com cinta e mola de repouso: esse tipo é utilizado quando é exigida uma grande capacidade de carga, porém o espaço de instalação é reduzido. Quando combinado com outros tipos de mola, pode ser utilizada em truques sem travessa em trens de transporte urbano. Ao ser desinflada, a caixa repousa em molas planas de borracha.

Suspensão pneumática de rolamento sobre molas do tipo "half-hourglass": a vantagem deste tipo de suspensão é que permite grandes deflexões laterais a partir de uma altura reduzida. Por outro lado, possui a desvantagem de necessitar de um espaço maior de instalação. Os truques do tipo "Jacob" que são utilizados nos TGVs são providos deste tipo de suspensão.

Suspensão pneumática com guia e mola cônica: neste caso, a câmara de ar é guiada por um anteparo que reduz o espaço útil tornando o sistema mais compacto. A utilização de amortecedores auxiliares possibilita um aumento da pressão de operação permitindo que, com pequenos diâmetros, seja possível conseguir uma grande capacidade de carga. São normalmente utilizadas em tramways, especialmente os de piso baixo. 
Além das suspensões primárias e secundárias mencionadas acima, existe um outro tipo que é utilizada em veículos com rodas de ferro. Nesse caso, a roda é dividida em um anel externo de contato com o trilho e um disco interno solidário ao eixo. Entre essas duas partes é instalada uma camada de polímero que minimiza os choques e permite igualmente uma redução do ruído de rolamento. Essas duas vantagens fazem com que esse dispositivo seja utilizado no transporte urbano onde as exigências relativas à poluição sonora são cada vez mais restritivas. Além disso, a redução de choques diminui o desgaste dos trilhos e da roda permitindo intervalos de manutenção maiores. A figura abaixo mostra uma vista explodida deste tipo de roda.

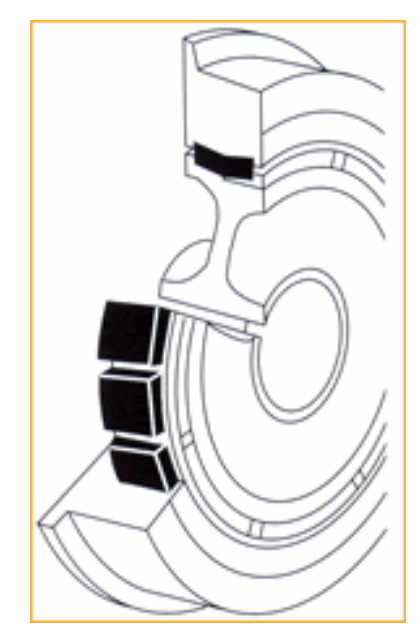

Figura 2.5 - Suspensão interior nas rodas de ferro (CONTINENTAL, 2007)

\subsubsection{Vantagens e desvantagens das suspensões pneumáticas}

A freqüência natural de um sistema massa-mola é diretamente proporcional à raiz quadrada da rigidez e a deflexão é inversamente proporcional à freqüência ao quadrado. Desta forma, quanto menor a rigidez da mola menor será a freqüência natural e, conseqüentemente, maior será a deflexão. Visto que a energia potencial de uma mola é uma função da força aplicada e da deflexão, uma mola metálica que seja capaz de armazenar uma grande energia potencial deve ser muito volumosa, pois deve resistir a um grande esforço em um pequeno deslocamento exigindo, assim muito do material. Por outro lado, uma mola pneumática é capaz de suportar 
uma grande carga tendo uma pequena deflexão graças à compressibilidade do gás sob pressão e da elasticidade da bolsa elastomérica que o comprime.

As molas pneumáticas, além da capacidade de regulagem da altura, são mais leves que as helicoidais ou poliméricas, pois a capacidade de armazenamento de energia do ar por unidade de massa é muito maior que nos outros dois casos. Dessa forma, quando os parâmetros de carga suportada, deflexão e espaço disponível para instalação devem ser otimizados, as molas pneumáticas são as mais indicadas. Assim, a isolação de vibrações de baixa freqüência com deslocamento reduzido tornam as suspensões pneumáticas ideais em aplicações metroferroviárias.

A seguir, é apresentada uma lista das principais vantagens das suspensões pneumáticas face às suspensões de molas metálicas:

- Fácil obtenção de sistemas com baixa freqüência natural em boas condições de via onde não há a presença de choques ou ondulações excessivas;

- A freqüência natural do sistema é quase constante independentemente da carga transportada;

- Com o auxílio de um sistema de controle, é possível manter uma altura constante independente da carga. Esta capacidade é muito útil no transporte urbano em que a altura do veículo com relação à plataforma de embarque deve variar muito pouco para facilitar o acesso de passageiros em cadeiras de roda, por exemplo;

- Melhor capacidade de transporte devido à redução de peso do veículo e altura constante independente da carga;

- Economia de energia devido à redução de massa;

- Maior segurança dos passageiros e da carga transportada uma vez que não existe fricção entre as partes móveis que podem causar a ruptura de componentes ao longo de sua utilização.

Como desvantagens podem-se listar:

- Controle de rolamento e estabilidade difícil de ser feito pois as suspensões pneumáticas possuem pequena rigidez e oscilam à baixa freqüência;

- Alto custo devido aos acessórios como o sistema de compressão de ar e controle de nivelamento; 
- Sensibilidade às variações de temperatura devido às características do ar comprimido;

- Confiabilidade reduzida e aumento do custo de mão de obra, pois se utiliza uma maior quantidade de componentes para executar uma mesma função;

- Maior complexidade de modelagem matemática uma vez que a rigidez varia com a carga.

Os três fatores principais que influenciam na escolha das suspensões pneumáticas são a capacidade de carga, a rigidez e a transmissibilidade. Como os veículos ferroviários urbanos necessitam de uma baixa transmissibilidade, controle de altura e adaptação freqüente à variação de carga, a maioria dos sistemas de suspensão secundária utilizados atualmente é pneumática.

\subsubsection{Modelamento de suspensões pneumáticas}

Os estudos de suspensões pneumáticas utilizam, na maioria dos casos, modelamento não linear como apresentado por (PRESTHUS, 2002) e (BALDI; MEIRELLES, 2003), o mesmo ocorrendo com amortecedores como feitos por (GONÇALVES; MEIRELLES, 2005). A partir desses trabalhos e de outros que serão apresentados em seguida, serão mostrados alguns modelos termodinâmicos de suspensões secundárias usadas por programas multicorpos.

Um modelo bastante simplificado é apresentado na figura 2.6 que apresenta uma suspensão pneumática conectada a um reservatório de ar comprimido. Quando uma força $F_{z}$ comprime a suspensão pneumática (1), o ar é comprimido dentro da câmara ocorrendo uma diferença de pressão entre esta e o reservatório (2). A equalização da pressão é feita através de uma válvula de regulação (3) e o tempo para que isso seja feito varia em função do comprimento da tubulação (4), das características da válvula, das dimensões do reservatório e das bolsas de ar. 


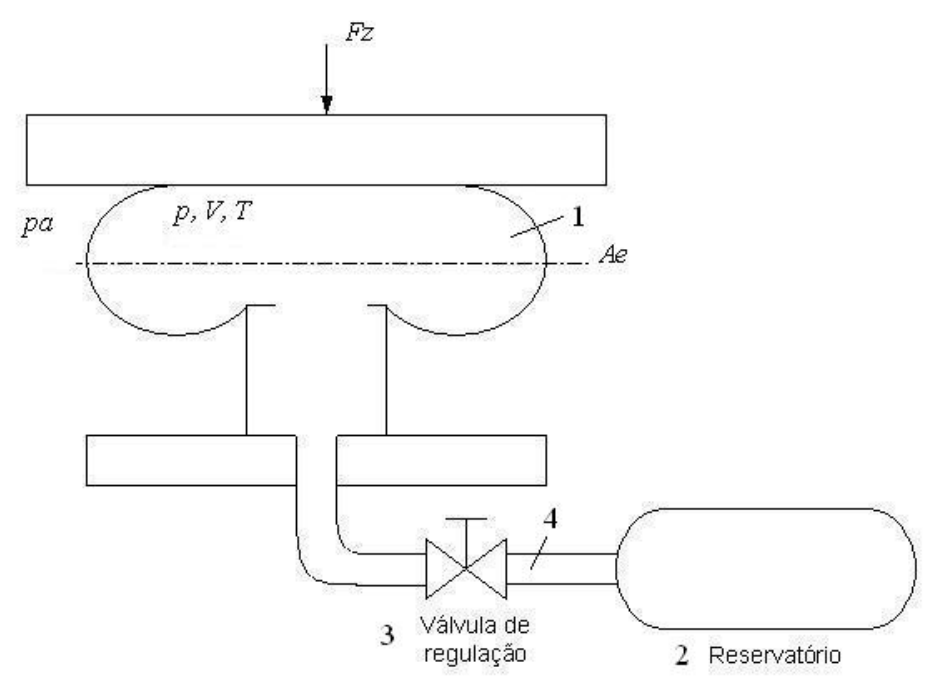

Figura 2.6 - Esquema de Uma Suspensão Pneumática com Reservatório Auxiliar

Uma das características das suspensões pneumáticas é que quanto maior o volume do conjunto bolsa de ar-reservatório menor será sua rigidez. Este fenômeno pode ser observado no gráfico 2.1 que mostra cinco curvas "Força x Rigidez" para os volumes do reservatório adicional variando entre zero e $50 \mathrm{dm}^{3}$ de uma suspensão CONTITECH 743N.10/17/1818. Como pode ser observado quanto menor o volume de ar do conjunto maior será a rigidez, onde neste caso por exemplo, para uma força de $116 \mathrm{kN}$ as rijezas podem variar de até $40 \%$ em função do volume adicional.

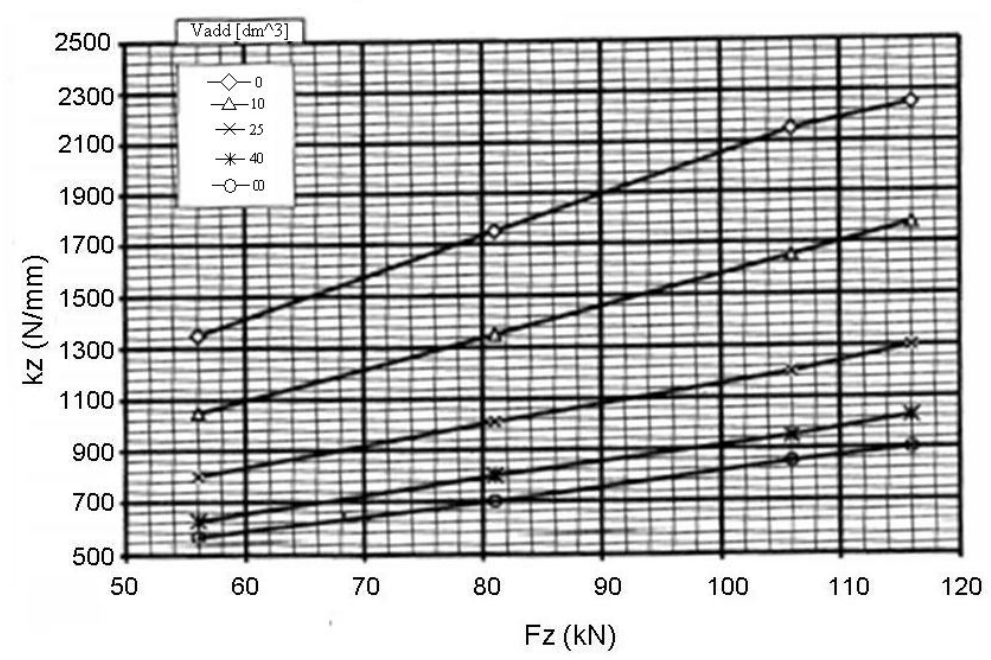

Gráfico 2.1 - Influência do Volume Adicional na Rigidez de uma Suspensão Pneumatica (METALOCAUCHO, 2001)

Devido à quantidade de perâmetros que definem as suspensões pneumáticas como as características do gás, volume, densidade, temperatura e construção entre 
outros, sua modelagem é complexa e os modelos existentes são mais ou menos elaborados e representativos da realidade. A seguir alguns modelos de suspensões pneumáticas serão apresentados com o intuito de demonstrar quais parâmetros e simplificações podem influenciar os resultados e conseqüentemente as simulações de veículos ferroviários.

Um modelo de suspensão pneumática bastante simples parte do princípio dos processos de compressão quasi-estático (isotérmico) e dinâmico a pressão constante (isobárico) que apresentam uma relação entre as pressões e volumes no estado inicial " $i$ " e final " $f$ " da compressão dada por:

$$
\text { Isotérmico } \frac{p_{i}}{p_{f}}=\frac{V_{f}}{V_{i}} \text {, adiabático } \frac{p_{i}}{p_{f}}=\left(\frac{V_{f}}{V_{i}}\right)^{\gamma}
$$

Onde:

- $\quad \gamma=\mathrm{Cp} / \mathrm{Cv}$;

- Cp: calor específico de um gás a pressão constante $(\mathrm{J} / \mathrm{kg})$;

- Cv: calor específico de um gás a volume constante $(\mathrm{J} / \mathrm{kg})$;

- $\quad V$ : volume do sistema bolsa de ar, tubulação e reservatório $\left(\mathrm{m}^{3}\right)$.

No processo real, devido a perda de calor e variação de temperatura, o comportamento de uma suspensão pneumática não é adiabático nem isotérmico, mas politrópico. $\mathrm{O}$ valor de gama para o ar normalmente adotado se situa entre 1,3 e 1,4 .

A área efetiva $\left(A_{e}\right)$ de uma mola pneumática é dada pela força aplicada dividida pela pressão efetiva $\left(p_{e}\right)$ e devido à flexibilidade da câmera de ar esta área varia dependendo do caso. Assumindo que a área efetiva seja constante e que a pressão absoluta $(p)$ no interior do sistema seja igual a soma das pressões atmosférica $\left(p_{a}\right)$ e efetiva $\left(p_{e}\right)$, a rigidez dinâmica será dada por (PRESTHUS, 2002):

$$
K_{z \operatorname{din}}=\frac{\gamma \cdot\left(p_{e}+p_{a}\right) \cdot A_{e}^{2}}{V}
$$


O caso do movimento quasi-estático (isotérmico) é uma particularidade do dinâmico (politrópico) quando $\gamma=1$. Através desta equação pode-se perceber que o aumento da rigidez $\left(K_{z}\right.$ din $)$ é inversamente proporcional ao volume $(V)$ conforme mostrado no gráfico 2.1 .

A equação deduzida acima possui pouca utilidade prática devido a sua simplicidade. Os modelos mais complexos utilizados no cálculo do comportamento dinâmico de veículos ferroviários consideram diversos outros fatores ignorados na dedução da equação 2.2. A seguir dois desses modelos são explicados mais em detalhe.

Um modelo muito utilizado por softwares de análise dinâmica como o ADAMS (Automatic Dynamic of Mechanical Systems) é o de Nishimura (MECHANICAL DYNAMICS INC, 2002). Ao contrário da hipótese assumida na dedução da equação 2.2, o modelo de Nishimura leva em consideração a variação da área efetiva e de um amortecimento $(c)$ dado por uma relação linear empírica entre diferença de pressão e a massa do fluxo de ar que passa pelo orifício da válvula de regulação (ver figura 2.6). A figura 2.7 mostra um esquema do arranjo das molas molas $k_{1}, k_{2} \mathrm{e}$ $k_{3}$ e do amortecedor $c$ que compõem tal modelo:

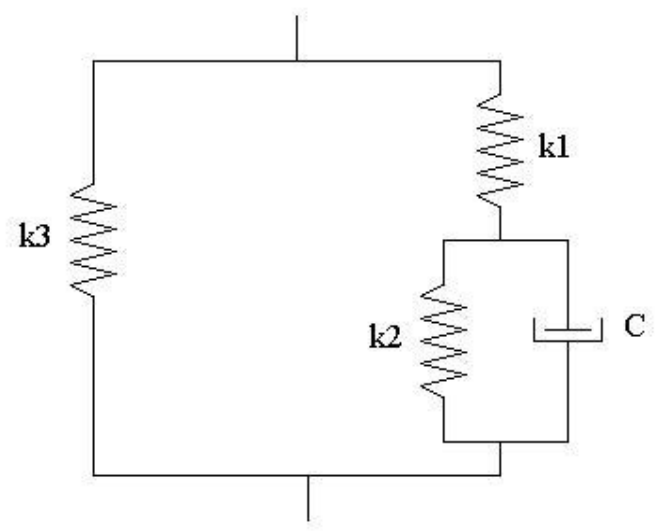

Figura 2.7 - Modelo Nishimura de Suspensão Pneumática (MECHANICAL DYNAMICS INC, 2002)

Onde:

- $k_{1}$ : rigidez devido a compressão do ar no interior da câmera quando a válvula de regulação está fechada;

- $\quad k_{2}$ : rigidez devido a compressão do ar no interior do reservatório; 
- $\quad k_{3}$ : rigidez devido a variação da área efetiva em função da espessura vertical da câmara;

- $\quad c$ : amortecimento do orifício da válvula de regulação.

Algumas variantes do modelo de Nishimura foram desenvolvidas e entre elas está a utilizada pelo software VAMPIRE (Vehicle dynAmic Modeling Package In a Railway Environment). Neste caso, um amortecimento devido inércia da massa de ar que circula através da válvula de regulação e pela tubulação que liga a bolsa de ar ao reservatório é considerado em paralelo com a rigidez $k_{2}$ e com o amortecimento $c$ mostrados na figura 2.7. (AEA TECHNOLOGY, 2006).

Um outro modelo de suspensão pneumática mais detalhado e complexo que o descrito acima foi desenvolvido por Mattias Wallin e Mats Berg, do "Department of Vehicle Engineering" do "Royal Institute of Technology", Suécia, em cooperação com a empresa ASEA. Este modelo utilizado pelo software GENSYS (SAMAVEDAM; GOMES, 2002), possui a particularidade de depender de parâmetros obtidos experimentalmente como por exemplo o amortecimento viscoso do fluxo de ar se deslocando pela tubulação, a força de atrito entre as partes móveis, a rigidez e o amortecimento vertical, a inércia da massa de ar em movimento entre outros. Neste caso a inércia do ar contido na tubulação que liga a câmera ao reservatório é obtida através de uma equação diferencial de segunda ordem e o fluxo de ar em seu interior pressupõe quatro tipos de perda de pressão:

- Perda de pressão devido ao fluxo de ar no tubo;

- Perda de pressão no orifício da válvula de regulação;

- Perda de pressão nas curvas e cotovelos;

- Perda de pressão nas entradas e saídas do reservatório e bolsa de ar.

Uma vez que o comportamento dinâmico dos veículos ferroviários depende diretamente das características das suspensões secundárias, quanto mais realístico for o modelo melhores serão os resultados obtidos pelas simulações. As suspensões pneumáticas utilizadas nas simulações deste trabalho foram obtidas a partir de informações contidas em catálogos de fornecedores, por isso não foi feita a abordagem matemática dos modelos citados neste capítulo. 


\subsection{Válvula de nivelamento}

O uso de sistemas de nivelamento de veículos ferroviários é muito difundido nos equipamentos de transporte de passageiros principalmente nas regulagens de altura em estação. A norma ASCE 21-98 que regulamenta a construção de "people movers", especifica que a diferença de altura entre a plataforma de embarque e o piso do veículo deve ser de $\pm 15,5 \mathrm{~mm}$ para facilitar a entrada e saída de pessoas idosas ou em cadeiras de roda. A seguir, é explicado como os sistemas de nivelamento funcionam e quais tecnologias são aplicadas atualmente.

A figura 2.8 mostra um esquema típico de instalação de válvula de nivelamento. Segundo (ANDERSON, 1992), este sistema funciona da seguinte maneira: a válvula de nivelamento (10) está conectada à caixa (1) através de uma fixação (45). A alavanca de ajuste (14) que faz a abertura e o fechamento da válvula de nivelamento é conectada à armação do truque (3) via o braço de ligação (4). Quando ocorre o embarque de passageiro em uma estação, por exemplo, o aumento da massa suspensa comprime a bolsa de ar (2) fazendo a caixa se movimentar no sentido descendente. Quando isto ocorre, o conjunto braço de ligação e alavanca de ajuste fazem a abertura da válvula e esta libera a passagem de ar comprimido do reservatório (5) à bolsa de ar através das tubulações (6 e 7). Uma vez que a pressão do reservatório é maior que a da bolsa, o fluxo de ar de insuflamento faz com que esta expansione e conseqüentemente movimente a caixa no sentido ascendente. Neste momento, o conjunto braço de ligação e alavanca de ajuste funciona da maneira oposta, fechando a passagem de ar assim que a caixa atinja a altura de regulagem. Quando ocorre $o$ desembarque de passageiros e a conseqüente redução da massa suspensa, a bolsa de ar então com uma pressão interna maior que a prevista para tal massa, faz a elevação da caixa. Neste momento, o conjunto braço de ligação e alavanca de ajuste faz com que a válvula libere a exaustão do ar da bolsa para a atmosfera reduzindo a pressão interna no interior da mesma e baixando o nível da caixa até o momento que esta chegue à posição de equilíbrio quando o fluxo de ar através da válvula é então interrompido. 


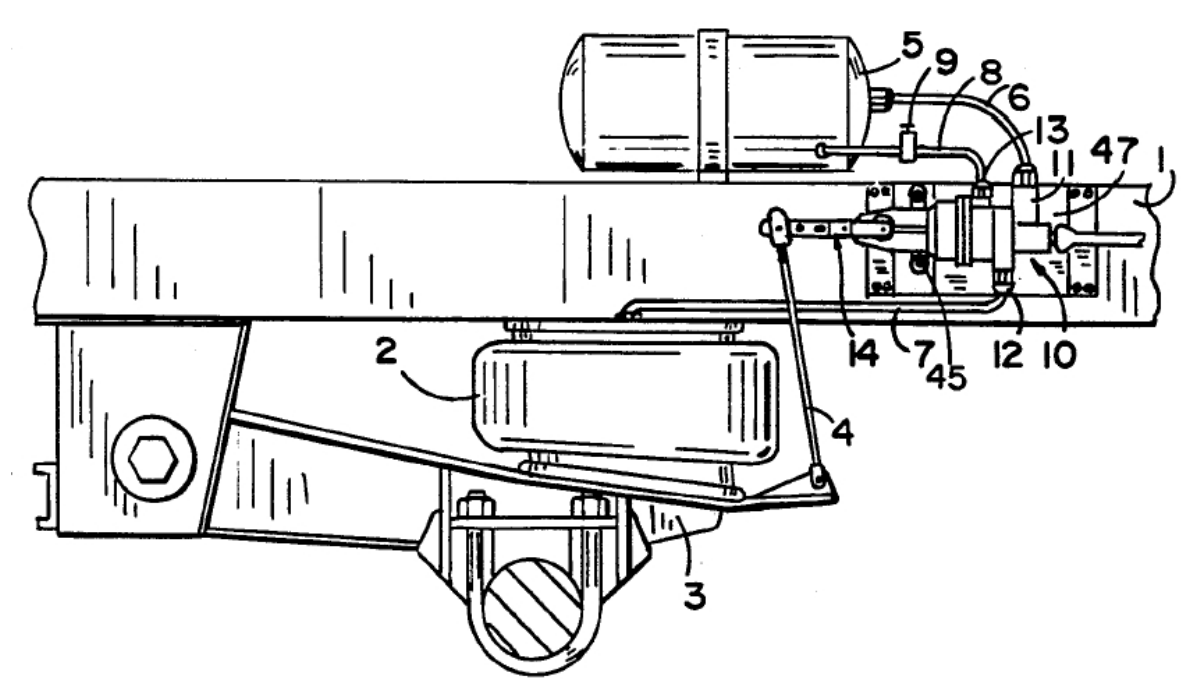

Figura 2.8 - Esquema de Instalação de uma Válvula de Nivelamento (ANDERSON, 1992)

O princípio de funcionamento das válvulas de nivelamento em veículos ferroviários é aparentemente simples como foi explicado anteriormente. Porém torna-se bastante complexo a partir do momento em que se deseja criar um sistema de controle. O primeiro problema que pode ser mencionado se trata do curso imposto pelas dimensões da alavanca de ajuste, pois quanto mais curta ela for maior será o ângulo de abertura da válvula que, por sua vez, possui um curso de movimento limitado, dificultando assim a absorção de grandes deslocamentos.

O segundo problema consiste na necessidade de se absorver os movimentos rápidos do sistema, que pode ser feito por um dispositivo exterior, por exemplo, uma mola acoplada às alavancas de controle ou incorporado na própria válvula (DAUM; LATIF; O'RELLY, 1992). Este amortecimento pode ser dado pelo atraso no tempo de resposta de maneira que alterações momentâneas da carga sobre a suspensão causadas pelas irregularidades da via não permitam o fluxo de insuflamento ou exaustão. Da mesma forma sua operação não pode ser influenciada pelas freqüências naturais da suspensão do veículo. A definição dos parâmetros acima como tempo de resposta e acoplamento com as freqüências naturais do veículo variam em função da massa suspensa, das condições da via, entre outros. (DAVIS, 1960).

O terceiro trata-se de um problema construtivo pois os movimentos freqüentes causam um desgaste nas superfícies de contato que fazem a vedação de ar, 
principalmente nas válvulas providas de pivô. Tais superfícies de contato não podem ser muito pequenas para que o controle do fluxo seja feito com precisão, isso implica um aumento do custo de produção devido à usinagem das partes móveis (CHING, 2006).

Nos últimos 60 anos, muitos tipos de válvula de nivelamento foram desenvolvidos com o objetivo de solucionar os diversos problemas mencionados acima em que cada criador alega solucionar os encontrados nas versões anteriores. Uma das primeiras propostas de introdução de um sistema de amortecimento com o objetivo de evitar a operação excessiva da válvula devido às irregularidades da via foi feita por (DEIST, 1959) que consistia de uma mola helicoidal entre o atuador ligado na alavanca de ajuste e o atuador central de controle de fluxo de insuflamento e exaustão. Outro método desenvolvido e que possui diversas variantes consiste na utilização de um fluído viscoso que, ao passar por um orifício, absorve os movimentos de imperfeições da via. Esse princípio foi utilizado por (CHRISTENSEN, 1960) e (ANDERSON, 1992).

A partir dos anos 70, começaram a surgir os primeiros sistemas em que o tempo de atraso é dado por um circuito eletrônico que, por sua vez, controla o fluxo de ar. Tal princípio foi utilizado por (HIRUMA, 1978) e mais recentemente por (CHING, 2006). O princípio de funcionamento deste último consiste basicamente de uma válvula solenóide que, através de ranhuras e orifícios, libera ou restringe a passagem de ar a partir de um movimento longitudinal. Uma das vantagens alegadas pelo idealizador deste equipamento é que a válvula solenóide controla mais facilmente um pistão que se move no sentido longitudinal do que um rotor. A a outra vantagem consiste na reduzida quantidade de partes que necessitam usinagem de precisão e, conseqüentemente, reduzindo seu custo de fabricação como mencionado anteriormente.

Diversos sistemas eletrônicos estão disponíveis no mercado e podem ser aplicados tanto pelos veículos rodoviários quanto pelos ferroviários. De maneira geral, tais sistemas são providos de sensores de deslocamento que medem a distância entre a armação do truque e da caixa nos quatro pontos de instalação das suspensões secundárias que enviam o sinal a uma unidade de controle eletrônica e, através de válvulas solenóides, regulam a abertura das válvulas de nivelamento que são 
instaladas em cada bolsa de ar. Entre as vantagens dos sistemas eletrônicos está a capacidade de controle a partir de interferências externas. Por exemplo, os movimentos de rolamento devido à força de vento lateral sobre o veículo tão importante no cálculo de gabarito podem ser reduzidos, fazendo com que, a partir de uma determinada velocidade de vento pré-definida, as suspensões pneumáticas sejam desinfladas. Assim, a caixa repousa sobre os batentes e a velocidade de circulação é reduzida até a próxima estação onde é feita a evacuação dos passageiros. Neste exemplo, o fato da caixa apoiar-se sobre os batentes, que são muito mais rígidos que as bolsas de ar, reduzem-se os movimentos de roll (rotação da caixa no eixo longitudinal $-x$ ). Este mesmo princípio pode ser aplicado no caso de colapso de uma suspensão, de um pneu no caso de metrôs ou demais fenômenos que possam influenciar no gabarito dinâmico do veículo (gabarito maior implica túneis e viadutos maiores e conseqüentemente mais caros). Esses sistemas podem até mesmo compensar o desgaste dos pneus quando são utilizados. Neste caso, entra-se com uma curva de desgaste em função da distância percorrida obtida ao longo da operação que o comando eletrônico corrige automaticamente. Outra maneira de se fazer o controle de altura em estação consiste de um leitor óptico instalado no veículo que identifica a posicão do mesmo em relação à plataforma, controlando a altura de maneira mais precisa em função da estação e não de uma altura fixa. Porém, tais sistemas ainda estão em desenvolvimento e não são disponíveis comercialmente.

A figura 2.9 mostra duas curvas que relacionam o fluxo de ar pelo ângulo de rotação do rotor de controle da válvula de nivelamento. O primeiro caso (à esquerda), corresponde à válvula "VN6 type $P$ " da SabWabco utilizada no metrô VAL 208 NG da cidade de Turin (SAB WABCO, 1999). Neste gráfico pode-se ver que existe uma "zona morta" entre $0^{\circ}$ e $\pm 2^{\circ}$ em que o movimento do braço de controle não provoca um fluxo de ar. Entre os ângulos de $\pm 2^{\circ} / 2,5$ e $\pm 6^{\circ} / 8^{\circ}$ a válvula permite um pequeno fluxo constante de ar que serve para fazer o ajuste fino da altura. A partir da faixa de $\pm 6^{\circ} / 8^{\circ}$, o fluxo aumenta a uma razão de aproximadamente $3,7 \mathrm{l} / \mathrm{s} / \mathrm{grau}$. Segundo a mesma referência, o comprimento do braço de controle pode variar entre $140 \mathrm{~mm}$ e $180 \mathrm{~mm}$. Para o valor típico de $164 \mathrm{~mm}$ pode-se deduzir que os movimentos da suspensão secundária de até $5,7 \mathrm{~mm}$ são absorvidos pela própria bolsa de ar. Entre 
$5,7 \mathrm{~mm}$ e $20 \mathrm{~mm}$ entra-se na zona de ajuste fino e a partir de $20 \mathrm{~mm}$ tem-se o fluxo de ar de regulagem.

O segundo gráfico (à direita) mostra a curva de "fluxo x ângulo" da válvula de nivelamento proposta por (LEE, 2005). Neste caso, percebe-se que para ângulos de até $\pm 5^{\circ}$ há um aumento progressivo do fluxo de ar; entre $\pm 5^{\circ}$ e $\pm 10^{\circ}$ existe uma faixa em que o fluxo se mantém constante; entre $\pm 10^{\circ}$ e $\pm 12,5^{\circ}$ o fluxo volta a aumentar estabilizando-se a partir deste valor. O comportamento desta válvula, segundo seu criador, permite que seja feito um controle na região normal de operação, onde se tem pequenos ângulos de rolamento e um outro tipo de ajuste para os rolamentos excepcionais.
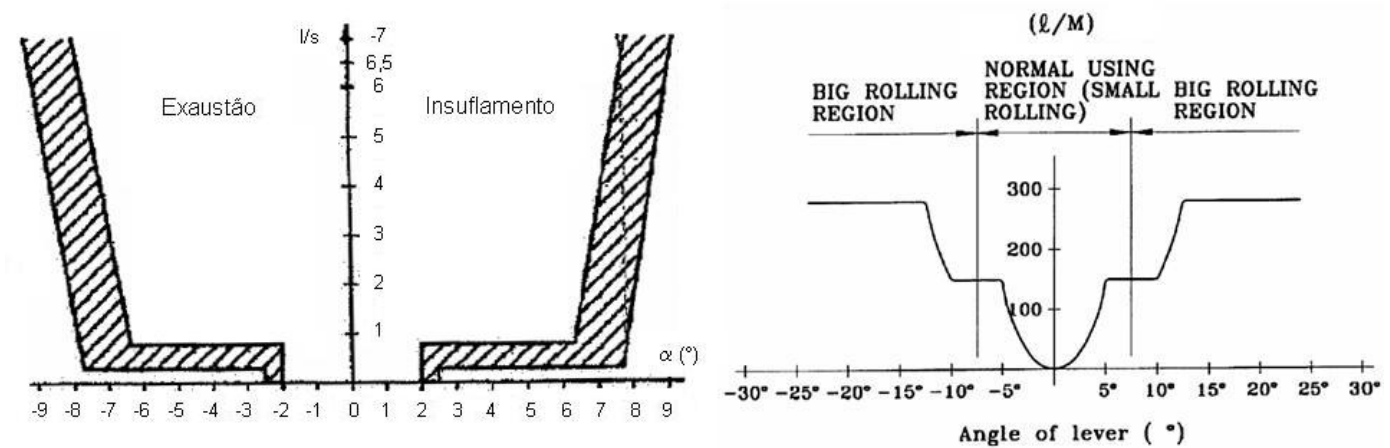

Figura 2.9 - Curvas de Válvulas de Nivelamento (SAB WABCO, 1999) e (LEE, 2005)

Além do tipo de válvula, o sistema de nivelamento depende também da quantidade e disposição de instalação. O princípio mais utilizado consiste de três válvulas por veículo. Em um dos truques são instaladas duas válvulas que controlam as bolsas de ar de maneira independente. Desta forma, a caixa fica sempre paralela à armação do truque. A terceira válvula tem sua medida tomada no centro do outro truque, entre as duas bolsas de ar. Também existe o princípio de quatro válvulas, uma para cada bolsa de ar, onde a caixa tende a ficar paralela a ambos os truques. A vantagem do sistema de três válvulas pode ser explicada quando um veículo provido de duas válvulas no truque dianteiro e uma no truque trazeiro faz uma inscrição em curva, por exemplo. Neste caso, devido ao ângulo de inclinação, as duas válvulas dianteiras irão comandar as suspensões de maneira que a caixa incline e fique paralela à armação do truque. Esta rotação da caixa imposta pelo truque dianteiro é transmitida ao truque traseiro através da rigidez torcional da 
estrutura fazendo com que ocorra um desnivelamento entre as suspensões. Como a válvula do truque traseiro atua baseada na altura média das bolsas de ar, ela permite que a caixa execute o movimento de rolamento controlado pelas válvulas dianteiras. Assim, o movimento de rolamento da caixa se torna possível sem que haja esforços torcionais sobre a mesma. Quando são instaladas quatro válvulas, supondo o caso acima, a regulagem das válvulas dianteiras faz com que a caixa rotacione e a das válvulas traseiras que ela permaneça paralela ao plano horizontal provocando uma torção da caixa. Por outro lado, quando o veículo opera em vias de bitola estreita, o uso de três válvulas apresenta uma certa dificuldade em manter a estabilidade rotacional do veículo podendo causar seu descarrilhamento. Neste caso o uso de quatro válvulas é mais recomendado (MOHACSI, 1987).

Com relação ao conjunto braço de ligação e alavanca de ajuste, a Buckeye Steel Castings desenvolveu um sistema que faz o nivelamento da caixa de maneira mais precisa, pois a deflexão da suspensão primária também é levada em consideração. As duas ilustrações da figura 2.9 mostram o princípio de funcionamento comparando um caso típico em que a válvula de nivelamento é controlada somente pelo deslocamento da suspensão secundária e o caso proposto que leva em consideração os deslocamentos das suspensões primárias e secundárias.

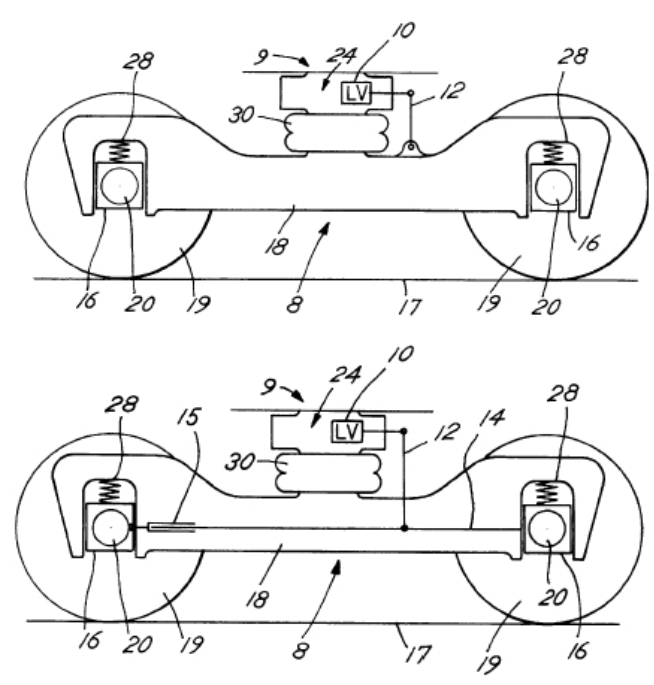

Figura 2.9 - Dispositivo de Comando Preciso de Válvulas de Nivelamento (POLLEY, 1999)

Na figura superior pode-se observar que o braço de ligação (12) é conectado de um lado à armação do truque (18) e do outro à alavanca de controle que comanda a 
válvula de nivelamento (10). O princípio de funcionamento deste caso foi explicado no início deste capítulo. A idéia mostrada na figura inferior consiste em instalar uma barra rígida (14) entre a armação do truque e a caixa de rolamento (16). Um braço telescópico (15) permite o movimento longitudinal da barra rígida entre os eixos dianteiro e traseiro. No momento do embarque de passageiros, ocorre uma deflexão da bolsa de ar (30) e das suspensões primárias (28). Quando o braço de ligação está conectado à armação do truque (figura superior) o movimento das suspensões primárias não é transmitido à válvula de nivelamento. Porém, segundo esta proposta, quando ocorre a deflexão das suspensões primárias, o movimento relativo entre a armação do truque e a caixa de rolamento é transmitido à válvula de nivelamento através da barra rígida e da alavanca de ligação, possibilitando assim que a regulagem da altura seja feita de maneira mais precisa (POLLEY, 1999).

\subsection{Flexibilidade da caixa em modelos dinâmicos}

A utilização de modelos numéricos pela indústria ferroviária, assim como é feito pela indústria automobilística, vem se desenvolvendo cada dia mais com o objetivo de reduzir custos através da antecipação de problemas durante a fase de concepção que só seriam descobertos uma vez que o produto estivesse concluído.

Vários algoritmos de modelagem virtual de veículos ferroviários foram desenvolvidos cada qual com suas particularidades. Porém um ponto em comum entre os diversos métodos é o uso de diferentes softwares de auxílio de concepção (computer aided engineering - CAE) em que cada qual executa uma função específica como, por exemplo, a análise de elementos finitos (finite element analysis, FEA), o comportamento de fluídos dinâmicos (computational fluid dynamics - CFD), a análise vibracional multicorpos (multibody system - MBS), a concepção numérica (computer aided design - CAD) entre outros. A interação entre esses diferentes tipos de softwares que mais interessa a este trabalho é a realizada entre o cálculo de elementos finitos (FEM) e a análise vibracional multicorpos (MBS).

Dentre os vários tipos de análise que podem ser feitos utilizando os softwares de multicorpos está o cálculo do nível de conforto dos passageiros. Como é afirmado 
por diversos autores entre eles (STRIBERSKY; MOSER; RULKA, 2000) e (YAGIZ; GURSEL, 2005), o cálculo de conforto deve levar em consideração a flexibilidade da caixa, incluindo os equipamentos de grande porte que nela são instalados. As conclusões apresentadas neste capítulo foram baseadas nos dois trabalhos citados acima, no artigo de (DIANA et al., 2002) e na tese de (CARLBOM, 2000).

A Tabela 2.1 apresenta as freqüências dos principais modos de vibração de três veículos diferentes conforme descritos a seguir. Tais resultados foram obtidos a partir da análise de elementos finitos da estrutura da caixa e medidos experimentalmente.

Tabela 2.1 - Freqüências dos Principais Modos de Vibração da Caixa para Três Tipos de Veículo (índice "c" para valores calculados e "e" para experimentais)

\begin{tabular}{|c|c|c|c|c|}
\hline Modo & $\mathrm{V} .1(\mathrm{~Hz})$ & V.1' $(\mathrm{Hz})$ & $\mathrm{V} .2(\mathrm{~Hz})$ & V.3 (Hz) \\
\hline Flexão vertical - 1 & $19,7^{\mathrm{c}} / 19,8^{\mathrm{e}}$ & $\begin{array}{l}10,9^{\mathrm{c}} / 12,4^{\mathrm{e}} \\
10,3^{\mathrm{c}} / 12,8^{\mathrm{e}}\end{array}$ & $9,1^{\mathrm{c}} / 8,6^{\mathrm{e}}$ & 6,4 \\
\hline Flexão vertical - 2 & $29,8^{\mathrm{c}} / 29,2^{\mathrm{e}}$ & 16,6 & 16,2 & - \\
\hline Torção - 1 & $19,9^{\mathrm{c}} / 21,8^{\mathrm{e}}$ & $14,5^{\mathrm{c}} / 16,5^{\mathrm{e}}$ & 12,8 & - \\
\hline Torção - 2 & - & $15,3^{\mathrm{c}} / 17,5^{\mathrm{e}}$ & 13,9 & - \\
\hline "Respiração" - 1 & $18,1^{\mathrm{c}} / 17,4^{\mathrm{e}}$ & - & 13,4 & - \\
\hline "Respiração" - 2 & $22,9^{\mathrm{c}} / 22,4^{\mathrm{e}}$ & - & 14,3 & - \\
\hline "Respiração" - 3 & - & - & 15,0 & - \\
\hline Distorção diagonal- 1 & $15,3^{\mathrm{c}} / 16,0^{\mathrm{e}}$ & $10,3^{\mathrm{c}} / 11,6^{\mathrm{e}}$ & 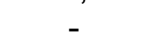 & - \\
\hline Distorção diagonal- 2 & $27,2^{\mathrm{c}} / 29,7^{\mathrm{e}}$ & 18,2 & - & - \\
\hline Flexão lateral & 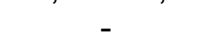 & - & 12,2 & - \\
\hline
\end{tabular}

- Veículo V.1 (STRIBERSKY; MOSER; RULKA, 2000): metrô de Viena, construção SIEMENS em alumínio. Inicialmente o modelo FEA possuía 88.000 elementos, 62.000 nós e 369.000 graus de liberdade. Através do método de redução de Guyan foram escolhidos 391 nós e 1326 graus de liberdade principais a partir dos quais foram calculados os modos de vibração mostrados na tabela 2.1;

- Veículo V.1': a diferença entre este modelo e o anterior, é que, neste caso, os dois equipamentos de ar-condicionado foram fixados na cobertura e o equipamento de tração no sub-estrado. Tais equipamentos foram modelados como sendo corpo rígido instalado através de juntas flexíveis na caixa. $\mathrm{Na}$ freqüência de $10,9 \mathrm{~Hz}$ o equipamento de tração vibra em fase com a caixa e na freqüência de $12,4 \mathrm{~Hz}$ em oposição de fase; 
- Veículo V.2 (CARLBOM, 2000): trem de passageiros sueco SJ-S4M, 26,4 m de comprimento, construção ADTRANZ (atualmente BOMBARDIER) em açocarbono, modelo FEA de 23.000 graus de liberdade;

- Veículo V.3 (DIANA et al., 2002): trem de passageiros de $37.000 \mathrm{~kg}$ com dois conversores elétricos de $2000 \mathrm{~kg}$ e $2900 \mathrm{~kg}$ considerados como corpo-rígido instalados no sub-estrado através de juntas flexíveis. O modelo FEA possui 48.000 elementos, 33.000 nós e 152.000 graus de liberdade.

O gráfico 2.2 mostra o resultado da simulação do modelo V.1 para uma velocidade de $80 \mathrm{~km} / \mathrm{h}$ em uma via com irregularidades onde a caixa flexível foi utilizada pelo software de análise de multicorpos.

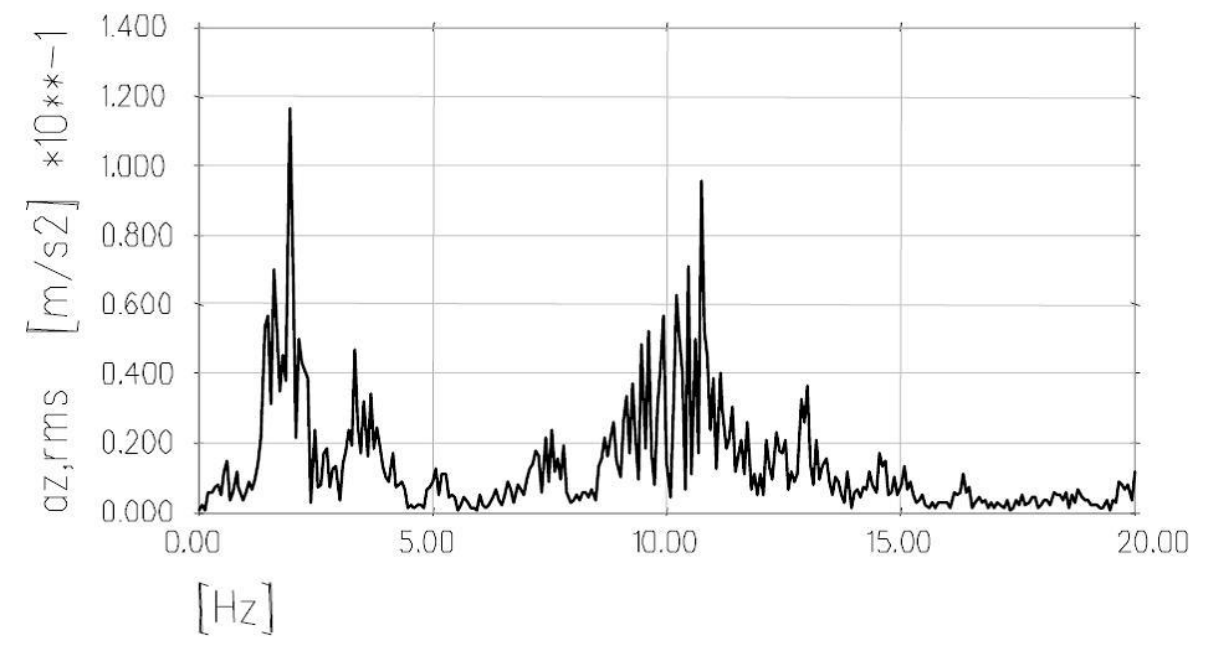

Gráfico 2.2 - Aceleração Vertical no Centro da Caixa - Veículo V.1 (STRIBERSKY; MOSER; RULKA, 2000)

No caso do veículo $V .2$, as freqüências nos modos de vibrar foram calculadas utilizando um software de elementos finitos. O espectro de freqüência mostrado no gráfico 2.3 foi obtido experimentalmente por onde o veículo circulou: em uma via reta com qualidade normal e a uma velocidade de $130 \mathrm{~km} / \mathrm{h}$. 


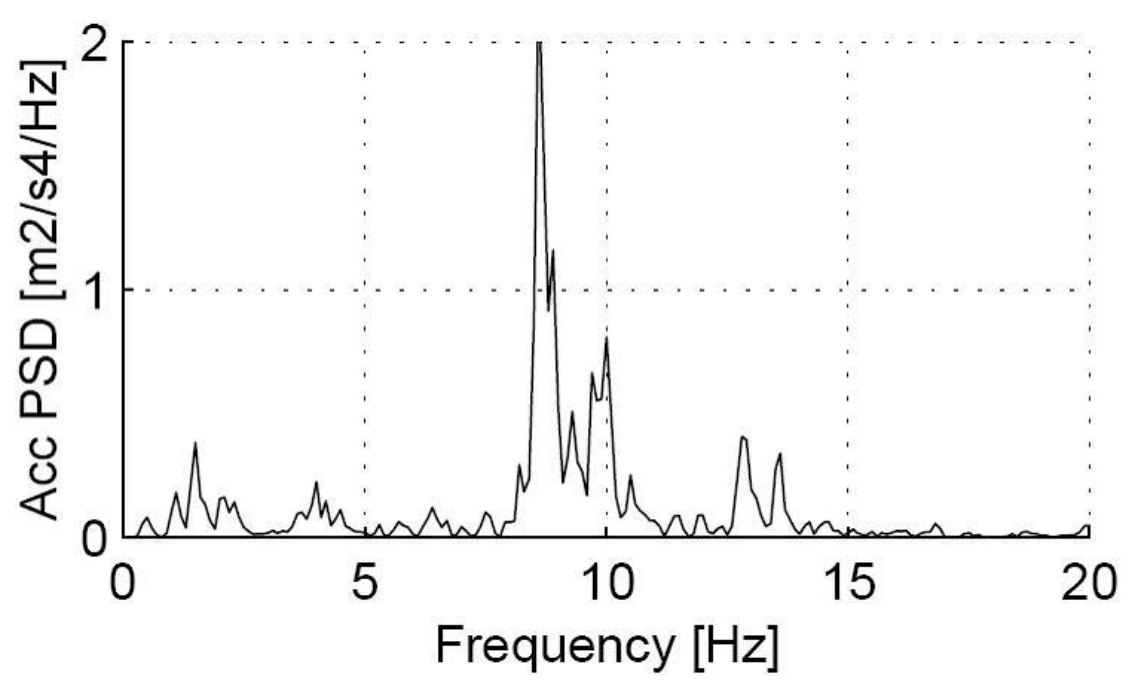

Gráfico 2.3 - PSD do Movimento Vertical no Centro da Caixa - Veículo V.2 (CARLBOM, 2000)

Os dois diagramas do gráfico 2.4, mostram uma comparação entre o modelo de multicorpos com caixa flexível e caixa rígida para o veículo V.3 circulando a 195 $\mathrm{km} / \mathrm{h}$.
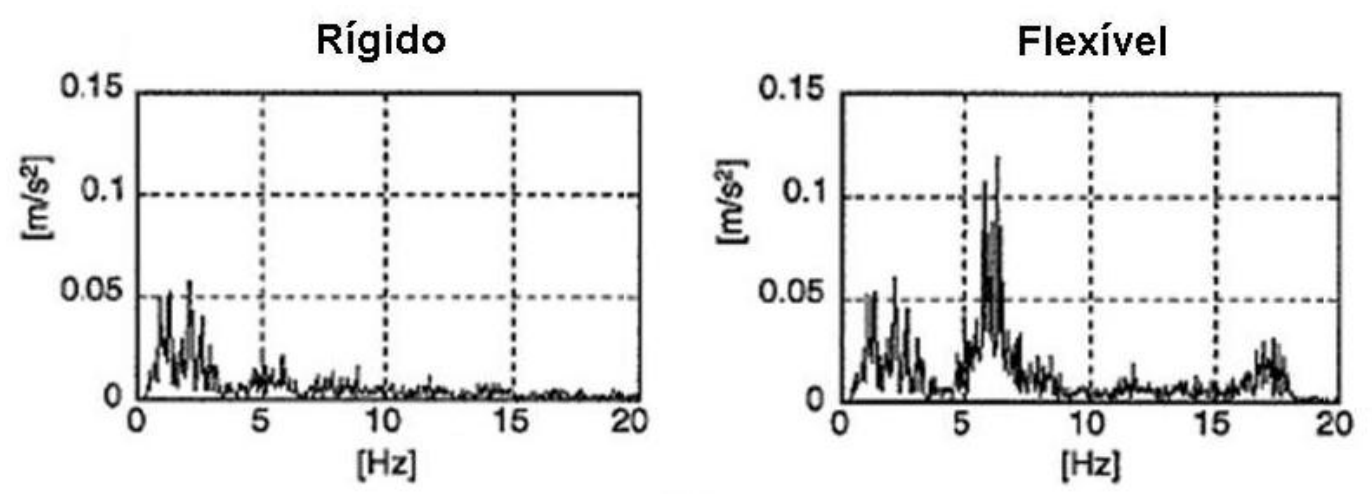

Gráfico 2.4 - Aceleração Vertical no Centro da Caixa - Veículo V.3 - caixa como corpo rígido e flexível (DIANA et al., 2002)

O último gráfico desta série consiste de uma comparação entre os níveis de aceleração vertical detectadas no centro da caixa e na linha do pivô do truque para os veículos V.1 e V.3. 

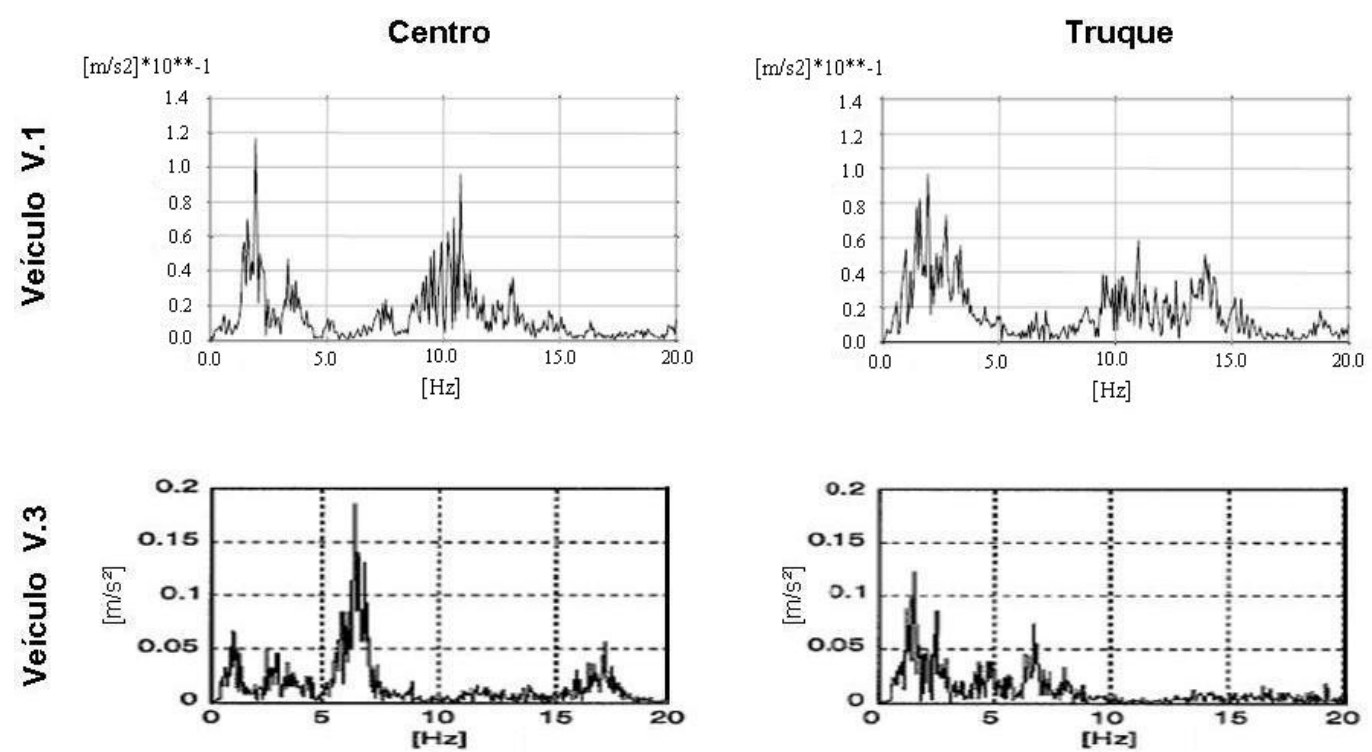

Gráfico 2.5 - Acelerações Verticais no Centro e no Pivô dos Truques para os Veículos V.1 (STRIBERSKY; MOSER; RULKA, 2000) e V.3 (DIANA et al., 2002)

A partir das informações acima e baseado nos trabalhos mencionados no início do capítulo, as seguintes conclusões podem ser tiradas:

- A instalação de equipamentos no sub-estrado ou na cobertura não pode ser negligenciada, pois influencia de maneira considerável nas freqüências dos modos de vibrar da caixa e, conseqüentemente, na resposta à excitação provocada pela via;

- Os picos situados abaixo de $5 \mathrm{~Hz}$ pertencem às vibrações de corpo rígido e acima de $7 \mathrm{~Hz}$ são originados pela flexibilidade da caixa;

- Pelos gráficos que mostram a comparação entre os resultados de corpo rígido e flexível percebe-se claramente que nas freqüências inferiores a $5 \mathrm{~Hz}$ o fato de se ter usado uma caixa flexível quase não influencia os resultados. Porém, o mesmo não ocorre quando as freqüências são superiores a $5 \mathrm{~Hz}$;

- Os maiores picos de aceleração vertical no centro do veículo são detectados nas freqüências correspondentes ao modo de flexão vertical da caixa. Por outro lado quando medido na região do pivô dos truques, as acelerações devem-se principalmente aos modos de corpo rígido inferiores a $5 \mathrm{~Hz}$. Esse fenômeno pode ser percebido nas comparações mostradas no gráfico 2.5;

- As acelerações verticais acima do pivô dos truques é menor que no centro do veículo para a faixa de freqüência do modo de flexão vertical da caixa. 
Um fenômeno que não pode ser observado pela análise dos gráficos acima mas foi ressaltado no artigo de (STRIBERSKY; MOSER; RULKA, 2000) é que as variações de massa e das propriedades físicas da estrutura da caixa juntamente com a presença de equipamentos que são instalados no sub-estrado podem induzir o aparecimento de modos de vibração localizado na estrutura. Durante os experimentos práticos deve-se ter uma atenção especial a este efeito pois tais vibrações localizadas podem deturpar os resultados esperados para o veículo.

Tendo em vista que o objetivo deste trabalho é a análise da vibração lateral em veículos ferroviários, o gráfico 2.6 é de grande valia, pois mostra que a contribuição para o cálculo de conforto das acelerações de corpo rígido inferiores a $7 \mathrm{~Hz}$ (em branco) é muito maior que as acelerações de corpo flexível situadas entre 7-20 Hz (em preto) quando se trata da análise lateral. Esta discrepância é ainda maior na região dos truques quando comparado com o centro do veículo. Isso nos permite concluir que a estimação da contribuição da vibração lateral no conforto de passageiros utilizando um modelo de corpo rígido difere muito pouco do resultado que seria obtido a partir de um modelo de corpo flexível.
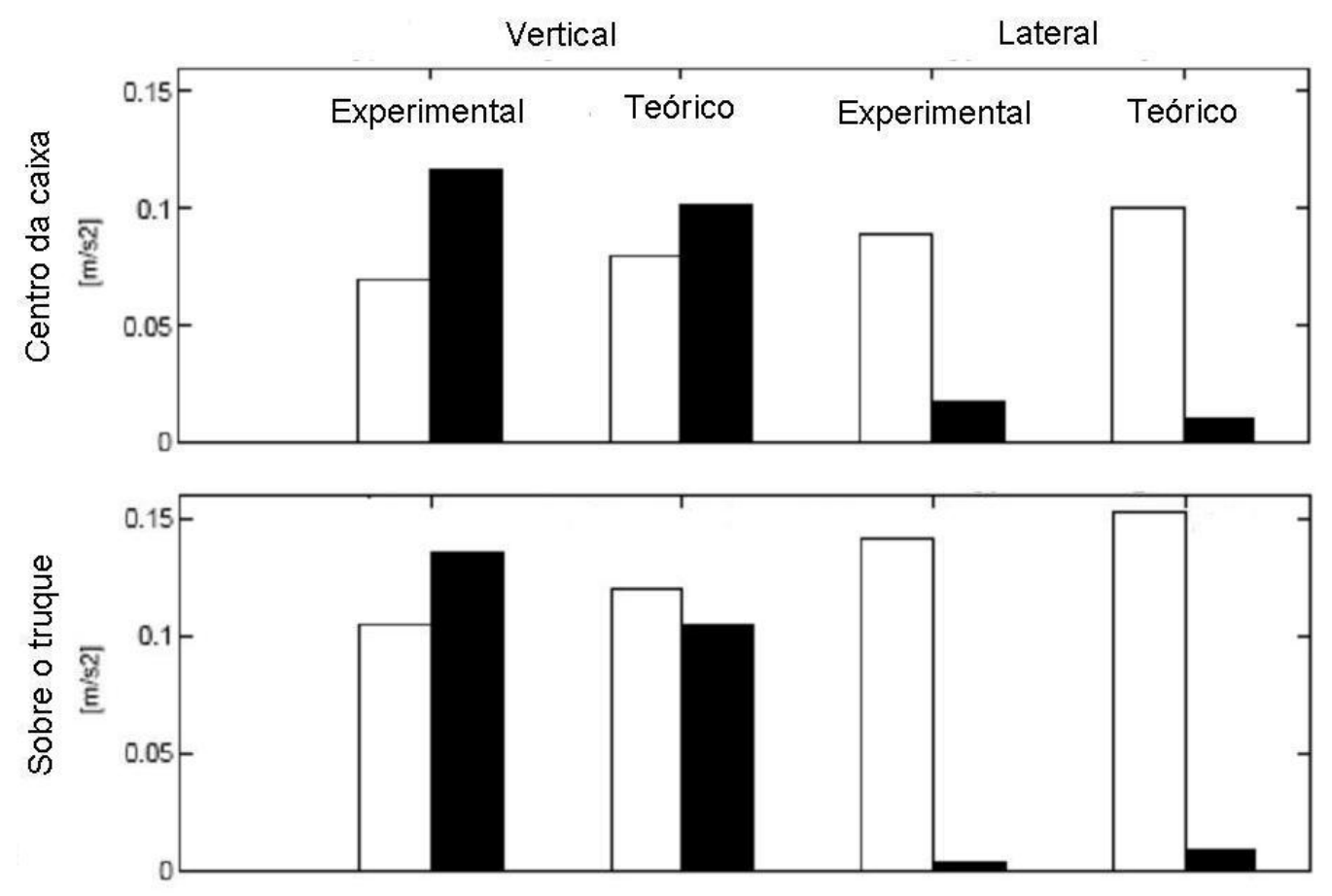

Gráfico 2.6 - Ponderação do Conforto Vertical e Lateral em Análise de Corpo Rígido (branco 0,3-7 $\mathrm{Hz}$ ) e Flexível (preto 7-20 Hz). (CARLBOM, 2000) 


\subsection{Perfil de vias férreas}

Os dois principais fatores externos de excitação mecânica de um veículo ferroviário devem-se a via e à aerodinâmica do veículo. Os efeitos aerodinâmicos tornam-se muito importantes na análise de trens a grande velocidade como é o caso do TGV francês, ICE (Inter City Express) alemão e Shinkansen japonês. Os estudos no sentido de melhor entender o comportamento do fluxo de ar em torno do veículo em movimento possibilita, entre outros, a redução do consumo de energia perdida devido ao efeito de arraste, ruído e vibração. Porém, como esses efeitos são menos significativos a baixa velocidade podem ser negligenciados (RAGHU; KIM; SETOGUCHI, 2002) e não fazem parte do escopo deste trabalho.

Além dos efeitos de contato entre a roda e o trilho, as excitações mecânicas são causadas em grande parte pela geometria da via. Existem diversos fatores que definem a qualidade geométrica de instalação dos trilhos que variam de acordo com as normas adotadas e com o país em questão. Tais fatores são detalhados a seguir.

\subsubsection{Bitola}

A bitola de uma via é definida como a menor distância entre dois trilhos tomada entre a superfície de rolamento e a uma linha paralela a esta situada a uma distância $Z p=(14 \pm 1) \mathrm{mm}$ abaixo da mesma conforme descrito pela norma NF EN 13848-1. A superfície de rolamento é definida como uma linha perpendicular ao eixo central vertical da via tangente às duas superfícies superiores do trilho. Segundo esta mesma norma, a tolerância de instalação é de $+/-1 \mathrm{~mm}$ e é dado pela medida " $G$ " mostrada na figura 2.10 .

Os valores de bitola não são padronizados ao redor do mundo. Nos principais países da Europa (com exceção da Irlanda, Grand-Bretanha e Finlândia) e na América do Norte o valor de bitola mais freqüente é o de $1435 \mathrm{~mm}$. No Brasil encontram-se quatro bitolas diferentes: as de $760 \mathrm{~mm}, 1000 \mathrm{~mm}, 1440 \mathrm{~mm}$ e a mais difundida que 
é a de $1600 \mathrm{~mm}$. Além do Brasil, a bitola de $1600 \mathrm{~mm}$ só é encontrada na Austrália, Grand-Bretanha, e Irlanda (F 50-704, 1987).

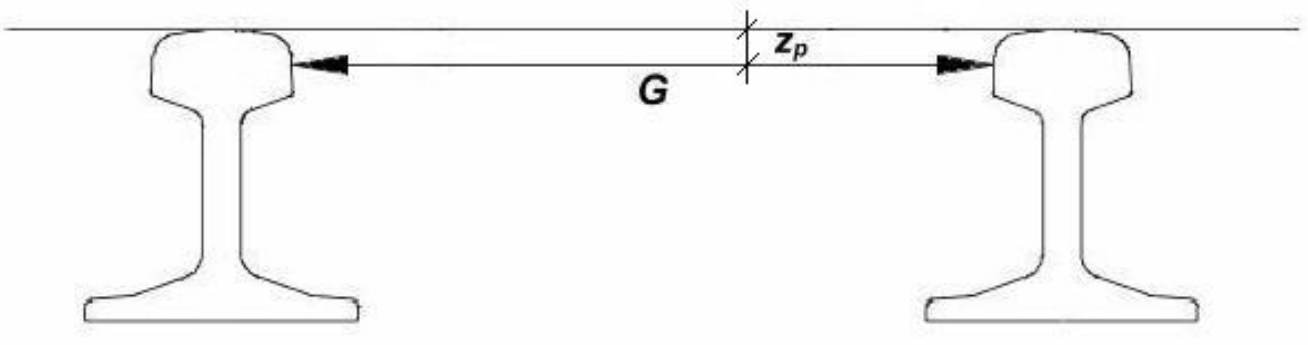

Figura 2.10 - Bitola (NF EN 13848-1)

\subsubsection{Nivelamento longitudinal}

Este parâmetro consiste no deslocamento vertical do trilho com relação à posição média da linha de referência calculado a partir de medidas sucessivas para comprimentos de onda pré-definidos. A norma NF EN 13848-1 define três comprimentos de onda e, para cada um deles, a incerteza máxima do nivelamento longitudinal conforme mostrado na tabela 2.2 .

Tabela 2.2 - Tolerância do Nivelamento Longitudinal

\begin{tabular}{ccc}
\hline Domínio & Comprimento de onda $(\mathrm{m})$ & Tolerância $(\mathrm{mm})$ \\
\hline D1 & $3<\lambda \leq 25$ & \pm 1 \\
D2 & $25<\lambda \leq 70$ & \pm 3 \\
D3 & $70<\lambda \leq 150$ & \pm 5 \\
\hline
\end{tabular}

O domínio D1 pode ter o valor inferior reduzido a $1 \mathrm{~m}$ caso se deseje detectar os defeitos para pequenos comprimentos de onda. Quanto ao domínio D3, este deve ser utilizado para vias onde a velocidade de circulação seja superior a $250 \mathrm{~km} / \mathrm{h}$.

Os valores acima definem a qualidade de via de utilização comercial. Os valores referentes as vias de teste são definidos pela norma NF EN 14363 e mostrados na tabela 2.3. A abordagem deste parâmetro é feita de maneira diferente e são definidos três níveis de exigência: 
- QN 1: não exige nenhum tipo de intervenção de manutenção mas um processo de observação da evolução das irregularidades deve ser instaurado;

- QN 2: necessita de manutenção à curto prazo;

- QN 3: não representa um trecho com qualidade normal porém é admissível.

Para o intervalo de comprimento de onda D1 definido na tabela $2.2(3<\lambda \leq 25)$ e considerando uma velocidade de circulação inferior a $80 \mathrm{~km} / \mathrm{h}$ os níveis de máximo absoluto $\left(\Delta Z_{\text {max }}^{0}\right)$ e típico $\left(\Delta Z^{0}{ }_{\sigma}\right)$ segundo a norma mencionada acima são apresentados na tabela a seguir.

Tabela 2.3 - Tolerâncias Segundo a Qualidade da Via

\begin{tabular}{ccc}
\hline Qualidade & Máxima absoluta $(\mathrm{mm})-\Delta \mathbf{Z}_{\max }^{0}$ & Típica $(\mathrm{mm})-\Delta \mathbf{Z}_{\sigma}^{0}$ \\
\hline QN 1 & \pm 12 & $\pm 2,3$ \\
QN 2 & \pm 16 & $\pm 2,6$ \\
QN 3 & $\pm 20,8$ & Não definido \\
\hline
\end{tabular}

\subsubsection{Nivelamento cruzado}

Consiste na diferença de altura entre o topo de dois trilhos adjacentes e o plano horizontal de referência. As tolerâncias máximas de nivelamento cruzado admitido pelas normas NF EN 13848-1 em via comercial e NF EN 14363 em via de teste são mostradas nas tabelas 2.4 e 2.5 .

Tabela 2.4 - Alinhamento Transversal e Gradiente Segundo a Norma EN 13848

\begin{tabular}{ccc} 
Altura $(\mathrm{mm})$ & $\lambda \leq 5,5 \mathrm{~m}$ & $5,5 \mathrm{~m}<\lambda \leq 20 \mathrm{~m}$ \\
\pm 5 & $\pm 1 / \lambda \%$ & $\pm 2 / \lambda \%$ \\
\hline
\end{tabular}

Tabela 2.5 - Alinhamento Transversal e Gradiente Segundo a Norma EN 14363

\begin{tabular}{ccccc}
\hline Qualidade & $\begin{array}{c}\text { Máx. absoluta } \\
\Delta \mathrm{Y}_{\max }^{0}(\mathrm{~mm})\end{array}$ & $\begin{array}{c}\text { Típica } \\
\Delta \mathrm{Y}_{\sigma}^{0}(\mathrm{~mm})\end{array}$ & $1,3 \mathrm{~m}<\lambda \leq 2,5 \mathrm{~m}$ & $2,5 \mathrm{~m}<\lambda \leq 20 \mathrm{~m}$ \\
\hline QN 1 & \pm 12 & $\pm 1,5$ & & \\
QN 2 & \pm 14 & $\pm 1,8$ & $20 / 2 \lambda+3 \%$ & $7 \%$ \\
QN 3 & $\pm 18,2$ & Não definido & & \\
\hline
\end{tabular}




\subsubsection{Alinhamento longitudinal}

O último dos quatro itens principais que definem a qualidade geométrica da via é a variação horizontal entre a linha de centro de dois trilhos e a linha de centro de referência. De acordo com o domínio de comprimento de onda D1, D2 e D3 da norma (EN 13848, 2004), as tolerâncias de instalação são apresentadas na tabela a seguir.

Tabela 2.6 - Tolerância do Alinhamento Longitudinal

\begin{tabular}{ccc}
\hline Domínio & Comprimento de onda $(\mathrm{m})$ & Tolerância $(\mathrm{mm})$ \\
\hline D1 & $3<\lambda \leq 25$ & $\pm 1,5$ \\
D2 & $25<\lambda \leq 70$ & \pm 4 \\
D3 & $70<\lambda \leq 150$ & \pm 10 \\
\hline
\end{tabular}

A figura 2.11 mostra os quatro tipos de irregularidade apresentados neste capítulo.

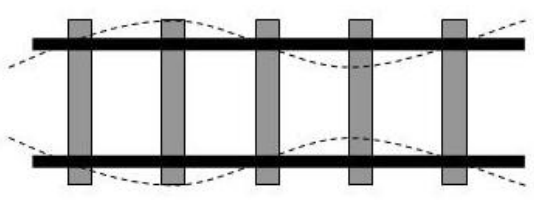

Bitola

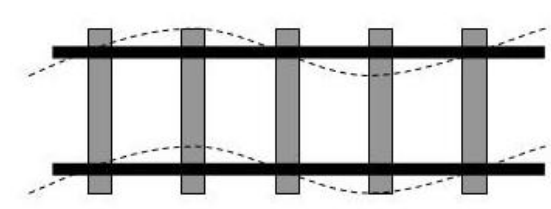

Alinhamento Longitudinal

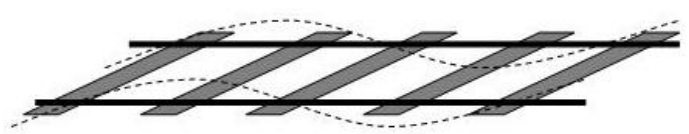

Nivelamento Longitudinal

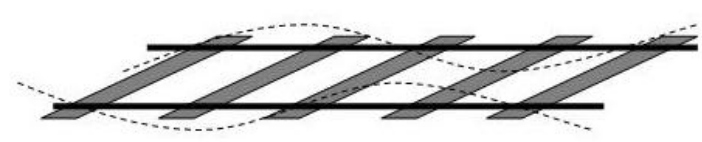

Nivelamento Cruzado

Figura 2.11 - Parâmetros da Qualidade Geométrica de Via Férrea (BARBOSA, 1999)

Os quatro parâmetros da qualidade geométrica da via apresentados anteriormente são definidos como intervalos, isto é, o respeito dos critérios faz com que a instalação dos trilhos esteja entre um limite superior e inferior. Da mesma forma, quando a norma se refere a comprimento de onda, novamente é definido em termos de intervalos. Isso quer dizer que em um caso real, por exemplo, para um comprimento de onda D1 pode-se ter em um determinado trecho de via uma irregularidade com um comprimento de onda de $4 \mathrm{~m}$ e amplitude $0,3 \mathrm{~mm}$ e outro 
com $20 \mathrm{~m}$ de comprimento de onda e 0,9 mm de amplitude. Logo, existem infinitas combinações entre os parâmetros que definem o perfil de via.

Uma das maneiras de se determinar um perfil de via tipo para ser utilizado como dado de entrada de um modelo de análise vibratória é a partir de medidas experimentais. Através de medições topográficas ou com a utilização de veículos especiais, pode-se obter uma curva PSD (Power Spectral Density) das irregularidades que é uma função do inverso do comprimento de onda (1/ $\lambda$ ). A figura abaixo mostra uma função PSD das irregularidades de alinhamento vertical de uma via típica com qualidade de manutenção média.

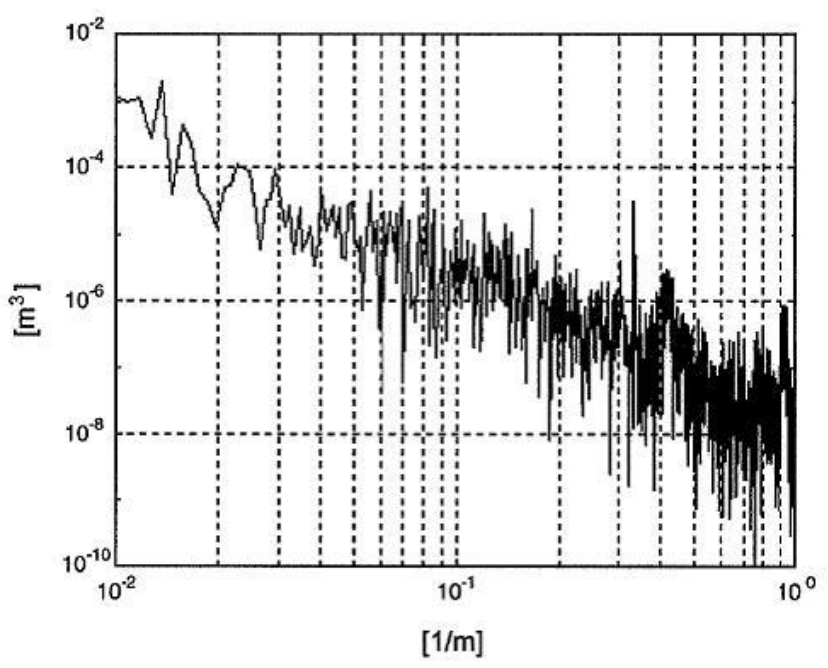

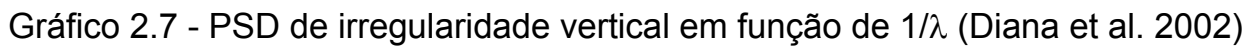

A obtenção das irregularidades aleatórias de uma via pode também ser aproximada com a utilização da fórmula a seguir (PEARCE; THOMPSOM, 2004):

$$
\Phi(\omega)=\frac{c V}{\omega^{2}} \mathrm{~m}^{2} / \mathrm{rad} / \mathrm{s}
$$

onde constante $c$ representa a rugosidade da via e $V$ a velocidade de deslocamento. O interesse principal desta curva é que ela representa um "ruído branco", isto é, cobre todas as faixas de freqüência de um dado intervalo e que o valor médio quadrático da aceleração ( $\mathrm{rms}$ ) do sinal de saída é proporcional a integral da raiz quadrada da resposta a uma entrada degrau de valor unitário. Além disso, todos os 
tipos de via quer sejam lisas ou rugosas podem ser representadas em função da constante $c$.

Seja uma componente $\lambda$ qualquer de uma via irregular, a excitação nos truques dianteiro $\left(z_{d}\right)$ e traseiro $\left(z_{t}\right)$ em um veículo que possui uma distância entre pivôs de truques dado por $I_{t}$ e com velocidade de deslocamento $V$ será dada pelas seguintes fórmulas:

$$
z_{d}=Z \operatorname{seno}\left(\frac{2 \pi V}{\lambda} t\right) \quad \text { e } \quad z_{t}=Z \operatorname{seno}\left(\frac{2 \pi V}{\lambda}\left(t-\frac{l_{t}}{V}\right)\right)
$$

A amplitude $Z$ é obtida a partir da curva PSD.

Assim, existem infinitas combinações de velocidade e comprimento de onda $V / \lambda$ que podem excitar o truque em uma dada freqüência. Devido à distância entre pivôs, há uma defasagem entre os sinais de entrada nos truques dianteiro $\left(z_{d}\right)$ e traseiro $\left(z_{t}\right)$. Portanto, para que as entradas $z_{d}$ e $z_{t}$ estejam em fase, é necessário que o comprimento de onda $\lambda$ seja proporcional a distância entre pivôs. A figura 2.12 mostra três casos em que o modo vertical de vibração é excitado (quando os dois truques estão em fase) para diferentes comprimentos de onda.

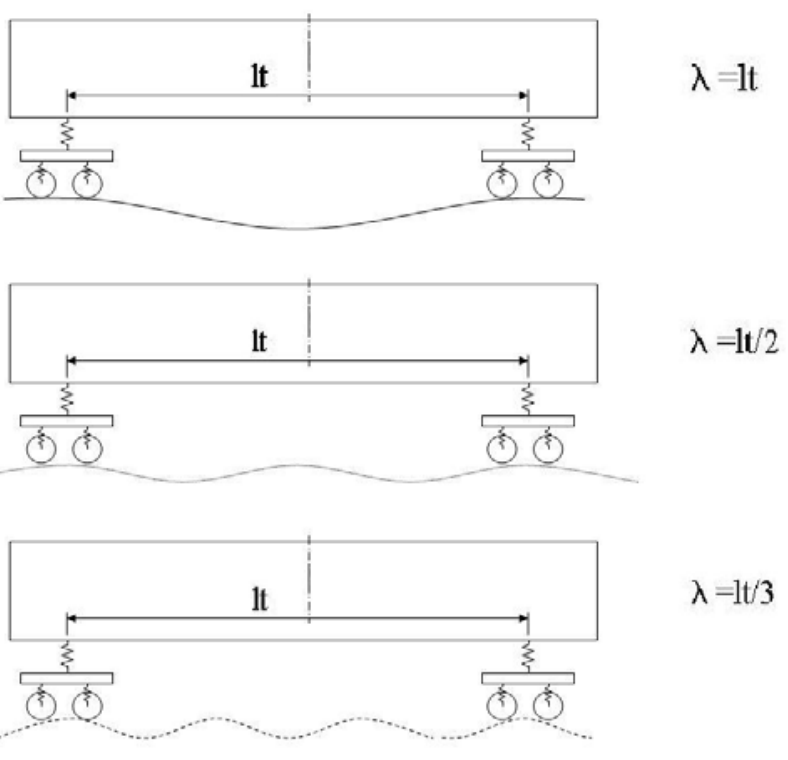

Figura 2.12 - Comprimento de Onda Associado a Distância Entre Pivôs 
A partir dos casos da figura anterior, a excitação da freqüência de ressonância do modo vertical será feita a três velocidades diferentes chamadas de "velocidade crítica". A velocidade crítica $V c_{1}$ do primeiro caso $\left(\lambda=I_{t}\right)$ é o dobro de $V c_{2}\left(\lambda=I_{t} / 2\right)$ e o triplo de $V c_{3}\left(\lambda=l_{t} / 3\right)$, pois como pode ser percebido na equação 2.4 a freqüência de excitação é diretamente proporcional à $V$ e inversamente proporcional a $\lambda$.

O gráfico 2.7 mostra que, em uma curva PSD típica, quanto maior for o comprimento de onda $\lambda$, maior são as amplitudes das componentes harmônicas. Baseado na figura 2.12, a partir da PSD típica, a amplitude, o comprimento de onda e a velocidade crítica para o primeiro caso seria maior que para os outros dois. Portanto para grandes comprimentos de onda, a energia introduzida no sistema será maior e conseqüentemente as vibrações serão mais significativas.

Como foi mostrado no capítulo 2.4 , a freqüência natural do modo vertical de vibração de uma caixa se situa entre $6 \mathrm{~Hz}$ e $13 \mathrm{~Hz}$. Partindo dos valores dados por (YAGIZ; GURSEL, 2005) em que o primeiro modo de vibração da caixa é de $8,1 \mathrm{~Hz}$ e a distância entre pivôs é de 19 m, as três primeiras velocidades críticas serão:

- $V c_{1}=\lambda_{1} \cdot f=19.8,1=153,9 \mathrm{~m} / \mathrm{s}=554 \mathrm{~km} / \mathrm{h}$;

- $V c_{2}=\lambda_{2} \cdot f=\frac{19}{2} \cdot 8,1=76,95 \mathrm{~m} / \mathrm{s}=277 \mathrm{~km} / \mathrm{h}$;

- $V c_{3}=\lambda_{3} \cdot f=\frac{19}{3} \cdot 8,1=51,3 \mathrm{~m} / \mathrm{s}=185 \mathrm{~km} / \mathrm{h}$.

Logo, pela ordem de grandeza do comprimento de onda e da freqüência natural da caixa apresentadas acima pode-se perceber que somente os trens de grande velocidade poderiam ser excitados nas primeiras velocidades crítica o que não é o caso. Por outro lado, tais velocidades não devem ser completamente negligenciadas no estudos de metrôs e vagões de carga em que as distâncias entre pivôs são relativamente menores. 


\section{Modelagem do veículo}

\subsection{Introdução}

Para obtenção de resultados confiáveis é necessário cumprir uma série de etapas conforme descrito por (BARBOSA, 1999). Baseado nessas etapas foi desenvolvida a estrutura deste capítulo que consiste de:

- Hipóteses: levantamento de todas as considerações de simplificação que serão utilizadas no modelamento;

- Modelo do veículo: detalhamento dos corpos e vínculos que compõem os truques e a caixa formando o veículo como um todo;

- Equações de movimento: dedução das equações diferenciais de movimento que definem o modelo matemático do sistema dinâmico;

- Processo numérico de soluções: dois tipos de soluções são propostas. $\mathrm{Na}$ primeira delas foi utilizada a abordagem de Espaço de Estado e será aqui chamada de "Solução Analítica". A segunda solução, que visa um sistema não linear, foi elaborada utilizando um software de diagrama de blocos e será chamada de "Solução por Integração Numérica";

- Análise e interpretação dos resultados: este tópico será abordado no capítulo 4 .

\subsection{Levantamento das hipóteses}

A série de hipóteses e simplificações listadas abaixo servirão de base à elaboração do modelo.

1) O veículo é simétrico tanto no sentido longitudinal quanto transversal;

2) As rijezas das molas são lineares em torno do ponto de operação; 
3) Os deslocamentos angulares são pequenos, logo os valores de seno, arco seno, tangente e arco tangente podem ser aproximados ao valor do próprio ângulo (SHENG, 2003). Esta aproximação se aplica somente aos sistemas lineares (MEIROVITCH, 1975);

4) Todos os componentes do veículo movem-se a mesma velocidade no sentido longitudinal e não existe deslocamento relativo entre eles. Desta forma o movimento longitudinal da caixa $X_{c}$ e dos dois truques $X_{t 1}$ e $X_{t 2}$ foram desconsiderados. Uma vez que esses movimentos longitudinais não excitam os movimentos laterais devido à simetria e linearidade do sistema, os resultados não são severamente influenciados;

5) Rijezas e amortecimentos do trilho e de sua fixação sobre os dormentes são desprezados como nulo conforme adotado por (SHENG, 2003);

6) A dinâmica do contato roda trilho é desconsiderada e sua geometria não é deformável. Efeitos dos movimentos de corpo rígido e demais propriedades de contato não são considerados. A partir desta hipótese e da anterior o movimento do rodeiro é considerado como se percorresse o perfil exato dos trilhos, não havendo movimento relativo ou deslocamento entre eles. Os movimentos de hunting dos truques não são simulados;

7) A variação do alinhamento longitudinal da via é nula; logo, os rodeiros não se movimentam lateralmente. A partir desta hipótese os movimentos laterais da armação do truque $\left(Y_{t 1}\right.$ e $\left.Y_{t 2}\right)$ e de yaw $\left(\theta_{t 1 z}\right.$ e $\left.\theta_{t 2 z}\right)$ do truque são desconsiderados;

8) Um truque de dois eixos foi aproximado a um truque de um eixo que executa $o$ caminho médio percorrido pelo duplo rodeiro. Esta aproximação elimina o movimento de pitch (rotação no eixo transversal $-y)$ da armação do truque $\left(\theta_{t 1 y} \mathrm{e}\right.$ $\left.\theta_{t 2 y}\right)$;

9) Uma vez que os rodeiros percorrem o exato perfil dos trilhos (hipótese 6), e que não há variação do alinhamento longitudinal da via (hipótese 7 ) a excitação do sistema é feita pelo movimento de deslocamento vertical $\left(Z_{t 1}\right.$ e $\left.Z_{t 2}\right)$ e roll $\left(\theta_{t 1 x}\right.$ e $\left.\theta_{t 2 x}\right)$ dos rodeiros; 
10) A caixa e as armações dos truques são consideradas como um corpo rígido. Baseado nesta simplificação, duas considerações feitas no capítulo 2 são aplicáveis:

10.1) Os picos situados abaixo de $5 \mathrm{~Hz}$ pertencem às vibrações de corpo rígido e acima de $7 \mathrm{~Hz}$ são originados pela flexibilidade da caixa, comprovados por (DIANA et al., 2002) e apresentado no gráfico 2.4. Como análises do capítulo 4 se concentram na faixa entre $0,5 \mathrm{~Hz}$ e $2 \mathrm{~Hz}$, tal hipótese não afeta consideravelmente os resultados;

10.2) Segundo (CARLBOM, 2000) a estimação da contribuição da vibração lateral no conforto de passageiros pode ser feita utilizando um modelo de corpo rígido (ver gráfico 2.6). Este trabalho faz somente a análise dos movimentos laterais conforme definido nos objetivos;

11) $O$ centro de gravidade $(C G)$ da caixa se localiza em uma linha perpendicular ao plano horizontal passado pelo centro geométrico da caixa a uma altura $h_{c g}$ do plano de rolamento (ver figura 3.1);

12) A rigidez de suspensões primárias no sentido lateral é muito maior que no sentido vertical, podendo chegar a ser 11 vezes mais rígida como é o caso da suspensão Metacone $^{\mathrm{TM}}$ 17-2087 (TRELLEBORG, 2007). A partir desta constatação e da hipótese 7 é assumido que os movimentos relativos entre o rodeiro e a armação do truque no sentido lateral são desconsiderados, portanto as suspensões primárias atuam somente no sentido vertical.

Uma vez que as principais hipóteses do sistema foram levantadas é possível elaborar o modelo físico do veículo, o que será feito no capítulo a seguir.

\subsection{Modelo do veículo}

No capítulo anterior foram levantadas hipóteses e simplificações que permitem o desenvolvimento do modelo do veículo. A seguir serão definidos os corpos, vínculos e principais dimensões dos modelos da caixa e em seguida dos truques e do veículo como um todo. 
A caixa é o componente de sustentação utilizado para o confinamento de passageiros e instalação dos equipamentos de modo geral. Suas características dimensionais, de massa e inércias utilizadas pelo modelo são:

- $m_{c}$ : massa;

- $I_{c x}, I_{c y}$ e $I_{c z}:$ momento de inércia nos eixos $x, y$ e $z$;

- $h_{m}$ : altura do centro de gravidade (CG) da caixa em relação ao piso;

- $I_{c t}$ : semi-distância entre os pivôs dos truques;

- $I_{m}$ : distância do banco a partir da linha de centro transversal;

- $b_{m}$ : distância do banco a partir da linha de centro longitudinal.

Além da caixa o outro componente modelado é o truque. As únicas juntas que são exclusivas ao modelo dos truques são as suspensões primárias, uma vez que os demais elementos de suspensão compõem a interface caixa-truque. Conforme as hipóteses 5 e 6 o rodeiro percorre o exato perfil da via; logo, suas características de massa e inércia não são levadas em consideração na definição das equações do sistema. O movimento do rodeiro é definido a partir da posição vertical dos trilhos da seguinte forma:

- $Z_{r}$ : variação da altura do centro do rodeiro em relação a sua posição nominal quando os dois trilhos estão no nível de referência. Este valor é dado pela média das alturas dos trilhos e representa as irregularidades de nivelamento vertical (ver figura 2.11);

- $\theta_{r x}$ : ângulo formado entre o eixo do rodeiro e o plano horizontal dado pelo arco tangente da diferença de altura dos trilhos dividido pela bitola. Como este valor é pequeno, o ângulo pode ser aproximado diretamente como a razão entre a diferença de altura pela bitola conforme hipótese feita anteriormente. Este ângulo representa as excitações de nivelamento cruzado (ver figura 2.11).

Com relação à suspensão primária, para que ela conserve as mesmas características quando se passa de dois rodeiros para um conforme a hipótese 8 , a rigidez e o amortecimento de cada conjunto instalado na extremidade do eixo devem ser multiplicados por dois. Esta suspensão foi aproximada a uma mola em paralelo a um amortecedor atuando no sentido vertical como mencionado na hipótese 12 . Dessa forma, as características dos corpos e vínculos que formam o truque são: 
- $m_{t}$ : massa do truque;

- $I_{t x z}$ : momento de inércia no eixo $x$;

- $C_{p z}$ : amortecimento da suspensão primária no eixo z;

- $K_{p z}$ : rigidez da suspensão primária no eixo z;

- $\quad b_{p}$ : semi-distância entre suspensões primárias;

- $b_{b}$ : bitola.

Uma vez definidos os truques e a caixa passa-se ao modelamento do veículo como um todo, para isso deve-se definir os vínculos e as dimensões da interface caixatruque. Esta interface é composta por um conjunto de amortecedores (dois verticais e dois horizontais), pelas suspensões secundárias e pela barra anti-rolamento.

A função da barra anti-rolamento é de reduzir o movimento de rotação da caixa em torno do eixo $x$. Quando a caixa, devido a um efeito qualquer, sofre uma rotação em $x$ formando um ângulo entre ela e a armação do truque, a barra anti-rolamento provoca um momento contrário ao ângulo formado no sentido de realinhar a caixa e a armação do truque.

Os amortecedores verticais e horizontais são instalados entre a armação do truque e a caixa, dois de cada lado do veículo e simétricos em relação ao centro do veículo. Dependendo do caso pode haver somente um amortecedor que devido ao ângulo de instalação execute a função de amortecimento em y e z.

O último elemento da interface caixa-truque é a suspensão secundária. Tendo em vista a possibilidade de simular o comportamento dinâmico do veículo com o uso de suspensões pneumáticas, as componentes verticais e horizontais desta suspensão foram aproximadas por dois conjuntos mola-amortecedor um atuando no sentido vertical e outro no sentido horizontal.

Os parâmetros das juntas e dimensões da interface caixa-truque são listados a seguir.

- $K_{s z}$ : rigidez vertical da suspensão secundária;

- $C_{s z}$ : amortecimento vertical da suspensão secundária;

- $K_{s y}$ : rigidez horizontal da suspensão secundária; 
- $C_{s y}$ : amortecimento horizontal da suspensão secundária;

- $K_{b t}$ : rigidez angular da barra anti-rolamento;

- $C_{a y}$ : amortecimento do amortecedor lateral;

- $C_{a z}$ : amortecimento do amortecedor vertical;

- $b_{s}$ : semi-distância entre suspensões secundárias;

- $b_{a y}$ : semi-distância entre amortecedores horizontais;

- $b_{a z}$ : semi-distância entre amortecedores verticais;

- $h_{\text {ayt }}$ : altura entre o CG da armação do truque e o amortecedor horizontal;

- $h_{s t}$ : altura entre o centro da armação do truque e o centro de aplicação de esforço da suspensão secundária;

- $h_{a z}$ : altura entre o CG da caixa e o amortecedor vertical;

- $h_{s}$ : altura entre o CG da caixa e o centro de aplicação de esforço da suspensão secundária;

- $h_{a y}$ : altura entre o CG da caixa e o amortecedor horizontal;

- $h_{t}$ : altura entre os centros de gravidade da caixa e do truque;

- $h_{p}$ : altura entre o CG da caixa e o centro de aplicação de esforço da suspensão primária;

- $h_{r}$ : altura entre o CG da caixa e o eixo do rodeiro;

- $h_{c g}$ : altura entre o CG da caixa e o plano de rolamento.

Os detalhes dos parâmetros listados acima são representados no modelo do veículo mostrado na figura 3.1. e servirão de base para a dedução das equações de movimento.

\subsection{Equações de movimento}

Baseado nas hipóteses do capítulo 3.2 foi desenvolvido o modelo representado na figura 3.1. A princípio, um veículo composto por três corpos (uma caixa e dois truques) deveria possuir 18 graus de liberdade. De acordo com a hipótese 4 os movimentos no eixo $x$ dos três corpos foram desconsiderados por se deslocarem a mesma velocidade. Os movimentos laterais, de yaw e pitch dos truques também foram desconsiderados baseado nas hipóteses 7 (variação nula do alinhamento 
longitudinal da via) e 8 (um rodeiro por truque). Desta forma o sistema que inicialmente possuía 18 graus de liberdade passou a ter 9 somente.

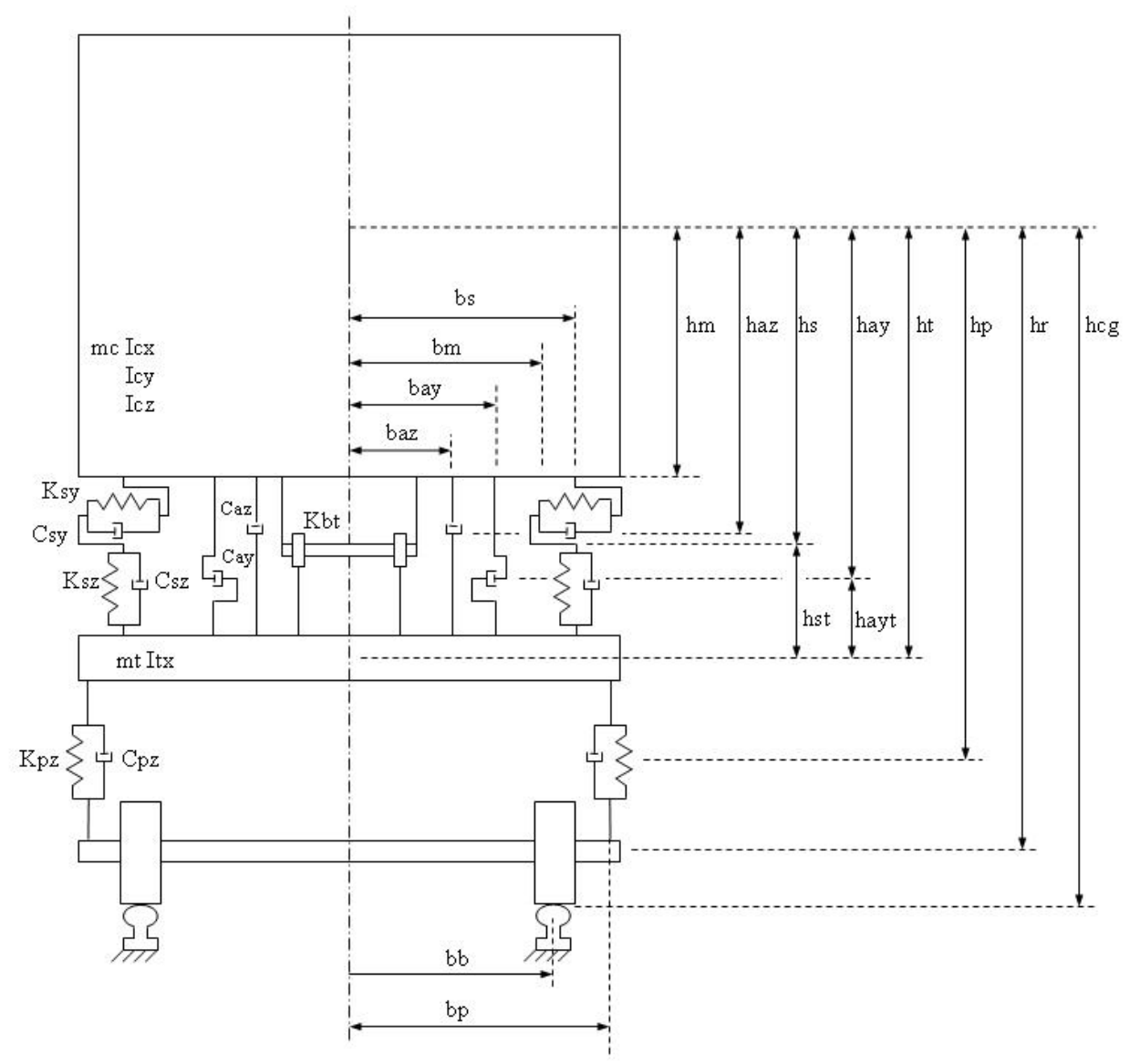

Figura 3.1 - Vista Frontal do Modelo

A figura 3.2 mostra onde estão localizados os 9 graus de liberdade considerados no sistema e logo a seguir uma lista de quais são eles.

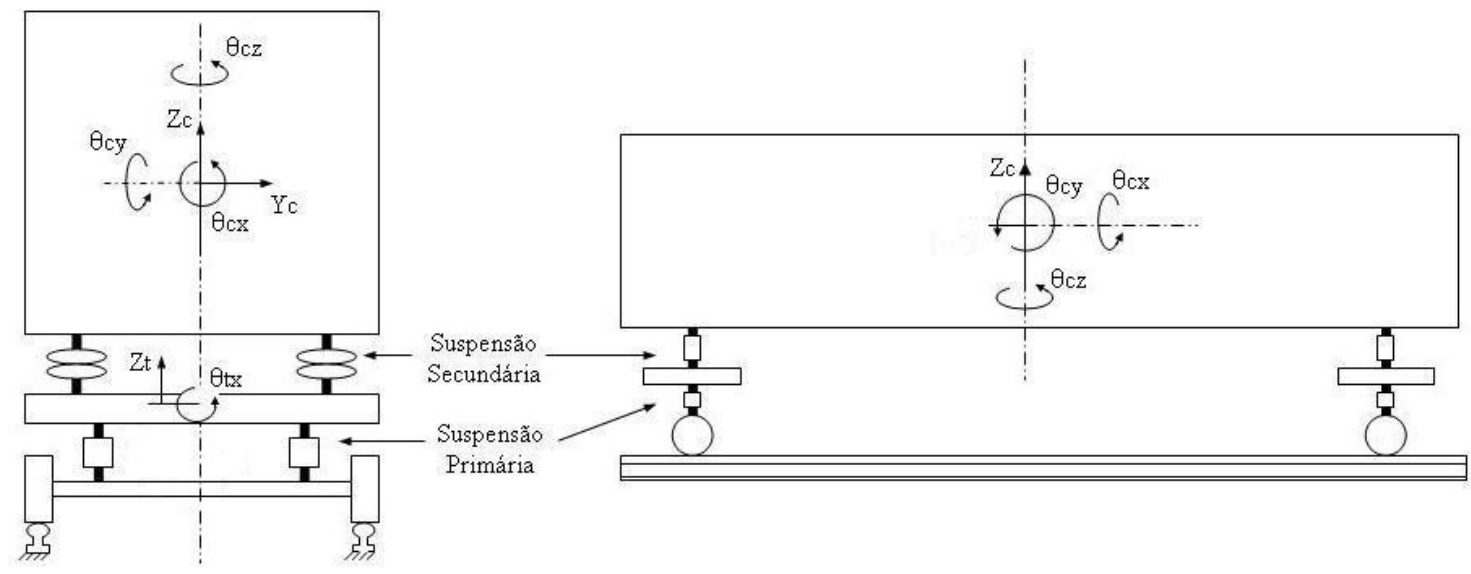

Figura 3.2 - Graus de Liberdade 
- $Z_{c}$ : movimento vertical da caixa;

- $Y_{c}$ : movimento lateral da caixa;

- $Z_{t 1}$ : movimento vertical do truque 1 - dianteiro;

- $Z_{t 2}$ : movimento vertical do truque 2 - traseiro;

- $\theta_{c x}$ : movimento de rolamento da caixa no eixo $x$ (roll);

- $\theta_{c y}$ : movimento de rotação da caixa no eixo y (pitch);

- $\theta_{c z}$ : movimento de rotação da caixa no eixo z (yaw);

- $\theta_{t 1 x}$ : movimento de rolamento da armação do truque 1 - dianteiro;

- $\theta_{\text {t2x }}$ : movimento de rolamento da armação do truque 2 - traseiro.

A seguir são deduzidas as equações diferenciais de movimento.

$\left.1^{\circ}\right)$ Movimento vertical da caixa $-Z_{c}$

$$
\begin{aligned}
& m_{c} \ddot{Z}_{c}+4\left(C_{s z}+C_{a s}\right) \dot{Z}_{c}-2\left(C_{s z}+C_{a s}\right) \dot{Z}_{t 1}-2\left(C_{s z}+C_{a s}\right) \dot{Z}_{t 2}+ \\
& +4 K_{s z} Z_{c}-2 K_{s z} Z_{t 1}-2 K_{s z} Z_{t 2}=0
\end{aligned}
$$

Logo

$$
\begin{aligned}
\ddot{Z}_{c} & =-\frac{4\left(C_{s z}+C_{a s}\right)}{m_{c}} \dot{Z}_{c}+\frac{2\left(C_{s z}+C_{a s}\right)}{m_{c}} \dot{Z}_{t 1}+\frac{2\left(C_{s z}+C_{a s}\right)}{m_{c}} \dot{Z}_{t 2}- \\
& -\frac{4 K_{s z}}{m_{c}} Z_{c}+\frac{2 K_{s z}}{m_{c}} Z_{t 1}+\frac{2 K_{s z}}{m_{c}} Z_{t 2}
\end{aligned}
$$

$2^{\circ}$ ) Movimento lateral da caixa $-Y_{c}$

$$
\begin{aligned}
& m_{c} \ddot{Y}_{c}+ \\
& +4\left(C_{s y}+C_{a y}\right) \dot{Y}_{c}+4\left(C_{s y}+C_{a y}\right) h_{s} \dot{\theta}_{c x}+2\left(C_{s y} h_{s t}+C_{a y} h_{a y t}\right) \dot{\theta}_{t x 1}+2\left(C_{s y} h_{s t}+C_{a y} h_{a y t}\right) \dot{\theta}_{t x 2}+ \\
& +4 K_{s y} Y_{c}+4 K_{s y} h_{s} \theta_{c x}+2 K_{s y} h_{s t} \theta_{t x 1}+2 K_{s y} h_{s t} \theta_{t x 2}=0
\end{aligned}
$$

Logo

$$
\begin{aligned}
\ddot{Y}_{C}= & -\frac{4\left(C_{s y}+C_{a y}\right)}{m_{c}} \dot{Y}_{c}-\frac{4\left(C_{s y}+C_{a y}\right) h_{s}}{m_{c}} \dot{\theta}_{c x}-\frac{2\left(C_{s y} h_{s t}+C_{a y} h_{a y t}\right)}{m_{c}} \dot{\theta}_{t x 1}-\frac{2\left(C_{s y} h_{s t}+C_{a y} h_{a y t}\right)}{m_{c}} \dot{\theta}_{t \times 2}- \\
& -\frac{4 K_{s y}}{m_{c}} Y_{c}-\frac{4 K_{s y} h_{s}}{m_{c}} \theta_{c x}-\frac{2 K_{s y} h_{s t}}{m_{c}} \theta_{t x 1}-\frac{2 K_{s y} h_{s t}}{m_{c}} \theta_{t x 2}
\end{aligned}
$$


$3^{\circ}$ ) Movimento vertical do truque 1 (dianteiro) $-Z_{t 1}$

$$
\begin{aligned}
& m_{t} \ddot{Z}_{t 1}- \\
& -2\left(C_{s z}+C_{a s}\right) \dot{Z}_{c}+2\left(C_{s z}+C_{a z}+C_{p z}\right) \dot{Z}_{t 1}+2\left(C_{s z}+C_{a s}\right) l_{c t} \dot{\theta}_{c y}- \\
& -2 K_{s z} Z_{c}+2\left(K_{s z}+K_{p z}\right) Z_{t 1}+2 K_{s z} l_{c t} \theta_{c y}= \\
& =2 C_{p z} \dot{Z}_{r 1}+2 K_{p z} Z_{r 1}
\end{aligned}
$$

Logo

$$
\begin{aligned}
\ddot{Z}_{t 1} & =\frac{2\left(C_{s z}+C_{a s}\right)}{m_{t}} \dot{Z}_{c}-\frac{2\left(C_{s z}+C_{a z}+C_{p z}\right)}{m_{t}} \dot{Z}_{t 1}-\frac{2\left(C_{s z}+C_{a z}\right) l_{c t}}{m_{t}} \dot{\theta}_{c y}+ \\
& +\frac{2 K_{s z}}{m_{t}} Z_{c}-\frac{2\left(K_{s z}+K_{p z}\right)}{m_{t}} Z_{t 1}-\frac{2 K_{s z} l_{c t}}{m_{t}} \theta_{c y}+ \\
& +2 C_{p z} \dot{Z}_{r 1}+2 K_{p z} Z_{r 1}
\end{aligned}
$$

$4^{\circ}$ ) Movimento vertical do truque 2 (traseiro) $-Z_{t 2}$

$$
\begin{aligned}
& m_{t} \ddot{Z}_{t 2}- \\
& -2\left(C_{s z}+C_{a s}\right) \dot{Z}_{c}+2\left(C_{s z}+C_{a z}+C_{p z}\right) \dot{Z}_{t 2}+2\left(C_{s z}+C_{a s}\right) l_{c t} \dot{\theta}_{c y}- \\
& -2 K_{s z} Z_{c}+2\left(K_{s z}+K_{p z}\right) Z_{t 2}+2 K_{s z} l_{c t} \theta_{c y}= \\
& =2 C_{p z} \dot{Z}_{r 2}+2 K_{p z} Z_{r 2}
\end{aligned}
$$

Logo

$$
\begin{aligned}
\ddot{Z}_{t 2} & =\frac{2\left(C_{s z}+C_{a s}\right)}{m_{t}} \dot{Z}_{c}-\frac{2\left(C_{s z}+C_{a z}+C_{p z}\right)}{m_{t}} \dot{Z}_{t 2}-\frac{2\left(C_{s z}+C_{a z}\right) l_{c t}}{m_{t}} \dot{\theta}_{c y}+ \\
& +\frac{2 K_{s z}}{m_{t}} Z_{c}-\frac{2\left(K_{s z}+K_{p z}\right)}{m_{t}} Z_{t 2}-\frac{2 K_{s z} l_{c t}}{m_{t}} \theta_{c y}+ \\
& +2 C_{p z} \dot{Z}_{r 2}+2 K_{p z} Z_{r 2}
\end{aligned}
$$


$\left.5^{\circ}\right)$ Movimento de rolamento da caixa no eixo $x($ roll $)-\theta_{c x}$

$$
\begin{aligned}
& I_{c x} \ddot{\theta}_{c x}+ \\
& +4\left(C_{s y}+C_{a y}\right) h_{s} \dot{Y}_{c}+4\left(C_{s z} b_{s}{ }^{2}+C_{a z} b_{a z}{ }^{2}+C_{s y} h_{s}{ }^{2}+C_{a y} h_{a y}{ }^{2}\right) \dot{\theta}_{c x}- \\
& -2\left(C_{s z} b_{s}{ }^{2}+C_{a z} b_{a z}{ }^{2}-C_{s y} h_{s t} h_{s}-C_{a y} h_{a y t} h_{a y}\right) \dot{\theta}_{t \times 1}- \\
& -2\left(C_{s z} b_{s}{ }^{2}+C_{a z} b_{a z}{ }^{2}-C_{s y} h_{s t} h_{s}-C_{a y} h_{a y t} h_{a y}\right) \dot{\theta}_{t x 2}+ \\
& +4 K_{s y} h_{s} Y_{c}+\left(4\left(K_{s z} b_{s}{ }^{2}+K_{s y} h_{s}{ }^{2}\right)+K_{b t}\right) \theta_{c x}- \\
& -\left(2\left(K_{s z} b_{s}^{2}-K_{s y} h_{s t} h_{s}\right)+K_{b t}\right) \theta_{t x 1}- \\
& -\left(2\left(K_{s z} b_{s}{ }^{2}-K_{s y} h_{s t} h_{s}\right)+K_{b t}\right) \theta_{t x 2}=0
\end{aligned}
$$

\section{Logo}

$$
\begin{aligned}
& \ddot{\theta}_{c x}= \\
& -\frac{4\left(C_{s y}+C_{a y}\right) h_{s}}{I_{c x}} \dot{Y}_{c}-\frac{4\left(C_{s z} b_{s}{ }^{2}+C_{a z} b_{a z}{ }^{2}+C_{s y} h_{s}{ }^{2}+C_{a y} h_{a y}{ }^{2}\right)}{I_{c x}} \dot{\theta}_{c x}+ \\
& +\frac{2\left(C_{s z} b_{s}{ }^{2}+C_{a z} b_{a z}{ }^{2}-C_{s y} h_{s t} h_{s}-C_{a y} h_{a y t} h_{a y}\right)}{I_{c x}} \dot{\theta}_{t x 1}+ \\
& +\frac{2\left(C_{s z} b_{s}{ }^{2}+C_{a z} b_{a z}{ }^{2}-C_{s y} h_{s t} h_{s}-C_{a y} h_{a y t} h_{a y}\right)}{I_{c x}} \dot{\theta}_{t x 2}- \\
& -\frac{4 K_{s y} h_{s}}{I_{c x} Y_{c}-\frac{\left(4\left(K_{s z} b_{s}{ }^{2}+K_{s y} h_{s}{ }^{2}\right)-K_{b t}\right)}{I_{c x}} \theta_{c x}+} \\
& +\frac{\left(2\left(K_{s z} b_{s}{ }^{2}-K_{s y} h_{s t} h_{s}\right)+k_{b t}\right)}{I_{c x}} \theta_{t x 1}+ \\
& +\frac{\left(2\left(K_{s z} b_{s}{ }^{2}-K_{s y} h_{s t} h_{s}\right)+k_{b t}\right)}{I_{c x}} \theta_{t x 2}
\end{aligned}
$$

$\left.6^{\circ}\right)$ Movimento de rotação da caixa no eixo y (pitch) $-\theta_{c y}$

$$
\begin{aligned}
& I_{c y} \ddot{\theta}_{c y}+ \\
& +2\left(C_{s z}+C_{a z}\right) l_{c t} \dot{Z}_{t 1}-2\left(C_{s z}+C_{a z}\right) l_{c t} \dot{Z}_{t 2}+4\left(C_{s z}+C_{a z}\right) l_{c t}{ }^{2} \dot{\theta}_{c y}+ \\
& +2 K_{s z} l_{c t} Z_{t 1}-2 K_{s z} l_{c t} Z_{t 2}+4 K_{s z} l_{c t}{ }^{2} \theta_{c y}=0
\end{aligned}
$$




$$
\begin{aligned}
\ddot{\theta}_{c y}= & -\frac{2\left(C_{s z}+C_{a z}\right) l_{c t}}{I_{c y}} \dot{Z}_{t 1}+\frac{2\left(C_{s z}+C_{a z}\right) l_{c t}}{I_{c y}} \dot{Z}_{t 2}-\frac{4\left(C_{s z}+C_{a z}\right) l_{c t}{ }^{2}}{I_{c y}} \dot{\theta}_{c y}- \\
& -\frac{2 K_{s z} l_{c t}}{I_{c y}} Z_{t 1}+\frac{2 K_{s z} l_{c t}}{I_{c y}} Z_{t 2}-\frac{4 K_{s z} l_{c t}{ }^{2}}{I_{c y}} \theta_{c y}
\end{aligned}
$$

$7^{\circ}$ ) Movimento de rotação da caixa no eixo $z($ yaw $)-\theta_{c z}$

$$
\begin{aligned}
& I_{c z} \ddot{\theta}_{c z}+ \\
& +4\left(C_{s y}+C_{a y}\right) l_{c t}{ }^{2} \dot{\theta}_{c z}+2\left(C_{s y} h_{s t}+C_{a y} h_{a y t}\right) l_{c t} \dot{\theta}_{t x 1}-2\left(C_{s y} h_{s t}+C_{a y} h_{a y t}\right) l_{c t} \dot{\theta}_{t x 2}+ \\
& +4 K_{s y} l_{c t}{ }^{2} \theta_{c z}+2 K_{s y} h_{s t} l_{c t} \theta_{t x 1}-2 K_{s y} h_{s t} l_{c t} \theta_{t x 2}=0
\end{aligned}
$$

Logo

$$
\begin{aligned}
& \ddot{\theta}_{c z}= \\
& -\frac{4\left(C_{s y}+C_{a y}\right) l_{c t}{ }^{2}}{I_{c z}} \dot{\theta}_{c z}-\frac{2\left(C_{s y} h_{s t}+C_{a y} h_{a y t}\right) l_{c t}}{I_{c z}} \dot{\theta}_{t x 1}+\frac{2\left(C_{s y} h_{s t}+C_{a y} h_{a y t}\right) l c t}{I_{c z}} \dot{\theta}_{t \times 2}- \\
& -\frac{4 K_{s y} l_{c t}{ }^{2}}{I_{c z}} \theta_{c z}-\frac{2 K_{s y} h_{s t} l_{c t}}{I_{c z}} \theta_{t x 1}+\frac{2 K_{s y} h_{s t} l_{c t}}{I_{c z}} \theta_{t x 2}
\end{aligned}
$$

$\left.8^{\circ}\right)$ Movimento de rolamento da armação do truque 1 (dianteiro) $-\theta_{t 1 x}$

$$
\begin{aligned}
& I_{t} \ddot{\theta}_{t x 1}+ \\
& +2\left(C_{s y} h_{s t}+C_{a y} h_{a y t}\right) \dot{Y}_{c}-2\left(C_{s z} b_{s}{ }^{2}+C_{a z} b_{a z}{ }^{2}-C_{s y} h_{s t} h_{s}-C_{a y} h_{a y} h_{a y t}\right) \dot{\theta}_{c x}+ \\
& +2\left(C_{s y} h_{s t}+C_{a y} h_{a y t}\right) l_{c t} \dot{\theta}_{c z}+2\left(C_{s z} b_{s}{ }^{2}+C_{a z} b_{a z}{ }^{2}+C_{s y} h_{s t}{ }^{2}+C_{a y} h_{a y t}{ }^{2}+C_{p z} b_{p}{ }^{2}\right) \dot{\theta t}_{x 1}+ \\
& +2 K_{s y} h_{s t} Y_{c}-\left(2\left(K_{s z} b_{s}{ }^{2}-K_{s y} h_{s t} h_{s}\right)+K_{b t}\right) \theta_{c x}+2 K_{s y} h_{s t} l_{c t} \theta_{c z}+ \\
& +\left(2\left(K_{s z} b_{s}{ }^{2}+K_{s y} h_{s t}{ }^{2}+K_{p z} b_{p}{ }^{2}\right)-K_{b t}\right) \theta_{t x 1}= \\
& =2 C_{p z} b_{p}{ }^{2} \dot{\theta}_{r 1}+2\left(b_{p}{ }^{2} K_{p z}\right) \theta_{r 1}
\end{aligned}
$$




$$
\begin{aligned}
& \ddot{\theta}_{t x 1}= \\
& -\frac{2\left(C_{s y} h_{s t}+C_{a y} h_{a y t}\right)}{I_{t}} \dot{Y}_{c}+\frac{2\left(C_{s z} b_{s}{ }^{2}+C_{a z} b_{a z}{ }^{2}-C_{s y} h_{s t} h_{s}-C_{a y} h_{a y} h_{a y t}\right)}{I_{t}} \dot{\theta}_{c x}- \\
& -\frac{2\left(C_{s y} h_{s t}+C_{a y} h_{a y t}\right) l_{c t}}{I_{t}} \dot{\theta}_{c z}-\frac{2\left(C_{s z} b_{s}{ }^{2}+C_{a z} b_{a z}{ }^{2}+C_{s y} h_{s t}{ }^{2}+C_{a y} h_{a y t}{ }^{2}+C_{p z} b_{p}{ }^{2}\right)}{I_{t}} \dot{\theta}_{t x 1}- \\
& -\frac{2\left(K_{s y} h_{s t}\right)}{I_{t}} Y_{c}+\frac{\left(2\left(K_{s z} b_{s}{ }^{2}-K_{s y} h_{s t} h_{s}\right)+K_{b t}\right)}{I_{t}} \theta_{c x}-\frac{2 K_{s y} h_{s t} l_{c t}}{I_{t}} \theta_{c z}- \\
& -\frac{\left(2\left(K_{s z} b_{s}{ }^{2}+K_{s y} h_{s t}{ }^{2}+K_{p z} b_{p}{ }^{2}\right)-K_{b t}\right)}{I_{t}} \theta_{t x 1}+ \\
& +\frac{2 C_{p z} b_{p}{ }^{2}}{I_{t}} \dot{\theta}_{r 1}+\frac{2\left(b_{p}{ }^{2} K_{p z}\right)}{I_{t}} \theta_{r 1}
\end{aligned}
$$

$9^{\circ}$ Movimento de rolamento da armação do truque 2 (traseiro) $-\theta_{t 2 x}$

$$
\begin{aligned}
& I_{t} \ddot{\theta}_{t x 2}+ \\
& +2\left(C_{s y} h_{s t}+C_{a y} h_{a y t}\right) \dot{Y}_{c}-2\left(C_{s z} b_{s}{ }^{2}+C_{a z} b_{a z}{ }^{2}-C_{s y} h_{s t} h_{s}-C_{a y} h_{a y} h_{a y t}\right) \dot{\theta}_{c x}- \\
& -2\left(C_{s y} h_{s t}+C_{a y} h_{a y t}\right) l_{c t} \dot{\theta}_{c z}+2\left(C_{s z} b_{s}{ }^{2}+C_{a z} b_{a z}{ }^{2}+C_{s y} h_{s t}{ }^{2}+C_{a y} h_{a y t}{ }^{2}+C_{p z} b_{p}{ }^{2}\right) \dot{\theta}_{t x 2}+ \\
& +2 K_{s y} h_{s t} Y_{c}-\left(2\left(K_{s z} b_{s}{ }^{2}-K_{s y} h_{s t} h_{s}\right)+K_{b t}\right) \theta_{c x}-2 K_{s y} h_{s t} l_{c t} \theta_{c z}+ \\
& +\left(2\left(K_{s z} b_{s}{ }^{2}+K_{s y} h_{s t}{ }^{2}+K_{p z} b_{p}{ }^{2}\right)-K_{b t}\right) \theta_{t x 2}= \\
& =2 C_{p z} b_{p}{ }^{2} \dot{\theta}_{r 2}+2\left(b_{p}{ }^{2} K_{p z}\right) \theta_{r 2}
\end{aligned}
$$

Logo

$$
\begin{aligned}
& \ddot{\theta}_{t x 2}= \\
& -\frac{2\left(C_{s y} h_{s t}+C_{a y} h_{a y t}\right)}{I_{t}} \dot{Y}_{c}+\frac{2\left(C_{s z} b_{s}{ }^{2}+C_{a z} b_{a z}{ }^{2}-C_{s y} h_{s t} h_{s}-C_{a y} h_{a y} h_{a y t}\right)}{I_{t}} \dot{\theta}_{c x}+ \\
& +\frac{2\left(C_{s y} h_{s t}+C_{a y} h_{a y t}\right) l_{c t}}{I_{t}} \dot{\theta}_{c z}-\frac{2\left(C_{s z} b_{s}{ }^{2}+C_{a z} b_{a z}{ }^{2}+C_{s y} h_{s t}{ }^{2}+C_{a y} h_{a y t}{ }^{2}+C_{p z} b_{p}{ }^{2}\right)}{I_{t}} \dot{\theta}_{t x 2}- \\
& -\frac{2\left(K_{s y} h_{s t}\right)}{I_{t}} Y_{c}+\frac{\left(2\left(K_{s z} b_{s}{ }^{2}-K_{s y} h_{s t} h_{s}\right)+K_{b t}\right)}{I_{t}} \theta_{c x}+\frac{2 K_{s y} h_{s t} l_{c t}}{I_{t}} \theta_{c z}- \\
& -\frac{\left(2\left(K_{s z} b_{s}{ }^{2}+K_{s y} h_{s t}{ }^{2}+K_{p z} b_{p}{ }^{2}\right)-K_{b t}\right)}{I_{t}} \theta_{t x 1}+ \\
& +\frac{2 C_{p z} b_{p}{ }^{2}}{I_{t}} \dot{\theta}_{r 1}+\frac{2\left(b_{p}{ }^{2} K_{p z}\right)}{I_{t}} \theta_{r 1}
\end{aligned}
$$


O movimento lateral de qualquer ponto no interior da caixa é dado em função dos movimentos de deslocamento lateral $\left(Y_{c}\right)$, roll $\left(\theta_{c x}\right)$ e yaw $\left(\theta_{c x}\right)$ desta, assim, as análises feitas neste trabalho serão baseadas nesses três tipos de movimento.

\subsection{Solução analítica}

Dois tipos de soluções das equações de movimento são propostas. Na primeira delas é feita a abordagem por Espaços de Estado que tem como vantagem o fornecimento dos resultados temporais e no domínio da freqüência, porém, só foram simulados sistemas lineares. Embora o processo de solução através do uso do software Scicos seja numérico, a denominação "Solução Analítica" foi escolhida uma vez que o sistema é linear ou seja, pode ser resolvida para qualquer instante de tempo sem conhecimento do instante anterior. O segundo tipo é a solução por integração numérica de um sistema não linear. Este tipo de solução é muito mais flexível que a solução analítica, por outro lado só é possível a obtenção de resultados temporais.

Segundo (OGATA, 2004), o "estado" de um sistema é dado pelo menor conjunto de variáveis que a partir das condições iniciais (quando $t=t_{0}$ ) e das entradas (para todo $t \geq t_{0}$ ) se torna possível a determinação do comportamento do mesmo. Tomando este conjunto de variáveis, chamadas de "variáveis de estado", e organizando-as de forma vetorial obtém-se um "vetor de estado". Logo, o "estado" de um sistema pode ser determinado pelo "vetor de estado" para todo tempo $t \geq t_{0}$. Um espaço $n$ dimensional onde cada dimensão é dada por um eixo definido a partir de cada "variável de estado" é chamado de "espaço de estado". Todo "estado" do sistema em questão pode ser definido como um ponto no "espaço de estado". A expressão em forma de "espaço de estado" que representa tal sistema é dada pela seguinte equação de vetores e matrizes:

$$
\begin{aligned}
& \overrightarrow{\dot{x}}=A \vec{x}+B \vec{u} \\
& \vec{y}=C \vec{x}+D \vec{u}
\end{aligned}
$$

Onde: 
- $\vec{x}$ : vetor de estado:

- $\vec{u}$ : vetor de entrada:

- $\quad \vec{y}$ : vetor de saída:

- A: matriz de estado:

- $B$ : matriz de entrada:

- C: matriz de saída:

- $\quad D$ : matriz de transmissão direta.

Baseado nas equações de movimento deduzidas no capítulo 3.4 as matrizes e vetores da equação 3.19 são definidos da seguinte maneira.

Inicialmente devem-se definir as "variáveis de estado". Como foi dito no capítulo anterior, a definição da posição de qualquer ponto da caixa devido ao movimento lateral da mesma é definida por três variáveis: deslocamento lateral $\left(Y_{c}\right)$, roll $\left(\theta_{c x}\right)$ e yaw $\left(\theta_{\mathrm{cz}}\right)$. Porém, como pode ser observado nas equações $3.4,3.10$ e 3.14 esses três movimentos são excitados pelas rotações em torno do eixo $x$ dos truques "t1" $\left(\theta_{t 1 x}\right)$ e "t2" ( $\left.\theta_{t 2 x}\right)$ que por sua vez são excitados a partir das oscilações do trilho. Assim, desconsiderou-se quatro graus de liberdade, dos nove definidos inicialmente, uma vez que eles não são excitados pelos movimentos de rotação dos rodeiros. As "variáveis de estado" são definidas como:

$$
\begin{array}{lllll}
x_{1}=Y_{c} & x_{3}=\theta_{c x} & x_{5}=\theta_{c z} & x_{7}=\theta_{t 1 x} & x_{9}=\theta_{t 2 x} \\
\dot{x}_{1}=\dot{Y}_{c} & \dot{x}_{3}=\dot{\theta}_{c x} & \dot{x}_{5}=\dot{\theta}_{c z} & \dot{x}_{7}=\dot{\theta}_{t 1 x} & \dot{x}_{9}=\dot{\theta}_{t 2 x} \\
x_{2}=\dot{x}_{1}=\dot{Y}_{c} & x_{4}=\dot{x}_{3}=\dot{\theta}_{c x} & x_{6}=\dot{x}_{5}=\dot{\theta}_{c z} & x_{8}=\dot{x}_{7}=\dot{\theta}_{t 1 x} & x_{10}=\dot{x}_{9}=\dot{\theta}_{t 2 x} \\
\dot{x}_{2}=\ddot{Y}_{c} & \dot{x}_{4}=\ddot{\theta}_{c x} & \dot{x}_{6}=\ddot{\theta}_{c z} & \dot{x}_{8}=\ddot{\theta}_{t 1 x} & \dot{x}_{10}=\ddot{\theta}_{t 2 x}
\end{array}
$$

Onde as derivadas segunda $\ddot{Y}_{c}, \ddot{\theta}_{c x}, \ddot{\theta}_{c z}, \ddot{\theta}_{t 1 x}$ e $\ddot{\theta}_{t 2 x}$ são dadas pelas equações 3.4 , $3.10,3.14,3.16$ e 3.18 .

O vetor de estado $\vec{x}$ é definido como:

$$
\begin{aligned}
\vec{x}^{T} & =\left[\begin{array}{llllllllll}
x_{1} & x_{2} & x_{3} & x_{4} & x_{5} & x_{6} & x_{7} & x_{8} & x_{9} & x_{10}
\end{array}\right]= \\
& =\left[\begin{array}{llllllllll}
Y_{c} & \dot{Y}_{c} & \theta_{c x} & \dot{\theta}_{c x} & \theta_{c z} & \dot{\theta}_{c z} & \theta_{t 1 x} & \dot{\theta}_{t 1 x} & \theta_{t 2 x} & \dot{\theta}_{t 2 x}
\end{array}\right]
\end{aligned}
$$


O vetor de entrada $\vec{u}$ no caso proposto é um escalar dado por uma função de entrada apresentada nas equações 3.29 e 3.30. Esta função de entrada representa a excitação dos rodeiros no eixo $x$ e pode ser uma função seno, impulso ou degrau, por exemplo, escolhida de acordo com o caso estudado.

O vetor de saída $\vec{y}$ é dado pelos termos que definem o deslocamento lateral da caixa, isto é, $Y c, \theta c x$ e $\theta c z$ :

$$
y_{1}=x_{1}=Y_{c} \quad, \quad y_{2}=x_{3}=\theta_{c x} \quad \text { e } \quad y_{3}=x_{5}=\theta_{c z} \quad \text { logo } \quad \vec{y}=\left[\begin{array}{c}
Y_{c} \\
\theta_{c x} \\
\theta_{c z}
\end{array}\right]
$$

Para obter a matriz de estado $A$, as variáveis de entrada $\theta_{r 1 x} \theta_{r 2 x}, \dot{\theta}_{r 1 x}$ e $\dot{\theta}_{r 2 x}$ (rotação em $x$ dos rodeiros) são retiradas das equações 3.4 , 3.10, 3.14, 3.16 e 3.18 restando somente as "variáveis de estado" conforme mostrado a seguir:

$$
A=\left[\begin{array}{cccccccccc}
0 & 1 & 0 & 0 & 0 & 0 & 0 & 0 & 0 & 0 \\
K_{22} & C_{22} & K_{25} & C_{25} & 0 & 0 & K_{28} & C_{28} & K_{29} & C_{29} \\
0 & 0 & 0 & 1 & 0 & 0 & 0 & 0 & 0 & 0 \\
K_{52} & C_{52} & K_{55} & C_{55} & 0 & 0 & K_{58} & C_{58} & K_{59} & C_{59} \\
0 & 0 & 0 & 0 & 0 & 1 & 0 & 0 & 0 & 0 \\
0 & 0 & 0 & 0 & K_{77} & C_{77} & K_{78} & C_{78} & K_{79} & C_{79} \\
0 & 0 & 0 & 0 & 0 & 0 & 0 & 1 & 0 & 0 \\
K_{82} & C_{82} & K_{85} & C_{85} & K_{87} & C_{87} & K_{88} & C_{88} & 0 & 0 \\
0 & 0 & 0 & 0 & 0 & 0 & 0 & 0 & 0 & 1 \\
K_{92} & C_{92} & K_{95} & C_{95} & K_{97} & C_{97} & 0 & 0 & K_{99} & C_{99}
\end{array}\right]
$$

Onde os $K_{i j}$ e $C_{i j}$ são elementos das matrizes de rigidez e amortecimento derivadas a partir das equações de movimento conforme mostrado no apêndice $A$.

A matriz de entrada $B$ é definida como:

$$
B^{T}=\left[\begin{array}{llllllllll}
0 & 0 & 0 & 0 & 0 & 0 & 0 & 1 & 0 & 1
\end{array}\right]
$$


As variações dos parâmetros não nulos desta matriz permitem a simulação de excitações dos rodeiros em fase e em oposição de fase, bastando inverter um dos sinais.

A matriz de saída $C$ é dada por:

$$
C=\left[\begin{array}{llllllllll}
1 & 0 & 0 & 0 & 0 & 0 & 0 & 0 & 0 & 0 \\
0 & 0 & 1 & 0 & 0 & 0 & 0 & 0 & 0 & 0 \\
0 & 0 & 0 & 0 & 1 & 0 & 0 & 0 & 0 & 0
\end{array}\right]
$$

Finalmente, a matriz de transposição direta $D$ é uma matriz $3 \times 1$ nula.

$$
D=\left[\begin{array}{l}
0 \\
0 \\
0
\end{array}\right]
$$

No apêndice $D$ é apresentado o programa desenvolvido no software SCILAB para a simulação utilizando a abordagem de Espaço de Estado. Uma particularidade deste software é que o "vetor de entrada" $\vec{u}$ deve sempre ser apresentado como um escalar na forma de "função de entrada". Este caso é chamado de SIMO (Single Input Multiple Output), ou seja, uma entrada e várias saídas. Como foi mencionado anteriormente, a variação dos parâmetros da matriz $B$ permite somente simulações em fase e em e em oposição de fase, mas em um caso real, a diferença de fase varia em função do comprimento de onda da irregularidade e da distância entre eixos. Assim, a maneira utilizada para contornar este problema é utilizar o conceito do "princípio da superposição" (OGATA, 2004) que diz que em um sistema linear, a resposta produzida pela aplicação de duas forças de entrada simultâneas é igual à soma das respostas produzidas por cada força individualmente. Assim, excitando inicialmente somente o rodeiro " $r 1$ " e depois somente o rodeiro " $r 2$ " com uma diferença de fase, o resultado será dado pela soma dos sinais das duas respostas.

Na primeira parte do programa são definidas as matrizes $A, B, C$ e $D$ conforme descrito nas equações $3.23,3.24,3.25$ e 3.26 . $O$ termo $B[1,8]$ da matriz apresentada em 3.24 caracteriza a excitação do rodeiro dianteiro e o termo $B[1,10]$ do rodeiro traseiro. Assim duas matrizes $B$ são necessárias para realizar as excitações nos rodeiros "r1" e "r2" de modo separado. 


$$
\begin{aligned}
& B_{1}=\left[\begin{array}{llllllllll}
0 & 0 & 0 & 0 & 0 & 0 & 0 & 1 & 0 & 0
\end{array}\right] \\
& B_{2}=\left[\begin{array}{llllllllll}
0 & 0 & 0 & 0 & 0 & 0 & 0 & 0 & 0 & 1
\end{array}\right]
\end{aligned}
$$

Na segunda parte, são criadas duas "funções de entrada" cada qual associada a um rodeiro. As funções de deslocamento dos rodeiros "r1" e "r2" são dadas por:

$$
\begin{gathered}
\theta_{r 1}=\frac{r_{m}}{b_{b}} \operatorname{seno}\left(2 \pi \frac{v}{\lambda} t\right) \\
\theta_{r 2}=\frac{r_{m}}{b_{b}} \operatorname{seno}\left(\left(2 \pi \frac{v}{\lambda} t\right)-\left(2 \pi\left(\frac{2 l_{c t}}{\lambda}\right)\right)\right)
\end{gathered}
$$

Onde:

- $r_{m} / b_{b}$ : amplitude de oscilação dada à seguinte aproximação $\operatorname{tg}-1(\mathrm{rm} / \mathrm{bb}) \mathrm{R} \mathrm{rm} / \mathrm{bb}$ segundo a hipótese 3 do capítulo 3.2;

- $\quad v / \lambda$ : freqüência da oscilação em $\mathrm{Hz}$, onde $v$ é a velocidade de deslocamento do veículo e $\lambda$ é o comprimento de onda da irregularidade do trilho;

- $\frac{2 l_{c t}}{\lambda}:$ diferença de fase entre rodeiros, onde $I_{c t}$ é a meia-distância entre centros de pivô.

Outro problema deste tipo de solução é que a entrada é dada pela força de excitação de rotação dos rodeiros e não pelo seu movimento angular. $O$ artifício utilizado foi de gerar um momento aplicado ao rodeiro que faça a armação do truque movimentar-se com os mesmos ângulos e velocidades que ele teria, caso a entrada fosse as irregularidades da via. Assim, a excitação transmitida à caixa será a mesma. Seja $\theta_{r 1 x}$ e $\dot{\theta}_{r 1 x}$ o deslocamento e velocidade angular do rodeiro " $r 1$ " e $\theta_{r 2 x} \mathrm{e}$ $\dot{\theta}_{r 2 x}$ do rodeiro " $r 2$ ", os momentos são definidos a partir da segunda parte da igualdade das equações 3.15 e 3.17 e são dados por:

$$
\text { Momento } \theta_{r 1}=\frac{2 b_{p}{ }^{2} K_{p z}}{I_{t x}} \theta_{r 1 x}+\frac{2 b_{p}{ }^{2} C_{p z}}{I_{t x}} \dot{\theta}_{r 1 x}
$$




$$
\text { Momento } \theta_{r 2}=\frac{2 b_{p}{ }^{2} K_{p z}}{I_{t x}} \theta_{r 2 x}+\frac{2 b_{p}{ }^{2} C_{p z}}{I_{t x}} \dot{\theta}_{r 2 x}
$$

Na terceira parte do programa, duas simulações são feitas, uma para a excitação de cada rodeiro e a saída final é dada pela soma dos resultados. Os resultados são registrados, então, em um arquivo do tipo texto.

A última parte do programa gera o diagrama de Bode que apresenta a resposta em freqüência para a magnitude e fase. No capítulo 4.5 é feita uma análise em detalhe de tais diagramas.

\subsection{Solução por integração numérica}

A outra solução proposta, por integração numérica, possui como vantagens a facilidade de simular os nove graus de liberdade do sistema, as excitações dos rodeiros podem ser combinadas nivelamento cruzado ou nivelamento vertical e a principal delas,o modelamento de suspensões lineares e não lineares é muito mais simples. Por outro lado sua grande limitação é que só é possível obter resultados temporais, as respostas em freqüência como mostrado na solução analítica não é possível sem que seja feito um tratamento de sinal.

A obtenção deste tipo de solução foi feita utilizando o software de modelagem e simulação de sistemas dinâmicos SCICOS (CAMPBELL; CHANCELIER; NIKOUKHAH, 2000).

\subsubsection{Entradas}

Conforme explicado no capítulo 2.4 a excitação do sistema é feita pelas irregularidades dos trilhos que são transmitidas aos rodeiros. Cada rodeiro é excitado de duas maneiras, pela variação da altura gerada pelas irregularidades de nivelamento vertical $(Z r)$ e pelas variações de ângulos geradas pelas irregularidades 
de nivelamento cruzado $\left(\theta_{r x}\right)$. As quatro entradas do sistema foram modeladas da mesma maneira, variando somente as definições dos parâmetros de cada bloco. Tomando o exemplo do rodeiro "r1", a figura 3.3 mostra o princípio utilizado na definição da excitação vertical no mesmo.

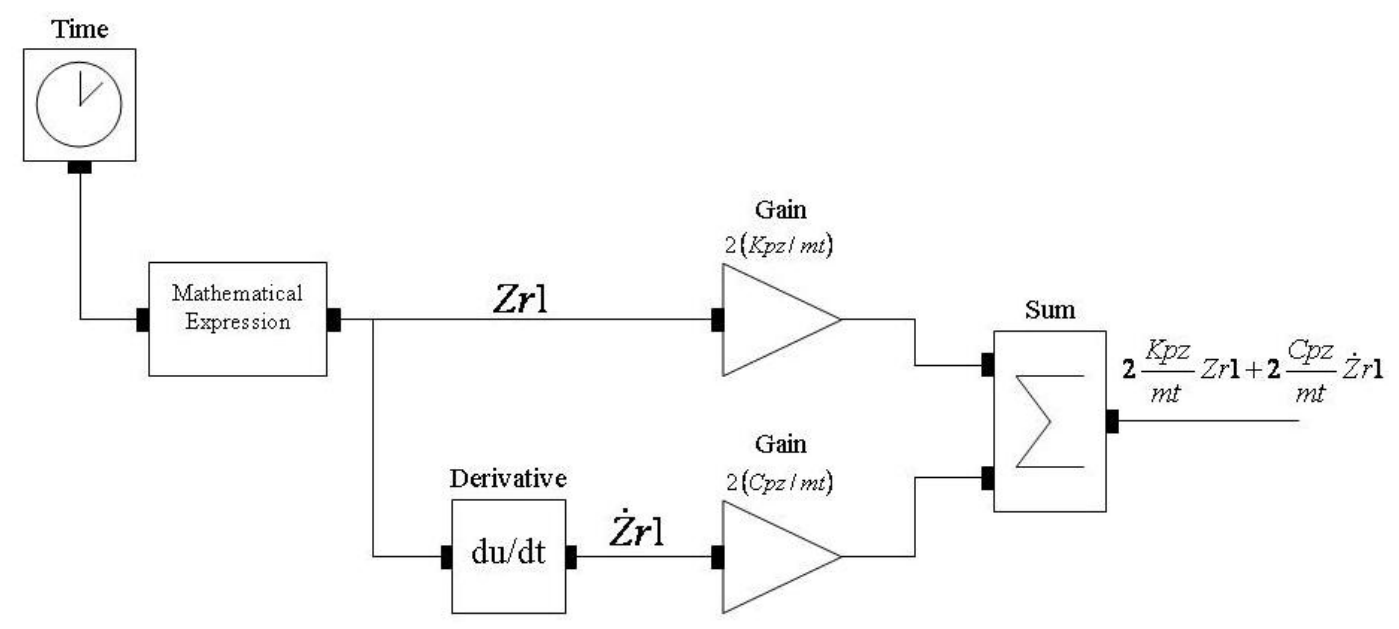

Figura 3.3 - Diagrama de Cálculo da Excitação Vertical do Rodeiro "r1"

O bloco "Time" é um gerador de tempo com uma freqüência pré-definida pelo usuário. O bloco "Mathematical Expression" utiliza o tempo gerado pelo bloco "Time" para calcular as oscilações verticais do rodeiro, fornecendo assim o deslocamento $Z_{r 1}$. Na equação 3.6 que define o movimento vertical da armação do truque 1 , os termos referentes às variáveis $Z_{r 1}$ e $\dot{Z}_{r 1}$ representam a entrada do sistema. $O$ detalhe referente à excitação do rodeiro em $z$ é mostrado a seguir:

$$
\text { oscilação de entrada }=2 \frac{K_{p z}}{m_{t}} Z_{r 1}+2 \frac{C_{p z}}{m_{t}} \dot{Z}_{r 1}
$$

Como a saída do bloco "Mathematical Expression" se refere ao deslocamento $Z_{r 1}$, sua derivada, que é feita através do bloco "Derivative", fornece a velocidade de deslocamento $\dot{Z}_{r 1}$. Multiplicando então o deslocamento pela expressão $2\left(K_{p z} / m_{t}\right)$ e a velocidade 2( $\left.C_{p z} / m_{t}\right)$ através dos blocos "Gain" e fazendo o somatório dos resultados utilizando o bloco "Sum" é obtida uma das quatro entradas do sistema.

O mesmo conjunto de blocos é repetido quatro vezes e em cada uma delas os ganhos e as expressões matemáticas são definidos conforme mostrado a seguir: 
Rodeiro "r1", excitação do modo $Z_{t 1}$ conforme equação 3.6:

- Expressão matemática de $Z_{r 1}: \quad r_{m} \cdot \operatorname{seno}\left(2 \pi \frac{v}{\lambda} t\right)$

- Ganho do deslocamento $Z_{r 1}$ : $\quad 2\left(K_{p z} / m_{t}\right)$

- Ganho da velocidade $\dot{Z}_{r 1}$ : $\quad 2\left(C_{p z} / m_{t}\right)$

Rodeiro "r1", excitação do modo $\theta_{t 1 x}$ conforme equação 3.16:

- Expressão matemática de $\theta r_{1 x}: \quad \frac{r_{m}}{b_{b}} \operatorname{seno}\left(2 \pi \frac{v}{\lambda} t\right)$

- Ganho do deslocamento $\theta r_{1 x}$ : $\quad 2\left(b_{p}{ }^{2} K_{p z} / I_{t x}\right)$

- Ganho da velocidade $\dot{\theta}_{r 1 x}: \quad 2\left(b_{p}{ }^{2} C_{p z} / I_{t x}\right)$

Rodeiro "r2", excitação do modo $Z_{t 2}$ conforme equação 3.8:

- Expressão matemática de $Z_{r 2}: \quad r_{m} \cdot \operatorname{seno}\left(\left(2 \pi \frac{v}{\lambda} t\right)-\left(2 \pi\left(\frac{2 l_{c t}}{v}\right)\right)\right)$

- Ganho do deslocamento $Z_{r 2}$ : $\quad 2\left(K_{p z} / m_{t}\right)$

- Ganho da velocidade $\dot{Z}_{r 2}$ : $\quad 2\left(C_{p z} / m_{t}\right)$

Rodeiro "r1", excitação do modo $\theta_{t 2 x}$ conforme equação 3.18 :

- Expressão matemática de $\theta r_{2 x}: \quad \frac{r_{m}}{b_{b}} \cdot \operatorname{seno}\left(\left(2 \pi \frac{v}{\lambda} t\right)-\left(2 \pi\left(\frac{2 l_{c t}}{v}\right)\right)\right)$

- Ganho do deslocamento $\theta r_{2 x}$ : $\quad 2\left(b_{p}{ }^{2} K_{p z} / I_{t x}\right)$

- Ganho da velocidade $\dot{\theta}_{r 2 x}: \quad 2\left(b_{p}{ }^{2} C_{p z} / I_{t x}\right)$

A diferença de fase apresentada nas expressões referentes ao rodeiro "r2" quando comparadas com o rodeiro " $r 1$ " se devem à distância entre pivôs conforme explicado anteriormente nas equações 3.29 e 3.30. Os demais parâmetros como rigidez, amortecimento, inércias e massas foram definidos no capítulo 3.3. 


\subsubsection{Processamento e saídas}

Assim como foi feito no capítulo anterior, a explicação da solução completa partirá de um bloco representativo para facilitar a compreensão.

Como apresentado no capítulo 3.2 o sistema possui nove graus de liberdade. Assim, o simulador como um todo foi dividido em nove diagramas dos quais cada um possui como saída um dos nove deslocamentos correspondentes aos graus de liberdade. Seja, por exemplo, o deslocamento vertical do truque " $r 1$ " definido como $Z_{t 1}$, cuja equação do movimento 3.6 é transcrita abaixo:

$$
\begin{aligned}
\ddot{Z}_{1} & =\frac{2\left(C_{s z}+C_{a s}\right)}{m_{t}} \dot{Z}_{c}-\frac{2\left(C_{s z}+C_{a z}+C_{p z}\right)}{m_{t}} \dot{Z}_{t 1}-\frac{2\left(C_{s z}+C_{a z}\right) l c t}{m_{t}} \dot{\theta}_{c y}+ \\
& +\frac{2 K_{s z}}{m_{t}} Z_{c}-\frac{2\left(K_{s z}+K_{p z}\right)}{m_{t}} Z_{t 1}-\frac{2 K_{s z} l c t}{m_{t}} \theta_{c y}+ \\
& +2 C_{p z} \dot{Z}_{r 1}+2 K_{p z} Z_{r 1}
\end{aligned}
$$

A partir da equação acima foi possível desenvolver o diagrama mostrado na figura 3.4 .

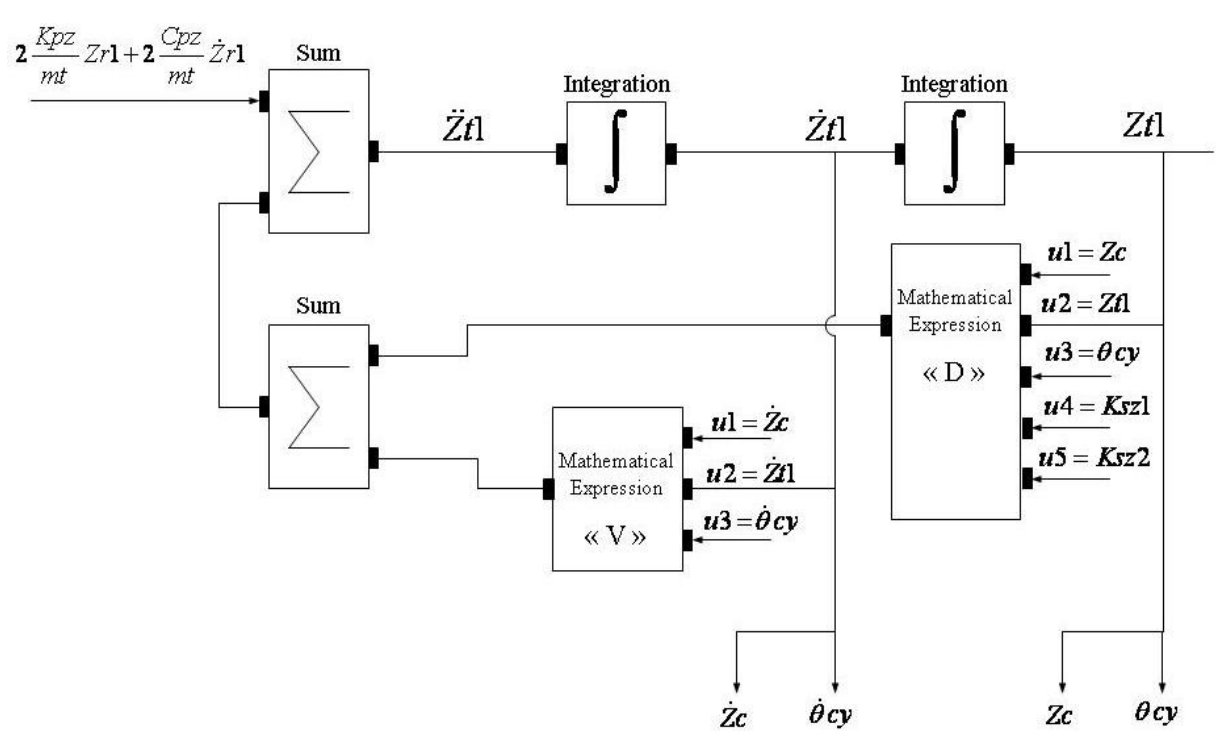

Figura 3.4 - Diagrama de Cálculo do Movimento Vertical do Truque "t1" $\left(Z_{t 1}\right)$

A velocidade $\dot{Z}_{t 1}$ e o deslocamento $Z_{t 1}$ são obtidos a partir de integrações sucessivas da aceleração $\ddot{Z}_{t 1}$ utilizando o bloco "Integration". Como pode ser observado na 
equação 3.34, a aceleração final é obtida por três somatórios. O primeiro deles consiste dos termos referentes às velocidades $\dot{Z}_{c}, \dot{Z}_{t 1}$ e $\dot{\theta}_{c y}$ (primeira linha da equação). O segundo somatório se refere aos deslocamentos $Z_{c}, Z_{t 1}$ e $\theta_{c y}$ (segunda linha da equação) e o terceiro é a excitação provocada pelo rodeiro (terceira linha da equação).

Os blocos "Mathematical Expression" da figura 3.4 possuem entradas denotadas por $u_{i}$. Na expressão "V" a entrada $u 2(\dot{Z} t 1)$ é tomada diretamente após a integração de $\ddot{Z} t 1$. Da mesma maneira, as entradas $u 1\left(\dot{Z}_{c}\right)$ e $u 3(\dot{\theta} c y)$ são obtidas nas ligações de saída dos integradores de seus respectivos blocos. Assim como as velocidades $\dot{Z}_{c}$ e $\dot{\theta} c y$ são necessárias para a determinação de $\dot{Z} 1$, este último é também necessário para a determinação das outras duas devido à simetria das matrizes de amortecimento e rigidez. Esta saída que alimenta os diagramas de $Z_{c}$ e $\theta_{c y}$ é mostrada pelas duas setas apontadas para baixo na figura. Finalmente a expressão matemática tal como encontrada no programa que representa o somatório da primeira linha da equação 3.34 assumindo $u 1=\dot{Z}_{c}, u 2=\dot{Z} t 1$ e $u 3=\dot{\theta} c y$ é dado por:

$$
u 1^{*}\left(2^{*}(c s z+c a z) / m t\right)+u 2^{*}\left(-2^{*}(c s z+c a z+c p z) / m t\right)+u 3^{*}\left(-2^{*} l c t^{*}(c s z+c a z) / m t\right)
$$

O mesmo princípio é adotado na obtenção da equação da expressão "D”, porém, ela conta com duas outras entradas denominadas de $u 4$ e u5, que representam as suspensões secundárias. Uma das etapas da análise do sistema consiste na adoção das suspensões secundárias como não lineares, mas, por hora, enquanto o sistema for considerado como linear $u 4$ e $u 5$ serão as constantes de rigidez $K_{s z}$. Os índices "1" e "2" de $K_{s z}$ mostrados na figura se referem às suspensões à direita e à esquerda da linha de centro. Assim, a expressão "D" que representa o somatório da segunda linha da equação 3.34 assumindo $u 1=Z_{c}, u 2=Z_{t 1}, u 3=\theta_{c y}$ e $u 4=u 5=K_{s z}$ (caso linear) é dado por:

$$
u 1^{*}((u 4+u 5) / m t)+u 2^{*}\left(-(u 4+u 5) / m t-2^{*} k p z / m t\right)+u 3^{*}(-((u 4+u 5) * / c t) / m t)(3.36)
$$

Finalmente a aceleração Z̈t1 é dada pelo somatório dos resultados das expressões $3.33,3.35$ e 3.36 . 
O exemplo mostrado se refere somente a equação diferencial do movimento vertical do truque. Quando se aplica o mesmo princípio as outras oito equações, obtém-se o diagrama final composto de nove blocos dos quais quatro possuem entradas provenientes das excitações dos rodeiros.

Como foi dito anteriormente, o modelo desenvolvido é capaz de fazer simulações considerando as suspensões secundárias como não lineares. Logo o princípio da superposição não pode ser aplicado como feito na solução analítica. O fato das suspensões secundárias serem não lineares significa que sua rigidez varia em função do deslocamento (MEIROVITCH, 1975). O processo utilizado para tal simulação é descrito a seguir.

Tomando como exemplo o truque dianteiro "t1", a altura de cada suspensão secundária definida por $s_{z 1}$ e $s_{z 2}$ pode ser deduzida em função do posicionamento da caixa e da armação do truque no espaço. A variação da deflexão vertical das suspensões depende da posição vertical e rolamento da caixa $\left(Z_{c}\right.$ e $\left.\theta_{c x}\right)$, do truque $\left(Z_{t 1}\right.$ e $\left.\theta_{t 1 x}\right)$ e do movimento de "pitch" da caixa $\left(\theta_{c y}\right)$. Seja a variável hbolsa a altura no ponto de operação da suspensão secundária quando o veículo está em repouso, as alturas das suspensões $h_{s z 1}$ e $h_{s z 2}$ serão dadas pelas seguintes equações:

$$
\begin{aligned}
& h s_{z 1}=\left(Z_{c}-Z_{t 1}-\theta_{c x} b_{s}-\theta_{c y} l_{c t}+\theta_{t 1 x} b_{s}\right)+\text { hbolsa } \\
& h s_{z 2}=\left(Z_{c}-Z_{t 1}+\theta_{c x} b_{s}-\theta_{c y} l_{c t}-\theta_{t 1 x} b_{s}\right)+\text { hbolsa }
\end{aligned}
$$

A variação da rigidez em função da deflexão de uma suspensão pneumática não linear é caracterizada por uma curva em um gráfico do tipo $K_{s z} \times h_{s z}$ enquanto no caso linear, por ser constante em função da deflexão, é dado por uma reta como mostrado na figura 3.5 . 


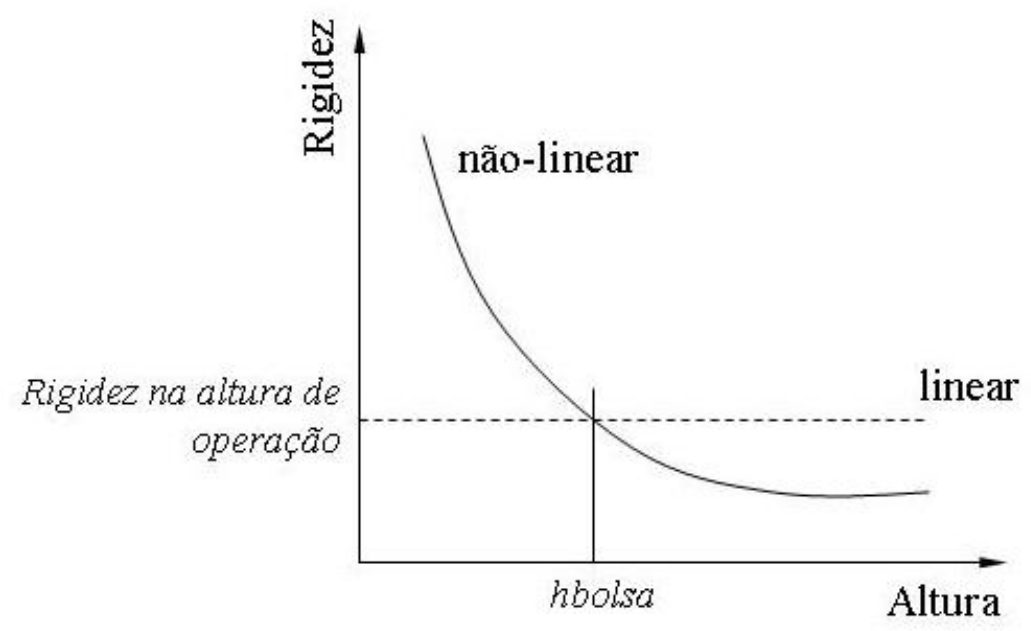

Figura 3.5 - Suspensão Secundária Linear e Não Linear

No apêndice $A$ é descrito como se obtém a curva de uma suspensão não linear a partir de tabelas comerciais que fornecem a rigidez em função das alturas e da massa suspensa. Utilizando o bloco "Interp", carregam-se as coordenadas dos pontos que formam a curva característica da suspensão secundária não linear " $K x$ $h$ " como mostrado na figura 3.5 e a partir do cálculo da altura de cada suspensão conforme definido nas equações 3.37 e 3.38 tem-se rigidez instantânea. Este resultado é utilizado então como entrada nas expressões matemáticas que utilizam a rigidez das suspensões secundárias como pode ser visto nas entradas u4 e u5 da figura 3.4. O diagrama de blocos da figura 3.6 mostra a lógica desta operação.

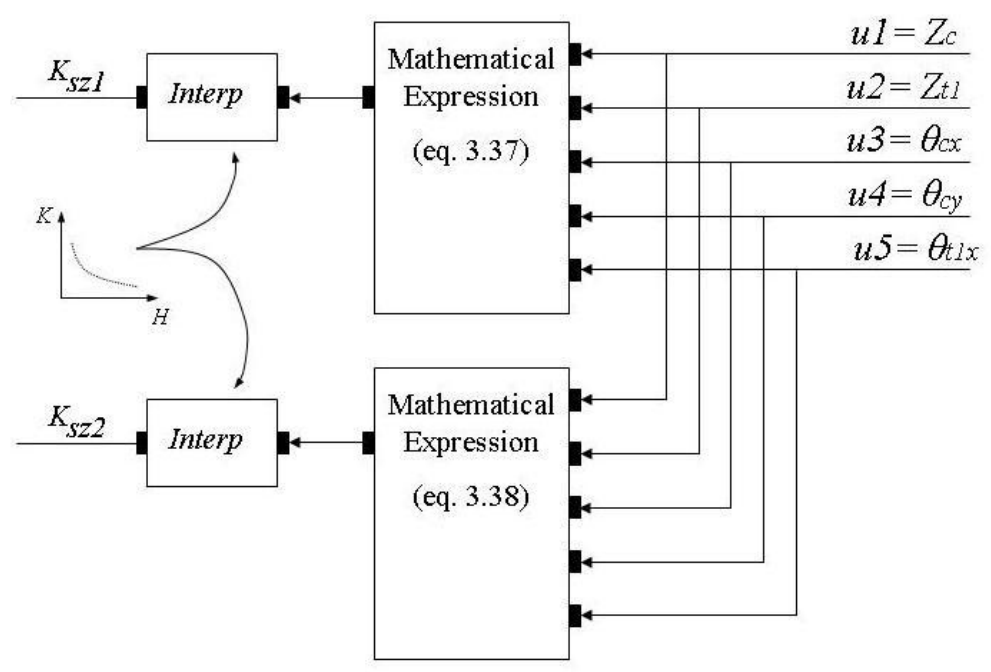

Figura 3.6 - Diagrama de Cálculo de Rigidez das Suspensões Secundárias do Truque "t1" 
Uma variável "nli" (não linear) foi criada e multiplica os termos variáveis das equações 3.37 e 3.38. Quando seu valor é igual a "1", a saída das expressões matemáticas mostradas na figura 3.6 é a altura instantânea da suspensão pneumática. Quando esta variável é igual a zero, a saída desses blocos é a altura "hbolsa" (constante), logo o bloco "Interp" fornecerá como resultado o valor da rigidez na altura de operação o que caracteriza os sistemas lineares. 


\section{Simulações}

Este capítulo está divido em cinco partes. Na primeira são definidos os dados de entrada, na segunda são apresentados os resultados da análise modal, terceira são feitas as simulações temporais e no domínio da freqüência pela solução analítica e na quarta tem-se os resultados temporais para suspensões secundárias lineares e não lineares. Na última parte é apresentada uma análise dos resultados obtidos.

\subsection{Dados de entrada}

Os parâmetros da simulação listados a seguir foram obtidos a partir do Benchmark Manchester (IWNICKI, 1999). Este trabalho foi iniciado no congresso internacional de Simulação Computacional de Dinâmica de Veículos Ferroviários ("Computer Simulation of Rail Vehicle Dynamics") em junho de 1997 com apoio da Universidade Metropolitana de Manchester ("Manchester Metropolitan University"). O objetivo principal foi permitir àqueles que desenvolvem equipamentos de suspensão e que estudam a dinâmica de veículos ferroviários validar de maneira acurada os resultados obtidos comparando esses com as medidas feitas em um veículo real. Onde for mencionado Benchmark no texto deve-se entender como a atividade detalhada no artigo (IWNICKI , 1999).

No artigo acima mencionado são apresentados dois tipos de veículo: o primeiro se trata de um veículo de transporte de passageiros e serve de base para este estudo, e o segundo concerne um vagão de transporte de carga. As seguintes simplificações são adotadas pelos autores do estudo:

- Suspensão primária simples, isto é, uma mola por rolamento;

- Veículo simétrico;

- Amortecedores verticais e horizontais.

Os dados de entrada se encontram no arquivo "dadosdeentrada.sci" apresentado no apêndice I. Este arquivo, além de registrar as características físicas do veículo, 
armazena também as hipóteses referentes às excitações da via, não linearidade das suspensões, tempo de simulação, velocidades acelerações entre outros. A seguir são apresentados os dados de entrada oriundos do Benchmark, a exceção da rigidez vertical da suspensão secundária (caso não linear) os demais valores são assumidos como constante para todas as simulações. Entre parênteses são apresentadas as unidades e as referências da nomenclatura adotada pelo artigo.

- $m_{c}=32000:$ massa da caixa $(\mathrm{kg})$;

- $m_{t}=2615:$ massa da armação do truque $(\mathrm{kg})$;

- $I_{c x}=56800$ : momento de inércia longitudinal da caixa $\left(\mathrm{kg} \cdot \mathrm{m}^{2}\right)$;

- $I_{c y}=1970000$ : momento de inércia transversal da caixa $\left(\mathrm{kg} \cdot \mathrm{m}^{2}\right)$;

- $I_{c z}=1970000$ : momento de inércia vertical da caixa $\left(\mathrm{kg} \cdot \mathrm{m}^{2}\right)$;

- $I_{t x}=1722$ : momento de inércia longitudinal do truque $\left(\mathrm{kg} \cdot \mathrm{m}^{2}\right)$;

- $K_{p z}=2440000: 2$ vezes a rigidez vertical da suspensão primária $(\mathrm{N} / \mathrm{m})$;

- $K_{s y}=160000$ : rigidez lateral da suspensão secundária $(\mathrm{N} / \mathrm{m})$;

- $K_{s z}=430000$ : rigidez vertical da suspensão secundária $(\mathrm{N} / \mathrm{m})$;

- $K_{b t}=940000$ : rigidez rotacional da barra de torção ( $\left.\mathrm{Nm} / \mathrm{rad}\right)$;

- $C_{a y}=32000$ : amortecimento lateral truque-caixa - dois por truque ( $\left.\mathrm{Ns} / \mathrm{m}\right)$;

- $C_{a z}=20000$ : amortecimento vertical truque-caixa - dois por truque ( $\left.\mathrm{Ns} / \mathrm{m}\right)$;

- $C_{p z}=8000: 2$ vezes o amortecimento vertical da suspensão primária $(\mathrm{Ns} / \mathrm{m})$;

- $C_{s y}=0$ : amortecimento horizontal da suspensão secundária;

- $C_{s z}=0$ : amortecimento vertical da suspensão secundária;

- $b_{a z}=1.3$ : semi-distância entre amortecedores verticais ( $m$ - ref. $\left.\mathrm{y}_{6}\right)$;

- $b_{p}=1$ : semi-distância entre suspensões primárias ( $\mathrm{m}-$ ref. $\left.\mathrm{y}_{1}\right)$;

- $b_{s}=1$ : semi-distância entre suspensões secundárias (m - ref. $\mathrm{y}_{3}$ );

- $h_{a y}=1.1$ : altura entre o CG da caixa $(1800 \mathrm{~mm})$ e o amortecedor horizontal $\left(h_{7}=700 \mathrm{~mm}\right)$ em relação ao nível da via $(\mathrm{m})$;

- $h_{\text {ayt }}=0.1$ : altura entre o CG da armação $(600 \mathrm{~mm})$ e a altura do amortecedor lateral caixa-truque (ref. $h_{7}=700 \mathrm{~mm}$ ) em relação ao nível da via $(\mathrm{m})$;

- $h_{m}=0.470$ : altura do CG da caixa em relação ao piso, dado pela diferença entre a altura do CG da caixa $(1800 \mathrm{~mm})$ e a instalação superior da suspensão secundária (ref. $\left.h_{8}=925 \mathrm{~mm}\right)(\mathrm{m})$; 
- $h_{s}=0.9725$ : altura entre o CG da caixa e o centro de aplicação de esforço da suspensão secundária, dado pela diferença entre a altura do CG da caixa (1800 $\mathrm{mm}$ ) e a altura média entre as instalações superior e inferior da suspensão secundária $\left[\left(\mathrm{h}_{3}-\mathrm{h}_{4}\right) / 2+\mathrm{h}_{4}=(1130-525) / 2+525\right](\mathrm{m})$;

- $h_{s t}=0.2275$ : altura entre o centro da armação do truque e o centro de aplicação de esforço da suspensão secundária, dado pela distância entre a altura do CG do truque $(600 \mathrm{~mm})$ e a altura média entre as instalações superior e inferior da suspensão secundária $\left[\left(h_{3}-h_{4}\right) / 2+h_{4}=(1130-525) / 2+525\right](m)$;

- $I_{c t}=9.5$ : semi-distância entre os pivôs dos truques (distância entre pivôs dos truques e as suspensões secundárias são idênticas) (m);

- $b_{b}=1.435$ : bitola do trilho $(\mathrm{m})$.

O artigo Benchmark define quatro tipos de oscilações da via, cada qual com o objetivo de analisar um determinado comportamento do veículo. O primeiro caso visa ao estudo quasi-estático e descarrilamento em curva; o segundo à estabilidade em um desvio longitudinal da via; o terceiro aos modos yaw e sway e o quarto são às perturbações verticais da via com os trilhos em fase (nivelamento longitudinal). Nenhum dos quatro casos excita a rotação dos rodeiros em alinhamento cruzado, porém o quarto caso é o que mais se aproxima.

O inconveniente do caso quatro apresentado no artigo é que o comprimento de onda de $9 \mathrm{~m}$ é muito próximo do valor da semi-distância entre pivôs dos truques $\left(I_{c t}=9,5\right.$ $m$ ). Neste caso a diferença de fase de rotação em $x$ entre os dois rodeiros seria de $40^{\circ}$ e o desejado para a excitação do modo $\theta_{c z}$ é de $180^{\circ}$. Por outro lado, o comprimento de onda definido no terceiro caso é de 11,88 m (39 pés) visto que este valor se refere ao comprimento comercial de trilho mais encontrado no mercado. Assim, a diferença de fase entre as excitações dos rodeiros para uma distância entre eixos de $19 \mathrm{~m}$ passa a ser de $218,75^{\circ}$. A vantagem de não ser exatamente $180^{\circ}$ é que tanto $\theta_{c z}$ como $\theta_{c x}$ são excitados, logo o comprimento de onda $\lambda$ adotado será de $11,88 \mathrm{~m}$.

A amplitude de pico a pico proposta pelo artigo é de $20 \mathrm{~mm}$, embora este valor não respeite os limites para vias de teste e de operação comercial dados pelas normas NF EN 14363 e NF EN 13848-1 como mostrado no capítulo 2.5, os efeitos 
oscilatórios no veículo são maiores e a suspensão é mais exigida podendo influenciar nos resultados, sobretudo na comparação entre os modelos linear e não linear.

De acordo com as freqüências naturais da tabela 4.1, os modos de interesse estão situados na faixa próxima a $1 \mathrm{~Hz}$, assim a velocidade de deslocamento do veículo para as simulações será de 42,77 km/h $(11,88 \mathrm{~m} / \mathrm{s})$ pois nesta velocidade e para o comprimento de onda acima definido as excitações ocorrem na freqüência desejada.

O comprimento da pista proposta pelo artigo Benchmark, no caso número 4, é constituído de dois trechos retilíneos. O primeiro possui $50 \mathrm{~m}$ onde o veículo percorre a velocidade constante de $20 \mathrm{~m} / \mathrm{s}$, a seguir vem um trecho de $200 \mathrm{~m}$ onde o veículo é acelerado de $20 \mathrm{~m} / \mathrm{s}$ a $24 \mathrm{~m} / \mathrm{s}$ (aceleração de $0,44 \mathrm{~m} / \mathrm{s}^{2}$ ). O objetivo desta aceleração é de excitar a faixa de freqüência entre $2,22 \mathrm{~Hz}$ e 2,66 Hz, uma vez que modos $Z_{c}$ e pitch do veículo proposto (tipo 2, vagão de carga) são excitados nas freqüencias de 2,11 Hz e 2,01 Hz segundo (UNIVERSAL MECHANISM, 2007).

A partir do caso descrito acima, dois cenários foram definidos para a execução das simulações.

- Cenário 1:

- Velocidade constante : 11,88 m/s;

- Tempo: 17 s;

- Distância percorrida: 201,96 m;

- Freqüência de excitação dos rodeiros: $1 \mathrm{~Hz}$.

- Cenário 2:

- Velocidade inicial: $5 \mathrm{~m} / \mathrm{s}$;

- Velocidade final: $13,5 \mathrm{~m} / \mathrm{s}$;

- Aceleração: 0,5 m/s ;

- Tempo: $17 \mathrm{~s}$;

- Distância percorrida: 157,25 m.

- Freqüências inicial e final de excitação dos rodeiros: 0,42 Hz e 1,14 Hz

No primeiro cenário os rodeiros serão excitados com rotação em $x$ a uma freqüência constante de $1 \mathrm{~Hz}$ e no "Cenário 2" a freqüência varia de $0,42 \mathrm{~Hz}$ a $1,14 \mathrm{~Hz}$, o que é 
suficiente para o estudo dos modos $Y_{c}(0,71 \mathrm{~Hz}), \theta_{c z}(0,86 \mathrm{~Hz})$ e $\theta_{c x}(1,03 \mathrm{~Hz})$ conforme mostrado na tabela 4.1. Em ambos os casos há uma defasagem de $218,74^{\circ}$ entre rodeiros.

Portanto, os parâmetros que definem as excitações da via nas simulações são:

- $\lambda=11,88 \mathrm{~m}$ : comprimento de onda da irregularidade do trilho;

- $r_{m}=0,020 \mathrm{~m}$ : amplitude da irregularidade do trilho;

- $v=11,88 \mathrm{~m} / \mathrm{s}$ : velocidade de deslocamento do veiculo;

- $v i=5 \mathrm{~m} / \mathrm{s}$ : velocidade inicial;

- $\mathrm{acl}=0,5 \mathrm{~m} / \mathrm{s}^{2}$ : aceleração.

\subsection{Análise Modal}

O problema da análise modal consiste na determinação dos autovetores e autovalores do sistema. Para tal foi utilizado o método do determinante característico (MEIROVICH, 1975) feito através do programa "autovetval.sci" apresentado no apêndice $C$.

Definindo a matriz dinâmica $[D]$ como:

$$
[D]=[k]^{-1}[m]=[a][m]
$$

onde $[k]$ é a matriz de rigidez, $[m]$ a matriz de massa e $[a]$ a matriz de flexibilidade (dado pelo inverso da matriz de rigidez) conforme apresentado no apêndice B. A equação característica pode ser escrita da seguinte forma:

$$
\Delta(\lambda)=\left|D_{i j}-\lambda \delta_{i j}\right|=0
$$

sendo $\lambda \delta_{i j}$ definido como delta de Kronecker, $\Delta(\lambda)$ será um polinômio de ordem $n$ (neste caso $n=9$ pois o problema possui nove graus de liberdade) com $n$ raízes diferentes, reais e positivas $\lambda_{r}$ cada qual associada a uma freqüência natural $\omega_{r}$ através da equação abaixo: 


$$
\omega_{r}=\sqrt{\frac{1}{\lambda_{r}}}
$$

A solução do problema de autovalor abaixo associa a cada autovalor $\lambda_{r}$ um autovetor $\left\{u^{(r)}\right\}$ único:

$$
\left([D]-\lambda_{r}[1]\right)\left\{u^{(r)}\right\}=\{0\}
$$

O programa "autovetval.sci" mostrado no apêndice C utiliza a função "spec" que a partir da matriz dinâmica $[D]$ retorna os autovalores na forma de uma matriz quadrada diagonal $n \times n$ e os autovetores na forma também de uma matriz quadrada $n \times n$.

O vetor de freqüências naturais foi obtido a partir da relação entre $\lambda_{r}$ e $\omega_{r}$ dado pela equação (4.3) e transformando as freqüências de rad/s em Hz. A normalização dos autovetores foi feita mantendo as respectivas relações entre seus componentes sendo que o maior deles possui um valor unitário. Esta operação é utilizada apenas para facilitar a interpretação dos valores obtidos. Na tabela a seguir são apresentados os autovetores normalizados associados a seus respectivos autovalores dados em $\mathrm{Hz}$.

\begin{tabular}{|c|c|c|c|c|c|c|c|c|c|}
\hline \multirow{2}{*}{ Modos } & \multicolumn{5}{|c|}{ Caixa } & \multicolumn{4}{|c|}{ Truque } \\
\hline & 1 & 2 & 3 & 4 & 5 & 6 & 7 & 8 & 9 \\
\hline $\mathrm{F}(\mathrm{Hz})$ & 0,61 & 0,86 & 1,07 & 1,27 & 1,30 & 7,47 & 7,48 & 9,93 & 9,95 \\
\hline Zc & 0 & 0 & -1 & 0 & 0 & 0,025 & 0 & 0 & 0 \\
\hline$Y_{c}$ & 1 & 0 & 0 & $-0,473$ & 0 & 0 & 0 & 0 & $-0,002$ \\
\hline $\mathrm{Zt} 1$ & 0 & 0 & $-0,153$ & 0 & -1 & -1 & 1 & 0 & 0 \\
\hline $\mathrm{Zt2}$ & 0 & 0 & $-0,153$ & 0 & 1 & -1 & -1 & 0 & 0 \\
\hline$\theta \mathrm{cx}$ & $-0,265$ & 0 & 0 & -1 & 0 & 0 & 0 & 0 & 0,016 \\
\hline$\theta$ cy & 0 & 0 & 0 & 0 & 0,681 & 0 & 0,004 & 0 & 0 \\
\hline$\theta c z$ & 0 & 1 & 0 & 0 & 0 & 0 & 0 & $-0,0002$ & 0 \\
\hline$\theta t 1 x$ & $-0,080$ & $-0,104$ & 0 & $-0,257$ & 0 & 0 & 0 & -1 & -1 \\
\hline$\theta$ t $2 x$ & $-0,080$ & 0,104 & 0 & $-0,257$ & 0 & 0 & 0 & 1 & -1 \\
\hline
\end{tabular}

Tabela 4.1 - Freqüências Naturais e Modos de Vibrar Normalizados

As colunas 1 e 4 da tabela 4.1 mostram os acoplamentos do movimento lateral $\left(Y_{c}\right)$ e roll $\left(\theta_{c x}\right)$ que resultam os movimentos de balanço lateral inferior e superior. Para facilitar a compreenção, quando forem feitas referências no texto aos modos "lateral" e "roll" significa que esses movimentos são preponderantes mas não exclusivos. 
A partir do mesmo programa de cálculo de autovalores e autovetores mostrado no apêndice $C$ e do cálculo das rijezas das suspensões pneumáticas $S 1$, S2, S3 e $S 4$ linearizadas conforme apresentado no apêndice $A$, determinou-se a freqüência natural nos três modos de interesse mostrados na tabela 4.2.

Tabela 4.2 - Freqüências Naturais Para Cinco Tipos de Suspensão

\begin{tabular}{ccccc}
\hline \multirow{2}{*}{$\begin{array}{c}\text { Tipo de } \\
\text { Suspensão }\end{array}$} & $\begin{array}{c}\text { Rigidez na altura } \\
\text { média }(\mathrm{N} / \mathrm{m})\end{array}$ & $\begin{array}{c}\text { Freqüência Natural }(\mathrm{Hz}) \\
\text { Balanço Lateral } \\
\text { Inferior }\end{array}$ & $\begin{array}{c}\text { BalançoLateral } \\
\text { Superior }\end{array}$ & Yaw \\
\hline Benchmark & 430000 & 0.6055 & 1.2688 & 0,8607 \\
S1 & 736941 & 0,6240 & 1,3632 & 0,8608 \\
S2 & 753863 & 0.6247 & 1.3678 & 0,8608 \\
S3 & 793962 & 0.6264 & 1.3786 & 0,8608 \\
S4 & 863006 & 0.6290 & 1.3964 & 0,8608 \\
\hline
\end{tabular}

A seguir é mostrada uma tabela comparativa entre os autovalores aqui calculados e os obtidos pelos softwares "Universal Mechanism", "ADAMS" e pelos demais participantes do Benchmark Manchester (MEDYNA, GENSYS, NUCARS, SIMPACK e VAMPIRE). Esses resultados se encontram no relatório (UNIVERSAL MECHANISM, 2007).

Tabela 4.3 - Comparação da Análise Modal

\begin{tabular}{|c|c|c|c|c|c|}
\hline & \multirow[b]{2}{*}{ Modo } & \multicolumn{4}{|c|}{ Freqüência (Hz) } \\
\hline & & $\begin{array}{c}\text { Valor } \\
\text { Calculado }\end{array}$ & $\begin{array}{c}\text { Universal } \\
\text { Mechanism }\end{array}$ & ADAMS & Outros \\
\hline \multirow{5}{*}{ Caixa } & Zc (bounce) & 1,07 & 1,07 & 1,07 & $1,07 / 1,08$ \\
\hline & $\theta$ cy (pitch) & 1,30 & 1,29 & 1,28 & $1,28 / 1,30$ \\
\hline & $\theta \mathrm{cz}($ yaw) & 0,86 & 0,73 & 0,71 & $0,76 / 0,86$ \\
\hline & $\begin{array}{l}\text { Balanço lateral } \\
\text { inferior }\end{array}$ & 0,61 & 0,58 & 0,60 & $0,53 / 0,59$ \\
\hline & $\begin{array}{c}\text { Balanço lateral } \\
\text { superior }\end{array}$ & 1,27 & 1,10 & 1,09 & $1,10 / 1,23$ \\
\hline \multirow{4}{*}{ Truque } & $\mathrm{Zt}\left(\angle 0^{\circ}\right)$ & 7,48 & $7,42 / 7,51$ & 7,50 & $7,33 / 7,60$ \\
\hline & $\mathrm{Zt}\left(\angle 180^{\circ}\right)$ & 7,47 & $7,44 / 7,53$ & 7,52 & $7,35 / 7,62$ \\
\hline & $\theta \operatorname{tx}\left(\angle 0^{\circ}\right)$ & 9,93 & $9,92 / 9,62$ & 9,93 & $9,32 / 9,84$ \\
\hline & $\theta \operatorname{tx}\left(\angle 180^{\circ}\right)$ & 9,95 & $9,95 / 9,66$ & 9,93 & $9,32 / 9,84$ \\
\hline
\end{tabular}

\subsection{Simulações pela solução analítica}

A partir do primeiro cenário descrito no capítulo 4.1 (deslocamento em velocidade constante de $11,88 \mathrm{~m} / \mathrm{s}$ ) e dispondo de cinco tipos de suspensões foram feitas várias 
simulações por meio do programa "statespace.sci" (ver apêndice D) quando foram calculados os deslocamentos, rotações e acelerações laterais dos modos lateral, roll e yaw. A seguir são mostrados dois gráficos para os deslocamentos e acelerações do veículo segundo a configuração do Benchmark. Esses gráficos foram gerados pelo programa "graficos_result_statespace.sci" apresentado no apêndice F.

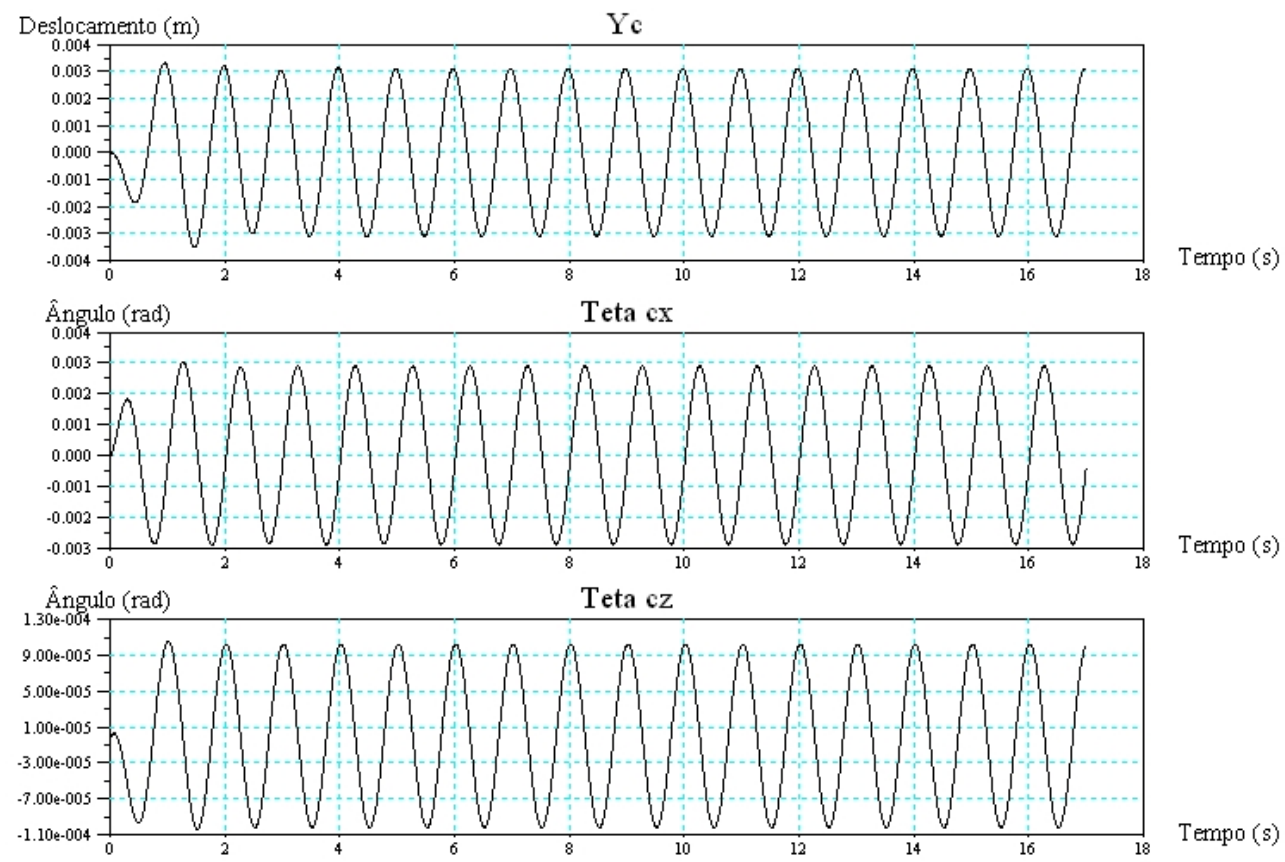

Gráfico 4.1 - Deslocamento e Rotações no CG da Caixa Segundo a Configuração do Benchmark para Velocidade de $11.88 \mathrm{~km} / \mathrm{h}$ - "Cenário 1"

Através do programa "result_statespace.sci" apresentado no apêndice E foram calculados os valores máximos do deslocamento, aceleração e a aceleração rms. Como pode ser visto nos gráficos acima, no início de cada série de cálculos existe uma fase de transitório em que os valores de pico são maiores que ao longo da região de regime permanente. Assim, os valores de máximo apresentados a seguir foram tomados a partir da metade do tempo total de cálculo. Esta hipótese foi baseada no fato de que os nove últimos valores de pico são todos iguais e estão distantes do mesmo período, não existindo então variação de freqüência nem de amplitude. Como exemplo, no caso do deslocamento lateral para a rigidez da suspensão secundária de $430000 \mathrm{~N} / \mathrm{m}$, os nove últimos picos situados entre t=8,5 s e $\mathrm{t}=17 \mathrm{~s}$ possuem um valor de pico de $0,0003115 \mathrm{~m}$ e um período de $1 \mathrm{~s}$ entre si. 


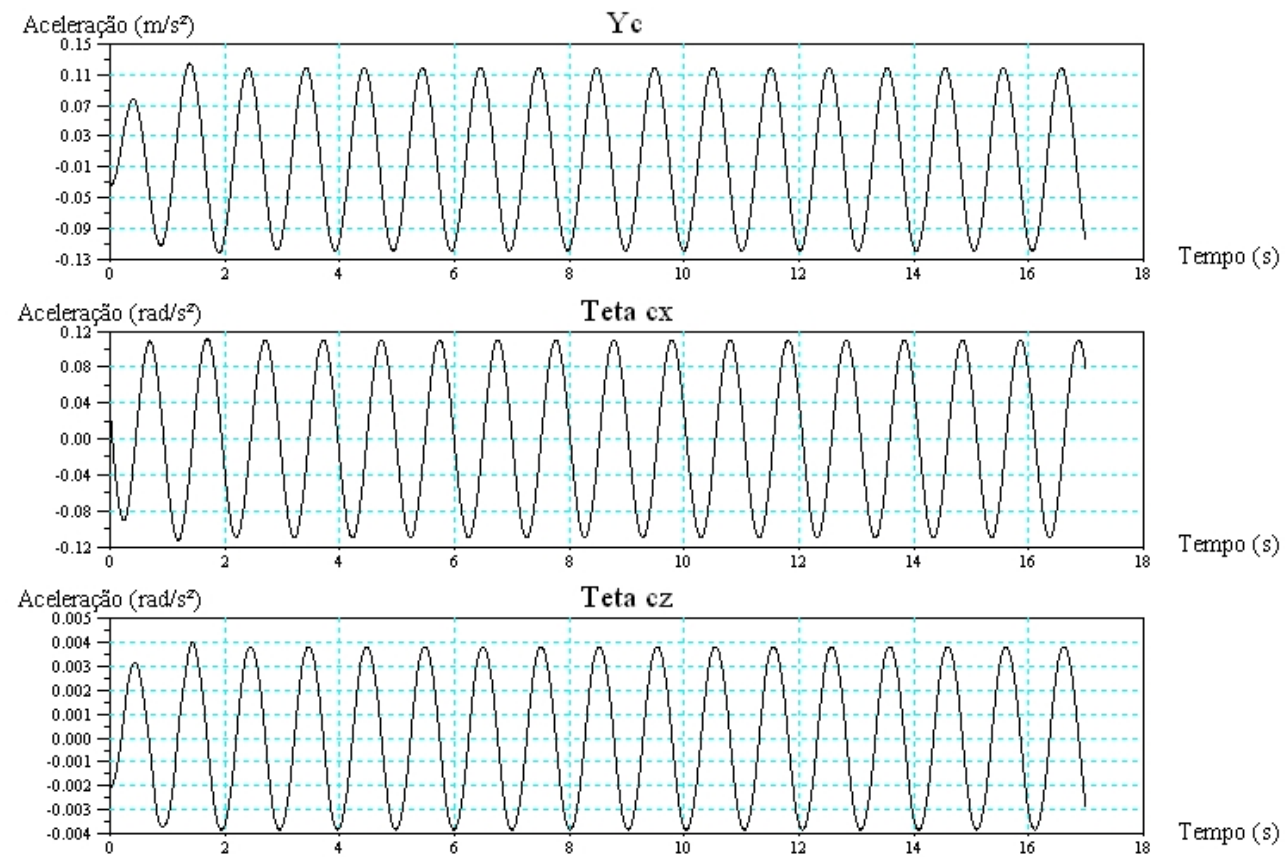

Gráfico 4.2 - Acelerações no CG da Caixa Segundo a Configuração do Benchmark para Velocidade de $11.88 \mathrm{~km} / \mathrm{h}$ - "Cenário 1"

As tabelas a seguir mostram os resultados dos valores máximos e rms obtidos para cada tipo de suspensão em cada um dos três tipos de movimento estudados.

Tabela 4.4 - Deslocamento Lateral Yc

\begin{tabular}{ccccc}
\hline \multirow{2}{*}{$\begin{array}{c}\text { Tipo de } \\
\text { Suspensão }\end{array}$} & $\begin{array}{c}\text { Rigidez na altura } \\
\text { média }(\mathrm{N} / \mathrm{m})\end{array}$ & Deslocamento $(\mathrm{m})$ & $\begin{array}{c}\text { Aceleração } \\
\left(\mathrm{m} / \mathrm{s}^{2}\right)\end{array}$ & $\begin{array}{c}\text { Aceleração rms } \\
\left(\mathrm{m} / \mathrm{s}^{2}\right)\end{array}$ \\
\cline { 3 - 4 } & 430000 & 0,003115 & 0,118969 & 0,084608 \\
Benchmark & 736941 & 0,003679 & 0,14052 & 0,099778 \\
S1 & 753863 & 0,003697 & 0,141192 & 0,100286 \\
S2 & 793962 & 0,003738 & 0,142799 & 0,101379 \\
S3 & 863006 & 0,003796 & 0,144991 & 0,102936 \\
S4 & & & & \\
\hline
\end{tabular}

Tabela 4.5 - Rolamento $\theta c x$

\begin{tabular}{ccccc}
\hline \multirow{2}{*}{$\begin{array}{c}\text { Tipo de } \\
\text { Suspensão }\end{array}$} & $\begin{array}{c}\text { Rigidez na altura } \\
\text { média }(\mathrm{N} / \mathrm{m})\end{array}$ & Rolamento $(\mathrm{rad})$ & $\begin{array}{c}\text { Aceleração } \\
\left(\mathrm{rad} / \mathrm{s}^{2}\right)\end{array}$ & $\begin{array}{c}\text { Aceleração rms } \\
\left(\mathrm{rad} / \mathrm{s}^{2}\right)\end{array}$ \\
\cline { 3 - 4 } & 430000 & 0,002888 & 0,110306 & 0,077586 \\
Benchmark & 736941 & 0,003382 & 0,129141 & 0,090818 \\
S1 & 753863 & 0,003398 & 0,129764 & 0,091252 \\
S2 & 793962 & 0,003431 & 0,131039 & 0,092184 \\
S3 & 863006 & 0,00348 & 0,132972 & 0,093494 \\
S4 & & &
\end{tabular}


Tabela 4.6- Rotação em z, $\theta c z$

\begin{tabular}{ccccc}
\hline \multirow{2}{*}{$\begin{array}{c}\text { Tipo de } \\
\text { Suspensão }\end{array}$} & $\begin{array}{c}\text { Rigidez na altura } \\
\text { média }(\mathrm{N} / \mathrm{m})\end{array}$ & $\begin{array}{c}\text { Rolamento } \\
(\mathrm{rad})\end{array}$ & $\begin{array}{c}\text { Aceleração } \\
\left(\mathrm{rad} / \mathrm{s}^{2}\right)\end{array}$ & $\begin{array}{c}\text { Aceleração } \mathrm{rms} \\
\left(\mathrm{rad} / \mathrm{s}^{2}\right)\end{array}$ \\
\hline Benchmark & 430000 & 0,000102 & 0,003819 & 0,002775 \\
S1 & 736941 & 0,000094 & 0,003619 & 0,002540 \\
S2 & 753863 & 0,000093 & 0,003565 & 0,002522 \\
S3 & 793962 & 0,000092 & 0,003431 & 0,002501 \\
S4 & 863006 & 0,00009 & 0,003512 & 0,002458 \\
\hline
\end{tabular}

Baseado nas três tabelas acima pode-se observar que para a freqüência de excitação de $1 \mathrm{~Hz}$, os valores máximos e as acelerações rms aumentam com a rigidez nos modos lateral e roll, por outro lado em yaw os valores diminuem.

A partir das matrizes $A, B, C$ e $D$ que definem as equações de Espaço de Estado conforme mostrado no capítulo 3.5 e utilizando a função "bode" no Scilab uma curva da magnitude e uma curva do ângulo de fase da função de transferência foram plotadas em função da freqüência dada em forma logarítmica (OGATA, 2004) e os resultados são mostrados nos gráficos $4.3,4.4$ e 4.5 .

Uma limitação do software utilizado é que embora seja possível obter saídas múltiplas $\left(Y_{c}, \theta_{c x}\right.$ e $\left.\theta_{c z}\right)$, só existe uma entrada. Uma particularidade deste sistema é que os modos de balanço lateral inferior e superior são excitados quando os rodeiros rotacionam em fase e o modo $\theta_{c z}$ quando esses estão defasados de $180^{\circ}$. A matriz $\mathrm{B}$ mostrada pela equação 3.24 no capítulo 3.5 e repetida abaixo possui dois componentes não nulos. Isso significa que a excitação do sistema nos rodeiros dianteiro e traseiro possui a mesma amplitude e mesma fase. Fazendo com que um dos dois valores não nulos seja igual a menos um (-1) o sistema será excitado com uma diferença de fase de $180^{\circ}$. Dessa forma no programa "statespace.sci" foi utilizada uma variável chamada "fase" que substitui o último termo da matriz $B$ e é definida pelo usuário como sendo $+/-1$ de acordo com o modo de vibração que se deseja analisar.

$$
B=\left[\begin{array}{llllllllll}
0 & 0 & 0 & 0 & 0 & 0 & 0 & 1 & 0 & 1
\end{array}\right]
$$

A seguir são apresentados os diagramas de Bode de $Y_{c}, \theta_{c x}$ e $\theta_{c z}$ para o veículo na configuração do Benchmark, isto é, com a rigidez da suspensão secundária de 
$430000 \mathrm{~N} / \mathrm{m}$ e para o mesmo veículo provido da suspensão $S 4$, ou seja, rigidez de $806003 \mathrm{~N} / \mathrm{m}$.

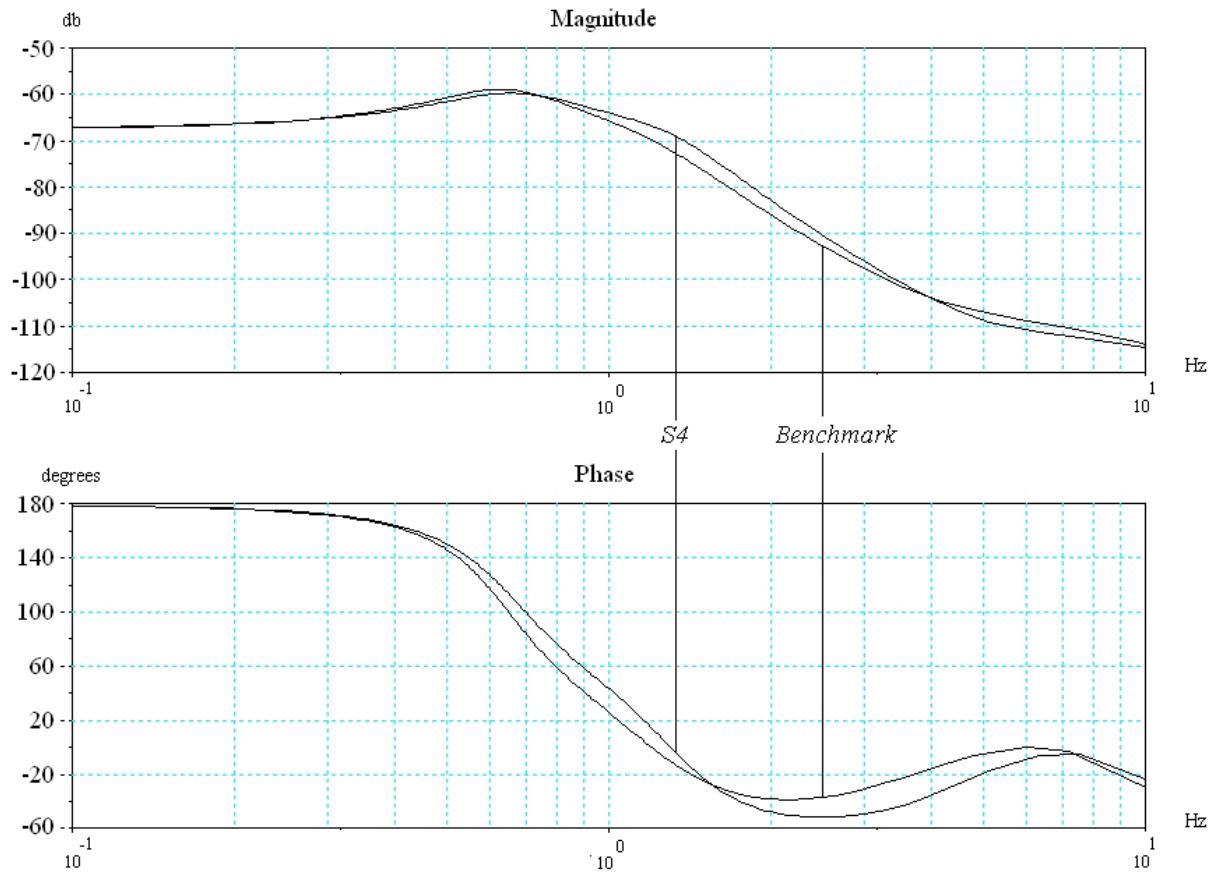

Gráfico 4.3 - Diagrama de Bode para $Y_{c}$, Rotação dos Rodeiros em Fase e Configuração do Veículo Segundo o Benchmark e com Rigidez da Suspensão Secundária S4

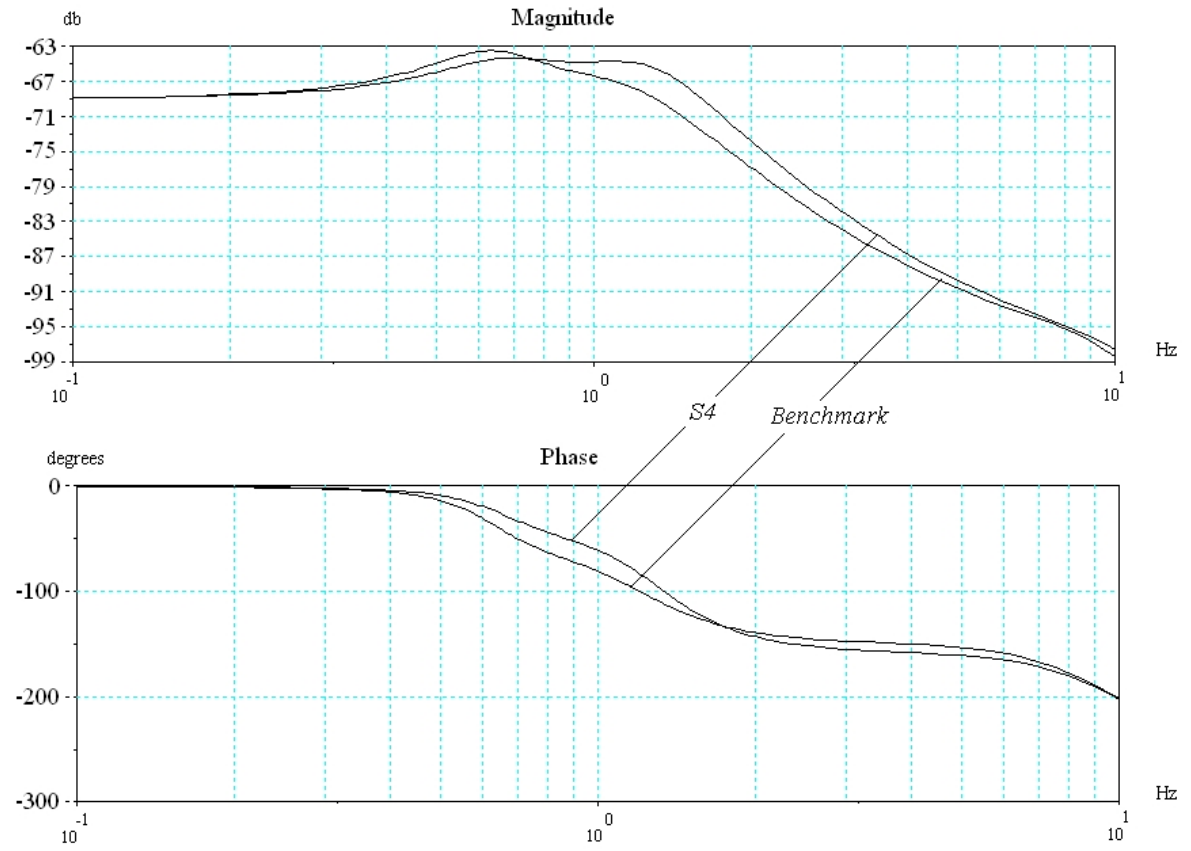

Gráfico 4.4 - Diagrama de Bode para $\theta_{c x}$, Rotação dos Rodeiros em Fase e Configuração do Veículo Segundo o Benchmark e com Rigidez da Suspensão Secundária S4 


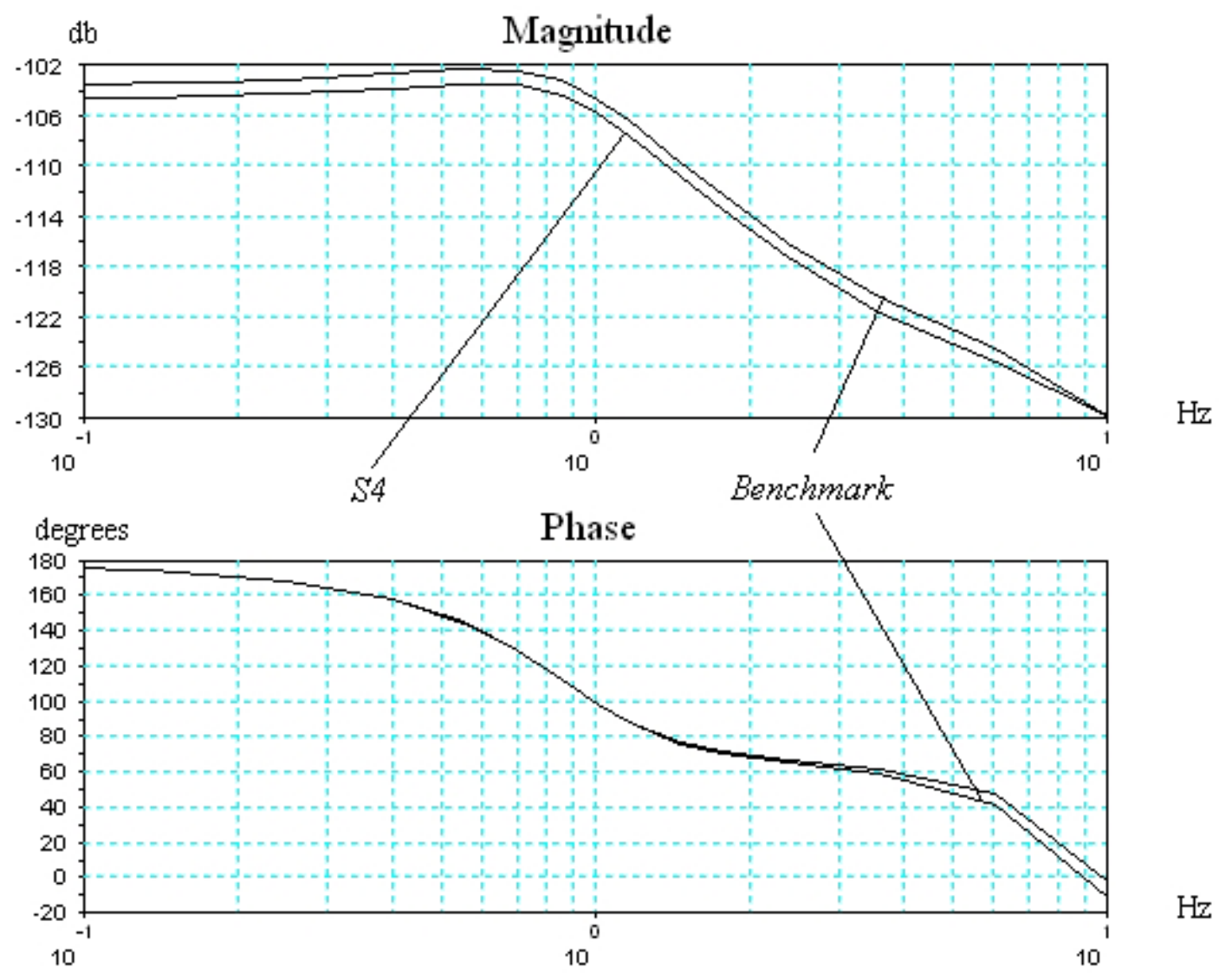

Gráfico 4.5 - Diagrama de Bode para $\theta_{c z}$, Rotação dos Rodeiros Defasados de $180^{\circ}$ e Configuração do Veículo Segundo o Benchmark e com Rigidez da Suspensão Secundária S4

A magnitude dos três gráficos acima relaciona a força de excitação em Newtons com o deslocamento de saída em metros para $Y_{c}$ e em radianos para $\theta_{c x}$ e $\theta_{c z}$. Isso explica porque os valores das magnitudes nos três gráficos são tão baixos.

Devido ao elevado coeficiente de amortecimento do sistema, não fica muito claro a posição dos picos de magnitude localizados nas freqüências naturais. Assim, foram plotados duas curvas do diagrama de Bode, uma para o movimento lateral e outra para o roll e cada qual foi deslocada para a origem. Outra modificação a partir dos parâmetros originais foi a redução de $50 \%$ dos amortecimentos $C_{a z}$ (amortecedor vertical) $C_{a y}$ (amortecedor lateral) e $C_{p z}$ (amortecimento vertical da suspensão primária). Visto que os valores das magnitudes são dados nos gráficos 4.3 e 4.4 e que o importante no gráfico a seguir é a forma das curvas, este deslocamento não influenciará na interpretação dos resultados desde que seja conhecido. Para tal, as forças de entrada do modo lateral foram multiplicadas por 2290,87 (equivalente a $67,2 \mathrm{db}$ ) e do modo roll por 2792,54 (equivalente a 68,92 db). Segundo (OGATA, 2004), um número que aumenta de um fator 10 , tem seu respectivo valor em decibel 
aumentado de 20. Assim, a correspondência entre um valor $K$ e seu correspondente em decibel é dado por:

$$
L=20 \cdot \log _{10} K
$$

A seguir são apresentadas duas curvas dos modos mencionados.

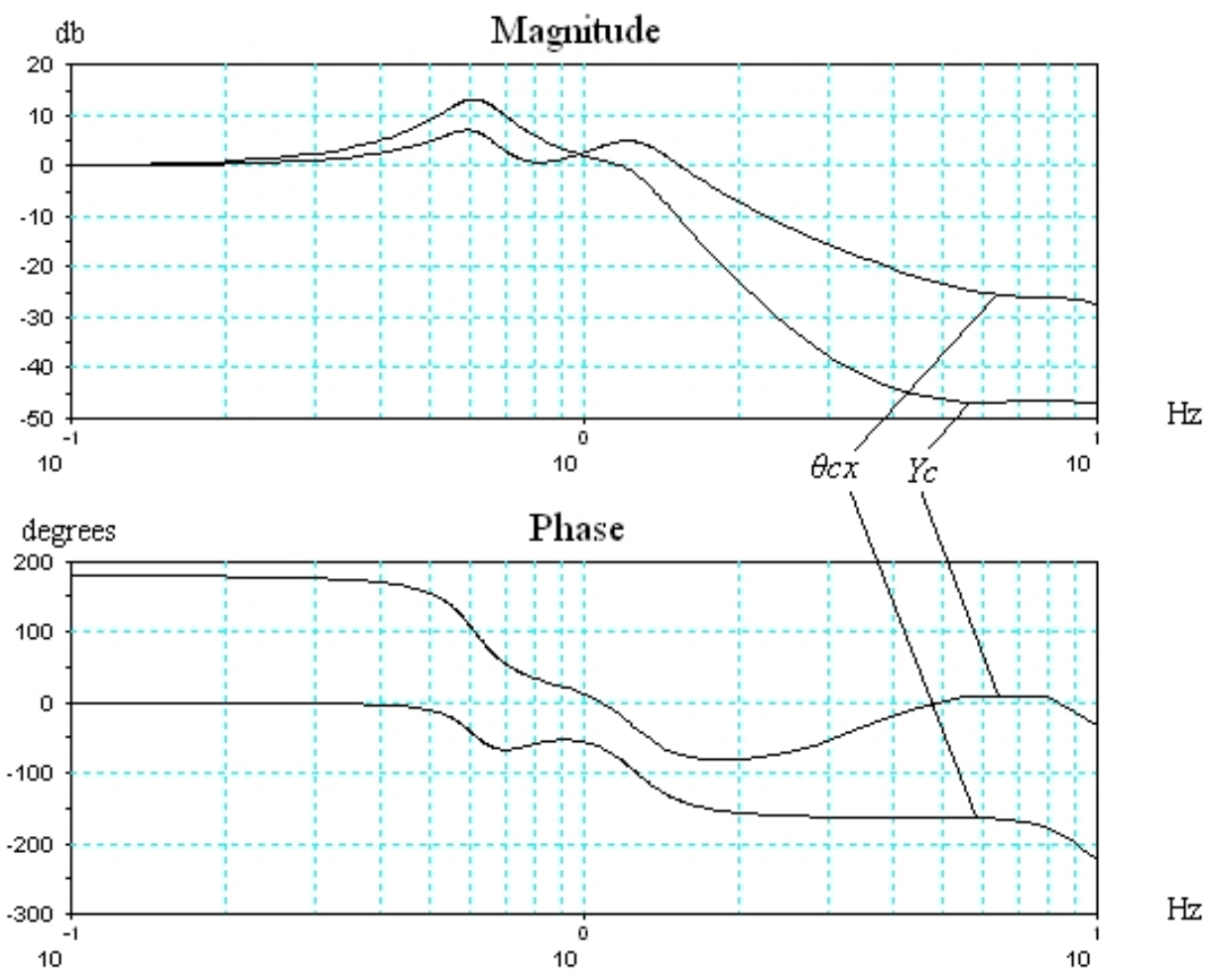

Gráfico 4.6 - Diagrama de Bode para $Y_{c}$ e $\theta_{c x}$, Rotação dos Rodeiros em Fase, Amortecimentos $C_{a z}$, $C_{a y}$ e $C_{p z}$ Reduzidos de $50 \%$, Deslocamento das Curvas de Magnitude para a Origem ( $+67,2 \mathrm{db}$ para $Y_{c}$ e $+68,92 \mathrm{db}$ para $\left.\theta_{c x}\right)$.

Uma análise dos resultados mostrados acima é apresentada no capítulo 4.5.

\subsection{Simulação por integração numérica}

O último método de análise aqui realizado consiste na solução por integração numérica utilizando software SCICOS conforme detalhado no capítulo 3.6. 
Foram feitas várias simulações e em cada uma delas foram obtidos os resultados dos movimentos lateral, roll e yaw. Nove tipos de configuração de veículos foram definidos, sendo elas um modelo linear segundo descrito pelo Benchmark e oito modelos dos quais quatro lineares e quatro não lineares substituindo as suspensões secundária pelos tipos definidos no apêndice A (S1, S2, S3 e S4). Para cada uma dessas nove configurações, foi feita uma simulação à velocidade constante segundo o "Cenário 1" definido no capítulo 4.1.

O "Cenário 2" (veículo acelerando) foi utilizado em duas simulações de um veículo provido da suspensão do tipo $S 4$ nos casos linear e não linear (gráficos 4.7 e 4.8). Os resultados obtidos por cada simulação foram registrados na forma de arquivo texto a partir dos quais foram gerados os gráficos utilizando o programa "graficos_result_scicos.sci" mostrado no apêndice G.

Além dos parâmetros que definem o veículo apresentados no capítulo 4.1 existem outros utilizados pelo programa para definir a via (ex. $\lambda$, amplitude) e o tipo de simulação (ex. tempo, velocidade, aceleração). Esses valores são definidos no menu "Context" do software SCICOS e foram divididos em duas séries. A primeira série mostrada a seguir especifica as características da via e do veículo em que os parâmetros são invariáveis para todos os tipos de simulação.

- tfinal: tempo total da simulação - "17 s";

- deltat: intervalo de tempo entre duas iterações sucessivas - "0,01 s";

- lambda: comprimento de onda da irregularidade dos trilho - "11,88 m";

- rm: amplitude da irregularidade dos trilhos - "0,02 m";

- a_zr1 / a_zr2: quando iguais a zero as oscilações verticais dos rodeiros são nulas, quando iguais a um as amplitudes das oscilações são iguais a amplitude da irregularidade $\mathrm{rm}$. Como no modelo estudado os trilhos estão defasados de $180^{\circ}$. Este tipo de excitação não é simulada. - "0";

- a_tetar1 / a_tetar2: quando iguais a zero as oscilações verticais dos rodeiros são nulas, quando iguais a um as amplitudes das oscilações são iguais a $\mathrm{rm} / \mathrm{bb}$ (tangente da amplitude da irregularidade dividido pela bitola). Como no modelo estudado os trilhos estão defasados de $180^{\circ}$, somente este tipo de excitação é simulada. - "1"; 
A segunda série de parâmetros definem as características particulares à cada simulação.

- $\quad$ nli: quando $n l i=0$ o programa executa a simulação para o modelo linear, caso contrário, (nli=1) o modelo é considerado como não linear;

- hbolsa: altura da "bolsa" de suspensão entre o batente superior (interface com a caixa) e o batente inferior (interface com o truque);

- $\quad v$ : velocidade de deslocamento do veículo - "11,88 m/s" ;

- vi: velocidade inicial - "Cenário 1" = $11.88 \mathrm{~m} / \mathrm{s}$, "Cenário 2" = $5 \mathrm{~m} / \mathrm{s}$;

- acl: aceleração - "Cenário 1" = $0 \mathrm{~m} / \mathrm{s}^{2}$, "Cenário 2" = 0,5 m/s

- $\quad k s z:$ rigidez da suspensão secundária. Conforme explicado no apêndice $A$, este valor de rigidez é dado pelas curvas características das suspensões secundárias em função da altura das suspensões. No caso linear, tanto a altura quanto a rigidez são constante e no caso não linear ambos valores variam.

A tabela a seguir apresenta as rijezas no ponto de operação e a altura da bolsa para cada tipo de suspensão. Como pode ser percebido, a altura da bolsa no caso do Benchmark é zero pois a rigidez independe desta variável. Os parâmetros de definição das suspensões secundárias não lineares são apresentados no apêndice A.

Tabela 4.7 - Parâmetros que Definem as Suspensões Secundárias Lineares

\begin{tabular}{ccc}
\hline Tipo & Altura nominal da bolsa de ar & $\begin{array}{c}\text { Rigidez da Suspensão } \\
\text { Secundária (N/m) }\end{array}$ \\
\hline Benchmark & 0 & 430000 \\
S1 & 0.23495 & 736941 \\
S2 & 0.22225 & 753863 \\
S3 & 0.22225 & 793962 \\
S4 & 0.2159 & 863006 \\
\hline
\end{tabular}

Para cada simulação foram geradas as respostas em deslocamento e acelerações. Visto que a forma das curvas são semelhantes e que no capítulo anterior foram apresentados os resultados para um veículo a velocidade constante, os resultados das demais simulações não são apresentados. 
Além das simulações a velocidade constante, foi executada uma a velocidade variável para um veículo provido da suspensão tipo $S 4$ linear e não linear segundo o especificado pelo "Cenário 2" (aceleração de $5 \mathrm{~m} / \mathrm{s}$ a 13,5 m/s em 17 segundos). Os resultados dos deslocamentos e acelerações desta simulação são mostrados a seguir, juntamente com a evolução da velocidade do veículo e da freqüência de excitação dos rodeiros.
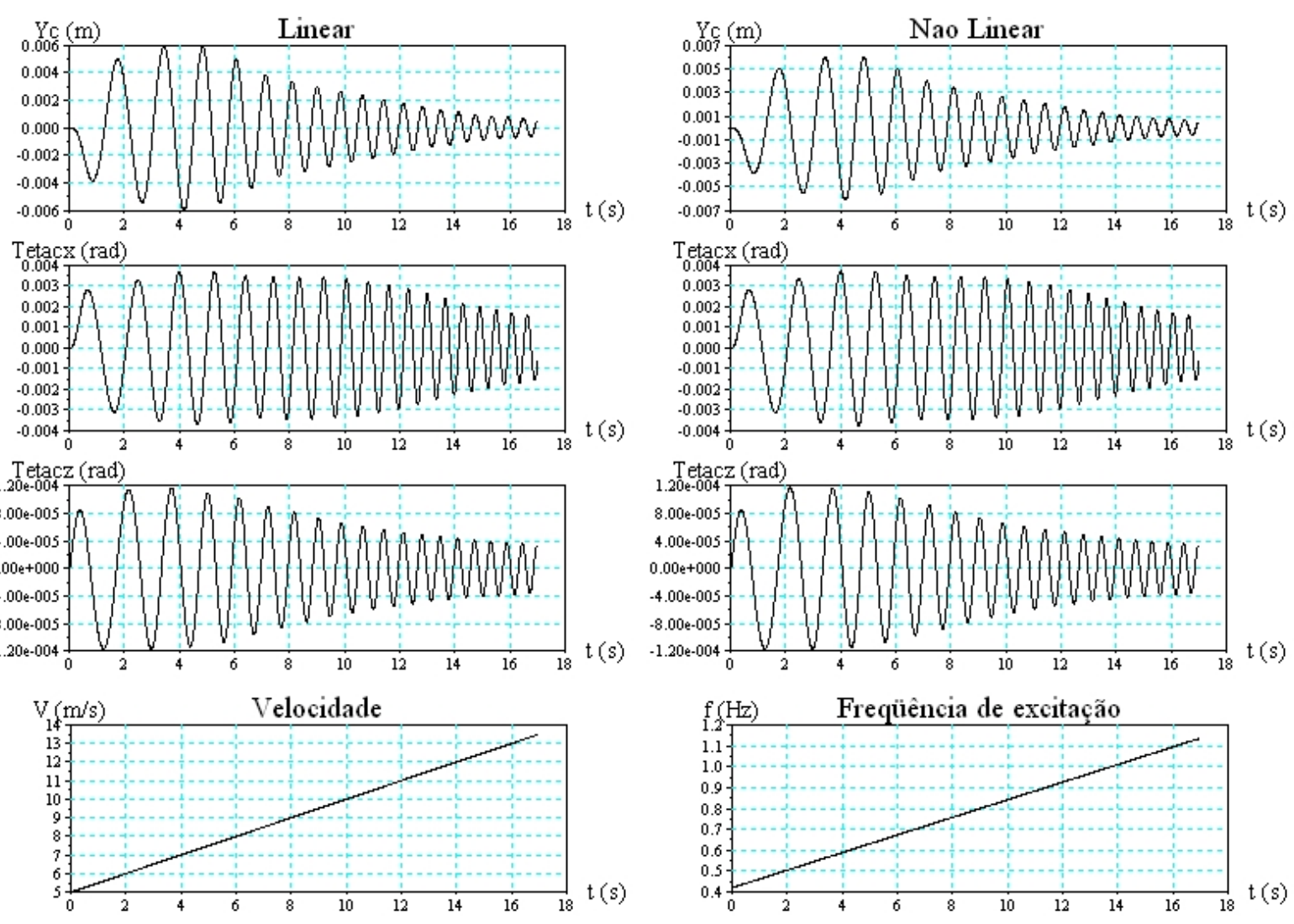

Gráfico 4.7 - Deslocamentos Lineares e Angulares, Velocidade do Veículo e Freqüências de Excitação dos Rodeiros para Suspensão do Tipo S4

A partir dos resultados obtidos das simulações a velocidade constante para as suspensões secundárias lineares e não lineares, foram calculadas as amplitudes máxima de deslocamento, aceleração e a aceleração rms utilizando o programa "result_scicos.sci" apresentado no anexo G. Assim como foi explicado no capítulo 4.3, foram desconsiderados os primeiros ciclos para evitar a região de transitórios. Os resultados são apresentados nas tabelas 4.8, 4.9 e 4.10. 

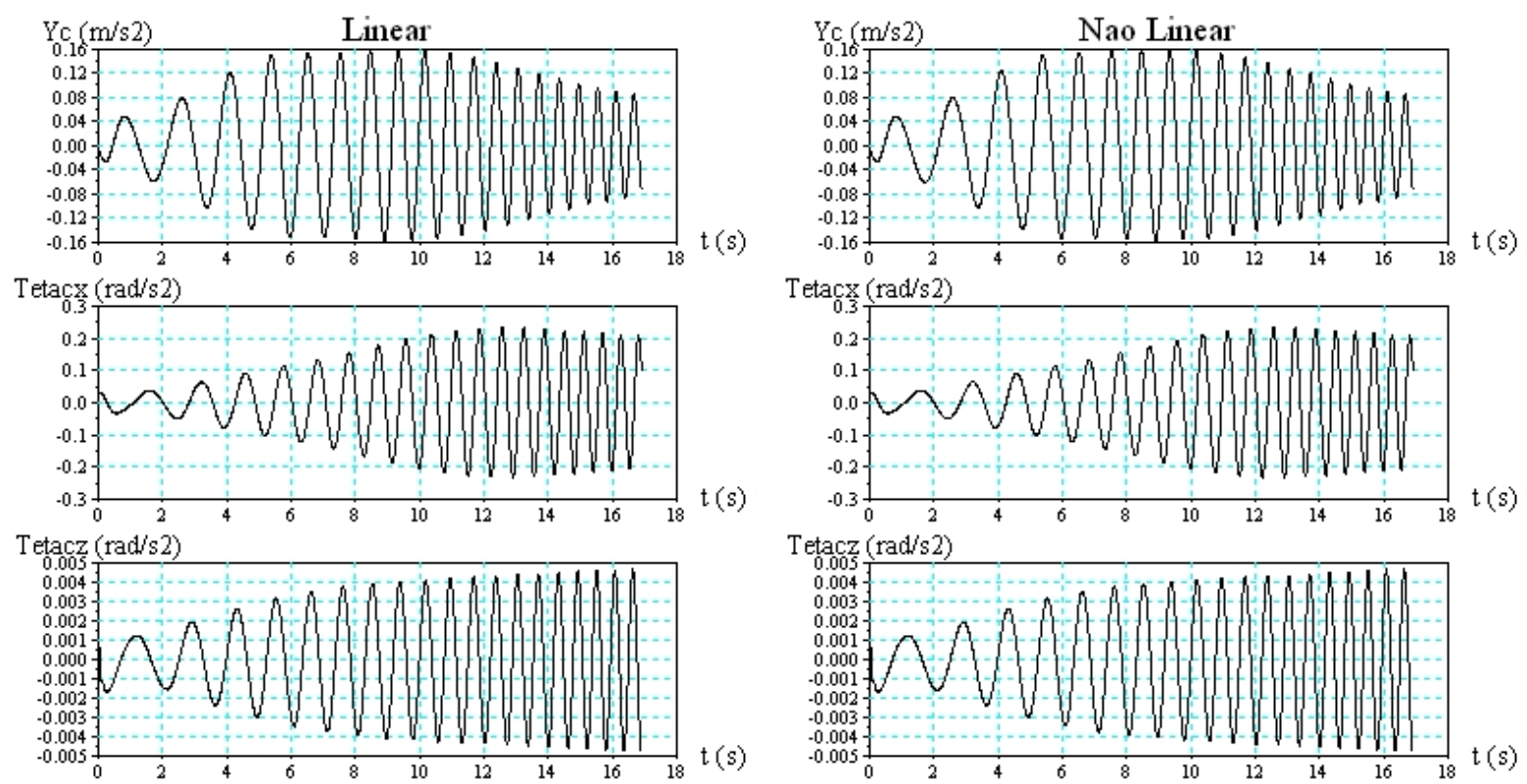

Gráfico 4.8 - Acelerações Lineares e Angulares para Suspensão do Tipo S4 (as evoluções de velocidade e freqüência de excitação dos rodeiros são idênticas às do gráfico 4.7)

Tabela 4.8- Deslocamento Lateral Yc: $v=11,88 \mathrm{~m} / \mathrm{s}$

\begin{tabular}{ccccccc}
\hline \multirow{2}{*}{$\begin{array}{c}\text { Tipo de } \\
\text { Suspensão }\end{array}$} & \multicolumn{4}{c}{ Máximos } & \multicolumn{2}{c}{$\begin{array}{c}\text { Aceleração rms } \\
\left(\mathrm{m} / \mathrm{s}^{2}\right)\end{array}$} \\
\cline { 2 - 6 } & \multicolumn{2}{c}{ Deslocamento $(\mathrm{m})$} & \multicolumn{2}{c}{ Aceleração $\left(\mathrm{m} / \mathrm{s}^{2}\right)$} & & Linear \\
\cline { 2 - 6 } & Não Linear & Linear & Não Linear & Linear & $\begin{array}{c}\text { Não } \\
\text { Linear }\end{array}$ \\
\hline Benchmark & 0,003160 & - & 0,124000 & - & 0,087303 & - \\
S1 & 0,003740 & 0,00372 & 0,147000 & 0,147 & 0,103073 & 0,10336 \\
S2 & 0,003760 & 0,00375 & 0,149000 & 0,148 & 0,104321 & 0,103661 \\
S3 & 0,003790 & 0,00375 & 0,150000 & 0,149 & 0,105374 & 0,104699 \\
S4 & 0,003860 & 0,00381 & 0,153000 & 0,151 & 0,106848 & 0,106296 \\
\hline
\end{tabular}

Tabela 4.9 - Rolamento $\theta c x: v=11,88 \mathrm{~m} / \mathrm{s}$

\begin{tabular}{|c|c|c|c|c|c|c|}
\hline \multirow{3}{*}{$\begin{array}{c}\text { Tipo de } \\
\text { Suspensão }\end{array}$} & \multicolumn{4}{|c|}{ Máximos } & \multirow{2}{*}{\multicolumn{2}{|c|}{$\begin{array}{c}\text { Aceleração rms } \\
\left(\mathrm{rad} / \mathrm{s}^{2}\right)\end{array}$}} \\
\hline & \multicolumn{2}{|c|}{ Deslocamento (rad) } & \multicolumn{2}{|c|}{ Aceleração $\left(\mathrm{rad} / \mathrm{s}^{2}\right)$} & & \\
\hline & Linear & Não Linear & Linear & Não Linear & Linear & Não Linear \\
\hline Benchmark & 0,002910 & - & 0,115000 & 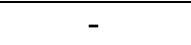 & 0,081337 & \\
\hline S1 & 0,003410 & 0,00341 & 0,136000 & 0,136 & 0,095519 & 0,095342 \\
\hline S2 & 0,003450 & 0,00343 & 0,136000 & 0,136 & 0,096137 & 0,095863 \\
\hline S3 & 0,003480 & 0,00345 & 0,138000 & 0,138 & 0,096812 & 0,096898 \\
\hline S4 & 0,003530 & 0,00352 & 0,140000 & 0,141 & 0,098301 & 0,098622 \\
\hline
\end{tabular}


Tabela 4.10 - Rotação $\theta c z: v=11,88 \mathrm{~m} / \mathrm{s}$

\begin{tabular}{|c|c|c|c|c|c|c|}
\hline \multirow{3}{*}{$\begin{array}{c}\text { Tipo de } \\
\text { Suspensão }\end{array}$} & \multicolumn{4}{|c|}{ Máximos } & \multirow{2}{*}{\multicolumn{2}{|c|}{$\begin{array}{l}\text { Aceleração rms } \\
\left(\mathrm{rad} / \mathrm{s}^{2}\right)\end{array}$}} \\
\hline & \multicolumn{2}{|c|}{ Deslocamento (rad) } & \multicolumn{2}{|c|}{ Aceleração $\left(\mathrm{rad} / \mathrm{s}^{2}\right)$} & & \\
\hline & Linear & Não Linear & Linear & Não Linear & Linear & Não Linear \\
\hline Benchmark & 0,000103 & - & 0,004080 & & 0,002870 & - \\
\hline S1 & 0,000094 & 0,000094 & 0,003740 & 0,00374 & 0,002629 & 0,002632 \\
\hline S2 & 0,000094 & 0,000094 & 0,003730 & 0,00371 & 0,002627 & 0,002617 \\
\hline S3 & 0,000093 & 0,000092 & 0,003690 & 0,00368 & 0,002592 & 0,002591 \\
\hline S4 & 0,000091 & 0,000091 & 0,003620 & 0,00361 & 0,002545 & 0,002539 \\
\hline
\end{tabular}

Como se pode perceber, as diferenças entre os resultados do modelo linear e não linear são praticamente desprezíveis. As diferenças médias para os três casos (deslocamento, aceleração e aceleração rms) são de $0,45 \%, 0,37 \%$ e $0,31 \%$ sendo as diferenças máximas encontradas 1,31\%, 1,32\% e 0,59\%.

A partir dos resultados das simulações lineares utilizando a solução analítica (tabelas 4.4, 4.5 e 4.6) e a solução por integração numérica (tabelas 4.8, 4.9 e 4.10) foi possível construir as tabelas comparativas mostradas a seguir:

Tabela 4.11 - Deslocamento Lateral Yc: $v=11,88 \mathrm{~m} / \mathrm{s}$

\begin{tabular}{ccccccc}
\hline \multirow{2}{*}{$\begin{array}{c}\text { Tipo de } \\
\text { Suspensão }\end{array}$} & \multicolumn{4}{c}{ Máximos } & \multicolumn{2}{c}{$\begin{array}{c}\text { Aceleração rms } \\
\left(\mathrm{m} / \mathrm{s}^{2}\right)\end{array}$} \\
\cline { 2 - 6 } & \multicolumn{2}{c}{ Deslocamento $(\mathrm{m})$} & \multicolumn{2}{c}{ Aceleração $\left(\mathrm{m} / \mathrm{s}^{2}\right)$} & \\
\cline { 2 - 6 } & Analítica & Numérica & Analítica & Numérica & Analítica & Numérica \\
\hline Benchmark & 0,003160 & 0,003115 & 0,124000 & 0,118969 & 0,087303 & 0,084608 \\
S1 & 0,003740 & 0,003679 & 0,147000 & 0,14052 & 0,103073 & 0,099778 \\
S2 & 0,003760 & 0,003697 & 0,149000 & 0,141192 & 0,104321 & 0,100286 \\
S3 & 0,003790 & 0,003738 & 0,150000 & 0,142799 & 0,105374 & 0,101379 \\
S4 & 0,003860 & 0,003796 & 0,153000 & 0,144991 & 0,106848 & 0,102936 \\
\hline
\end{tabular}

Tabela 4.12 - Rolamento $\theta c x: v=11,88 \mathrm{~m} / \mathrm{s}$

\begin{tabular}{ccccccc}
\hline \multirow{2}{*}{$\begin{array}{c}\text { Tipo de } \\
\text { Suspensão }\end{array}$} & \multicolumn{4}{c}{ Máximos } & \multicolumn{2}{c}{$\begin{array}{c}\text { Aceleração rms } \\
\left(\mathrm{m} / \mathrm{s}^{2}\right)\end{array}$} \\
\cline { 2 - 6 } & \multicolumn{2}{c}{ Deslocamento $(\mathrm{m})$} & \multicolumn{2}{c}{ Aceleração $\left(\mathrm{m} / \mathrm{s}^{2}\right)$} & \multicolumn{2}{c}{ Analín } \\
\cline { 2 - 6 } & Analítica & Numérica & Analítica & Numérica & Analítica & Numérica \\
\hline Benchmark & 0,002910 & 0,002888 & 0,115000 & 0,110306 & 0,081337 & 0,077586 \\
S1 & 0,003410 & 0,003382 & 0,136000 & 0,129141 & 0,095519 & 0,090818 \\
S2 & 0,003450 & 0,003398 & 0,136000 & 0,129764 & 0,096137 & 0,091252 \\
S3 & 0,003480 & 0,003431 & 0,138000 & 0,131039 & 0,096812 & 0,092184 \\
S4 & 0,003530 & 0,00348 & 0,140000 & 0,132972 & 0,098301 & 0,093494 \\
\hline
\end{tabular}

Tabela 4.13 - Rolamento $\theta c z: v=11,88 \mathrm{~m} / \mathrm{s}$

\begin{tabular}{ccccccc}
\hline \multirow{2}{*}{$\begin{array}{c}\text { Tipo de } \\
\text { Suspensão }\end{array}$} & \multicolumn{4}{c}{ Máximos } & \multicolumn{2}{c}{$\begin{array}{c}\text { Aceleração rms } \\
\left(\mathrm{m} / \mathrm{s}^{2}\right)\end{array}$} \\
\cline { 2 - 6 } & \multicolumn{2}{c}{ Deslocamento $(\mathrm{m})$} & \multicolumn{2}{c}{ Aceleração $\left(\mathrm{m} / \mathrm{s}^{2}\right)$} & \multicolumn{2}{c}{ Analítica } \\
\cline { 2 - 7 } & Analítica & Numérica & Analítica & Numérica & Analítica & Numérica \\
\hline Benchmark & 0,000103 & 0,000102 & 0,004080 & 0,003819 & 0,002870 & 0,002775 \\
S1 & 0,000094 & 0,000094 & 0,003740 & 0,003619 & 0,002629 & 0,002540 \\
S2 & 0,000094 & 0,000093 & 0,003730 & 0,003565 & 0,002627 & 0,002522 \\
S3 & 0,000093 & 0,000092 & 0,003690 & 0,003431 & 0,002592 & 0,002501 \\
S4 & 0,000091 & 0,00009 & 0,003620 & 0,003512 & 0,002545 & 0,002458 \\
\hline
\end{tabular}


Nesta comparação os percentuais médios das diferenças entre os dois tipos de solução para deslocamento, aceleração e aceleração rms são 1,2\%, 5,0\% e 4,1\% e os máximos encontrados são 1,7\%, 7,5\% e 5,4\%.

Os resultados obtidos acima serão analisados no capítulo que segue.

\subsection{Análise dos resultados}

A tabela 4.1 onde são apresentados os autovetores e autovalores mostra que existem dois acoplamentos entre o movimento vertical dos truques $\left(Z_{t 1}\right.$ e $\left.Z_{t 2}\right)$ e os movimentos da caixa no plano $x-z\left(Z_{x}\right.$ e $\left.\theta_{c y}\right)$. O primeiro tipo de acoplamento, a baixas freqüências, ocorre devido às suspensões secundárias. Neste caso, quando os truques se movem em fase, o modo vertical da caixa é excitado e quando estão defasados de $180^{\circ}$ a excitação ocorre no modo pitch. O segundo acoplamento ocorre na faixa de $7,47 \mathrm{~Hz}$ e é causado pela suspensão primária, embora os acoplamentos sejam os mesmos, quando os truques estão em fase, o movimento vertical da caixa está defasado de $180^{\circ}$ destes. Isso fica caracterizado pelos sinais de $Z_{t 1}, Z_{t 2}$ e $Z_{x}$ na coluna 6 da tabela.

O acoplamento do modo lateral e roll mostrado nas colunas 1 e 4 da tabela 4.1 caracteriza os movimentos de balanço lateral. Para a freqüência de $0,61 \mathrm{~Hz}$ a inversão de sinais $\left(Y_{c}=1\right.$ e $\left.\theta_{c x}=-0,265\right)$ caracteriza o modo de balanço lateral inferior e para a freqüência de $1,27 \mathrm{~Hz}$, onde ambos os sinais são negativos $\left(Y_{C}=-0,473 \mathrm{e}\right.$ $\left.\theta_{c z}=-1\right)$, tem-se o modo de balanço lateral superior. A figura 4.9 mostra como ocorrem tais modos de vibração.

No capítulo 4.3 foi mencionado que a excitação dos modos lateral e roll se dava quando o movimento de rotação dos rodeiros estava em fase e que o modo pitch quando ambos estavam defasados de $180^{\circ}$. Isso pode ser comprovado nas colunas 1, 4 e 9 para os movimentos em fase dos truques $\left(\theta_{t 1 x}\right.$ e $\left.\theta_{t 2 x}\right)$ e nas colunas 2 e 8 para os movimentos defasados de $180^{\circ}$. Uma particularidade dos modos 1 e 9 é que a $0,61 \mathrm{~Hz}$ o movimento de rotação dos truques e da caixa se dá em fase e a $9,95 \mathrm{~Hz}$ essas mesmas rotações ocorrem com oposição de fase. 


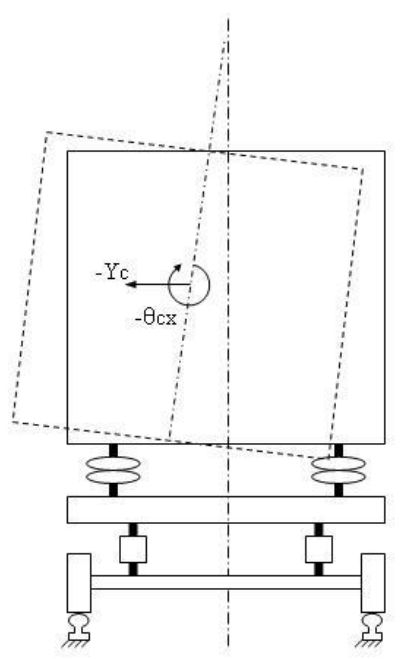

Balanço Lateral Superior

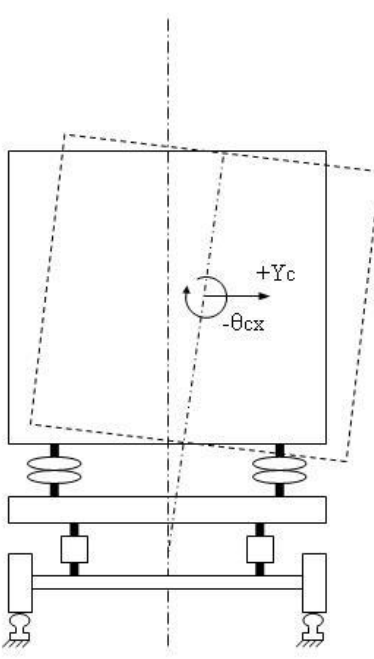

Balanço Lateral Inferior

Figura 4.9 - Balanços Laterais

Analisando a tabela 4.2 pode-se perceber que o modo cuja freqüência natural é mais sensível a variação da rigidez vertical da suspensão secundária é o movimento de balanço lateral superior (roll principal), que teve uma variação de $10 \%$ da freqüência para uma rigidez duas vezes maior. O balanço lateral inferior (deslocamento lateral principal), apresentou uma variação de $4 \%$ e o modo yaw de $0,01 \%$. Este fenômeno fica mais claro quando se analisa as equações de movimento apresentadas no capítulo 3.4 .

Como pode ser observado na equação 3.3 que descreve o movimento lateral e 3.13 para o modo yaw a única componente de rigidez presente em ambos os casos se trata de $K_{s y}$ (rigidez lateral). Por outro lado, a equação de movimento 3.9 do modo roll mostra que as rijezas verticais e laterais da suspensão secundária e a rigidez da barra de torção são levadas em consideração. Assim, uma variação da rigidez vertical $K_{s z}$, influencia diretamente a resposta do modo roll enquanto que para os outros dois modos a variação ocorre indiretamente, devido principalmente aos acoplamentos entre os vários modos de vibração do veículo. Comparando as colunas 4 e 1 da tabela 4.1 , vê-se que a componente $\theta_{c x}$ do autovetor normalizado é maior para a freqüência de $1,27 \mathrm{~Hz}$ do que para $0,61 \mathrm{~Hz}$, isso explica porque o autovalor do balanço lateral superior é mais sensível a variação da rigidez do que o balanço lateral inferior, onde o autovetor do modo $Y_{c}$ é mais significativo. $O$ fato do 
modo yaw estar acoplado somente com os movimentos rotacionais do truque faz com que este varie muito pouco em função da rigidez vertical das suspensões secundárias.

A tabela 4.3 apresenta uma comparação entre os resultados aqui obtidos e o dos demais participantes do Benchmark. Pode-se perceber que os resultados são praticamente os mesmos obtidos pelos softwares ADAMS e Universal Mechanism, a não ser nos modos yaw e balanço lateral superior. No primeiro caso, modo yaw, houve um dos participantes do Benchmark que obteve o mesmo resultado deste trabalho $(0,86 \mathrm{~Hz})$, e no caso do balanço lateral houve uma diferença de $3 \%(1,27$ $\mathrm{Hz}$ calculado aqui contra $1,23 \mathrm{~Hz}$ estimado por um dos participantes). Segundo as informações do artigo (UNIVERSAL MECHANISM, 2007) não é possível definir quais critérios assumidos por cada construtor de software interferiram de maneira que houvesse essa diferença, mas uma variação de $3 \%$ em um dos casos pode ser considerado que os resultados foram validados.

A partir do método de Espaços de Estado foram obtidos os resultados do movimento lateral, roll e yaw para o veículo circulando em uma linha segundo o "Cenário 1" (veículo se deslocando à velocidade constante de 11,88 m/s durante 17 segundos). Analisando as amplitudes de deslocamento nas tabelas 4.4, 4.5 e 4.6, percebe-se que nas duas primeiras $\left(Y_{c}\right.$ e $\left.\theta_{c x}\right)$ há um aumento das amplitudes com a variação da rigidez das suspensões secundárias e no terceiro caso $\left(\theta_{c z}\right)$ as amplitudes diminuem. Este fenômeno fica evidente quando se analisa os diagramas de Bode nos gráficos 4.3, 4.4 e 4.5. Nos gráficos 4.3 e 4.4 o valor da magnitude da curva correspondente à suspensão 54 é maior que o da curva Benchmark para a frequência de excitação dos rodeiros de $1 \mathrm{~Hz}$. No gráfico 4.5 ocorre justamente o inverso: a magnitude da curva 54 é inferior à curva Benchmark nesta mesma freqüência.

Como foi dito anteriormente, a tabela 4.2 mostra que a freqüência natural para o modo de balanço lateral inferior, onde há predominância do movimento lateral, aumenta em função da rigidez vertical da suspensão secundária. Isso pode ser confirmado analisando a curva de fase do gráfico 4.3. Para o ângulo de $90^{\circ}$, a curva da suspensão 54 , mais rígida está à direita da curva de suspensão do Benchmark. Em ambas as curvas de magnitude percebe-se um pico na faixa entre $0,6 \mathrm{~Hz}$ e 0,7 
$\mathrm{Hz}$. As curvas de pase cortam a linha de $90^{\circ}$ na freqüência de $0,68 \mathrm{~Hz}$ para a suspensão do Benchmark e $0,74 \mathrm{~Hz}$ para a suspensão S4. Há também uma pequena inflexão, atenuada pelo amortecimento, próxima à freqüência de $1,2 \mathrm{~Hz}$ devido ao acoplamento com o modo roll.

No gráfico 4.4 também podem ser percebidos os picos correspondentes ao acoplamento com o modo lateral próximo a $0,7 \mathrm{~Hz}$ e as inflexões que caracterizam os acoplamentos na faixa de 1,2 Hz. Além dessas duas inflexões serem mais nítidas que no caso anterior (balanço lateral inferior), é exatamente nesta faixa de freqüência que a curva de fase passa pelo ângulo de $-90^{\circ}$ (aproximadamente $1,1 \mathrm{~Hz}$ para a suspensão do Benchmark e 1,2 Hz para a suspensão S4).

O gráfico 4.5, correspondente ao movimento de yaw $\left(\theta_{c z}\right)$. As curvas de magnitude mostram que para todas as frequências compreendidas entre $0 \mathrm{~Hz}$ e $10 \mathrm{~Hz}$, as amplitudes de movimento sempre serão reduzidas com o aumento da rigidez vertical das suspensões secundárias. Embora haja um pico na faixa de $0,7 \mathrm{~Hz}$, (freqüência natural para o sistema não amortecido igual a $0,86 \mathrm{~Hz}$ ) a curva de fase assume o valor de $90^{\circ}$ por volta da freqüência de $1,2 \mathrm{~Hz}$. Isso ocorre devido ao amortecimento deste modo. O gráfico 4.9 mostra o diagrama de Bode para o modo roll de uma comparação entre o veículo segundo a configuração do Benchmark e o mesmo veículo com os amortecimentos reduzidos a $10 \%$ dos valores especificados.

O diagrama de Bode apresentado no gráfico 4.6 foi obtido reduzindo os amortecimentos amortecimentos $C_{a z}, C_{a y}$ e $C_{p z}$ de $50 \%$ dos valores especificados pelo Benchmark, com o objetivo de tornarem mais claros os fenômenos de acoplamento, uma vez que nos casos anteriores as curvas de magnitude eram atenuadas pelo amortecimento. Como foi explicado no capítulo 4.3, as curvas de magnitude foram deslocadas à origem para que a escala não ficasse muito reduzida. Em ambas as curvas percebem-se claramente os modos acoplados nas faixas de 0,6 Hz e 1,3 Hz. Uma outra característica que pode ser percebida é o fenômeno de batimento na curva $\theta_{c x}$ do gráfico 4.6. Este fenômeno ocorre quando dois modos de vibrar possuem freqüências muito próximas, fazendo com que elas tenham a tendência de se anularem, isso pode ser visto pelo "vale" formado entre os dois picos e quanto menor os amortecimentos, mais acentuado fica este fenômeno. 


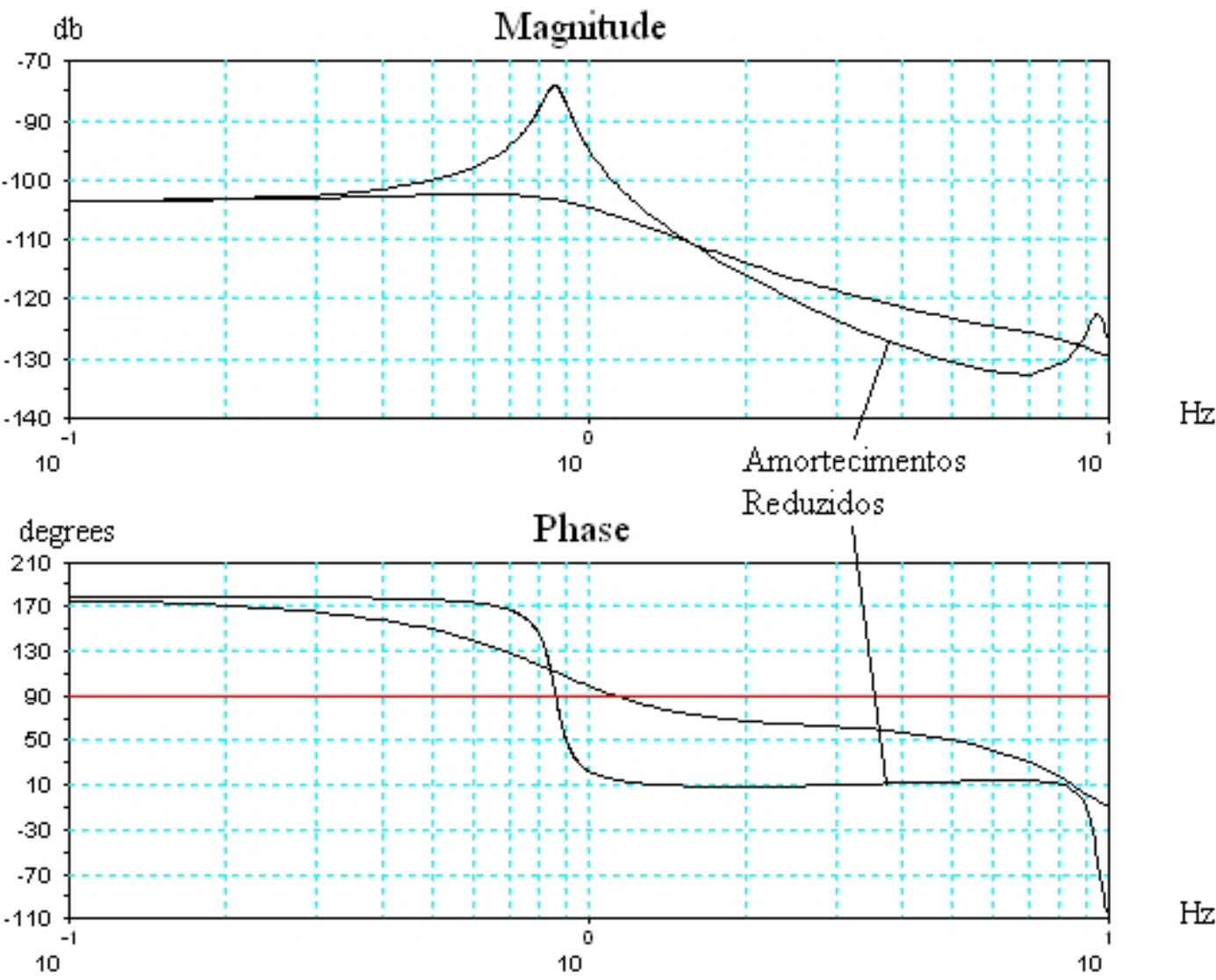

Gráfico 4.9 - Diagrama de Bode do Modo $\theta_{c z}$ para os Amortecimentos $C_{a z}, C_{a y}$ e $C_{p z}$ Reduzidos a $10 \%$ do Especificado pelo Benchmark.

O gráfico 4.7 mostra os deslocamentos e acelerações em $Y_{c}, \theta_{c x}$ e $\theta_{c z}$ resultantes de uma simulação linear e não linear para um veículo acelerando de $5 \mathrm{~m} / \mathrm{s}$ a $13,5 \mathrm{~m} / \mathrm{s}$ com uma aceleração de $0,5 \mathrm{~m} / \mathrm{s}^{2}$ (ver detalhe "Velocidade"). Como o comprimento de onda das irregularidades da via é constante $(11,88 \mathrm{~m})$, a aceleração do veículo faz com que a freqüência de excitação dos rodeiros seja variada entre $0,42 \mathrm{~Hz}$ e 1,14 Hz conforme mostrado no detalhe "Freqüência de Excitação". O fenômeno de ressônancia fica claro nessas curvas pelo aumento das amplitudes no momento em que o veículo atinge as "velocidades críticas" de cada modo conforme explicado no capítulo 2.4.4.

Observando o detalhe "Não Linear" da curva $Y_{c}$ do gráfico 4.7, percebe-se que a amplitude máxima é atingida por volta do instante $4 \mathrm{~s}$. Observando o detalhe "Freqüência de Excitação" no mesmo gráfico, vê-se que nesse instante os moviventos de roll dos rodeiros são excitados a freqüência de $0,6 \mathrm{~Hz}$. O diagrama de Bode do gráfico 4.3 para a suspensão $S 4$ (mesmo tipo utilizada na simulação) mostra que o pico da curva de magnitude ocorre entre $0,6 \mathrm{~Hz}$ e 0,7 Hz. Levando em 
consideração que no modelo numérico existe uma diferença de fase na excitação dos rodeiros pode-se concluir que existe uma coerência entre ambos os resultados (temporal e no domínio da freqüência) pois este mesmo fenômeno é observado nos três movimentos estudados.

Comparando os detalhes $Y_{c}$ e $\theta_{c x}$ do gráfico 4.7, percebe-se que no primeiro caso há um pico bem evidente no instante de $4 \mathrm{~s}(0,6 \mathrm{~Hz})$ enquanto no segundo existe uma redução das amplitudes relativamente pequena entre os instantes 4 s e 11 s $(0,6 \mathrm{~Hz}$ e 0,9 Hz). Isso é explicado quando se observa os diagramas de Bode dos gráficos 4.3 e 4.4 onde o decaimento da curva de magnitude $Y_{c}$ entre o valor de pico e a freqüência de $1,14 \mathrm{~Hz}$ é da ordem de $8 \mathrm{db}$ enquanto para o caso $\theta_{c x}$ na mesma faixa de freqüência é de apenas $3,5 \mathrm{db}$. Logo os resultados temporais e no domínio da freqüência são coerentes.

Através de uma comparação visual das curvas no gráfico 4.7 não é possível identificar uma diferença entre os resultados obtidos pelo modelo linear e pelo modelo não linear. Nas tabelas 4.8, 4.9 e 4.10 são mostrados os valores máximos obtidos nas simulações à velocidade constante $(11,88 \mathrm{~km} / \mathrm{h})$ utilizando ambos os tipos de suspensões. As diferenças médias se situam entre 0,3\% e 0,45\%.

As tabelas 4.11, 4.12 e 4.13 fazem uma comparação entre os resultados obtidos pela solução analítica e pelo método de integração numérica. Como os percentuais de diferença se situam entre 1,2 e 5\%, pode-se dizer que os dois modelos são equivalentes. Logo para os estudos dos três tipos de deslocamentos feitos neste trabalho, ambos podem ser utilizados.

\subsection{Considerações sobre o conforto de passageiros}

A análise deste capítulo se refere às condições de conforto especificadas pela norma ISO 2631-1. A percepção de conforto dos seres humanos quando sujeitos a vibrações depende da freqüência e do tempo de exposição às mesmas. Para cada um dos três eixos $(x, y$ e $z$ ) e interfaces passageiro-veículo (encosto dos bancos, cabeça de um passageiro em posição deitada) é definida uma curva ou tabela de 
ganho das freqüências ponderadas em função da freqüência de excitação. $O$ gráfico 4.10 mostra as curvas de ponderação para vibrações nos eixos $x, y, z$ e relacionada ao mal-estar.

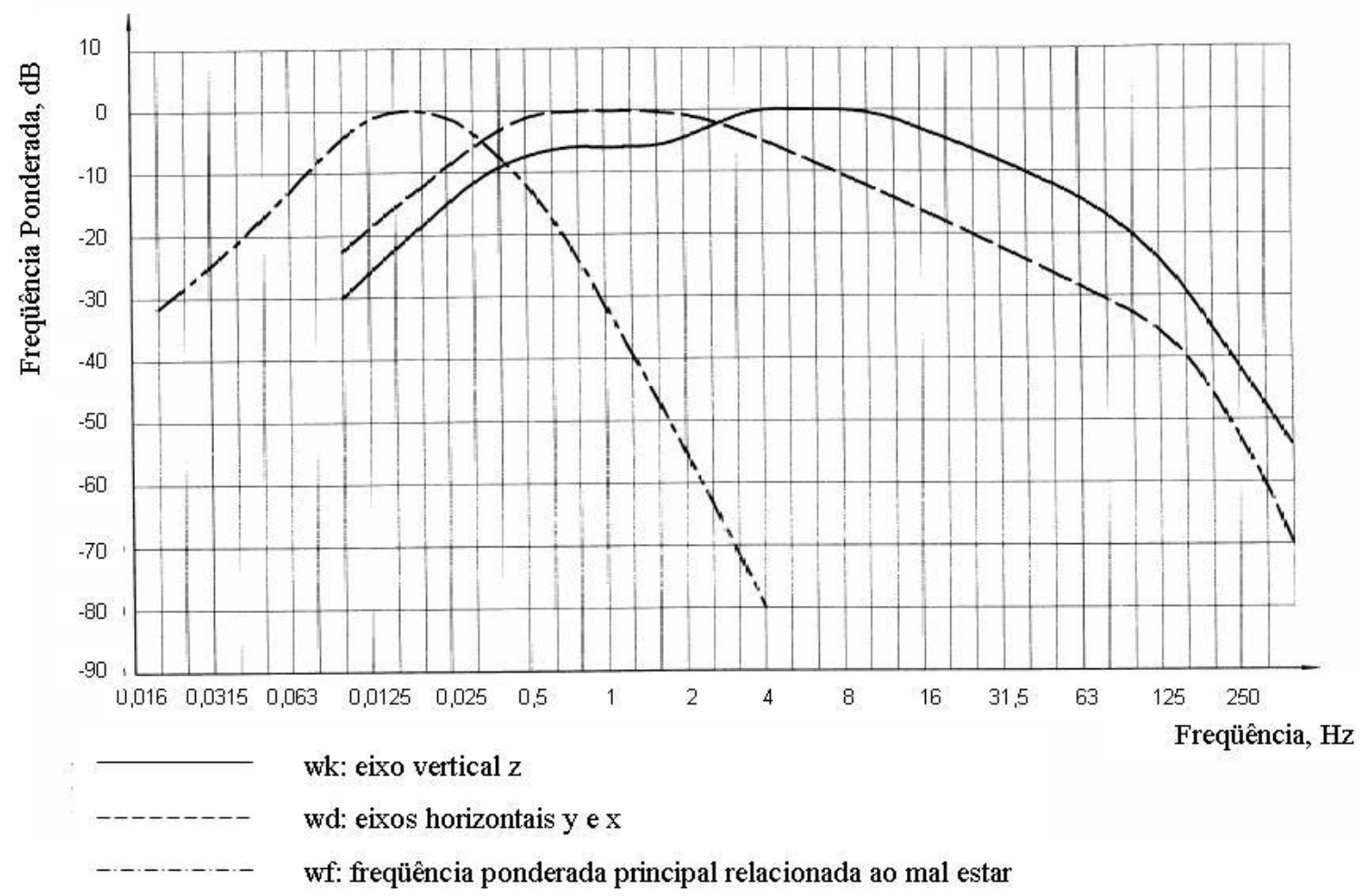

Gráfico 4.10 - Freqüências ponderadas em x, y, z e principal (ISO 2631-1)

A aceleração total da freqüência ponderada eficaz é definida de acordo com a fórmula abaixo para as freqüências de um terço de oitava de banda.

$$
a_{w}=\left[\sum_{i}\left(w_{i} a_{i}\right)^{2}\right]^{\frac{1}{2}}
$$

Onde:

- $a_{w}$ : aceleração de freqüência ponderada

- $w_{i}$ : fator de ponderação do iésimo terço de oitava de banda

- $a_{i}$ : aceleração rms do iésimo oitavo de banda 
A aceleração total rms $\left(a_{v}\right)$ mostrada na fórmula 4.7, depende das acelerações de freqüência ponderada $\left(a_{w i}\right)$ em cada eixo e dos fatores multiplicativos $\left(k_{i}\right)$ dados em função do local de medição nos bancos para estimações de passageiros sentados.

$$
a_{v}=\left(k_{x}^{2} a_{w x}^{2}+k_{y}^{2} a_{w y}^{2}+k_{z}^{2} a_{w z}^{2}\right)^{\frac{1}{2}}
$$

Como pode ser observado no gráfico 4.10 , na curva de ponderação de conforto para vibrações laterais $\left(w_{d}\right)$ o maior ganho é obtido na faixa entre $0,5 \mathrm{~Hz}$ e $2 \mathrm{~Hz}$. Os diagramas de Bode apresentados nos gráficos 4.3 para o movimento lateral e 4.4 para o rolamento mostram que entre as freqüências de $0,1 \mathrm{~Hz}$ e $0,7 \mathrm{~Hz}$ um aumento da rigidez das suspensões pneumáticas implica uma redução da magnitude. Por outro lado, entre $0,7 \mathrm{~Hz}$ e $2 \mathrm{~Hz}$ ocorre uma inversão em que as magnitudes mais altas são obtidas com suspensões mais rígidas. No caso do modo yaw, gráfico 4.5, um aumento da rigidez implica uma redução da magnitude para todas as freqüências entre $0,5 \mathrm{~Hz}$ e $2 \mathrm{~Hz}$. O aumento das amplitudes em yaw causado pela redução da rigidez não é suficiente o bastante para anular os aumentos em roll e lateral, mesmo para um passageiro situado na extremidade do veículo.

De acordo com a equação 4.7 mostrada acima e definida pela norma ISO 2631-1, a aceleração total rms é uma função das acelerações de freqüência ponderada em cada eixo. Assim, a constatação acima de que uma diminuição da rigidez implica em uma redução dos ganhos, melhorando as condições de conforto, deve ser aplicada somente aos movimentos laterais do veículo. Segundo (CARLBON, 2000) a utilização de caixas rígidas não afeta o conforto lateral, portanto este estudo pode ser conduzido sem que haja comprometimento das análises.

Outro fator importante que influi nas vibrações nas quais os passageiros estão submetidos é o local de medição no veículo. Através do modelo desenvolvido é possível obter as vibrações nos três eixos em qualquer posição da caixa a partir das coordenadas $I_{m}$ (distância do banco a partir da linha de centro transversal) e $b_{m}$ (distância do banco a partir da linha de centro longitudinal) definidas no capítulo 3.3. Assim, em função da posição escolhida, um ou mais tipos de movimento podem ser anulados ou amplificados, por exemplo, um passageiro localizado no centro do veículo não está sujeito aos efeitos das vibrações em yaw. 
Uma última consideração se refere ao coeficiente de amortecimento do sistema. As curvas S4 e Benchmark dos diagramas de Bode dos gráficos 4.3, 4.4 e 4.5 se referem a duas simulações onde somente as rijezas foram variadas. Quando se passou de uma rigidez de 430000 N/m (Benchmark) a uma de 863006 N/m (S4), os fatores de amortecimento foram reduzidos. O problema causado por esta redução se dá quando eles se tornam inferiores a zero, caracterizando que o sistema se tornou instável (BARBOSA, 1996). Neste caso, quando se aumentou somente a rigidêz sem variar os amortecimentos, a velocidade crítica para qual o veículo se torna instável será menor.

O gráfico 4.11 mostra três curvas no diagrama de Bode. Na primeira delas o veículo foi configurado como descrito no Benchmark. Na segunda, curva "S4", foi utilizado o mesmo veículo porém com a rigidez da suspensão secundária duas vezes maior (esses dois gráficos são representadas no gráfico 4.4). Na terceira, curva "S4 amortecido", a rigidez é a mesma que em S4 e os amortecimentos verticais e laterais foram aumentados $50 \%$.

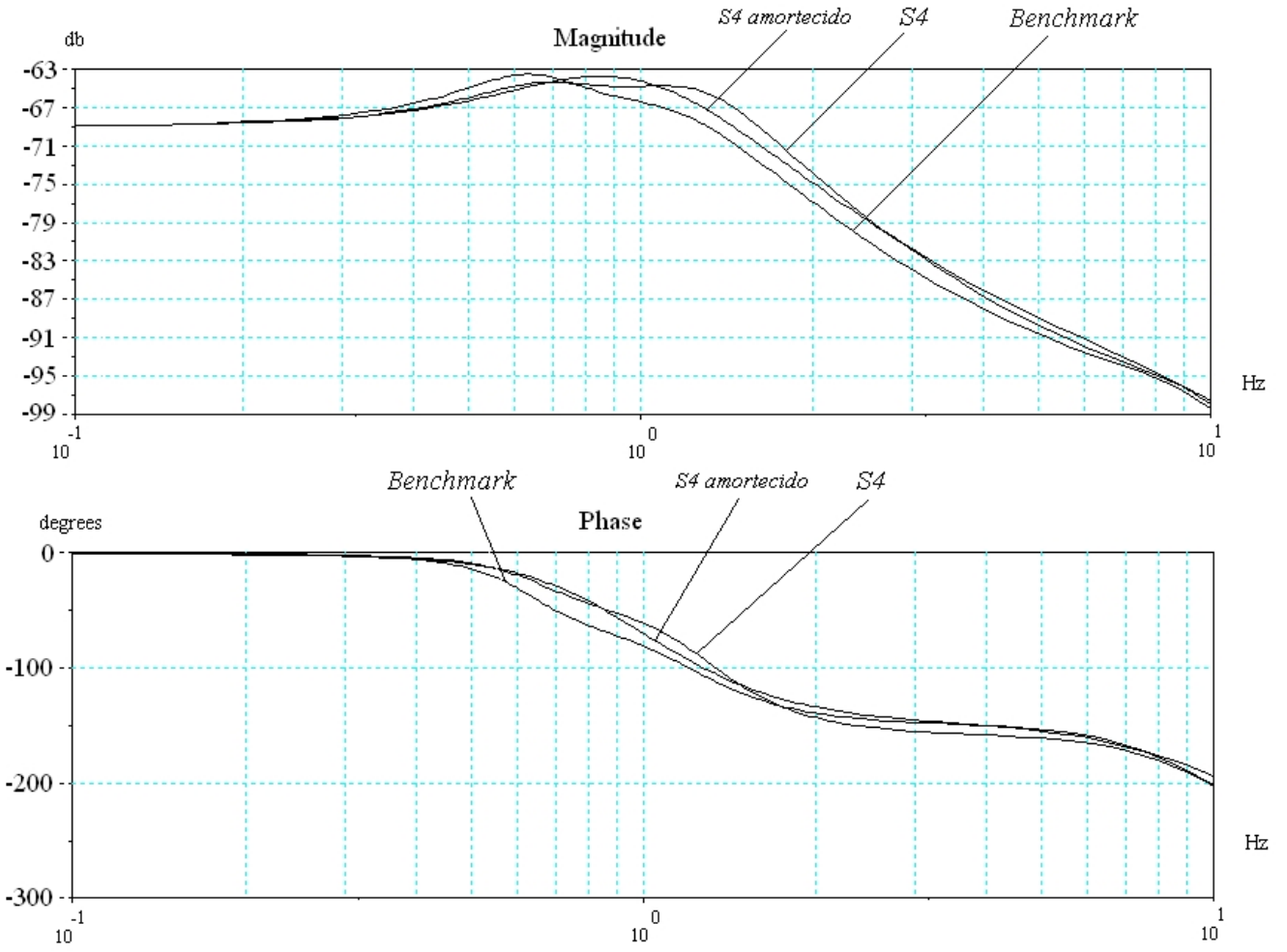

Gráfico 4.11 - Diagrama de Bode para $\theta_{c x}$, Rotação dos Rodeiros em Fase e Configuração do Veículo Segundo o Benchmark, com Aumento da Rigidez (S4) e Amortecimento (S4 amortecido) 
Como pode ser observado mesmo com um aumento de $50 \%$ do amortecimento da suspensão e conseqüentemente $\mathrm{O}$ fator de amortecimento, as magnitudes continuam maiores na faixa de freqüência de interesse (entre $0,5 \mathrm{~Hz}$ e $2 \mathrm{~Hz}$ ) quando comparadas com uma rigidez menor tal como definida pelo Benchmark. 


\section{Conclusões e Recomendações}

\subsection{Sumário das principais conclusões}

Com o objetivo de analisar a influência das suspensões secundárias no movimento lateral de um veículo ferroviário, realizou-se um estudo em que foi concebido um modelo físico de um veículo composto de uma caixa rígida e dois truques de um rodeiro cada. A partir deste modelo, foram construídas as equações de movimento do sistema baseado nas leis de Newton e, após serem feitas determinadas simplificações, chegou-se a um conjunto de nove equações de movimento que representam os nove graus de liberdade do sistema. Dois tipos de soluções foram aplicadas na resolução de tais equações, sendo a primeira delas uma solução analítica utilizando, a abordagem de Espaços de Estado e, a segunda, uma solução por integração numérica.

$\mathrm{Na}$ abordagem por Espaços de Estado, constatou-se que quatro dos nove graus de liberdade do sistema inicial não eram excitados. Isso se deve ao fato dos movimentos verticais dos truques e da caixa e a sua rotação no eixo y serem nulos, uma vez que a excitação dos rodeiros que é transmitida ao veículo ocorre somente em torno do eixo $x$. Logo, esses quatro graus de liberdade foram retirados e, como saídas, têm-se os movimentos de deslocamento lateral, roll e yaw da caixa. No caso da solução por integração numérica, existem quatro tipos de entrada, sendo elas os deslocamentos verticais e rotacionais em $x$ de cada rodeiro e nove saídas, uma para cada grau de liberdade inicialmente definido.

A definição dos atributos dos corpos e juntas que compõem o veículo e as bases para a especificação da via e dos cenários de simulação foram obtidas no "Manchester Benchmarks for rail vehicle simulation" (IWNICKI, 1999), o que possibilitou a comparação dos resultados obtidos neste trabalho com os apresentados no artigo.

A partir dos resultados da análise modal do sistema onde foram obtidos os autovetores e autovalores, uma comparação com os resultados dos fornecedores de 
software que participaram Benchmark foi conduzida e verificou-se que todos os valores obtidos e apresentados no capítulo 4.2 se encontram dentro das faixas de resultados dos demais participantes, a não ser para o modo de balanço lateral superior em que a diferença encontrada foi 3,2\% superior. Uma vez que não se teve acesso aos detalhes do modelamento e das simplificações de cada fornecedor, não se pode explicar o que originou tal diferença. Mas, tendo em vista a complexidade do sistema e as hipóteses assumidas, pode-se dizer que os resultados são coerentes.

Uma segunda comparação entre os resultados temporais obtidos pela solução analítica e por integração numérica para um sistema linear foi elaborada a partir de uma série de simulações em que se variou as rijezas verticais das suspensões pneumáticas. Neste caso, foram comparados os valores máximos das amplitudes dos deslocamentos e acelerações linear e angular e o valor médio quadrático da aceleração (rms). Conforme mostrado no capítulo 4.5 as porcentagens médias de diferença se situam entre $1,2 \%$ e $4,5 \%$, o que confirma a compatibilidade entre os dois tipos de solução, permitindo, assim, a utilização de um modelo de cinco graus de liberdade ao invés de nove quando se tratar do estudo dos modos laterais.

Na terceira série de comparações, foi feita uma verificação dos resultados obtidos pela solução por integração numérica, utilizando rijezas verticais das suspensões secundárias como lineares e não lineares, obtendo uma diferença média dos resultados entre $0,30 \%$ e $0,45 \%$ conforme mostrado no capítulo 4.5 . Uma vez que o caso estudado consiste de simulações em via reta com imperfeições de nivelamento cruzado, os deslocamentos e ângulos são pequenos e as diferenças entre as rijezas de valor constante (caso linear) e variável (caso não linear) não são significativas, o que explica a proximidade entre os dois tipos de resultados. Por outro lado, caso se tratasse de um estudo em curva ou vias de transição de um modelo mais completo, não seriam esperados resultados tão semelhantes.

As considerações feitas no capítulo 4.6, permitem concluir que quando se deseja obter uma melhora no conforto de passageiros atuando no movimento lateral do veículo, uma das alternativas consiste na redução da rigidez das suspensões secundárias. Como os estudos conduzidos neste trabalho se restringem somente 
aos movimentos laterais, este princípio não deve ser aplicado sem que sejam analisadas as influências nos demais modos para o veículo como um todo.

\subsection{Recomendações para trabalhos futuros}

A partir deste estudo são recomendados dois temas para trabalhos futuros.

O primeiro deles consiste em uma análise de sensibilidade da variação dos parâmetros dos elementos das suspensões primária e secundária, tais como rijezas e amortecimentos, da barra de torção e da carga de passageiros no comportamento do veículo para os cinco graus de liberdade definidos para a caixa. Este estudo permitiria dizer o quanto cada parâmetro influi nos resultados de cada modo e qual interação existe entre eles, de modo que seja possível desenvolver um algorítimo segundo o tipo de vibração em que se queira atuar.

A proposta para o segundo trabalho parte do fato de que a curva de rigidez de uma suspensão pneumática varia em função do volume do reservatório auxiliar, um estudo seria conduzido com o objetivo de verificar a possibilidade de utilizar este fenômeno no controle vibratório de um veículo. Um sistema de aquisição de dados mediria as vibrações instantâneas do veículo e, através de um sistema de controle os reservatórios adicionais seriam introduzidos ou retirados do circuito segundo a rigidez que melhor se adaptasse às condições do veículo e da via.

Em ambos os trabalhos poder-se-ia introduzir um sistema de controle que simulasse três e quatro válvulas de nivelamento e analisar sua influência no comportamento dinâmico do veículo. Outro parâmetro que não foi abordado aqui, mas que poderia tornar as simulações mais representativas, seria a utilização de dados que simulassem as irregularidades de uma via real onde há variações de amplitude e comprimentos de onda. 


\section{Referências}

AEA TECHNOLOGY RAIL. VAMPIRE User's manual: C.4 Shear elements. Derby, 2006: Delta Rail Group Ltd. Manual do usuário.

AMERICAN SOCIETY OF CIVIL ENGINEERS. (1998). Automated people mover standards - part 2. ASCE 21-98. Reston: ASCE

ANDERSON Junior, H. M. Leveling valve for air spring. US 5161579, 10 novembro 1992.

ASSOCIATION FRANÇAISE DE NORMALISATION. (1998). Applications ferroviaires - Comportement dynamique des véhicules vis-à-vis de la voie - Méthodes de mesure des forces. NF F 00-702. Paris : AFNOR.

ASSOCIATION FRANÇAISE DE NORMALISATION. (2002). Applications ferroviaires - Confort de marche des voyageurs - Mesurage et évaluation. AFNOR PR NF EN 12299. Paris : AFNOR.

ASSOCIATION FRANÇAISE DE NORMALISATION. (2004). Railway applications / Track geometry quality - Part 1: Characterisation of track geometry. NF EN 13848-1. Paris: AFNOR.

ASSOCIATION FRANÇAISE DE NORMALISATION. (2005). Applications ferroviaires - Essais en vue de l'homologation du comportement dynamique des véhicules ferroviaires - Essais en ligne et à poste fixe. NF EN 14363. Paris: AFNOR.

BALDI, M.; MEIRELLES, P. S. Analysis of performance of a hydropneumatic suspension system. In: INTERNATIONAL CONGRESS OF MECHANICAL ENGINEERING, 17., 2003, São Paulo. Proceedings of COBEM: ABCM, 2003.

BARBOSA, R. S; COSTA, A. Dinâmica do rodeiro ferroviário. Revista Brasileira de Ciências Mecânicas, v. 18, n. 4, p. 318-329, 1996.

BARBOSA, R. S.; Aplicação de sistemas multicorpos na dinâmica de veículos guiados. 1999. 296 p. Tese - Universidade de São Paulo, São Carlos, 1999. 
BARNETT, R. Tilting trains: the italian ETR and the Swedish X-2000. Berkley: University of California Transportation Center, 1992. 81 p. (Working Paper, No. 113).

BUREAU DE NORMALISATION DES CHEMINS DE FER. (1987). Installations fixes ferroviaires - Ecartement des voies de chemin de fer dans le monde. F 50-704. Paris: B.N.C.F..

CAMPBELL, S.; CHANCELIER, J-F.; NIKOUKHAH, R. Modeling and simulation in Scilab/Scicos. New York: Springer, 2006. 313 p.

CARLBOM, P. Carbody and passengers in rail vehicle dynamics. 2000. $113 \mathrm{p}$. Tese - Department of Vehicle Engineering, Royal Institute of Technology, Stockholm, 2000.

CHING, A. Shuttling vehicle leveling valve. US 7117890 B2, 10 outubro 2006.

CHRISTENSEN, N. B. Control device for vehicle pneumatic suspension. US 2947322, 2 agosto 1960.

CONTINENTAL. Contitech secondary suspensions. Disponível em: $<$ http://www.contitech.de/ct/contitech

/themen/produkte/luftfedersysteme/schiene/sekundaer_e.html>. Acesso em: 27 jan. 2007

DAUM, J. W.; LATIF, T. Fluid-operated leveling valve systems. US 5161817, 10 novembro 1992.

DAVIS, B. R.; THOMPSON, A. G. Power Spectral Density of Road Profiles. Journal of Vehicle System Dynamics, v. 35, n. 6, p. 409-415, 2001.

DAVIS, R. C. Control device dor vehicle suspension. US 2947530, 2 agosto 1960.

DEIST, H. H. Control device for vehicle pneumatic suspension systems. US 2905430, 16 março 1956.

DESOLVER. The GENSYS. 0601 Reference Manuals. Disponível em: <http://www.gensys.se/doc_html/calc_coupl.html\#jk_air3_mawa>. Acesso em: 27 jan. 2007. 
DIANA, G.; CHELI, F.; COLLINA, A.; CORRADI, R.; MELZI, S. The development of a numerical model for railway vehicles comfort assessment through comparison with experimental measurements. Vehicle System Dynamics. v. 38, n. 3, p. 165-183, 2002.

FIRESTONE. Rail applications design guide: catálogo. 2005. 49 p. Também disponível em <http://www.firestoneindustrial.com/pdfs/rail/Airail.pdf>. Acesso em: 27 jan. 2007.

FÖRSTBERG, J. Ride comfort and motion sickness in tilting trains: human responses to motion environments in train experimental and simulator experiments. 2000. 234 p. Tese - Department of Vehicle Engineering, Royal Institute of Technology, Stockholm, 2000.

FÖRSTBERG, J.; ANDERSSON, E.; LEDIN, T. Influence of different conditions for tilt compensation on symptoms of motion sickness in tilting trains. Brain Research Bulletin. v. 47, n. 5, p. 525-535, 1998.

GONÇALVES, A. J.; MEIRELLES, P. S. Damping control in hydropneumatic suspension. In: INTERNATIONAL CONGRESS OF MECHANICAL ENGINEERING, 18., 2005, Ouro Preto. Proceedings of COBEM: ABCM, 2005.

HIRUMA, M. Vehicle hydropneumatic suspension system with vehicle body height control means. US 4076275, 28 fevereiro 1978.

INTERNATIONAL ORGANIZATION FOR STANDARDIZATION. (1997). Mechanical vibration and shock - Evaluation of human exposure to whole-body vibration - Part 1: General requirements. ISO 2631-1. Genève: ISO.

IWNICKI, S. (editor): The Manchester Benchmarks for Rail Vehicle Simulation. Supplement to Journal of Vehicle System Dynamics, v. 30, p. 295-313, 1999.

LEE, Y. S. Variable leveling valve apparatus for vehicle. US 6948721, 27 setembro 2005.

LEWIS, J. Pneumatic spring. US 4965, 10 fevevereiro 1847.

MECHANICAL DYNAMICS INC. Building templates in ADAMS/Rail: component descriptions. Ann Arbor, MI, EUA, 2002. 126 p. Manual do usuário. 
MECHANICAL DYNAMICS INC. Manchester Benchmarks: vehicle 1, ADAMS/Rail 2003. Disponível em: <www.msc.com>. Acesso em 3 jun 2006: .

MEIROVITCH, L. Elements of vibration analysis. Tokyo: McGraw-Hill Kogakusha, Ltd, 1975. $491 \mathrm{p}$.

METALOCAUCHO. Informe homologacion. Urnieta, España: MTC Metalocaucho S.L., 2001. 118 p.

MOHACSI, S.; POTEL, G.; BUCHOLZ, K. H. Arrengement to increase roll stability of rail vehicles with air suspension. US 4665835, 19 maio 1997.

NARAYANASWAMY, S. A comparative study of modified passenger railway vehicle trucks. 1998. 228 p. Tese - Department of Mechanical Engineering, Concordia University, Montreal, 1988.

OGATA, K. System Dynamics. Upper Saddle River: Pearson Prentice Hall, 2004. $768 \mathrm{p}$.

PEARCE, C. E. M.; THOMPSON, A. G. Spectral Decomposition Methods for the Computation of RMS Values in an Active Suspension. Journal of Vehicle System Dynamics. v. 42, n. 6, p. 395-411, 2004.

PRESTHUS, M. Derivation of air spring model parameters for train simulation. 2002. 75 p. Dissertação - Department of Applied Physics and Mechanical Engineering, Luleå University of Technology, Luleå, 2002.

RAGHU, S. R.; KIM, H.-D.; SETOGUCHI, T. Aerodynamics of high-speed railway train. Progress in Aerospace Sciences. v. 38, p. 469-514, 2002.

SAB WABCO. Valve de nivelement VN6P. 15 outubro 1999. Fax do desenho original, $21 \mathrm{~cm}$ x 29,7 cm. Código de referência do desenho "780 635 EQ 08", propriedade Siemens AG.

SAMAVEDAM. G.; GOMES, J. Safety of railroad passenger vehicle dynamics: final summary report. Waltham: US Department of Transportation, 2002. $53 \mathrm{p}$. (DOT/FRA/ORD-01/05). 
SHENG, X. ; JONES, C. J. C.; THOMPSON, D. J. A comparison of a theoretical model for quasi-statically and induced environmental vibration from trains with measurements. Journal of Sound and Vibration. v. 267, p. 621-635, 2003.

STRIBERSKY, A.; MOSER, F.; RULKA, W. Structural dynamics of rail vehicle systems: a virtual system approach. IV: DEVELOPMENTS IN ENGINEERING COMPUTATIONAL TECHNOLOGY., 2000, Leuven. Edinburgh: Civil-Comp Press, 2000. p. 22-36.

THOMPSON, A. G.; DAVIS B. R. Technical Note: RMS Values for Control Force, Suspension Stroke and Tyre Deflection in an Active Suspension. Journal of Vehicle System Dynamics. v. 34, p. 143-150, 2000.

THOMPSON, A. G.; DAVIS, B. R. RMS Values of Force, Stroke and Tyre Deflection in a Half-Car Model with Preview Controlled Active Suspension. Journal of Vehicle System Dynamics. v. 39, n. 3, p. 245-253, 2003.

THOMPSON, A. G.; PEARCE, C. E. M. RMS Values for Force, Stroke and Deflection in a Quarter-car Model Active Suspension with Preview. Journal of Vehicle System Dynamics. v. 39, n. 1, p. 57-75, 2003.

TRELLEBORG INDUSTRIALS AVS. Metalastik ${ }^{\circledR}$ type vehicle Metacone $^{\mathrm{TM}}$ Springs. Disponível em $<$ http://trelleborg.com/industrialavs/images/products/MetaconeSprings.pdf > . Acesso em: 2 fev 2007.

UNIVERSAL MECHANISM. Manchester Benchmarks: Chapter 10. Disponível em: <http://umlab.ru/download/docs/eng/part10.pdf>. Acesso em: 27 jan 2007.

YAGIZ, N.; GURSEL, A. Active suspension control of a railway vehicle with a flexible body. International Journal Vehicle Autonomous Systems. v. 3, n. 1, p. 80-95, 2005. 


\section{Apêndice A - Suspensões secundárias não lineares}

A especificação de uma suspensão pneumática é uma tarefa que envolve um grande número de parâmetros construtivos e de performance. Entre os parâmetros construtivos estão as dimensões externas, modo de fixação, alturas máxima e mínima de operação, alturas dos batentes de fim decurso, temperatura de operação etc. A definição desses parâmetros depende basicamente das interfaces mecânicas entre o truque e a caixa e do gabarito do trem.

Uma vez que os parâmetros construtivos foram definidos, passa-se à atividade de escolha de tipos de suspensões pneumáticas que respondam às exigências definidas inicialmente. Por fim, faz-se uma análise de cada tipo escolhido para aquela que melhor se adapte ao produto desenvolvido.

A partir do veículo especificado pelo Benchmark mostrado no capítulo 4.1 e dos dados disponíveis no catálogo FIRESTONE foram definidos os seguintes parâmetros construtivos:

- Massa suspensa da caixa: $32000 \mathrm{~kg}$ (70547,9 libras);

- Massa suspensa por cada suspensão secundária: 8000 kg (17637 libras);

- Altura nominal das suspensões: entre 0,2032 m (8 polegadas) e 0,254 m (10 polegadas), conforme dados disponíveis no catálogo;

- Pressão de operação das suspensões: entre 130 kPa (20 psi) e 830 kPa (120 psi), conforme dados disponíveis no catálogo.

Baseado nos parâmetros acima, foram escolhidos quatro tipos de suspensão cujos códigos de referência são: 203, 218, 29 e 222. Para cada um desses quatro tipos o catálogo FIRESTONE fornece quatro tabelas e dois gráficos que são os dados de entrada para o cálculo da suspensão. As informações utilizadas na estimação das curvas características das suspensões não lineares e do valor das rijezas na altura de operação se encontram nas tabelas de características dinâmicas fornecidas logo a seguir. Essas tabelas fornecem, para três alturas de operação dentro da faixa recomendada pelo fornecedor, quatro valores de massa suspensa, pressão e rigidez. Como o fornecedor é Norte Americano as unidades encontradas no catálogo 
não estão no Sistema Internacional, porém foram convertidas e são apresentadas nas tabelas a seguir com os valores originais entre parênteses.

Tabela A,1 - Características Dinâmicas da Suspensão Pneumática S1 (tipo 203)

\begin{tabular}{cccc}
\hline $\begin{array}{c}\text { Altura } \\
\mathrm{m} \text { (in) }\end{array}$ & $\begin{array}{c}\text { Carga } \\
\mathrm{kg}(\mathrm{lbs})\end{array}$ & $\begin{array}{c}\text { Pressão } \\
\mathrm{kPa}(\mathrm{psig})\end{array}$ & $\begin{array}{c}\text { Rigidez } \\
\mathrm{N} / \mathrm{m} \text { (lbs/in) }\end{array}$ \\
\hline & $3629(8000)$ & $252(36,5)$ & $402274(2297)$ \\
$0,2159(8,5)$ & $5443(12000)$ & $378(54,8)$ & $560066(3198)$ \\
& $7711(17000)$ & $536(77,7)$ & $753584(4303)$ \\
& $9525(21000)$ & $661(95,9)$ & $909800(5195)$ \\
\hline \multirow{3}{*}{$0,2286(9)$} & $3629(8000)$ & $261(37,8)$ & $385811(2203)$ \\
& $5443(12000)$ & $391(56,7)$ & $538700(3076)$ \\
& $7711(17000)$ & $554(80,3)$ & $729942(4168)$ \\
& $9525(21000)$ & $684(99,2)$ & $883005(5042)$ \\
\hline \multirow{4}{0}{$0,254(10)$} & $3629(8000)$ & $283(41,1)$ & $366372(2092)$ \\
& $5443(12000)$ & $425(61,6)$ & $518735(2962)$ \\
& $7711(17000)$ & $602(87,3)$ & $709277(4050)$ \\
& $9525(21000)$ & $743(107,8)$ & $861640(4920)$ \\
\hline
\end{tabular}

Tabela A,2 - Características Dinâmicas da Suspensão Pneumática S2 (tipo 29)

\begin{tabular}{cccc}
\hline $\begin{array}{c}\text { Altura } \\
\mathrm{m} \text { (in) }\end{array}$ & $\begin{array}{c}\text { Carga } \\
\mathrm{kg}(\mathrm{lbs})\end{array}$ & $\begin{array}{c}\text { Pressão } \\
\mathrm{kPa}(\mathrm{psig})\end{array}$ & $\begin{array}{c}\text { Rigidez } \\
\mathrm{N} / \mathrm{m} \text { (lbs/in) }\end{array}$ \\
\hline & $4536(10000)$ & $245(35,6)$ & $512606(2927)$ \\
$0,2032(8)$ & $7257(16000)$ & $392(56,9)$ & $745879(4259)$ \\
& $9525(21000)$ & $515(74,7)$ & $940448(5370)$ \\
& $12247(27000)$ & $663(96,1)$ & $1173721(6702)$ \\
\hline \multirow{4}{*}{$0,2159(8,5)$} & $4536(10000)$ & $260(37,7)$ & $470224(2685)$ \\
& $7257(16000)$ & $416(60,4)$ & $693690(3961)$ \\
& $9525(21000)$ & $547(79,3)$ & $879853(5024)$ \\
& $12247(27000)$ & $703(101,9)$ & $1103319(6300)$ \\
\hline \multirow{4}{*}{$0,2286(9)$} & $4536(10000)$ & $270(39,2)$ & $460067(2627)$ \\
& $7257(16000)$ & $462(67,0)$ & $684233(3907)$ \\
& $9525(21000)$ & $567(82,3)$ & $870921(4973)$ \\
& $12247(27000)$ & $729(105,8)$ & $1095088(6253)$ \\
\hline
\end{tabular}

A determinação da matriz que define as curvas "Rigidez x Deslocamento" utilizadas pelo método de integração numérica é feita pelo programa "suspensao.sci". A seguir, baseado na suspensão $S 1$ será explicado como este programa funciona. 
Tabela A,3 - Características Dinâmicas da Suspensão Pneumática S3 (tipo 218)

\begin{tabular}{cccc}
\hline $\begin{array}{c}\text { Altura } \\
\text { m (in) }\end{array}$ & $\begin{array}{c}\text { Carga } \\
\text { kg (lbs) }\end{array}$ & $\begin{array}{c}\text { Pressão } \\
\text { kPa (psig) }\end{array}$ & $\begin{array}{c}\text { Rigidez } \\
\text { N/m (lbs/in) }\end{array}$ \\
\hline & $3629(8000)$ & $254(36,9)$ & $427142(2439)$ \\
$0,2032(8)$ & $5443(12000)$ & $382(55,4)$ & $592290(3382)$ \\
& $7711(17000)$ & $541(78,5)$ & $798768(4561)$ \\
& $9525(21000)$ & $669(97,0)$ & $963916(5504)$ \\
\hline & $3629(8000)$ & $263(38,2)$ & $407703(2328)$ \\
$0,2159(8,5)$ & $5443(12000)$ & $395(57,3)$ & $568997(3249)$ \\
& $7711(17000)$ & $560(81,2)$ & $770397(4399)$ \\
& $9525(21000)$ & $691(100,2)$ & $931692(5320)$ \\
\hline & $3629(8000)$ & $274(39,7)$ & $395444(2258)$ \\
$0,2286(9)$ & $5443(12000)$ & $411(59,6)$ & $555687(3173)$ \\
& $7711(17000)$ & $582(84,4)$ & $756211(4318)$ \\
& $9525(21000)$ & $718(104,2)$ & $916455(5233)$ \\
\hline
\end{tabular}

Tabela A,4 - Características Dinâmicas da Suspensão Pneumática S4 (tipo 222)

\begin{tabular}{cccc}
\hline $\begin{array}{c}\text { Altura } \\
\text { m (in) }\end{array}$ & $\begin{array}{c}\text { Carga } \\
\text { kg (lbs) }\end{array}$ & $\begin{array}{c}\text { Pressão } \\
\text { kPa (psig) }\end{array}$ & $\begin{array}{c}\text { Rigidez } \\
\text { N/m (lbs/in) }\end{array}$ \\
\hline & $6804(15000)$ & $270(39,1)$ & $797192(4552)$ \\
$0,2032(8)$ & $10206(22500)$ & $404(58,6)$ & $1104370(6306)$ \\
& $13608(30000)$ & $539(78,2)$ & $1411723(8061)$ \\
& $17010(37500)$ & $674(97,7)$ & $1719076(9816)$ \\
\hline & $6804(15000)$ & $276(40,1)$ & $758313(4330)$ \\
$0,2159(8,5)$ & $10206(22500)$ & $415(60,2)$ & $1056209(6031)$ \\
& $13608(30000)$ & $554(80,3)$ & $1354280(7733)$ \\
& $17010(37500)$ & $692(100,4)$ & $1652352(9435)$ \\
\hline & $6804(15000)$ & $285(41,4)$ & $731868(4179)$ \\
$0,2286(9)$ & $10206(22500)$ & $429(62,2)$ & $1025912(5858)$ \\
& $13608(30000)$ & $572(82,9)$ & $1320130(7538)$ \\
& $17010(37500)$ & $714(103,6)$ & $1614348(9218)$ \\
\hline
\end{tabular}

Inicialmente se faz o carregamento dos dados de entrada que são a massa suspensa da caixa (msci) e as colunas "Design Height" (altura), "Load" (massa) e "Rate" (rigidez) das tabelas A.1, A.2, A.3 e A.4.

Embora as tabelas acima forneçam uma relação entre a rigidez e a altura, esta não é feita para o exato valor da massa suspensa por cada suspensão que é de $8000 \mathrm{~kg}$ (17637 libras) (massa total do veículo dividido por 4 suspensões). Como para as três alturas de 0,2159 m (8.5"), 0,2286 m (9") e 0,254 m (10") (tabela A.1) foram fornecidos quatro valores de massa e rigidez, faz-se uma interpolação em que se define a rigidez para o valor de massa suspensa de 8000 kg (17637 libras) em cada 
altura diferente. Esta interpolação foi feita utilizando a função "interp" e "spli". $\mathrm{Na}$ tabela a seguir são mostrados os valores tabelados (em itálico) e os valores calculados (em negrito) respectivos à suspensão $S 1$.

Tabela A.5 - Interpolação da Rigidez da Suspensão S1 para uma Massa Suspensa de 8000 kg (17637 libras)

\begin{tabular}{|c|c|c|c|c|c|c|}
\hline \multicolumn{2}{|c|}{$\begin{array}{l}\text { Massa Suspensa - } \\
\text { kg (lbs) }\end{array}$} & $\begin{array}{c}3628 \\
(8000)\end{array}$ & $\begin{array}{c}5443 \\
(12000)\end{array}$ & $\begin{array}{c}7711 \\
(17000)\end{array}$ & $\begin{array}{c}8000 \\
(17637)\end{array}$ & $\begin{array}{c}9525 \\
(21000)\end{array}$ \\
\hline \multirow{3}{*}{ 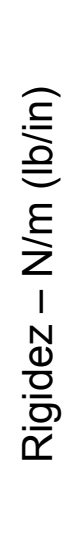 } & $\begin{array}{l}\text { Altura de } \\
0,2159 \mathrm{~m} \\
(8.5 ")\end{array}$ & $\begin{array}{l}402274 \\
(2297)\end{array}$ & $\begin{array}{l}558490 \\
(3189)\end{array}$ & $\begin{array}{l}753584 \\
(4303)\end{array}$ & $\begin{array}{l}769346 \\
(4393)\end{array}$ & $\begin{array}{r}909800 \\
(5195)\end{array}$ \\
\hline & $\begin{array}{l}\text { Altura de } \\
0,2286 \text { m (9") }\end{array}$ & $\begin{array}{r}385811 \\
(2203)\end{array}$ & $\begin{array}{r}558490 \\
(3076)\end{array}$ & $\begin{array}{l}729942 \\
(4168)\end{array}$ & $\begin{array}{l}745528 \\
(4257)\end{array}$ & $\begin{array}{r}883005 \\
(5042)\end{array}$ \\
\hline & $\begin{array}{l}\text { Altura de } 0,254 \\
\mathrm{~m}\left(10^{\prime \prime}\right)\end{array}$ & $\begin{array}{r}366372 \\
(2092)\end{array}$ & $\begin{array}{l}518735 \\
(2962)\end{array}$ & $\begin{array}{l}709277 \\
(4050)\end{array}$ & $\begin{array}{l}724863 \\
(4139)\end{array}$ & $\begin{array}{r}861640 \\
(4920)\end{array}$ \\
\hline
\end{tabular}

As três rijezas calculadas (coluna 5) e de suas respectivas alturas (coluna 1) são mostradas no gráfico A.1 pelos pontos " $"$ ". Uma segunda interpolação foi feita e obteve-se uma curva de "Rigidez x Deslocamento" que passa pelos três pontos da tabela A.5 obtendo uma matriz de tamanho $301 \times 2$. Para que a função que utiliza esta curva como dado de entrada no cálculo da rigidez instantânea no módulo não linear do programa de integração numérica não fosse sobrecarregado, fez-se uma redução com aproximadamente dez vezes menos pontos, marcados pelo sinal " $x$ " no gráfico A.1.

No apêndice I são mostradas as matrizes utilizadas para definir as curvas de rigidez no programa de integração linear conforme explicado anteriormente (no exemplo do gráfico A.1 corresponde aos pontos " $x$ "). A suspensão $S 4$ possui menos pontos pois a amplitude de trabalho é de $0,0254 \mathrm{~m}$ (uma polegada) e nos outros três casos $0,0381 \mathrm{~m}$ (uma polegada e meia). 


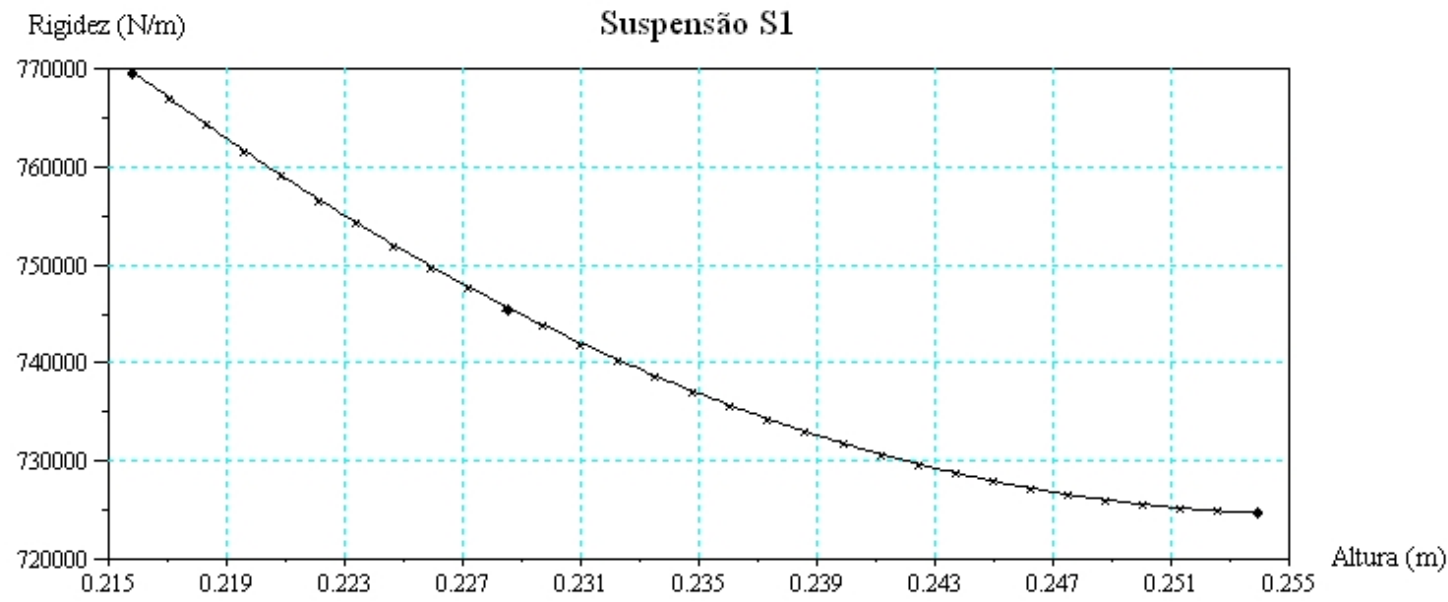

Gráfico A.1 - Característica Dinâmica da Suspensão S1 para Massa Suspensa de 8000 kg (17637 libras) 
Apêndice B - Matrizes de massa, rigidez e amortecimento

A seguir seguir são apresentadas as matrizes de massa, rigidez e amortecimento deduzidas a partir das equações de movimento apresentadas no capítulo 3.4

- Matriz de massa: $M=$

$$
=\left[\begin{array}{ccccccccc}
m_{c} & 0 & 0 & 0 & 0 & 0 & 0 & 0 & 0 \\
0 & m_{c} & 0 & 0 & 0 & 0 & 0 & 0 & 0 \\
0 & 0 & m_{t} & 0 & 0 & 0 & 0 & 0 & 0 \\
0 & 0 & 0 & m_{t} & 0 & 0 & 0 & 0 & 0 \\
0 & 0 & 0 & 0 & I_{c x} & 0 & 0 & 0 & 0 \\
0 & 0 & 0 & 0 & 0 & I_{c y} & 0 & 0 & 0 \\
0 & 0 & 0 & 0 & 0 & 0 & I_{c z} & 0 & 0 \\
0 & 0 & 0 & 0 & 0 & 0 & 0 & I_{t x} & 0 \\
0 & 0 & 0 & 0 & 0 & 0 & 0 & 0 & I_{t x}
\end{array}\right]
$$

- Matriz de rigidez: $\mathrm{K}=$

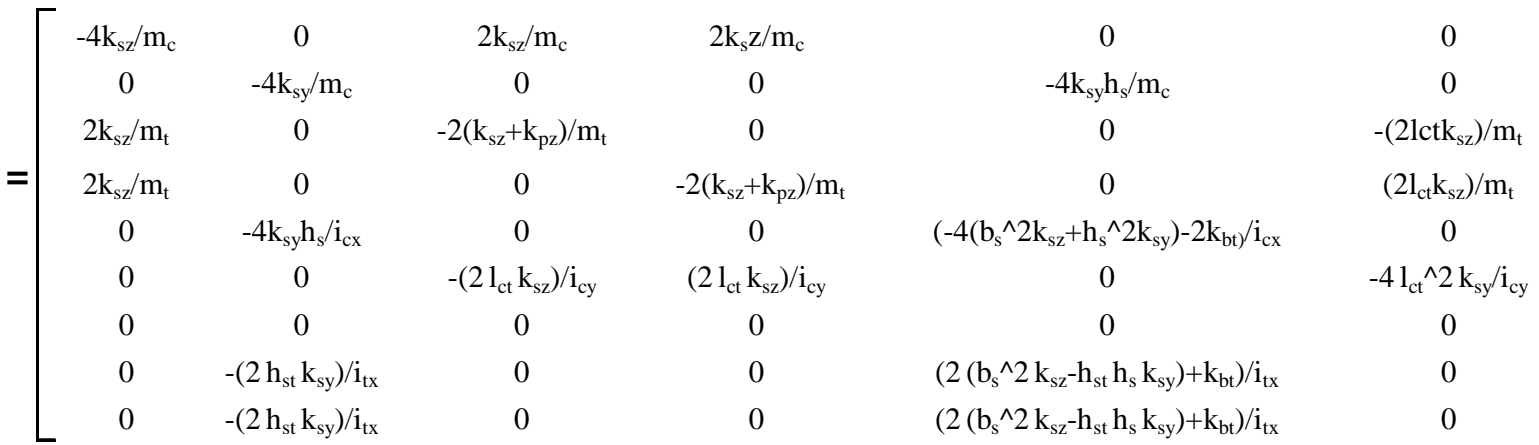

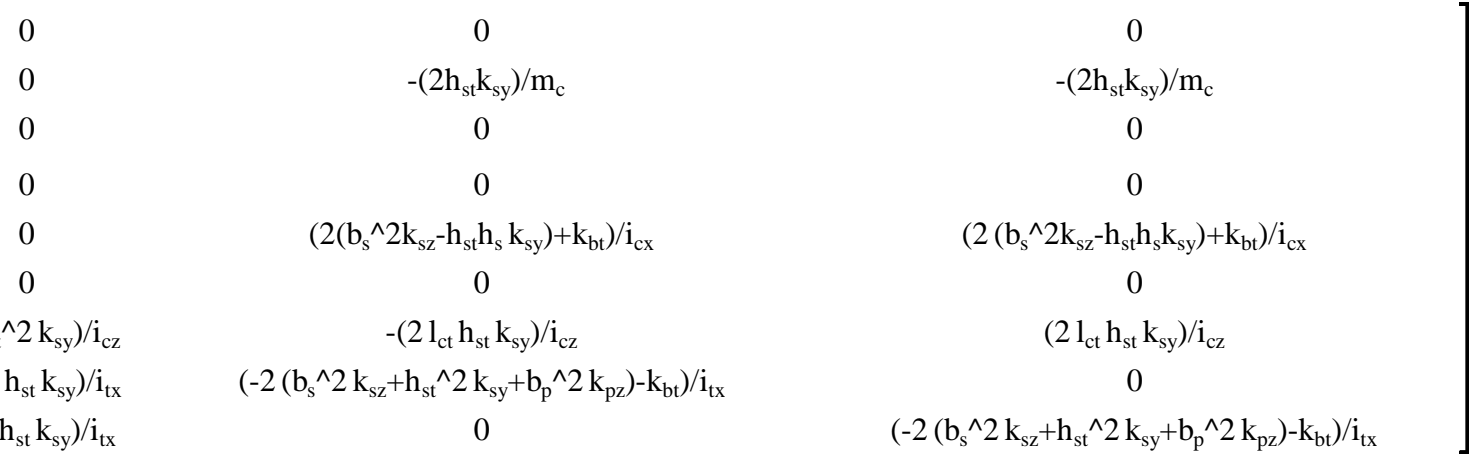


- Matriz de amortecimento: $\mathrm{C}=$

$=\left[\begin{array}{cccc}-4\left(\mathrm{C}_{\mathrm{sz}}+\mathrm{C}_{\mathrm{az}}\right) / \mathrm{m}_{\mathrm{c}} & 0 & 2\left(\mathrm{C}_{\mathrm{sz}}+\mathrm{C}_{\mathrm{az}}\right) / \mathrm{m}_{\mathrm{c}} & 2\left(\mathrm{C}_{\mathrm{sz}}+\mathrm{C}_{\mathrm{az}}\right) / \mathrm{m}_{\mathrm{c}} \\ 0 & -4\left(\mathrm{C}_{\mathrm{sy}}+\mathrm{C}_{\mathrm{ay}}\right) / \mathrm{m}_{\mathrm{c}} & 0 & 0 \\ 2\left(\mathrm{C}_{\mathrm{sz}}+\mathrm{C}_{\mathrm{az}}\right) / \mathrm{m}_{\mathrm{t}} & 0 & -2\left(\mathrm{C}_{\mathrm{sz}}+\mathrm{C}_{\mathrm{az}}+\mathrm{C}_{\mathrm{pz}}\right) / \mathrm{m}_{\mathrm{t}} & 0 \\ 0 & -4\left(\mathrm{C}_{\mathrm{sy}}+\mathrm{C}_{\mathrm{ay}}\right) \mathrm{h}_{\mathrm{s}} \mathrm{i}_{\mathrm{cx}} & 0 & 0 \\ 0 & 0 & 0 & 0 \\ 0 & -2\left(\mathrm{~h}_{\mathrm{st}} \mathrm{C}_{\mathrm{sy}}+\mathrm{h}_{\mathrm{ayt}} \mathrm{C}_{\mathrm{a}} \mathrm{y}\right) / \mathrm{i}_{\mathrm{tx}} & 0 & 0 \\ 0 & -2\left(\mathrm{~h}_{\mathrm{st}} \mathrm{C}_{\mathrm{sy}}+\mathrm{h}_{\mathrm{ayt}} \mathrm{C}_{\mathrm{ay}}\right) / \mathrm{i}_{\mathrm{tx}} & 0 & 0 \\ 2\left(\mathrm{C}_{\mathrm{sz}}+\mathrm{C}_{\mathrm{az}}\right) / \mathrm{m}_{\mathrm{t}} & 0 & 0 & -2\left(\mathrm{C}_{\mathrm{sz}}+\mathrm{C}_{\mathrm{az}}+\mathrm{C}_{\mathrm{pz}}\right) / \mathrm{m}_{\mathrm{t}} \\ 0 & 0 & -2 \mathrm{l}_{\mathrm{ct}}\left(\mathrm{C}_{\mathrm{sz}}+\mathrm{C}_{\mathrm{az}}\right) / \mathrm{i}_{\mathrm{cy}} & 2 \mathrm{l}_{\mathrm{ct}}\left(\mathrm{C}_{\mathrm{sz}}+\mathrm{C}_{\mathrm{az}}\right) / \mathrm{i}_{\mathrm{cy}}\end{array}\right.$

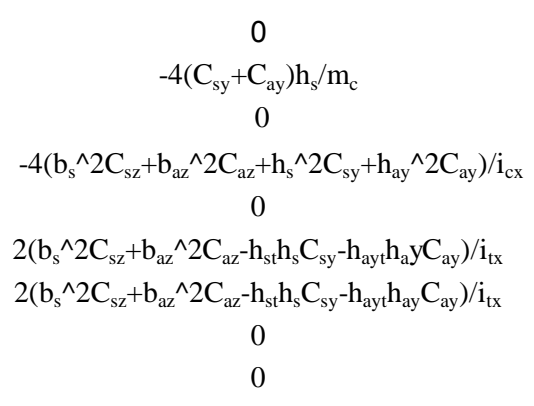

$\begin{array}{ccc}0 & 0 & 0 \\ 0 & 0 & -2\left(\mathrm{~h}_{\mathrm{st}} \mathrm{C}_{\mathrm{sy}}+\mathrm{h}_{\mathrm{ayt}} \mathrm{C}_{\mathrm{ay}}\right) / \mathrm{m}_{\mathrm{c}} \\ -2 \mathrm{l}_{\mathrm{ct}}\left(\mathrm{C}_{\mathrm{sz}}+\mathrm{C}_{\mathrm{az}}\right) / \mathrm{m}_{\mathrm{t}} & 0 & 0 \\ 0 & 0 & 2\left(\mathrm{~b}_{\mathrm{s}} \wedge 2 \mathrm{C}_{\mathrm{s}} \mathrm{z}+\mathrm{b}_{\mathrm{az}} \wedge 2 \mathrm{C}_{\mathrm{az}}-\mathrm{h}_{\mathrm{st}} \mathrm{h}_{\mathrm{s}} \mathrm{C}_{\mathrm{sy}}-\mathrm{h}_{\mathrm{ayt}} \mathrm{h}_{\mathrm{ay}} \mathrm{C}_{\mathrm{ay}}\right) / \mathrm{i}_{\mathrm{cx}} \\ 0 & -4 \mathrm{l}_{\mathrm{ct}} \wedge 2\left(\mathrm{C}_{\mathrm{sy}}+\mathrm{C}_{\mathrm{ay}}\right) / \mathrm{i}_{\mathrm{cz}} & -2 \mathrm{l}_{\mathrm{ct}}\left(\mathrm{h}_{\mathrm{st}} \mathrm{C}_{\mathrm{sy}}+\mathrm{h}_{\mathrm{ayt}} \mathrm{C}_{\mathrm{ay}}\right) / \mathrm{i}_{\mathrm{cz}} \\ 0 & -2 \mathrm{l}_{\mathrm{ct}}\left(\mathrm{h}_{\mathrm{st}} \mathrm{C}_{\mathrm{sy}}+\mathrm{h}_{\mathrm{ayt}} \mathrm{C}_{\mathrm{ay}}\right) / \mathrm{i}_{\mathrm{tx}} & -2\left(\mathrm{~b}_{\mathrm{s}} \wedge 2 \mathrm{C}_{\mathrm{sz}}+\mathrm{b}_{\mathrm{a}} \mathrm{z} \wedge 2 \mathrm{C}_{\mathrm{az}}+\mathrm{h}_{\mathrm{st}} \wedge 2 \mathrm{C}_{\mathrm{sy}}+\mathrm{h}_{\mathrm{ayt}} \wedge 2 \mathrm{C}_{\mathrm{ay}}+\mathrm{b}_{\mathrm{p}} \wedge 2 \mathrm{C}_{\mathrm{pz}}\right) / \mathrm{i}_{\mathrm{tx}} \\ 0 & 2 \mathrm{l}_{\mathrm{ct}}\left(\mathrm{h}_{\mathrm{st}} \mathrm{C}_{\mathrm{sy}}+\mathrm{h}_{\mathrm{ayt}} \mathrm{C}_{\mathrm{ay}}\right) / \mathrm{i}_{\mathrm{tx}} & 0 \\ 2 \mathrm{l}_{\mathrm{ct}}\left(\mathrm{C}_{\mathrm{sz}}+\mathrm{C}_{\mathrm{a}} \mathrm{z}\right) / \mathrm{m}_{\mathrm{t}} & 0 & 0 \\ -4 \mathrm{l}_{\mathrm{ct}} \wedge 2\left(\mathrm{C}_{\mathrm{sz}}+\mathrm{C}_{\mathrm{az}}\right) / \mathrm{i}_{\mathrm{cy}} & 0 & 0\end{array}$

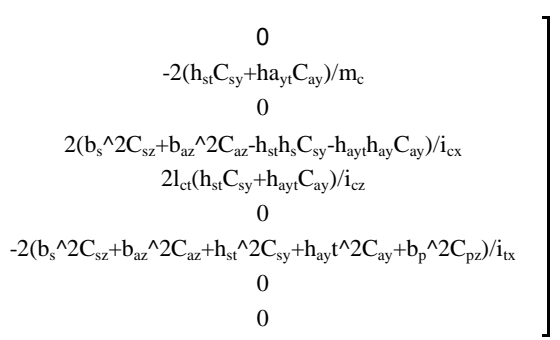




\section{Apêndice C - Programa de cálculo dos autovetores e autovalores}

Este programa determina os autovetores e autovalores a partir das matrizes de massa e rigidez apresentadas no apêndice $B$.

clear

//Carregamento dos dados de entrada

exec('C: IDocumentos de trabalholdadosdeentrada.sci');//disp('exec done');

//Matriz de massa - M

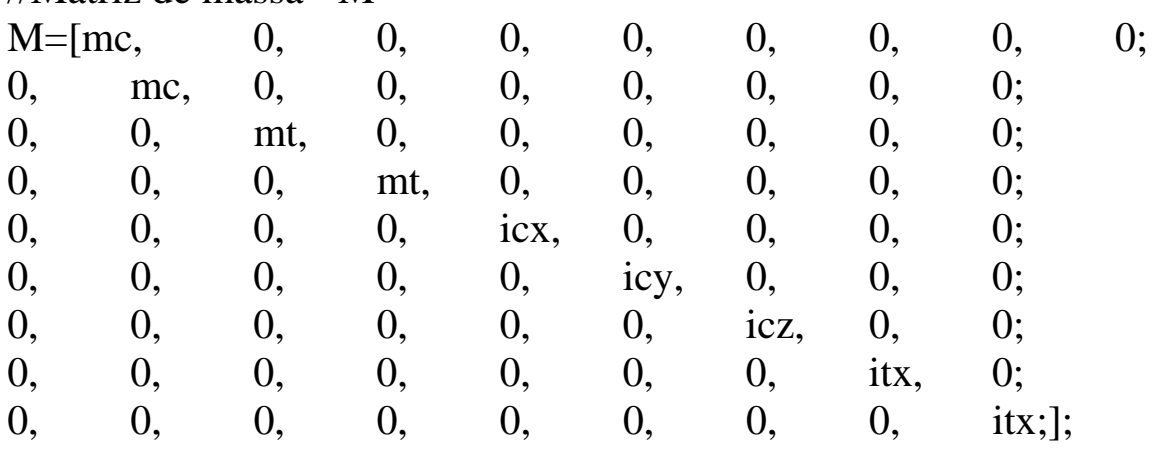

//Matriz de rigidez $-\mathrm{K}$

$\mathrm{K}=[4 * \mathrm{ksz}, \quad 0,-2 * \mathrm{ksz},-2 * \mathrm{ksz}, 0,0,0,0,0$;

0, 4*ksy, 0, 0, 4*ksy*hs, 0, 0, 2*hst*ksy, 2*hst*ksy;

$-2 * \mathrm{ksz}, 0,2 *(\mathrm{ksz}+\mathrm{kpz}), 0,0,2 * \mathrm{lct}^{*} \mathrm{ksz}, 0,0,0$;

$-2 * \mathrm{ksz}, 0,0,2 *(\mathrm{ksz}+\mathrm{kpz}), 0,-(2 * \mathrm{lct} * \mathrm{ksz}), 0,0,0$;

0, $4 *$ ksy*hs, $0,0,\left(4 *\left(b s^{\wedge} 2 * k s z+h s^{\wedge} 2 * k s y\right)+2 * k b t\right), 0,0,-\left(2 *\left(b s^{\wedge} 2 * k s z-h s t * h s^{*} k s y\right)+k b t\right),-$

$\left(2 *\left(\mathrm{bs}^{\wedge} 2 * \mathrm{ksz}-\mathrm{hst} * \mathrm{hs} * \mathrm{ksy}\right)+\mathrm{kbt}\right)$;

0, 0, 2*lct*ksz, -(2*lct*ksz), 0, 4*lct $\wedge 2 * \mathrm{ksz}, 0,0,0$;

$0,0,0,0,0,0,\left(4 * \mathrm{lct}_{\mathrm{c}} \wedge 2 * \mathrm{ksy}\right),(2 * \mathrm{lct} * \mathrm{hst} * \mathrm{ksy}),-(2 * \mathrm{lct} * \mathrm{hst} * \mathrm{ksy})$;

0, 2*hst*ksy, 0, 0, -(2*(bs^2*ksz-hst*hs*ksy)+kbt), 0, (2*lct*hst*ksy),

$\left(2 *\left(\mathrm{bs}^{\wedge} 2 * \mathrm{ksz}+\mathrm{hst} \wedge 2^{\wedge} * \mathrm{ksy}+\mathrm{bp} \wedge 2 * \mathrm{kpz}\right)+\mathrm{kbt}\right), 0$;

0, 2*hst*ksy, 0, 0, -(2*(bs^2*ksz-hst*hs*ksy)+kbt), 0,-(2*lct*hst*ksy), 0 ,

$\left.\left(2 *\left(\mathrm{bs}^{\wedge} 2 * \mathrm{ksz}+\mathrm{hst} \wedge 2 * \mathrm{ksy}+\mathrm{bp} \wedge 2 * \mathrm{kpz}\right)+\mathrm{kbt}\right)\right]$;

//Matriz de flexibilidade - A

$\mathrm{A}=1 / \mathrm{K}$

//Matriz dinâmica - D

$\mathrm{D}=\mathrm{A} * \mathrm{M}$; 
//Calculo dos autovetores (autvet) e autovalores (autval)

[autvet,autval]=spec(D);

//Transformação da matriz diagonal dos autovalores (autval) em um vetor (diag_autval) diag_autval=diag(autval);

//Correçao dos autovalores (autval_corr) e autovetores (autvet_corr) - a função "clean" aproxima à zero os valores pequenos autvet_corr=clean(real(autvet)); autval_corr=clean(diag_autval);

//Calculo das frequencias w(rad/s) e f(Hz) a partir do autovalor "lambda" for $i=1: 9$;

$\left.\mathrm{w}(\mathrm{i})=\left(1 /(\text { autval_corr(i) })^{\wedge} 0.5\right)\right) ; \quad$ //solução da equação lambda=1/( $\left.\mathrm{w}^{\wedge} 2\right)$ $\mathrm{f}(\mathrm{i})=\mathrm{w}(\mathrm{i}) /(2 * \% \mathrm{pi}) ; \quad / / \mathrm{w}=2 * \mathrm{pi}^{*} \mathrm{f}$

end

//Normalizaçao do autoveor

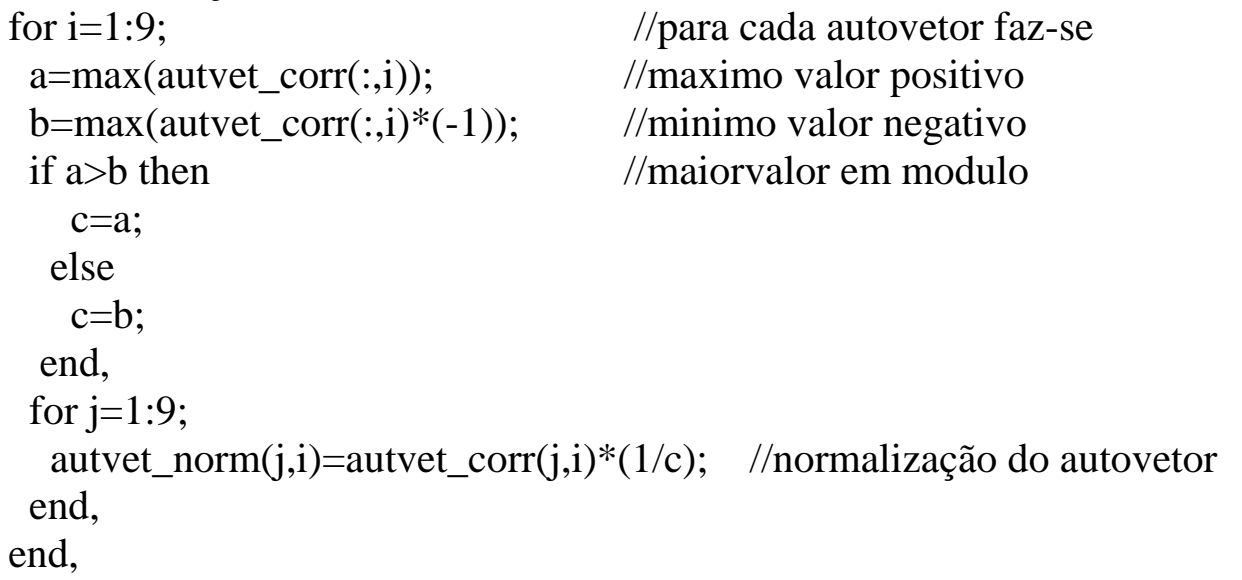

//Arquivo de saida ".txt" como os autovalores e autovetores resultado=[f';autvet_norm] fprintfMat ('C: Documentos de trabalholautovetval\resultado_autovetval_863006.txt',resultado);

//Graus de Liberdade - para informação gdl=['Zc';'Yc';'Zt1';'Zt2';'Teta cx';'Teta cy';'Teta cz';'Teta t1x';'Teta t2x']'; 


\section{Apêndice D - Solução Analítica}

Este programa resolve o sistema de equações diferenciais através da abordagem de Espaços de Estado.

clear

// carregamento dos dados de entrada exec('C:IDocumentos de trabalholdadosdeentrada.sci');disp('exec done');

//dados de entrada particular ao programa ksz=430000; //suspensão Benchmark deltat $=0.01$;

fase $=1$; //se $=1$, rodeiros em fase, se $=-1$ defasados de $180^{\circ}$

// Matriz de massa - M

$\begin{array}{lllllllll}\mathrm{M}=[\mathrm{mc}, & 0, & 0, & 0, & 0, & 0, & 0, & 0, & 0 ; \\ 0, & \mathrm{mc}, & 0, & 0, & 0, & 0, & 0, & 0, & 0 ; \\ 0, & 0, & \mathrm{mt}, & 0, & 0, & 0, & 0, & 0, & 0 ; \\ 0, & 0, & 0, & \mathrm{mt}, & 0, & 0, & 0, & 0, & 0 ; \\ 0, & 0, & 0, & 0, & \text { icx, } & 0, & 0, & 0, & 0 ; \\ 0, & 0, & 0, & 0, & 0, & \text { icy, } & 0, & 0, & 0 ; \\ 0, & 0, & 0, & 0, & 0, & 0, & \text { icz, } & 0, & 0 ; \\ 0, & 0, & 0, & 0, & 0, & 0, & 0, & \text { itx, } & 0 ; \\ 0, & 0, & 0, & 0, & 0, & 0, & 0, & 0, & \text { itx; }]\end{array}$

// Matriz de amortecimento - C

$\mathrm{C}=[-4 *(\mathrm{csz}+\mathrm{caz}) / \mathrm{mc}, 0,2 *(\mathrm{csz}+\mathrm{caz}) / \mathrm{mc}, 2 *(\mathrm{csz}+\mathrm{caz}) / \mathrm{mc}, 0,0,0,0,0$;

$0,-4 *($ csy + cay $) / m c, 0,0,-4 *($ csy+cay $) * h s / m c, 0,0,-2 *($ hst*csy+hayt*cay $) / m c,-$ $2 *($ hst* csy+hayt*cay)/mc;

$2 *(\mathrm{csz}+\mathrm{caz}) / \mathrm{mt}, 0,-2 *(\mathrm{csz}+\mathrm{caz}+\mathrm{cpz}) / \mathrm{mt}, 0,0,-2 * \mathrm{lct} *(\mathrm{csz}+\mathrm{caz}) / \mathrm{mt}, 0,0,0$;

$2 *(\mathrm{csz}+\mathrm{caz}) / \mathrm{mt}, 0,0,-2 *(\mathrm{csz}+\mathrm{caz}+\mathrm{cpz}) / \mathrm{mt}, 0,2 * \mathrm{lct} *(\mathrm{csz}+\mathrm{caz}) / \mathrm{mt}, 0,0,0$;

$0,-4 *($ csy+cay $) *$ hs/icx, $0,0,-4 *\left(b^{\wedge} 2^{*}{ }^{*} \operatorname{csz}+\right.$ baz $^{\wedge} 2 *$ caz + hs ${ }^{\wedge} 2 *$ csy + hay ${ }^{\wedge} 2 *$ cay $) /$ icx, 0,0 ,

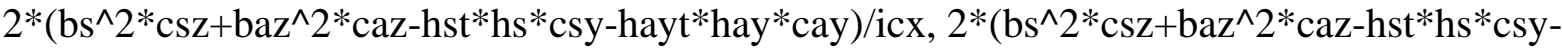
hayt*hay*cay)/icx;

0, 0, -2*lct*(csz+caz)/icy, $2 * \operatorname{lct} *(\operatorname{csz}+\mathrm{caz}) / \mathrm{icy}, 0,-4 * \mathrm{lct} \wedge 2 *(\mathrm{csz}+\mathrm{caz}) / \mathrm{icy}, 0,0,0$;

$0,0,0,0,0,0,-4 * \mathrm{lct}^{\wedge} 2 *(\mathrm{csy}+$ cay $) /$ icz, $-2 * \mathrm{lct}^{*}(\mathrm{hst} *$ csy + hayt*cay $) / \mathrm{icz}$,

2*lct*(hst*csy+hayt*cay)/icz; 


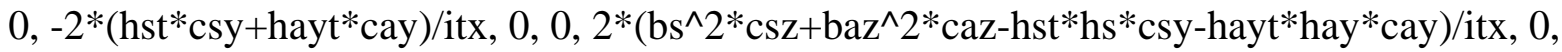
$-2 *$ lct*(hst*csy+hayt*cay)/itx, -

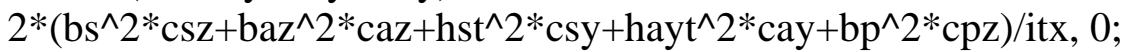

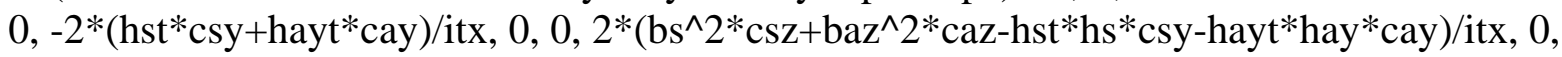
2*lct*(hst*csy+hayt*cay)/itx, 0 , -

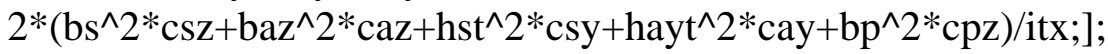

$\mathrm{C} 22=\mathrm{C}(2,2) ; \quad \mathrm{C} 25=\mathrm{C}(2,5) ; \quad \mathrm{C} 28=\mathrm{C}(2,8) ; \quad \mathrm{C} 29=\mathrm{C}(2,9)$;

$\mathrm{C} 52=\mathrm{C}(5,2) ; \quad \mathrm{C} 55=\mathrm{C}(5,5) ; \quad \mathrm{C} 58=\mathrm{C}(5,8) ; \quad \mathrm{C} 59=\mathrm{C}(5,9)$;

$\mathrm{C} 77=\mathrm{C}(7,7) ; \quad \mathrm{C} 78=\mathrm{C}(7,8) ; \quad \mathrm{C} 79=\mathrm{C}(7,9)$;

$\mathrm{C} 82=\mathrm{C}(8,2) ; \quad \mathrm{C} 85=\mathrm{C}(8,5) ; \quad \mathrm{C} 87=\mathrm{C}(8,7) ; \quad \mathrm{C} 88=\mathrm{C}(8,8) ; \quad \mathrm{C} 89=\mathrm{C}(8,9)$;

$\mathrm{C} 92=\mathrm{C}(9,2) ; \quad \mathrm{C} 95=\mathrm{C}(9,5) ; \quad \mathrm{C} 97=\mathrm{C}(9,7) ; \quad \mathrm{C} 98=\mathrm{C}(9,8) ; \quad \mathrm{C} 99=\mathrm{C}(9,9)$;

// Matriz de rigidez - K

$\mathrm{K}=[-4 * \mathrm{ksz} / \mathrm{mc}, 0,2 * \mathrm{ksz} / \mathrm{mc}, 2 * \mathrm{ksz} / \mathrm{mc}, 0,0,0,0,0$;

0, -4*ksy/mc, 0, 0, 0, 0, 0, -(2*hst*ksy)/mc, -(2*hst*ksy)/mc;

$2 * \mathrm{ksz} / \mathrm{mt}, 0,-2 *(\mathrm{ksz}+\mathrm{kpz}) / \mathrm{mt}, 0,0,-(2 * \mathrm{lct} * \mathrm{ksz}) / \mathrm{mt}, 0,0,0$;

$2 * \mathrm{ksz} / \mathrm{mt}, 0,0,-2 *(\mathrm{ksz}+\mathrm{kpz}) / \mathrm{mt}, 0,(2 * \mathrm{lct} * \mathrm{ksz}) / \mathrm{mt}, 0,0,0$;

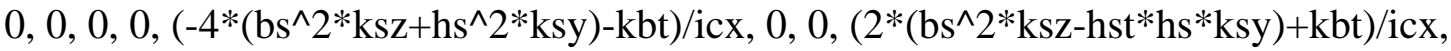

$\left(2 *\left(b^{\wedge}{ }^{2} *\right.\right.$ ksz-hst*hs*ksy)+kbt)/icx;

0, 0, -(2*lct*ksz)/icy, (2*lct*ksz)/icy, $0,-4 * \mathrm{lct}^{\wedge} \wedge 2 * \mathrm{ksy} / \mathrm{icy}, 0,0,0$;

0, 0, 0, 0, 0, 0, -(4*lct^2*ksy)/icz, -(2*lct*hst*ksy)/icz, $(2 *$ lct*hst*ksy)/icz;

0, -(2*hst*ksy)/itx, 0, 0, (2*(bs^2*ksz-hst*hs*ksy)+kbt)/itx, 0, -(2*lct*hst*ksy)/itx, ($\left.2 *\left(\mathrm{bs}^{\wedge} 2 * \mathrm{ksz}+\mathrm{hst} \wedge 2 * \mathrm{ksy}+\mathrm{bp} \wedge 2 * \mathrm{kpz}\right)-\mathrm{kbt}\right) / \mathrm{itx}, 0$;

0, -(2*hst*ksy)/itx, 0, 0, (2*(bs^2*ksz-hst*hs*ksy)+kbt)/itx, 0, (2*lct*hst*ksy)/itx, 0, (-

$\left.\left.2 *\left(\mathrm{bs}^{\wedge} 2 * \mathrm{ksz}+\mathrm{hst} \wedge 2 * \mathrm{ksy}+\mathrm{bp} \wedge 2 * \mathrm{kpz}\right)-\mathrm{kbt}\right) / \mathrm{itx}\right]$

$\mathrm{K} 22=\mathrm{K}(2,2) ; \mathrm{K} 25=\mathrm{K}(2,5) ; \mathrm{K} 28=\mathrm{K}(2,8) ; \mathrm{K} 29=\mathrm{K}(2,9)$;

$\mathrm{K} 52=\mathrm{K}(5,2) ; \mathrm{K} 55=\mathrm{K}(5,5) ; \mathrm{K} 58=\mathrm{K}(5,8) ; \mathrm{K} 59=\mathrm{K}(5,9)$;

$\mathrm{K} 77=\mathrm{K}(7,7) ; \mathrm{K} 78=\mathrm{K}(7,8) ; \mathrm{K} 79=\mathrm{K}(7,9)$;

$\mathrm{K} 82=\mathrm{K}(8,2) ; \mathrm{K} 85=\mathrm{K}(8,5) ; \mathrm{K} 88=\mathrm{K}(8,8) ; \mathrm{K} 87=\mathrm{K}(8,7) ; \mathrm{K} 89=\mathrm{K}(8,9)$;

$\mathrm{K} 92=\mathrm{K}(9,2) ; \mathrm{K} 95=\mathrm{K}(9,5) ; \mathrm{K} 97=\mathrm{K}(9,7) ; \mathrm{K} 98=\mathrm{K}(9,8) ; \mathrm{K} 99=\mathrm{K}(9,9)$;

// Movimentação dos rodeiros

$\mathrm{C} 812=2 * \mathrm{bp}^{\wedge} 2 * \mathrm{cpz} / \mathrm{itx}$;

$\mathrm{C} 913=2 * \mathrm{bp} \wedge 2 * \mathrm{cpz} / \mathrm{itx}$

$\mathrm{K} 812=2 * \mathrm{bp}^{\wedge} 2 * \mathrm{kpz} / \mathrm{itx}$

$\mathrm{K} 913=2 * \mathrm{bp} \wedge 2 * \mathrm{kpz} / \mathrm{itx}$;

// Matrizes dos espaços de estado

$\mathrm{A}=\left[\begin{array}{llllllllll}0 & 1 & 0 & 0 & 0 & 0 & 0 & 0 & 0 & 0 \text {; }\end{array}\right.$

K22 C22 $00000 \quad 0$ K28 C28 K29 C29;

$\begin{array}{lllllllllll}0 & 0 & 0 & 1 & 0 & 0 & 0 & 0 & 0 & 0 \text {; }\end{array}$

$\begin{array}{lllllll}0 & 0 & \mathrm{~K} 55 & \mathrm{C} 55 & 0 & 0 & \mathrm{~K} 58 \\ \mathrm{C} & 58 & \mathrm{~K} 59 & \mathrm{C} 59 ;\end{array}$

$\begin{array}{llllllllll}0 & 0 & 0 & 0 & 0 & 1 & 0 & 0 & 0 & 0 \text {; }\end{array}$

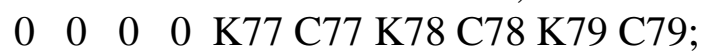

$\begin{array}{llllllllll}0 & 0 & 0 & 0 & 0 & 0 & 0 & 1 & 0 & 0 \text {; }\end{array}$ 
K82 C82 K85 C85 K87 C87 K88 C88 00 ;

$\begin{array}{llllllllll}0 & 0 & 0 & 0 & 0 & 0 & 0 & 0 & 0 & 1 \text {; }\end{array}$

K92 C92 K95 C95 K97 C97 0 0 K99 C99];

$\mathrm{B} 0=[0 ; 0 ; 0 ; 0 ; 0 ; 0 ; 0 ; 1 * a l f a ; 0 ;$ fase*alfa $]$ //Entradas iguais nos dois rodeiros

$\mathrm{B} 1=[0 ; 0 ; 0 ; 0 ; 0 ; 0 ; 0 ; 1 ; 0 ; 0] ; / /$ Entrada somente no rodeiro "r1"

$\mathrm{B} 2=[0 ; 0 ; 0 ; 0 ; 0 ; 0 ; 0 ; 0 ; 0 ; 1]$; //Entrada somente no rodeiro "r2"

$\mathrm{C}=\left[\begin{array}{llllllllll}1 & 0 & 0 & 0 & 0 & 0 & 0 & 0 & 0 & 0\end{array}\right.$

$\begin{array}{llllllllll}0 & 0 & 1 & 0 & 0 & 0 & 0 & 0 & 0 & 0\end{array}$

$\left.\begin{array}{llllllllll}0 & 0 & 0 & 0 & 1 & 0 & 0 & 0 & 0 & 0]\end{array}\right]$

$\mathrm{D}=[0 ; 0 ; 0]$

//Sinal de entrada, rotação dos rodeiros "r1" e "r2"

$\mathrm{t}=0$ :deltat:tfinal;

tetar1 $\mathrm{x}=(\mathrm{rm} / \mathrm{bb} * \sin ((2 * \% \mathrm{pi} / \mathrm{lambda}) *(\mathrm{v}) * \mathrm{t}+(2 * \% \mathrm{pi}$ *lct/lambda $))) ; / /$ rotação do rodeiro $\mathrm{r} 1$ em $\mathrm{x}$ derivtetar1 $\mathrm{x}=\operatorname{diff}(\operatorname{tetar} 1 \mathrm{x}) /$ deltat; derivtetar1x $(1,($ tfinal/deltat +1$))=0$; //derivada da rotação do rodeiro $\mathrm{r} 1 \mathrm{em} \mathrm{x}$

entradatetar $1 \mathrm{x}=(2 * \mathrm{bp} \wedge 2 * \mathrm{kpz} / \mathrm{itx}) * \operatorname{tetar} 1 \mathrm{x}+(2 * \mathrm{bp} \wedge 2 * \mathrm{cpz} / \mathrm{itx}) *$ derivtetar1x; //força de entrada de rotação do rodeiro $\mathrm{r} 1$ em $\mathrm{x}$

tetar2x=(rm/bb*sin((2*\%pi/lambda)*(v)*t-(2*\%pi*lct/lambda))); //rotação do rodeiro r2 em x - defasado de r1 devido a distância entre eixos

derivtetar2x=diff(tetar2x)/deltat; derivtetar2x $(1$,(tfinal/deltat +1$))=0$; //derivada da rotação do rodeiro $\mathrm{r} 2 \mathrm{em} \mathrm{x}$

entradatetar $2 \mathrm{x}=\left(2 * \mathrm{bp} \wedge 2^{\wedge} \mathrm{kpz} / \mathrm{itx}\right) * \operatorname{tetar} 2 \mathrm{x}+\left(2 * \mathrm{bp}{ }^{\wedge} 2 * \mathrm{cpz} / \mathrm{itx}\right) *$ derivtetar $2 \mathrm{x}$; //força de entrada de rotação do rodeiro $\mathrm{r} 2 \mathrm{em} \mathrm{x}$

//Criação da lista que representa o sistema linear

[s0]=syslin("c",A,B0,C,D);

[s1]=syslin("c",A,B1,C,D); //Somente rodeiro "r1"

[s2]=syslin("c",A,B2,C,D); //Somente rodeiro "r2"

//Simulaçao do espaço de estado

[edes0,xs] =csim(entradatetar1x,t,s0);

[edes1,xs]=csim(entradatetar1x,t,s1); //Somente rodeiro "r1"

[edes2,xs]=csim(entradatetar2x,t,s2); //Somente rodeiro "r2"

//Separação dos vetores de estado

Yc0=edes0(1,:);

Tetacx $0=\operatorname{edes} 0(2,:)$;

Tetacz $0=\operatorname{edes} 0(3,:)$;

Yc1=edes1(1,:);

Tetacx1=edes1(2,:);

Tetacz1=edes1(3,:); 
Yc2=edes2(1,:);

Tetacx2=edes2(2,:);

Tetacz2=edes2(3,:);

Yc=Yc1+Yc2; //Soma dos deslocamentos devido as entradas separadas em cada rodeiro Tetacx=Tetacx1+Tetacx2; //Soma dos deslocamentos devido as entradas separadas em cada rodeiro

Tetacz=Tetacz1+Tetacz2; //Soma dos deslocamentos devido as entradas separadas em cada rodeiro

$\mathrm{tf}=\mathrm{ss} 2 \mathrm{tf}(\mathrm{s} 0)$;

$\mathrm{tf} \_\mathrm{yc}=\mathrm{tf}(1,1)$;

tf_tetacx $=\mathrm{tf}(2,1)$;

tf_tetacz $=\mathrm{tf}(3,1)$;

//Arquivo de saida

entrada_statespace=[mc;mt;icx;icy;icz;itx;kpz;ksy;ksz;kbt;cay;caz;cpz;csy;csz;baz;bp;bs;hay; hayt;hm;hs;hst;lct;bb;lm;bm;lambda;rm;v;tfinal;deltat]; //Vetor coluna dod dados de entrada $\mathrm{z}=$ tfinal/deltat-32;

for $\mathrm{i}=33: 33+\mathrm{z}$

end

$$
\text { entrada_statespace }(\mathrm{i}, 1)=0 \text {; }
$$

result_statespace $=\left[\mathrm{t}^{\prime}, \mathrm{Yc}\right.$ ',Tetacx',Tetacz',entrada_statespace];

//fprintfMat ('C: IDocumentos de

trabalho\statespace \result_statespace_430000.txt',result_statespace);

//Curva de Bode SIMO (rotação nos dois eixos)

if fase $==1$ then,

$\mathrm{f} 1=\operatorname{scf}(1)$

// axes_properties

sda(); //volta os parâmetros de ajuste de grafico ao modo inicial

a=get("current_axes");

a.font_size $=1$; $\quad$ //ajuste do tamanho da fonte da escala

a.font_style $=2 ; \quad$ //ajuste do tipo da fonte da escala

a.grid $=[4,4] ; \quad$ //ajuste das cores dos eixos secundarios

$\mathrm{da}=\operatorname{gda}()$;

da.title.font_size $=4$; //ajuste do tamanho da fonte do titulo do grafico

da.title.font_style $=2$; //ajuste do tipo da fonte do titulo do grafico

da.x_label.font_size = 3; //ajuste do tamanho do titulo do eixo $\mathrm{x}$

da.x_label.font_style $=2$; //ajuste do tipo da fonte do eixo $\mathrm{x}$

da.y_label.font_size = 3; //ajuste do tamanho do titulo do eixo y

da.y_label.font_style $=2$; //ajuste do tipo da fonte do eixo y

bode(tf_yc,0.1,10); //curva de Bode

$\mathrm{f} 1=\operatorname{scf}(2)$;

// axes_properties

sda(); //volta os parâmetros de ajuste de grafico ao modo inicial

a=get("current_axes"); 
a.font_size=1; $\quad$ //ajuste do tamanho da fonte da escala

a.font_style $=2 ; \quad$ //ajuste do tipo da fonte da escala

a.grid=[4,4]; $\quad$ //ajuste das cores dos eixos secundarios

$\mathrm{da}=\operatorname{gda}()$;

da.title.font_size $=4$; //ajuste do tamanho da fonte do titulo do grafico

da.title.font_style = 2; //ajuste do tipo da fonte do titulo do grafico

da.x_label.font_size $=3$; $/$ /ajuste do tamanho do titulo do eixo $\mathrm{x}$

da.x_label.font_style $=2$; $/$ /ajuste do tipo da fonte do eixo $\mathrm{x}$

da.y_label.font_size = 3; //ajuste do tamanho do titulo do eixo y

da.y_label.font_style = 2; //ajuste do tipo da fonte do eixo y

bode(tf_tetacx,0.1,10); $\quad$ //curva de Bode

end

if fase $==-1$ then,

$\mathrm{f} 1=\operatorname{scf}(3)$;

// axes_properties

sda(); //volta os parâmetros de ajuste de grafico ao modo inicial a=get("current_axes");

a.font_size $=1$; $\quad$ //ajuste do tamanho da fonte da escala

a.font_style $=2 ; \quad$ //ajuste do tipo da fonte da escala

a.grid=[4,4]; $\quad$ //ajuste das cores dos eixos secundarios

da=gda();

da.title.font_size $=4$; //ajuste do tamanho da fonte do titulo do grafico

da.title.font_style $=2$; //ajuste do tipo da fonte do titulo do grafico

da.x_label.font_size $=3$; $/$ /ajuste do tamanho do titulo do eixo $\mathrm{x}$

da.x_label.font_style $=2$; $/$ /ajuste do tipo da fonte do eixo $\mathrm{x}$

da.y_label.font_size = 3; //ajuste do tamanho do titulo do eixo y

da.y_label.font_style $=2$; //ajuste do tipo da fonte do eixo y

bode(tf_tetacz,0.1,10); //curva de Bode

end 


\section{Apêndice E - Resultados da solução analítica}

Este programa acha os máximos do deslocamento e aceleração e aceleração rms a partir dos resultados gerados pelo programa apresentado no apêndice $E$. $O$ caso mostrado se aplica a suspensão $S 4$.

clear

// carregamento dos dados de entrada exec('C:|Documentos de trabalholdadosdeentrada.sci');disp('exec done');

$\mathrm{t}=0$ :deltat:tfinal; //vetor tempo deslocamento

$\mathrm{t}=\mathrm{t}$;';

tacl=0:deltat:(tfinal-deltat); //vetor tempo aceleraçao - uma unidade menor que deslocamento tacl=tacl';

$\mathrm{pi}=($ tfinal/2)/deltat;

$\mathrm{pf}=($ tfinal $) /$ deltat;

tcut=(0:deltat:(pf-pi)*deltat)';

$/ 1$

//Suspensão do Benchmark Manchester - 863006 N/m

//Carregamento dos vetores Yc, Tetacx e Tetacz

aux_863006=fscanfMat ('C: Documentos de

trabalholstatespace \result_statespace_863006.txt');

yc_863006=aux_863006(:,2);

tetacx_863006=aux_863006(:,3);

tetacz_863006=aux_863006(:,4);

//Derivada segunda (aceleração) dos vetores Yc, Tetacx e Tetacz

$\mathrm{y}=\mathrm{yc} \_$863006;

sy=round((size(y)*size $\left.\left.(y)^{\prime}\right)^{\wedge} 0.5\right)$; //dimensao do vetor $\mathrm{y}$

for $\mathrm{i}=1$ :round(sy/10)+1; $\mathrm{yr}(\mathrm{i}, 1)=\mathrm{y}(((10 * \mathrm{i})-9), 1)$; $\quad$ end //redução de 10x do tamanho do vetor $\mathrm{y}$

$\mathrm{d} 2 \mathrm{yr}=\operatorname{diff}(\mathrm{yr}, 2) /\left(\text { deltat*}^{*} 10\right)^{\wedge} 2$; //derivada segunda do vetor reduzido

//linearização ao mesmo tamanho do vetor y

$\mathrm{x}=$ linspace $\left(0 \text {, tfinal, round }\left(\left(\operatorname{size}(\mathrm{d} 2 \mathrm{yr})^{*} \operatorname{size}(\mathrm{d} 2 \mathrm{yr})^{\prime}\right) \wedge 0.5\right)\right)^{\prime}$;

$\mathrm{d}=\operatorname{splin}(\mathrm{x}, \mathrm{d} 2 \mathrm{yr})$;

$\mathrm{xx}=$ linspace $(0$, tfinal, sy)';

$\mathrm{d} 2 \mathrm{y}=$ interp $(\mathrm{xx}, \mathrm{x}, \mathrm{d} 2 \mathrm{yr}, \mathrm{d})$;

acl_yc_863006=d2y;

$\mathrm{y}=$ tetacx_863006; 
sy=round((size $\left.\left.(y)^{*} \operatorname{size}(y)^{\prime}\right)^{\wedge} 0.5\right)$; //dimensao do vetor $\mathrm{y}$

for i=1:round(sy/10)+1; yr(i,1)=y(((10*i)-9),1); $\quad$ end //redução de 10x do tamanho do vetor $\mathrm{y}$

$\mathrm{d} 2 \mathrm{yr}=\operatorname{diff}(\mathrm{yr}, 2) /($ deltat*10)^2; //derivada segunda do vetor reduzido

//linearização ao mesmo tamanho do vetor y

$\mathrm{x}=$ linspace $\left(0 \text {, tfinal, round }\left(\left(\operatorname{size}(\mathrm{d} 2 \mathrm{yr})^{*} \operatorname{size}(\mathrm{d} 2 \mathrm{yr})^{\prime}\right)^{\wedge} 0.5\right)\right)^{\prime}$;

$\mathrm{d}=\operatorname{splin}(\mathrm{x}, \mathrm{d} 2 \mathrm{yr})$;

$\mathrm{xx}=$ linspace $(0$, tfinal, sy)';

$\mathrm{d} 2 \mathrm{y}=$ interp (xx, $\mathrm{x}, \mathrm{d} 2 \mathrm{yr}, \mathrm{d})$;

acl_tetacx_863006=d2y;

$\mathrm{y}=$ tetacz_863006;

sy=round((size $\left.\left.(y)^{*} \operatorname{size}(y)^{\prime}\right)^{\wedge} 0.5\right)$; //dimensao do vetor $\mathrm{y}$

for $\mathrm{i}=1$ :round(sy/10)+1; $\mathrm{yr}(\mathrm{i}, 1)=\mathrm{y}(((10 * \mathrm{i})-9), 1)$; $\quad$ end //redução de 10x do tamanho do vetor $\mathrm{y}$

d2yr=diff(yr,2)/(deltat*10)^2; //derivada segunda do vetor reduzido

//linearização ao mesmo tamanho do vetor y

$\mathrm{x}=$ linspace $\left(0\right.$, tfinal, round $\left.\left.\left(\left(\operatorname{size}(\mathrm{d} 2 \mathrm{yr})^{*} \operatorname{size}(\mathrm{d} 2 \mathrm{yr})\right)^{\prime}\right) \wedge 0.5\right)\right)^{\prime}$;

$\mathrm{d}=\operatorname{splin}(\mathrm{x}, \mathrm{d} 2 \mathrm{yr})$;

$\mathrm{xx}=$ linspace $(0$, tfinal, sy)';

$\mathrm{d} 2 \mathrm{y}=$ interp (xx, $\mathrm{x}, \mathrm{d} 2 \mathrm{yr}, \mathrm{d})$;

acl_tetacz_863006=d2y;

//Redução dos vetores Yc, Tetacx e Tetacz para zona de regime permanente

for $i=p i: p f$

$$
\begin{aligned}
& \text { j=i-pi+1; } \\
& \text { yc_863006_cut(j)=yc_863006(i); } \\
& \text { acl_yc_863006_cut(j)=acl_yc_863006(i); } \\
& \text { tetacx_863006_cut(j)=tetacx_863006(i); } \\
& \text { acl_tetacx_863006_cut(j)=acl_tetacx_863006(i); } \\
& \text { tetacz_863006_cut(j)=tetacz_863006(i); } \\
& \text { acl_tetacz_863006_cut(j)=acl_tetacz_863006(i); }
\end{aligned}
$$

end

//Maximo das acelerações e deslocamentos dos vetores Yc, Tetacx e Tetac

max_yc_863006_cut=max(yc_863006_cut);

max_acl_yc_863006_cut=max(acl_yc_863006_cut);

max_tetacx_863006_cut=max(tetacx_863006_cut);

max_acl_tetacx_863006_cut=max(acl_tetacx_863006_cut);

max_tetacz_863006_cut=max(tetacz_863006_cut);

max_acl_tetacz_863006_cut=max(acl_tetacz_863006_cut);

//aceleraçao rms ponderada na zona de regime permanente segundo a definicao $1 \S 6.1$

ISO2631 
rms_acl_yc_863006 $=(($ inttrap(tcut, $((($ acl_yc_863006_cut $) . \wedge 2)))) /($ tfinal $/ 2)) \wedge 0.5$;

rms_acl_tetacx_863006 $=((\text { inttrap }(\text { tcut, }(((\text { acl_tetacx_863006_cut }) . \wedge 2)))) /(\text { tfinal } / 2))^{\wedge} 0.5$;

rms_acl_tetacz_863006=((inttrap(tcut, $((($ acl_tetacz_863006_cut).^2)) $)) /($ tfinal/2) $) \wedge 0.5$;

//Maximos na regiao de regime permanente

$\mathrm{g}=1$;

for $\mathrm{k}=2$ :pf-pi-1

$\mathrm{kp} 1=\mathrm{k}+1$;

$\mathrm{km} 1=\mathrm{k}-1$;

if yc_863006_cut(k,1)>yc_863006_cut(km1,1) \&

yc_863006_cut $(k, 1)>y c \_863006 \_c u t(k p 1,1)$ then

$\operatorname{maximo}(\mathrm{g})=\mathrm{k}$;

maximos_yc_863006(g,2)=yc_863006_cut(k,1);

maximos_yc_863006 $(\mathrm{g}, 1)=(\mathrm{k}+\mathrm{pi}) *$ deltat;

$\mathrm{g}=\mathrm{g}+1$;

end,

end

result_acl_statespace=[t,acl_yc_863006, acl_tetacx_863006, acl_tetacz_863006];

fprintfMat ('C: Documentos de

trabalho\statespace\result_acl_statespace_863006.txt',result_acl_statespace);

//Apresentação dos resultados

mat_max_acl_rms=[

863006, max_yc_863006_cut, max_acl_yc_863006_cut, rms_acl_yc_863006;

863006, max_tetacx_863006_cut, max_acl_tetacx_863006_cut, rms_acl_tetacx_863006

863006, max_tetacz_863006_cut, max_acl_tetacz_863006_cut, rms_acl_tetacz_863006];

fprintfMat('C:IDocumentos de

trabalholstatespacelmat_max_acl_rms_863006.txt',mat_max_acl_rms); 


\section{Apêndice F - Apresentação gráfica da solução analítica}

Este programa gera os gráficos de deslocamento e aceleração para $Y_{c}, \theta_{c x}$ e $\theta_{c z}$ a partir dos resultados obtidos pelo programa do apêndice $D$. $O$ caso mostrado se aplica a suspensão $S 1$.

clear

//sda();//volta os parâmetros de ajuste de grafico ao modo inicial

result_statespace=fscanfMat ('C: $\backslash$ Documentos de

trabalholstatespacelresult_statespace_736941.txt');

result_acl_statespace=fscanfMat ('C:IDocumentos de

trabalholstatespacelresult_acl_statespace_736941.txt');

$\mathrm{t}=$ result_statespace(:,1);

Yc=result_statespace(:,2);

Tetacx=result_statespace(:,3);

Tetacz=result_statespace(:,4);

entrada_statespace=result_statespace(:,5);

acl_Yc=result_acl_statespace(:,2);

acl_Tetacx=result_acl_statespace(:,3);

acl_Tetacz=result_acl_statespace(:,4);

//Grafico - YC

$\mathrm{f} 1=\operatorname{scf}(1)$; //criação do grafico

//ajuste do titulo e identificação dos eixos

$\mathrm{da}=\operatorname{gda}()$;

da.title.font_size $=4$; //ajuste do tamanho da fonte do titulo do grafico

da.title.font_style $=2$; //ajuste do tipo da fonte do titulo do grafico

da.x_label.font_size = 3; //ajuste do tamanho do titulo do eixo $\mathrm{x}$

da.x_label.font_style $=2$; //ajuste do tipo da fonte do eixo $\mathrm{x}$

da.y_label.font_size = 3; //ajuste do tamanho do titulo do eixo y

da.y_label.font_style = 2; //ajuste do tipo da fonte do eixo y

//geraçao do grafico

subplot(311);

plot2d(t,Yc); //grafico do deslocamento Yc

xtitle(' Yc ','Tempo (s)','Deslocamento (m)'); //titulos do grafico, eixo x e x

//ajuste do grafico

a=get("current_axes");

a.font_size $=1 ; \quad$ //ajuste do tamanho da fonte da escala

a.font_style $=2 ; \quad$ //ajuste do tipo da fonte da escala

a.grid $=[4,4] ; \quad$ //ajuste das cores dos eixos secundarios 
a.figure_size $=[800,500]$;

//Grafico - teta cx

//f1=scf(2); //criação do grafico

//ajuste do titulo e identificação dos eixos

$\mathrm{da}=$ gda();

da.title.font_size $=4$; //ajuste do tamanho da fonte do titulo do grafico

da.title.font_style $=2$; //ajuste do tipo da fonte do titulo do grafico

da.x_label.font_size $=3$; //ajuste do tamanho do titulo do eixo $\mathrm{x}$

da.x_label.font_style $=2$; $/ /$ ajuste do tipo da fonte do eixo $\mathrm{x}$

da.y_label.font_size = 3; //ajuste do tamanho do titulo do eixo y

da.y_label.font_style = 2; //ajuste do tipo da fonte do eixo y

//geraçao do grafico

subplot(312);

plot2d(t,Tetacx); //grafico do angulo Tetacx

xtitle(' Teta cx ','Tempo (s)','Ângulo (rad)'); //titulos do grafico, eixo x e x

//ajuste do grafico

a=get("current_axes");

a.font_size $=1 ; \quad$ //ajuste do tamanho da fonte da escala

a.font_style $=2 ; \quad$ //ajuste do tipo da fonte da escala

a.grid $=[4,4]$; $\quad$ //ajuste das cores dos eixos secundarios

a.figure_size $=[800,500]$;

//Grafico - teta cz

//f1=scf(3); //criação do grafico

//ajuste do titulo e identificação dos eixos

$\mathrm{da}=\mathrm{gda}()$;

da.title.font_size $=4$; //ajuste do tamanho da fonte do titulo do grafico

da.title.font_style = 2; //ajuste do tipo da fonte do titulo do grafico

da.x_label.font_size $=3$; //ajuste do tamanho do titulo do eixo $\mathrm{x}$

da.x_label.font_style $=2$; //ajuste do tipo da fonte do eixo $\mathrm{x}$

da.y_label.font_size = 3; //ajuste do tamanho do titulo do eixo y

da.y_label.font_style $=2$; //ajuste do tipo da fonte do eixo y

//geraçao do grafico

subplot(313);

plot2d(t,Tetacz); //grafico do deslocamento Tetacz

xtitle(' Teta cz ','Tempo (s)','Ângulo (rad)'); //titulos do grafico, eixo x e x

//ajuste do grafico

a=get("current_axes");

a.font_size $=1 ; \quad$ //ajuste do tamanho da fonte da escala

a.font_style $=2$; $\quad$ //ajuste do tipo da fonte da escala

a.grid $=[4,4]$; $\quad$ //ajuste das cores dos eixos secundarios

a.figure_size $=[800,500]$;

$/ /$

//Grafico - Aceleração YC

f2=scf(2); //criação do grafico

//ajuste do titulo e identificação dos eixos

$\mathrm{da}=\mathrm{gda}()$; 
da.title.font_size $=4$; //ajuste do tamanho da fonte do titulo do grafico da.title.font_style $=2$; //ajuste do tipo da fonte do titulo do grafico da.x_label.font_size = 3; //ajuste do tamanho do titulo do eixo $\mathrm{x}$ da.x_label.font_style $=2$; //ajuste do tipo da fonte do eixo $\mathrm{x}$ da.y_label.font_size = 3; //ajuste do tamanho do titulo do eixo y da.y_label.font_style = 2; //ajuste do tipo da fonte do eixo y //geraçao do grafico subplot(311); plot2d(t,acl_Yc); //grafico do deslocamento Yc xtitle(' Yc ','Tempo (s)','Aceleração (m/s²)'); //titulos do grafico, eixo x e x //ajuste do grafico a=get("current_axes"); a.font_size $=1$; //ajuste do tamanho da fonte da escala a.font_style = 2; $\quad$ //ajuste do tipo da fonte da escala a.grid $=[4,4]$; $\quad$ //ajuste das cores dos eixos secundarios a.figure_size $=[800,500]$;

//Grafico - teta cx //f1=scf(2); //criação do grafico //ajuste do titulo e identificação dos eixos $\mathrm{da}=\mathrm{gda}()$; da.title.font_size $=4$; //ajuste do tamanho da fonte do titulo do grafico da.title.font_style $=2$; //ajuste do tipo da fonte do titulo do grafico da.x_label.font_size $=3$; //ajuste do tamanho do titulo do eixo $\mathrm{x}$ da.x_label.font_style $=2$; //ajuste do tipo da fonte do eixo $\mathrm{x}$ da.y_label.font_size $=3$; //ajuste do tamanho do titulo do eixo y da.y_label.font_style = 2; //ajuste do tipo da fonte do eixo y //geraçao do grafico subplot(312); plot2d(t,acl_Tetacx); //grafico do angulo Tetacx xtitle(' Teta cx ','Tempo (s)','Aceleração (rad/s²)'); //titulos do grafico, eixo x e x //ajuste do grafico a=get("current_axes"); a.font_size $=1$; //ajuste do tamanho da fonte da escala a.font_style $=2 ; \quad$ //ajuste do tipo da fonte da escala a.grid $=[4,4] ; \quad$ //ajuste das cores dos eixos secundarios a.figure_size $=[800,500]$;

//Grafico - teta cz //f1=scf(3); //criação do grafico //ajuste do titulo e identificação dos eixos $\mathrm{da}=\mathrm{gda}()$; da.title.font_size $=4$; //ajuste do tamanho da fonte do titulo do grafico da.title.font_style $=2$; //ajuste do tipo da fonte do titulo do grafico da.x_label.font_size = 3; //ajuste do tamanho do titulo do eixo $\mathrm{x}$ da.x_label.font_style $=2$; //ajuste do tipo da fonte do eixo $\mathrm{x}$ da.y_label.font_size = 3; //ajuste do tamanho do titulo do eixo y da.y_label.font_style $=2$; //ajuste do tipo da fonte do eixo y //geraçao do grafico subplot(313); 
plot2d(t,acl_Tetacz); //grafico do deslocamento Tetacz xtitle(' Teta cz ','Tempo (s)','Aceleração (rad/s²)'); //titulos do grafico, eixo x e x //ajuste do grafico a=get("current_axes");
a.font_size $=1$;
//ajuste do tamanho da fonte da escala

a.font_style $=2$

a.grid $=[4,4]$

//ajuste do tipo da fonte da escala

a.figure_size $=[800,500]$;

//ajuste das cores dos eixos secundarios 


\section{Apêndice G - Apresentação gráfica da solução por integração numérica}

Dois tipos de programa foram desenvolvidos para gerar os gráficos de deslocamento e aceleração para Yc, $\theta c x$ e $\theta c z$ a partir dos resultados obtidos pelo simulador de diagrama de blocos. O promeiro se refere aos dados de entrada do Benchmark, linear, e o segundo foi utilizado para a geração dos gráficos lineares e não lineares das suspensões $S 1$, S2, S3 e S4. O caso mostrado se aplica a suspensão $S 4$.

\section{clear}

//sda();//volta os parâmetros de ajuste de grafico ao modo inicial

// carregamento dos dados de entrada exec('C:IDocumentos de trabalholdadosdeentrada.sci');disp('exec done');

$\mathrm{t}=0$ :deltat:tfinal;

$\mathrm{t}=\mathrm{t}$;

pi=round(8/deltat);

$\mathrm{pf}=($ tfinal $) /$ deltat;

tcut $=(0:$ deltat:(pf-pi)*deltat)';

$\mathrm{vi}=5$;

acl=0.5;

$/ / * * * * * * * * * * * * * * * * * * * * * * * * * * * * * * * * * * * * * * * * * * * * * * * *$

//LINEAR

//Deslocamentos

//carregamento dos vetores de deslocamento lineares

yc_li_863006=fscanfMat ('C:LDocumentos de trabalholscicos|scicos_863006lyc_li.txt');

tetacx_li_863006=fscanfMat ('C:LDocumentos de trabalholscicoslscicos_863006ltetacx_li.txt');

tetacz_li_863006=fscanfMat ('C:LDocumentos de trabalholscicoslscicos_863006ltetacz_li.txt');

//Acelerações

//carregamento dos vetores aceleraçao lineares

acl_yc_li_863006=fscanfMat ('C:IDocumentos de trabalholscicos\scicos_863006\acl_yc_li.txt'); acl_tetacx_li_863006=fscanfMat ('C: (Documentos de trabalho\scicos $\backslash$ scicos_863006lacl_tetacx_li.txt'); acl_tetacz_li_863006=fscanfMat ('C:IDocumentos de trabalholscicos $\backslash$ scicos_863006lacl_tetacz_li.txt');

//Redução dos vetores Yc, Tetacx e Tetacz para zona de regime permanente 


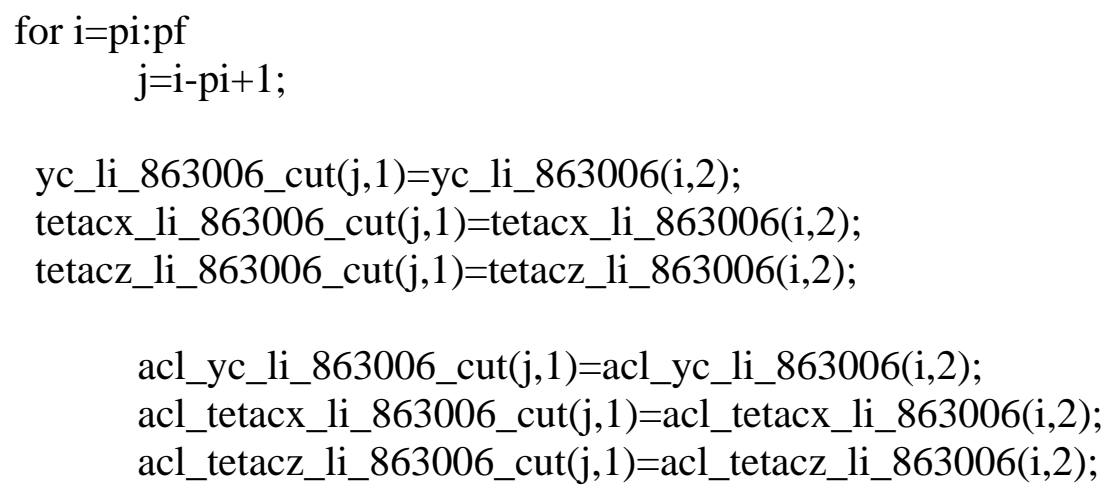

end

//Maximo das acelerações e deslocamentos dos vetores Yc, Tetacx e Tetac max_yc_li_863006_cut=max(yc_li_863006_cut); max_tetacx_li_863006_cut=max(tetacx_li_863006_cut); max_tetacz_li_863006_cut=max(tetacz_li_863006_cut);

max_acl_yc_li_863006_cut=max(acl_yc_li_863006_cut); max_acl_tetacx_li_863006_cut=max(acl_tetacx_li_863006_cut); max_acl_tetacz_li_863006_cut=max(acl_tetacz_li_863006_cut);

//aceleraçao rms ponderada na zona de regime permanente segundo a definicao $1 \S 6.1$ ISO2631

rms_acl_yc_li_863006_cut=((inttrap(tcut, $((($ acl_yc_li_863006_cut).^2) $))) /(\max ($ tcut $)))^{\wedge} 0.5$; rms_acl_tetacx_li_863006_cut=((inttrap(tcut,(((acl_tetacx_li_863006_cut).^2))) $) /(\max ($ tcut $)))$ $\wedge 0.5$;

rms_acl_tetacz_li_863006_cut=((inttrap(tcut, $((($ acl_tetacz_li_863006_cut).^2))))/(max(tcut))) $\wedge 0.5$;

//criação da matriz de maximos deslocamento, aceleração e acelaraçao rms mat_max_acl_li=[max_yc_li_863006_cut, max_acl_yc_li_863006_cut, rms_acl_yc_li_863006_cut;

max_tetacx_li_863006_cut, max_acl_tetacx_li_863006_cut, rms_acl_tetacx_li_863006_cut; max_tetacz_li_863006_cut, max_acl_tetacz_li_863006_cut, rms_acl_tetacz_li_863006_cut];

//criaçao da matriz de vetores de deslocamento aux1=[t,yc_li_863006(:,2),tetacx_li_863006(:,2),tetacz_li_863006(:,2)]; mat_li_863006=(aux1);

aux1=[tcut,yc_li_863006_cut,tetacx_li_863006_cut,tetacz_li_863006_cut]; mat_li_863006_cut=(aux1);

//criaçao da matriz de vetores aceleração aux1=[t,acl_yc_li_863006(:,2),acl_tetacx_li_863006(:,2),acl_tetacz_li_863006(:,2)]; acl_mat_li_863006=(aux1);

aux1=[tcut,acl_yc_li_863006_cut,acl_tetacx_li_863006_cut,acl_tetacz_li_863006_cut]; acl_mat_li_863006_cut=(aux1); 
$/ /$

\section{//NAO LINEAR}

//Deslocamentos

//carregamento dos vetores de deslocamento nlineares

yc_nli_863006=fscanfMat ('C:LDocumentos de trabalholscicos\scicos_863006\yc_nli.txt');

tetacx_nli_863006=fscanfMat ('C:IDocumentos de trabalholscicos\scicos_863006ltetacx_nli.txt');

tetacz_nli_863006=fscanfMat ('C:IDocumentos de trabalholscicos\scicos_863006\tetacz_nli.txt');

\section{//Acelerações}

//carregamento dos vetores aceleraçao nlineares acl_yc_nli_863006=fscanfMat ('C:IDocumentos de trabalho \scicos $\backslash$ scicos_863006\acl_yc_nli.txt'); acl_tetacx_nli_863006=fscanfMat ('C:IDocumentos de trabalholscicos $\backslash$ scicos_863006\acl_tetacx_nli.txt'); acl_tetacz_nli_863006=fscanfMat ('C:IDocumentos de trabalholscicos\scicos_863006lacl_tetacz_nli.txt');

//Redução dos vetores Yc, Tetacx e Tetacz para zona de regime permanente for i=pi:pf

$$
\mathrm{j}=\mathrm{i}-\mathrm{pi}+1 \text {; }
$$

yc_nli_863006_cut(j,1)=yc_nli_863006(i,2);

tetacx_nli_863006_cut(j,1)=tetacx_nli_863006(i,2);

tetacz_nli_863006_cut $(j, 1)=$ tetacz_nli_863006(i,2);

acl_yc_nli_863006_cut(j,1)=acl_yc_nli_863006(i,2);

acl_tetacx_nli_863006_cut $(j, 1)=$ acl_tetacx_nli_863006(i,2);

acl_tetacz_nli_863006_cut(j,1)=acl_tetacz_nli_863006(i,2);

end

//Maximo das acelerações e deslocamentos dos vetores Yc, Tetacx e Tetac

max_yc_nli_863006_cut=max(yc_nli_863006_cut);

max_tetacx_nli_863006_cut=max(tetacx_nli_863006_cut);

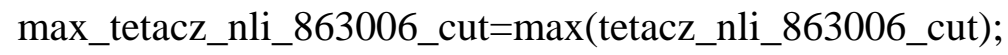

max_acl_yc_nli_863006_cut $=\max ($ acl_yc_nli_863006_cut);

max_acl_tetacx_nli_863006_cut=max(acl_tetacx_nli_863006_cut);

max_acl_tetacz_nli_863006_cut=max(acl_tetacz_nli_863006_cut);

//aceleraçao rms ponderada na zona de regime permanente segundo a definicao $1 \S 6.1$

ISO2631

rms_acl_yc_nli_863006_cut=((inttrap(tcut, $((($ acl_yc_nli_863006_cut $) . \wedge 2)))) /(\max (t c u t))) \wedge 0.5$; rms_acl_tetacx_nli_863006_cut=((inttrap $($ tcut, $((($ acl_tetacx_nli_863006_cut $) . \wedge 2)))) /(\max ($ tcut )$)^{\wedge} 0.5$; 
rms_acl_tetacz_nli_863006_cut=((inttrap(tcut, $((($ acl_tetacz_nli_863006_cut).^2)) $)) /(\max ($ tcut )$)^{\wedge} 0.5$;

//criação da matriz de maximos do deslocamento e aceleração e acelaraçao rms

mat_max_acl_nli=[max_yc_nli_863006_cut, max_acl_yc_nli_863006_cut,

rms_acl_yc_nli_863006_cut;

max_tetacx_nli_863006_cut, max_acl_tetacx_nli_863006_cut,

rms_acl_tetacx_nli_863006_cut;

max_tetacz_nli_863006_cut, max_acl_tetacz_nli_863006_cut,

rms_acl_tetacz_nli_863006_cut];

//criaçao da matriz de vetores de deslocamento

aux1=[t,yc_nli_863006(:,2),tetacx_nli_863006(:,2),tetacz_nli_863006(:,2)];

mat_nli_863006=(aux1);

aux1=[tcut,yc_nli_863006_cut,tetacx_nli_863006_cut,tetacz_nli_863006_cut];

mat_nli_863006_cut=(aux1);

//criaçao da matriz de vetores aceleração

aux1=[t,acl_yc_nli_863006(:,2),acl_tetacx_nli_863006(:,2),acl_tetacz_nli_863006(:,2)];

acl_mat_nli_863006=(aux1);

aux1=[tcut,acl_yc_nli_863006_cut,acl_tetacx_nli_863006_cut,acl_tetacz_nli_863006_cut];

acl_mat_nli_863006_cut=(aux1);

//*************************1/0

//Yc linear e não linear

$\mathrm{f} 1=\operatorname{scf}(1)$; //criação do grafico

//Linear

//ajuste do titulo e identificação dos eixos

da=gda();

da.title.font_size $=4$; //ajuste do tamanho da fonte do titulo do grafico

da.title.font_style $=2$; //ajuste do tipo da fonte do titulo do grafico

da.x_label.font_size $=3$; //ajuste do tamanho do titulo do eixo $\mathrm{x}$

da.x_label.font_style $=2$; //ajuste do tipo da fonte do eixo $\mathrm{x}$

da.y_label.font_size $=3$; //ajuste do tamanho do titulo do eixo y

da.y_label.font_style = 2; //ajuste do tipo da fonte do eixo y

//geraçao do grafico

subplot(321);

plot2d(t,mat_li_863006(:,2));//grafico do deslocamento Yc_li

xtitle('Linear','t (s)','Yc (m)'); //titulos do grafico, eixo x e x

//ajuste do grafico

a=get("current_axes");

a.font_size $=1 ; \quad$ //ajuste do tamanho da fonte da escala

a.font_style $=2 ; \quad$ //ajuste do tipo da fonte da escala 
a.grid $=[4,4] ; \quad$ //ajuste das cores dos eixos secundarios

a.figure_size $=[800,400]$;

//Não linear

//ajuste do titulo e identificação dos eixos

$\mathrm{da}=$ gda();

da.title.font_size $=4$; //ajuste do tamanho da fonte do titulo do grafico da.title.font_style $=2$; //ajuste do tipo da fonte do titulo do grafico da.x_label.font_size $=3$; //ajuste do tamanho do titulo do eixo $\mathrm{x}$ da.x_label.font_style $=2$; $/ /$ ajuste do tipo da fonte do eixo $\mathrm{x}$ da.y_label.font_size $=3$; / /ajuste do tamanho do titulo do eixo y da.y_label.font_style $=2$; //ajuste do tipo da fonte do eixo y //geraçao do grafico

subplot(322);

plot2d(t,mat_nli_863006(:,2)); //grafico do deslocamento Yc_nli xtitle('Nao Linear','t (s)','Yc (m)'); //titulos do grafico, eixo x e x //ajuste do grafico a=get("current_axes");

a.font_size $=1 ; \quad$ //ajuste do tamanho da fonte da escala

a.font_style $=2 ; \quad$ //ajuste do tipo da fonte da escala

a.grid $=[4,4] ; \quad$ //ajuste das cores dos eixos secundarios

a.figure_size $=[800,400]$;

//Tetacx linear e não linear

//f1=scf(1); //criação do grafico

//Linear

//ajuste do titulo e identificação dos eixos

$\mathrm{da}=$ gda();

da.title.font_size $=4$; //ajuste do tamanho da fonte do titulo do grafico da.title.font_style $=2$; //ajuste do tipo da fonte do titulo do grafico

da.x_label.font_size $=3$; //ajuste do tamanho do titulo do eixo $\mathrm{x}$

da.x_label.font_style $=2$; //ajuste do tipo da fonte do eixo $\mathrm{x}$

da.y_label.font_size = 3; //ajuste do tamanho do titulo do eixo y

da.y_label.font_style $=2$; //ajuste do tipo da fonte do eixo y

//geraçao do grafico

subplot(323);

plot2d(t,mat_li_863006(:,3));//grafico do deslocamento Yc_li

xtitle(' ','t (s)','Tetacx (rad)'); //titulos do grafico, eixo x e x

//ajuste do grafico

a=get("current_axes");

a.font_size $=1 ; \quad$ //ajuste do tamanho da fonte da escala

a.font_style $=2 ; \quad$ //ajuste do tipo da fonte da escala

a.grid=[4,4]; $\quad$ //ajuste das cores dos eixos secundarios

a.figure_size $=[800,400]$;

//Não linear

//ajuste do titulo e identificação dos eixos

$\mathrm{da}=\operatorname{gda}()$; 
da.title.font_size $=4$; //ajuste do tamanho da fonte do titulo do grafico da.title.font_style $=2$; //ajuste do tipo da fonte do titulo do grafico da.x_label.font_size = 3; //ajuste do tamanho do titulo do eixo $\mathrm{x}$ da.x_label.font_style = 2; //ajuste do tipo da fonte do eixo $\mathrm{x}$ da.y_label.font_size $=3$; //ajuste do tamanho do titulo do eixo y da.y_label.font_style = 2; //ajuste do tipo da fonte do eixo y //geraçao do grafico subplot(324);

plot2d(t,mat_nli_863006(:,3)); / /grafico do deslocamento Yc_nli xtitle(' ','t (s)','Tetacx (rad)'); //titulos do grafico, eixo x e x

//ajuste do grafico a=get("current_axes");

a.font_size $=1$; //ajuste do tamanho da fonte da escala a.font_style = 2; $\quad$ //ajuste do tipo da fonte da escala a.grid $=[4,4] ; \quad$ //ajuste das cores dos eixos secundarios a.figure_size $=[800,400]$;

//Tetacz linear e não linear //f1=scf(1); //criação do grafico

//Linear

//ajuste do titulo e identificação dos eixos da=gda(); da.title.font_size $=4$; //ajuste do tamanho da fonte do titulo do grafico da.title.font_style $=2$; //ajuste do tipo da fonte do titulo do grafico da.x_label.font_size $=3$; //ajuste do tamanho do titulo do eixo $\mathrm{x}$ da.x_label.font_style $=2$; //ajuste do tipo da fonte do eixo $\mathrm{x}$ da.y_label.font_size = 3; //ajuste do tamanho do titulo do eixo y da.y_label.font_style = 2; //ajuste do tipo da fonte do eixo y //geraçao do grafico subplot(325); plot2d(t,mat_li_863006(:,4));//grafico do deslocamento Yc_li xtitle(' ',t (s)','Tetacz (rad)'); //titulos do grafico, eixo x e x //ajuste do grafico a=get("current_axes");

a.font_size $=1 ; \quad$ //ajuste do tamanho da fonte da escala a.font_style $=2 ; \quad$ //ajuste do tipo da fonte da escala a.grid=[4,4]; //ajuste das cores dos eixos secundarios a.figure_size $=[800,400]$;

//Não linear

//ajuste do titulo e identificação dos eixos $\mathrm{da}=\mathrm{gda}()$; da.title.font_size $=4$; //ajuste do tamanho da fonte do titulo do grafico da.title.font_style $=2$; //ajuste do tipo da fonte do titulo do grafico da.x_label.font_size = 3; //ajuste do tamanho do titulo do eixo $\mathrm{x}$ da.x_label.font_style $=2$; //ajuste do tipo da fonte do eixo $\mathrm{x}$ da.y_label.font_size $=3$; //ajuste do tamanho do titulo do eixo y da.y_label.font_style = 2; //ajuste do tipo da fonte do eixo y 
//geraçao do grafico

subplot(326);

plot2d(t,mat_nli_863006(:,4)); //grafico do deslocamento Yc_nli

xtitle(' ','t (s)','Tetacz (rad)'); //titulos do grafico, eixo x e x

//ajuste do grafico

a=get("current_axes");

a.font_size $=1 ; \quad$ //ajuste do tamanho da fonte da escala

a.font_style $=2 ; \quad$ //ajuste do tipo da fonte da escala

a.grid $=[4,4] ; \quad$ //ajuste das cores dos eixos secundarios

a.figure_size $=[800,400]$;

$/ / * * * * * * * * * * * * * * * * * * * * * * * * * * * * * * * * * * * * * * * * * * * * * * * * * * * * * * * * * * * * * * * *$

//Grafico das acelerações

//Yc linear e não linear

$\mathrm{f} 1=\operatorname{scf}(2)$; //criação do grafico

//Linear

//ajuste do titulo e identificação dos eixos

$\mathrm{da}=\mathrm{gda}()$;

da.title.font_size $=4$; //ajuste do tamanho da fonte do titulo do grafico

da.title.font_style $=2$; //ajuste do tipo da fonte do titulo do grafico

da.x_label.font_size $=3$; //ajuste do tamanho do titulo do eixo $\mathrm{x}$

da.x_label.font_style $=2$; //ajuste do tipo da fonte do eixo $\mathrm{x}$

da.y_label.font_size = 3; //ajuste do tamanho do titulo do eixo y

da.y_label.font_style = 2; //ajuste do tipo da fonte do eixo y

//geraçao do grafico

subplot(321);

plot2d(tcut,acl_mat_li_863006_cut(:,2)); //grafico do deslocamento Yc_li

xtitle('Linear','t (s)','Yc (m/s2)'); //titulos do grafico, eixo x e x

//ajuste do grafico

a=get("current_axes");

a.font_size $=1$;

//ajuste do tamanho da fonte da escala

a.font_style $=2 ; \quad$ //ajuste do tipo da fonte da escala

a.grid=[4,4]; $\quad$ //ajuste das cores dos eixos secundarios

a.figure_size $=[800,400]$;

//Não linear

//ajuste do titulo e identificação dos eixos

$\mathrm{da}=$ gda();

da.title.font_size $=4$; //ajuste do tamanho da fonte do titulo do grafico

da.title.font_style $=2$; //ajuste do tipo da fonte do titulo do grafico

da.x_label.font_size $=3$; //ajuste do tamanho do titulo do eixo $\mathrm{x}$

da.x_label.font_style $=2$; //ajuste do tipo da fonte do eixo $\mathrm{x}$

da.y_label.font_size = 3; //ajuste do tamanho do titulo do eixo y

da.y_label.font_style $=2$; //ajuste do tipo da fonte do eixo y

//geraçao do grafico

subplot(322);

plot2d(tcut,acl_mat_nli_863006_cut(:,2)); //grafico do deslocamento Yc_nli

xtitle('Nao Linear','t (s)','Yc (m/s2)'); //titulos do grafico, eixo x e x 
//ajuste do grafico

a=get("current_axes");

a.font_size $=1 ; \quad$ //ajuste do tamanho da fonte da escala

a.font_style $=2 ; \quad$ //ajuste do tipo da fonte da escala

a.grid=[4,4]; $\quad$ //ajuste das cores dos eixos secundarios

a.figure_size $=[800,400]$;

//Tetacx linear e não linear

//f1=scf(1); //criação do grafico

\section{//Linear}

//ajuste do titulo e identificação dos eixos

$\mathrm{da}=\operatorname{gda}()$;

da.title.font_size $=4$; //ajuste do tamanho da fonte do titulo do grafico

da.title.font_style $=2$; //ajuste do tipo da fonte do titulo do grafico

da.x_label.font_size $=3$; //ajuste do tamanho do titulo do eixo $\mathrm{x}$

da.x_label.font_style $=2$; $/ /$ ajuste do tipo da fonte do eixo $\mathrm{x}$

da.y_label.font_size = 3; //ajuste do tamanho do titulo do eixo y

da.y_label.font_style $=2$; //ajuste do tipo da fonte do eixo y

//geraçao do grafico

subplot(323);

plot2d(tcut,acl_mat_li_863006_cut(:,3)); //grafico do deslocamento Yc_li

xtitle(' ','t (s)','Tetacx (rad/s2)'); //titulos do grafico, eixo x e x

//ajuste do grafico

a=get("current_axes");

a.font_size $=1 ; \quad$ //ajuste do tamanho da fonte da escala

a.font_style $=2 ; \quad$ //ajuste do tipo da fonte da escala

a.grid $=[4,4] ; \quad$ //ajuste das cores dos eixos secundarios

a.figure_size $=[800,400]$;

//Não linear

//ajuste do titulo e identificação dos eixos

$\mathrm{da}=\mathrm{gda}()$;

da.title.font_size $=4$; //ajuste do tamanho da fonte do titulo do grafico

da.title.font_style = 2; //ajuste do tipo da fonte do titulo do grafico

da.x_label.font_size $=3$; //ajuste do tamanho do titulo do eixo $\mathrm{x}$

da.x_label.font_style $=2$; //ajuste do tipo da fonte do eixo $\mathrm{x}$

da.y_label.font_size = 3; //ajuste do tamanho do titulo do eixo y

da.y_label.font_style = 2; //ajuste do tipo da fonte do eixo y

//geraçao do grafico

subplot(324);

plot2d(tcut,acl_mat_nli_863006_cut(:,3)); //grafico do deslocamento Yc_nli xtitle(' ','t (s)','Tetacx (rad/s2)'); //titulos do grafico, eixo x e x

//ajuste do grafico

a=get("current_axes");

a.font_size $=1 ; \quad$ //ajuste do tamanho da fonte da escala

a.font_style $=2$; $\quad$ //ajuste do tipo da fonte da escala

a.grid=[4,4]; $\quad$ //ajuste das cores dos eixos secundarios

a.figure_size $=[800,400]$; 


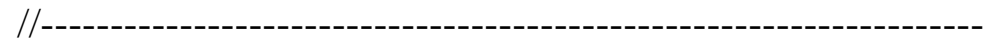

//Tetacz linear e não linear

//f1=scf(1); //criação do grafico

//Linear

//ajuste do titulo e identificação dos eixos

$\mathrm{da}=\mathrm{gda}()$;

da.title.font_size $=4$; //ajuste do tamanho da fonte do titulo do grafico

da.title.font_style $=2$; //ajuste do tipo da fonte do titulo do grafico

da.x_label.font_size $=3$; //ajuste do tamanho do titulo do eixo $\mathrm{x}$

da.x_label.font_style $=2$; //ajuste do tipo da fonte do eixo $\mathrm{x}$

da.y_label.font_size = 3; //ajuste do tamanho do titulo do eixo y

da.y_label.font_style = 2; //ajuste do tipo da fonte do eixo y

//geraçao do grafico

subplot(325);

plot2d(tcut,acl_mat_li_863006_cut(:,4)); //grafico do deslocamento Yc_li

xtitle(' ','t (s)','Tetacz (rad/s2)'); //titulos do grafico, eixo x e x

//ajuste do grafico

a=get("current_axes");

a.font_size $=1 ; \quad$ //ajuste do tamanho da fonte da escala

a.font_style $=2 ; \quad$ //ajuste do tipo da fonte da escala

a.grid $=[4,4]$; $\quad$ //ajuste das cores dos eixos secundarios

a.figure_size $=[800,400]$;

//Não linear

//ajuste do titulo e identificação dos eixos

$\mathrm{da}=\mathrm{gda}()$;

da.title.font_size $=4$; //ajuste do tamanho da fonte do titulo do grafico

da.title.font_style $=2$; //ajuste do tipo da fonte do titulo do grafico

da.x_label.font_size $=3$; //ajuste do tamanho do titulo do eixo $\mathrm{x}$

da.x_label.font_style $=2$; //ajuste do tipo da fonte do eixo $\mathrm{x}$

da.y_label.font_size = 3; //ajuste do tamanho do titulo do eixo y

da.y_label.font_style = 2; //ajuste do tipo da fonte do eixo y

//geraçao do grafico

subplot(326);

plot2d(tcut,acl_mat_nli_863006_cut(:,4)); //grafico do deslocamento Yc_nli

xtitle(' ','t (s)','Tetacz (rad/s2)'); //titulos do grafico, eixo x e x

//ajuste do grafico

a=get("current_axes");

a.font_size $=1 ; \quad$ //ajuste do tamanho da fonte da escala

a.font_style $=2 ; \quad$ //ajuste do tipo da fonte da escala

a.grid $=[4,4] ; \quad$ //ajuste das cores dos eixos secundarios

a.figure_size $=[800,400]$;

//Grafico das frequëncias e velocidades

vel $=\mathrm{vi}+\mathrm{acl} * \mathrm{t}$;

frequencia=vel/lambda; 
//Yc linear e não linear

f1=scf(3); //criação do grafico

//velocidade

//ajuste do titulo e identificação dos eixos

da=gda();

da.title.font_size $=4$; //ajuste do tamanho da fonte do titulo do grafico

da.title.font_style $=2$; //ajuste do tipo da fonte do titulo do grafico

da.x_label.font_size = 3; //ajuste do tamanho do titulo do eixo $\mathrm{x}$

da.x_label.font_style $=2$; //ajuste do tipo da fonte do eixo $\mathrm{x}$

da.y_label.font_size = 3; //ajuste do tamanho do titulo do eixo y

da.y_label.font_style = 2; //ajuste do tipo da fonte do eixo y

//geraçao do grafico

subplot(121);

plot2d(t,vel); //grafico do deslocamento Yc_li

xtitle('Velocidade','t (s)','V (m/s)'); //titulos do grafico, eixo x e x

//ajuste do grafico

a=get("current_axes");

a.font_size $=1 ; \quad$ //ajuste do tamanho da fonte da escala

a.font_style $=2 ; \quad$ //ajuste do tipo da fonte da escala

a.grid $=[4,4]$; $\quad$ //ajuste das cores dos eixos secundarios

a.figure_size $=[800,135]$;

//velocidade

//ajuste do titulo e identificação dos eixos

$\mathrm{da}=\mathrm{gda}()$;

da.title.font_size $=4$; //ajuste do tamanho da fonte do titulo do grafico

da.title.font_style $=2$; //ajuste do tipo da fonte do titulo do grafico

da.x_label.font_size = 3; //ajuste do tamanho do titulo do eixo $\mathrm{x}$

da.x_label.font_style $=2$; //ajuste do tipo da fonte do eixo $\mathrm{x}$

da.y_label.font_size $=3$; //ajuste do tamanho do titulo do eixo y

da.y_label.font_style $=2$; //ajuste do tipo da fonte do eixo y

//geraçao do grafico

subplot(122);

plot2d(t,frequencia); //grafico do deslocamento Yc_li

xtitle('Freqüência de excitação','t (s)','f (Hz)'); //titulos do grafico, eixo x e x

//ajuste do grafico

a=get("current_axes");

a.font_size $=1 ; \quad$ //ajuste do tamanho da fonte da escala

a.font_style $=2 ; \quad$ //ajuste do tipo da fonte da escala

a.grid $=[4,4]$; $\quad$ //ajuste das cores dos eixos secundarios

a.figure_size $=[800,135]$;

$/ / * * * * * * * * * * * * * * * * * * * * * * * * * * * * * * * * * * * * * * * * * * * * * * * * * * * * * * * * * * * * * * * * * * * * * * * * * *$

$* * * *$

//gravação dos resultados

fprintfMat ('C: Documentos de

trabalho\scicos\scicos_863006\result_scicos_li_863006.txt',acl_mat_li_863006); 
fprintfMat ('C: Documentos de trabalholscicos\scicos_863006\result_scicos_li_863006.txt',mat_li_863006);

fprintfMat ('C:IDocumentos de trabalholscicos $\backslash$ scicos_863006\mat_max_acl_li_863006.txt',mat_max_acl_li); fprintfMat ('C: Documentos de trabalholscicos\scicos_863006\mat_max_acl_nli_863006.txt',mat_max_acl_nli); 


\section{Apêndice H - Resultados do solução por integração numérica}

Este programa acha os máximos do deslocamento e aceleração e aceleração rms a partir dos resultados gerados pelo simulador de diagrama de blocos.

clear

// carregamento dos dados de entrada

exec('C:IDocumentos de trabalho\dadosdeentrada.sci');disp('exec done');

$\mathrm{t}=0$ :deltat:tfinal; //vetor tempo deslocamento

$\mathrm{t}=\mathrm{t}^{\prime}$;

tacl=0:deltat:(tfinal-deltat); //vetor tempo aceleraçao - uma unidade menor que deslocamento tacl=tacl';

$\mathrm{pi}=(\mathrm{tfinal} / 2) /$ deltat;

$\mathrm{pf}=($ tfinal $) /$ deltat;

tcut $=(0:$ deltat:(pf-pi)*deltat)';

//

//carregamento dos vetores lineares Yc

aux_430000=fscanfMat ('C: Documentos de trabalholscicos\scicos_430000lyc_li.txt');

yc_li_430000=aux_430000(:,2);

aux_430000=fscanfMat ('C:IDocumentos de trabalholscicos $\backslash$ scicos_430000\acl_yc_li.txt');

acl_yc_li_430000=aux_430000(:,2);

aux_736941=fscanfMat ('C:IDocumentos de trabalholscicos\scicos_736941\yc_li.txt');

yc_li_736941=aux_736941(:,2);

aux_736941=fscanfMat ('C:IDocumentos de trabalholscicos $\backslash$ scicos_736941\acl_yc_li.txt');

acl_yc_li_736941=aux_736941(:,2);

aux_753863=fscanfMat ('C:IDocumentos de trabalholscicos\scicos_753863\yc_li.txt');

yc_li_753863=aux_753863(:,2);

aux_753863=fscanfMat ('C:IDocumentos de trabalholscicos $\backslash$ scicos_753863\acl_yc_li.txt');

acl_yc_li_753863=aux_753863(:,2);

aux_793962=fscanfMat ('C:IDocumentos de trabalholscicos\scicos_793962\yc_li.txt');

yc_li_793962=aux_793962(:,2);

aux_793962=fscanfMat ('C:\Documentos de trabalholscicos $\backslash$ scicos_793962\acl_yc_li.txt'); acl_yc_li_793962=aux_793962(:,2);

aux_863006=fscanfMat ('C:\Documentos de trabalholscicos\scicos_863006lyc_li.txt');

yc_li_863006=aux_863006(:,2);

aux_863006=fscanfMat ('C:IDocumentos de trabalholscicos $\backslash$ scicos_863006\acl_yc_li.txt'); 
acl_yc_li_863006=aux_863006(:,2);

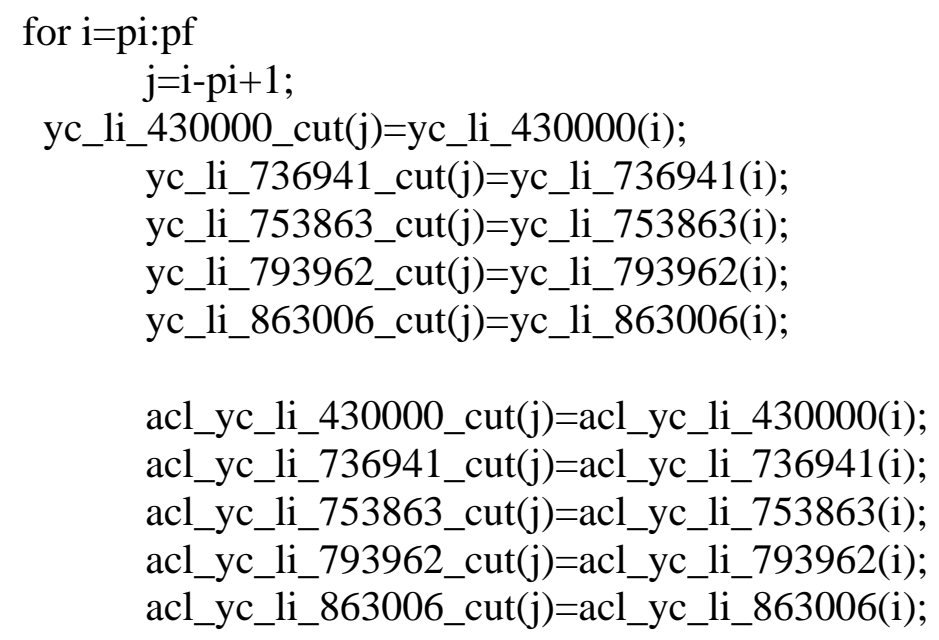

end

max_yc_li_430000_cut $=\max \left(y c \_l i \_430000 \_c u t\right) ;$

max_yc_li_736941_cut $=\max (y c$ _li_736941_cut);

max_yc_li_753863_cut $=\max \left(y c \_l i \_753863\right.$ _cut);

max_yc_li_793962_cut $=\max \left(y c \_l i \_793962 \_c u t\right) ;$

max_yc_li_863006_cut=max(yc_li_863006_cut);

max_acl_yc_li_430000_cut=max(acl_yc_li_430000_cut);

max_acl_yc_li_736941_cut=max(acl_yc_li_736941_cut);

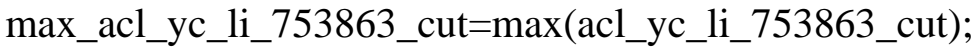

max_acl_yc_li_793962_cut $=\max ($ acl_yc_li_793962_cut);

max_acl_yc_li_863006_cut=max(acl_yc_li_863006_cut);

rms_acl_yc_li_430000=((inttrap(tcut, $((($ acl_yc_li_430000_cut).^2) $))) /($ tfinal $/ 2))^{\wedge} 0.5$;

//aceleraçao ponderada rms segundo a definicao $1 \S 6.1$ ISO2631

rms_acl_yc_li_736941=((inttrap(tcut, $((($ acl_yc_li_736941_cut $) . \wedge 2)))) /($ tfinal/2) $) \wedge 0.5$;

//aceleraçao ponderada rms segundo a definicao $1 \S 6.1$ ISO2631

rms_acl_yc_li_753863=((inttrap(tcut, $((($ acl_yc_li_753863_cut).$\wedge 2)))) /($ tfinal/2) $))^{\wedge 0.5 \text {; }}$

//aceleraçao ponderada rms segundo a definicao $1 \S 6.1$ ISO2631

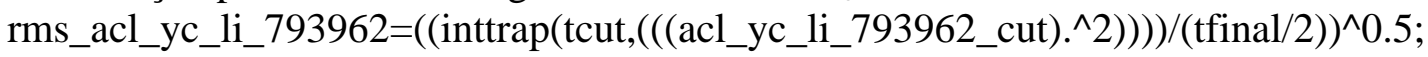

//aceleraçao ponderada rms segundo a definicao $1 \S 6.1$ ISO2631

rms_acl_yc_li_863006=((inttrap(tcut, $(((\text { acl_yc_li_863006_cut).^2)) })) /(\text { tfinal/2) }))^{\wedge} 0.5$;

//aceleraçao ponderada rms segundo a definicao $1 \S 6.1$ ISO2631

mat_max_acl_yc_li=[

430000, max_yc_li_430000_cut, max_acl_yc_li_430000_cut, rms_acl_yc_li_430000; 736941, max_yc_li_736941_cut, max_acl_yc_li_736941_cut, rms_acl_yc_li_736941; 753863, max_yc_li_753863_cut, max_acl_yc_li_753863_cut, rms_acl_yc_li_753863; 793962, max_yc_li_793962_cut, max_acl_yc_li_793962_cut, rms_acl_yc_li_793962;

863006, max_yc_li_863006_cut, max_acl_yc_li_863006_cut, rms_acl_yc_li_863006]; 
//carregamento dos vetores nao lineares Yc

aux_736941=fscanfMat ('C: Documentos de trabalholscicos\scicos_736941\yc_nli.txt'); yc_nli_736941=aux_736941(:,2);

aux_736941=fscanfMat ('C:IDocumentos de trabalholscicos $\backslash$ scicos_736941\acl_yc_nli.txt'); acl_yc_nli_736941=aux_736941(:,2);

aux_753863=fscanfMat ('C:IDocumentos de trabalholscicos\scicos_753863\yc_nli.txt'); yc_nli_753863=aux_753863(:,2);

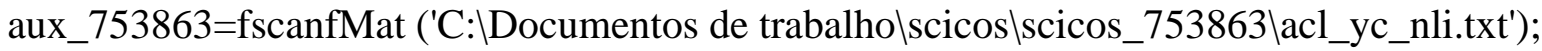
acl_yc_nli_753863=aux_753863(:,2);

aux_793962=fscanfMat ('C: Documentos de trabalholscicos\scicos_793962lyc_nli.txt'); yc_nli_793962=aux_793962(:,2);

aux_793962=fscanfMat ('C:IDocumentos de trabalholscicos $\backslash$ scicos_793962\acl_yc_nli.txt'); acl_yc_nli_793962=aux_793962(:,2);

aux_863006=fscanfMat ('C:(Documentos de trabalholscicos $\backslash$ scicos_863006lyc_nli.txt'); yc_nli_863006=aux_863006(:,2);

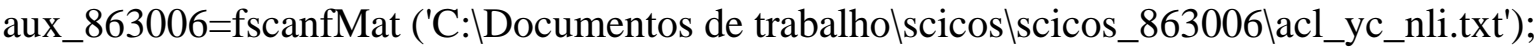
acl_yc_nli_863006=aux_863006(:,2);

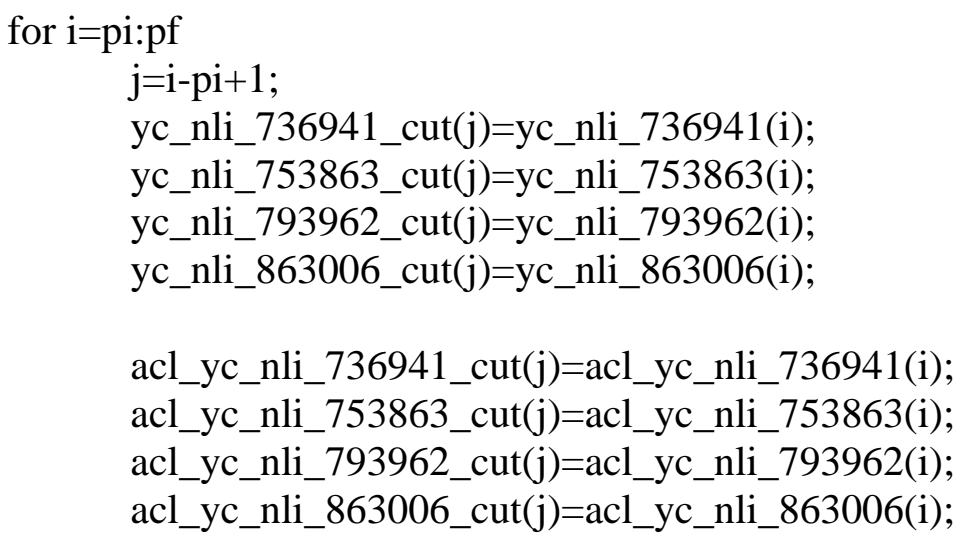

end

max_yc_nli_736941_cut=max(yc_nli_736941_cut);

max_yc_nli_753863_cut $=\max ($ yc_nli_753863_cut);

max_yc_nli_793962_cut=max(yc_nli_793962_cut);

max_yc_nli_863006_cut=max(yc_nli_863006_cut);

max_acl_yc_nli_736941_cut=max(acl_yc_nli_736941_cut);

max_acl_yc_nli_753863_cut=max(acl_yc_nli_753863_cut);

max_acl_yc_nli_793962_cut=max(acl_yc_nli_793962_cut);

max_acl_yc_nli_863006_cut=max(acl_yc_nli_863006_cut);

rms_acl_yc_nli_736941=((inttrap(tcut, $((($ acl_yc_nli_736941_cut).^2) $))) /($ tfinal/2) $) \wedge 0.5$;

//aceleraçao ponderada rms segundo a definicao $1 \S 6.1$ ISO2631 
rms_acl_yc_nli_753863=((inttrap(tcut, $((($ acl_yc_nli_753863_cut).^2) $))) /($ tfinal/2) $))^{\wedge} 0.5$;

//aceleraçao ponderada rms segundo a definicao $1 \S 6.1$ ISO2631

rms_acl_yc_nli_793962=((inttrap(tcut, $((($ acl_yc_nli_793962_cut $) . \wedge 2)))) /($ tfinal/2) $))^{\wedge} 0.5$;

//aceleraçao ponderada rms segundo a definicao 1§6.1 ISO2631

rms_acl_yc_nli_863006=((inttrap(tcut, $((($ acl_yc_nli_863006_cut $) . \wedge 2)))) /($ tfinal/2) $))^{\wedge} 0.5$;

//aceleraçao ponderada rms segundo a definicao $1 \S 6.1$ ISO2631

mat_max_acl_yc_nli=[

736941, max_yc_nli_736941_cut, max_acl_yc_nli_736941_cut, rms_acl_yc_nli_736941;

753863, max_yc_nli_753863_cut, max_acl_yc_nli_753863_cut, rms_acl_yc_nli_753863;

793962, max_yc_nli_793962_cut, max_acl_yc_nli_793962_cut, rms_acl_yc_nli_793962;

863006, max_yc_nli_863006_cut, max_acl_yc_nli_863006_cut, rms_acl_yc_nli_863006];

$/ /$

//carregamento dos vetores lineares tetacx

aux_430000=fscanfMat ('C:(Documentos de trabalho\scicos $\backslash$ scicos_430000\tetacx_li.txt'); tetacx_li_430000=aux_430000(:,2);

aux_430000=fscanfMat ('C: (Documentos de trabalholscicos $\backslash$ scicos_430000\acl_tetacx_li.txt');

acl_tetacx_li_430000=aux_430000(:,2);

aux_736941=fscanfMat ('C:IDocumentos de trabalholscicos\scicos_736941\tetacx_li.txt'); tetacx_li_736941=aux_736941(:,2);

aux_736941=fscanfMat ('C:|Documentos de trabalholscicos $\backslash$ scicos_736941\acl_tetacx_li.txt'); acl_tetacx_li_736941=aux_736941(:,2);

aux_753863=fscanfMat ('C:IDocumentos de trabalholscicoslscicos_753863\tetacx_li.txt'); tetacx_li_753863=aux_753863(:,2);

aux_753863=fscanfMat ('C:|Documentos de trabalholscicos $\backslash$ scicos_753863\acl_tetacx_li.txt');

acl_tetacx_li_753863=aux_753863(:,2);

aux_793962=fscanfMat ('C:(Documentos de trabalho\scicos\scicos_793962\tetacx_li.txt'); tetacx_li_793962=aux_793962(:,2);

aux_793962=fscanfMat ('C:IDocumentos de trabalholscicos\scicos_793962lacl_tetacx_li.txt'); acl_tetacx_li_793962=aux_793962(:,2);

aux_863006=fscanfMat ('C:IDocumentos de trabalho\scicos\scicos_863006\tetacx_li.txt'); tetacx_li_863006=aux_863006(:,2);

aux_863006=fscanfMat ('C:(Documentos de trabalholscicos $\backslash$ scicos_863006lacl_tetacx_li.txt'); acl_tetacx_li_863006=aux_863006(:,2);

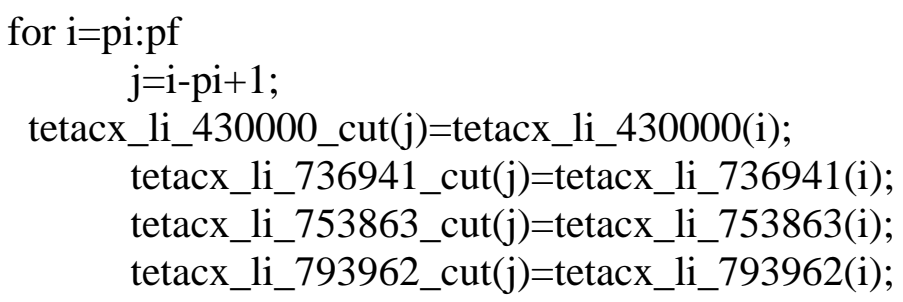


tetacx_li_863006_cut(j)=tetacx_li_863006(i);

acl_tetacx_li_430000_cut(j)=acl_tetacx_li_430000(i);

acl_tetacx_li_736941_cut(j)=acl_tetacx_li_736941(i);

acl_tetacx_li_753863_cut(j)=acl_tetacx_li_753863(i);

acl_tetacx_li_793962_cut(j)=acl_tetacx_li_793962(i);

acl_tetacx_li_863006_cut(j)=acl_tetacx_li_863006(i);

end

max_tetacx_li_430000_cut=max(tetacx_li_430000_cut);

max_tetacx_li_736941_cut=max(tetacx_li_736941_cut);

max_tetacx_li_753863_cut=max(tetacx_li_753863_cut);

max_tetacx_li_793962_cut=max(tetacx_li_793962_cut);

max_tetacx_li_863006_cut=max(tetacx_li_863006_cut);

max_acl_tetacx_li_430000_cut=max(acl_tetacx_li_430000_cut);

max_acl_tetacx_li_736941_cut=max(acl_tetacx_li_736941_cut);

max_acl_tetacx_li_753863_cut=max(acl_tetacx_li_753863_cut);

max_acl_tetacx_li_793962_cut=max(acl_tetacx_li_793962_cut);

max_acl_tetacx_li_863006_cut=max(acl_tetacx_li_863006_cut);

rms_acl_tetacx_li_430000=((inttrap(tcut, $(((\text { acl_tetacx_li_430000_cut).^2)) })) /(\text { tfinal/2) }))^{\wedge} 0.5$;

//aceleraçao ponderada rms segundo a definicao $1 \S 6.1$ ISO2631

rms_acl_tetacx_li_736941=((inttrap(tcut,(((acl_tetacx_li_736941_cut).^2))) $) /($ tfinal/2) $))^{\wedge} 0.5$;

//aceleraçao ponderada rms segundo a definicao $1 \S 6.1$ ISO2631

rms_acl_tetacx_li_753863=((inttrap(tcut,(((acl_tetacx_li_753863_cut).^2))) $) /($ tfinal/2) $) \wedge 0.5$;

//aceleraçao ponderada rms segundo a definicao $1 \S 6.1$ ISO2631

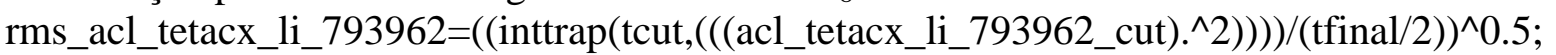

//aceleraçao ponderada rms segundo a definicao $1 \S 6.1$ ISO2631

rms_acl_tetacx_li_863006=((inttrap(tcut,(((acl_tetacx_li_863006_cut).^2))) $) /($ tfinal/2) $) \wedge 0.5$;

//aceleraçao ponderada rms segundo a definicao $1 \S 6.1$ ISO2631

mat_max_acl_tetacx_li=[

430000, max_tetacx_li_430000_cut, max_acl_tetacx_li_430000_cut,

rms_acl_tetacx_li_430000;

736941, max_tetacx_li_736941_cut, max_acl_tetacx_li_736941_cut,

rms_acl_tetacx_li_736941;

753863, max_tetacx_li_753863_cut, max_acl_tetacx_li_753863_cut, rms_acl_tetacx_li_753863;

793962, max_tetacx_li_793962_cut, max_acl_tetacx_li_793962_cut, rms_acl_tetacx_li_793962;

863006, max_tetacx_li_863006_cut, max_acl_tetacx_li_863006_cut, rms_acl_tetacx_li_863006];

//carregamento dos vetores nao lineares tetacx

aux_736941=fscanfMat ('C:IDocumentos de trabalholscicos\scicos_736941\tetacx_nli.txt'); 
tetacx_nli_736941=aux_736941(:,2);

aux_736941=fscanfMat ('C: Documentos de

trabalho\scicos\scicos_736941\acl_tetacx_nli.txt');

acl_tetacx_nli_736941=aux_736941(:,2);

aux_753863=fscanfMat ('C: Documentos de trabalholscicos $\backslash$ scicos_753863\tetacx_nli.txt');

tetacx_nli_753863=aux_753863(:,2);

aux_753863=fscanfMat ('C: $:$ Documentos de

trabalho\scicos\scicos_753863\acl_tetacx_nli.txt');

acl_tetacx_nli_753863=aux_753863(:,2);

aux_793962=fscanfMat ('C:|Documentos de trabalholscicos\scicos_793962\tetacx_nli.txt');

tetacx_nli_793962=aux_793962(:,2);

aux_793962=fscanfMat ('C: Documentos de

trabalho\scicos\scicos_793962\acl_tetacx_nli.txt');

acl_tetacx_nli_793962=aux_793962(:,2);

aux_863006=fscanfMat ('C: Documentos de trabalholscicos $\backslash$ scicos_863006\tetacx_nli.txt');

tetacx_nli_863006=aux_863006(:,2);

aux_863006=fscanfMat ('C:IDocumentos de

trabalho $\backslash$ scicos $\backslash$ scicos_863006\acl_tetacx_nli.txt');

acl_tetacx_nli_863006=aux_863006(:,2);

for $i=p i: p f$

$$
\begin{aligned}
& \text { j=i-pi+1; } \\
& \text { tetacx_nli_736941_cut(j)=tetacx_nli_736941(i); } \\
& \text { tetacx_nli_753863_cut(j)=tetacx_nli_753863(i); } \\
& \text { tetacx_nli_793962_cut(j)=tetacx_nli_793962(i); } \\
& \text { tetacx_nli_863006_cut(j)=tetacx_nli_863006(i); }
\end{aligned}
$$

acl_tetacx_nli_736941_cut(j)=acl_tetacx_nli_736941(i);

acl_tetacx_nli_753863_cut(j)=acl_tetacx_nli_753863(i);

acl_tetacx_nli_793962_cut(j)=acl_tetacx_nli_793962(i);

acl_tetacx_nli_863006_cut(j)=acl_tetacx_nli_863006(i);

end

max_tetacx_nli_736941_cut=max(tetacx_nli_736941_cut);

max_tetacx_nli_753863_cut=max(tetacx_nli_753863_cut);

max_tetacx_nli_793962_cut=max(tetacx_nli_793962_cut);

max_tetacx_nli_863006_cut=max(tetacx_nli_863006_cut);

max_acl_tetacx_nli_736941_cut=max(acl_tetacx_nli_736941_cut);

max_acl_tetacx_nli_753863_cut=max(acl_tetacx_nli_753863_cut);

max_acl_tetacx_nli_793962_cut=max(acl_tetacx_nli_793962_cut);

max_acl_tetacx_nli_863006_cut=max(acl_tetacx_nli_863006_cut);

rms_acl_tetacx_nli_736941=((inttrap(tcut, $((($ acl_tetacx_nli_736941_cut).^2) $))) /($ tfinal/2) $) \wedge 0.5$ ; //aceleraçao ponderada rms segundo a definicao 1§6.1 ISO2631 
rms_acl_tetacx_nli_753863=((inttrap(tcut, $((($ acl_tetacx_nli_753863_cut).^2) $))) /($ tfinal/2) $) \wedge 0.5$ ; //aceleraçao ponderada rms segundo a definicao 1§6.1 ISO2631

rms_acl_tetacx_nli_793962=((inttrap(tcut, $((($ acl_tetacx_nli_793962_cut).^2) $))) /($ tfinal/2) $) \wedge 0.5$ ; //aceleraçao ponderada rms segundo a definicao 1§6.1 ISO2631

rms_acl_tetacx_nli_863006=((inttrap(tcut, $((($ acl_tetacx_nli_863006_cut).^2) $))) /($ tfinal/2) $) \wedge 0.5$ ; //aceleraçao ponderada rms segundo a definicao $1 \S 6.1$ ISO2631

mat_max_acl_tetacx_nli=[

736941, max_tetacx_nli_736941_cut, max_acl_tetacx_nli_736941_cut, rms_acl_tetacx_nli_736941;

753863, max_tetacx_nli_753863_cut, max_acl_tetacx_nli_753863_cut, rms_acl_tetacx_nli_753863;

793962, max_tetacx_nli_793962_cut, max_acl_tetacx_nli_793962_cut, rms_acl_tetacx_nli_793962;

863006, max_tetacx_nli_863006_cut, max_acl_tetacx_nli_863006_cut, rms_acl_tetacx_nli_863006];

$/ 1$

//carregamento dos vetores lineares tetacz

aux_430000=fscanfMat ('C:IDocumentos de trabalholscicos $\backslash$ scicos_430000\tetacz_li.txt'); tetacz_li_430000=aux_430000(:,2);

aux_430000=fscanfMat ('C:|Documentos de trabalholscicos $\left.\backslash s c i c o s \_430000 \backslash a c l \_t e t a c z \_l i . t x t '\right)$; acl_tetacz_li_430000=aux_430000(:,2);

aux_736941=fscanfMat ('C:IDocumentos de trabalholscicos\scicos_736941\tetacz_li.txt'); tetacz_li_736941=aux_736941(:,2);

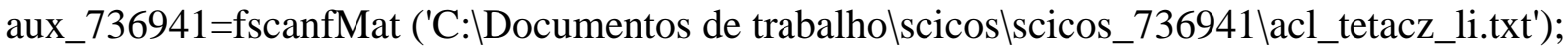
acl_tetacz_li_736941=aux_736941(:,2);

aux_753863=fscanfMat ('C:(Documentos de trabalholscicos\scicos_753863\tetacz_li.txt'); tetacz_li_753863=aux_753863(:,2);

aux_753863=fscanfMat ('C:IDocumentos de trabalholscicos $\backslash$ scicos_753863\acl_tetacz_li.txt'); acl_tetacz_li_753863=aux_753863(:,2);

aux_793962=fscanfMat ('C:IDocumentos de trabalholscicos\scicos_793962\tetacz_li.txt'); tetacz_li_793962=aux_793962(:,2);

aux_793962=fscanfMat ('C:\Documentos de trabalholscicos\scicos_793962\acl_tetacz_li.txt'); acl_tetacz_li_793962=aux_793962(:,2);

aux_863006=fscanfMat ('C:IDocumentos de trabalholscicos\scicos_863006\tetacz_li.txt'); tetacz_li_863006=aux_863006(:,2);

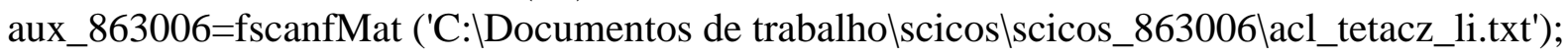
acl_tetacz_li_863006=aux_863006(:,2);

for i=pi:pf

$$
\mathrm{j}=\mathrm{i}-\mathrm{pi}+1 \text {; }
$$


tetacz_li_430000_cut(j)=tetacz_li_430000(i);

tetacz_li_736941_cut(j)=tetacz_li_736941(i);

tetacz_li_753863_cut(j)=tetacz_li_753863(i);

tetacz_li_793962_cut(j)=tetacz_li_793962(i);

tetacz_li_863006_cut(j)=tetacz_li_863006(i);

acl_tetacz_li_430000_cut(j)=acl_tetacz_li_430000(i);

acl_tetacz_li_736941_cut(j)=acl_tetacz_li_736941(i);

acl_tetacz_li_753863_cut(j)=acl_tetacz_li_753863(i);

acl_tetacz_li_793962_cut(j)=acl_tetacz_li_793962(i);

acl_tetacz_li_863006_cut(j)=acl_tetacz_li_863006(i);

end

max_tetacz_li_430000_cut=max(tetacz_li_430000_cut);

max_tetacz_li_736941_cut=max(tetacz_li_736941_cut);

max_tetacz_li_753863_cut $=\max ($ tetacz_li_753863_cut);

max_tetacz_li_793962_cut $=\max ($ tetacz_li_793962_cut);

max_tetacz_li_863006_cut=max(tetacz_li_863006_cut);

max_acl_tetacz_li_430000_cut=max(acl_tetacz_li_430000_cut);

max_acl_tetacz_li_736941_cut=max(acl_tetacz_li_736941_cut);

max_acl_tetacz_li_753863_cut=max(acl_tetacz_li_753863_cut);

max_acl_tetacz_li_793962_cut=max(acl_tetacz_li_793962_cut);

max_acl_tetacz_li_863006_cut=max(acl_tetacz_li_863006_cut);

rms_acl_tetacz_li_430000=((inttrap(tcut, $((($ acl_tetacz_li_430000_cut).^2) $))) /($ tfinal/2) $) \wedge 0.5$;

//aceleraçao ponderada rms segundo a definicao $1 \S 6.1$ ISO2631

rms_acl_tetacz_li_736941=((inttrap(tcut, $((($ acl_tetacz_li_736941_cut $) . \wedge 2)))) /($ tfinal/2) $))^{\wedge} 0.5$;

//aceleraçao ponderada rms segundo a definicao $1 \S 6.1$ ISO2631

rms_acl_tetacz_li_753863=((inttrap(tcut, $((($ acl_tetacz_li_753863_cut).^2) $))) /($ tfinal/2) $))^{\wedge 0.5}$;

//aceleraçao ponderada rms segundo a definicao 1§6.1 ISO2631

rms_acl_tetacz_li_793962=((inttrap(tcut,(((acl_tetacz_li_793962_cut).^2)) ))/(tfinal/2) $)^{\wedge} 0.5$;

//aceleraçao ponderada rms segundo a definicao $1 \S 6.1$ ISO2631

rms_acl_tetacz_li_863006=((inttrap(tcut, $((($ acl_tetacz_li_863006_cut).^2) $))) /($ tfinal/2) $))^{\wedge 0.5}$;

//aceleraçao ponderada rms segundo a definicao 1§6.1 ISO2631

mat_max_acl_tetacz_li=[

430000, max_tetacz_li_430000_cut, max_acl_tetacz_li_430000_cut, rms_acl_tetacz_li_430000;

736941, max_tetacz_li_736941_cut, max_acl_tetacz_li_736941_cut, rms_acl_tetacz_li_736941;

753863, max_tetacz_li_753863_cut, max_acl_tetacz_li_753863_cut, rms_acl_tetacz_li_753863;

793962, max_tetacz_li_793962_cut, max_acl_tetacz_li_793962_cut, rms_acl_tetacz_li_793962;

863006, max_tetacz_li_863006_cut, max_acl_tetacz_li_863006_cut, rms_acl_tetacz_li_863006]; 
//carregamento dos vetores nao lineares tetacz

aux_736941=fscanfMat ('C:LDocumentos de trabalholscicoslscicos_736941|tetacz_nli.txt'); tetacz_nli_736941=aux_736941(:,2);

aux_736941=fscanfMat ('C: Documentos de

trabalholscicos $\backslash$ scicos_736941\acl_tetacz_nli.txt');

acl_tetacz_nli_736941=aux_736941(:,2);

aux_753863=fscanfMat ('C:LDocumentos de trabalholscicoslscicos_753863ltetacz_nli.txt'); tetacz_nli_753863=aux_753863(:,2);

aux_753863=fscanfMat ('C:IDocumentos de

trabalholscicos $\backslash$ scicos_753863lacl_tetacz_nli.txt');

acl_tetacz_nli_753863=aux_753863(:,2);

aux_793962=fscanfMat ('C:IDocumentos de trabalholscicoslscicos_793962ltetacz_nli.txt');

tetacz_nli_793962=aux_793962(:,2);

aux_793962=fscanfMat ('C:Locumentos de

trabalholscicos\scicos_793962lacl_tetacz_nli.txt');

acl_tetacz_nli_793962=aux_793962(:,2);

aux_863006=fscanfMat ('C:LDocumentos de trabalholscicoslscicos_863006ltetacz_nli.txt');

tetacz_nli_863006=aux_863006(:,2);

aux_863006=fscanfMat ('C:Locumentos de

trabalholscicos $\mid s c i c o s \_863006$ acl_tetacz_nli.txt');

acl_tetacz_nli_863006=aux_863006(:,2);

for i=pi:pf

$$
\begin{aligned}
& \text { j=i-pi+1; } \\
& \text { tetacz_nli_736941_cut(j)=tetacz_nli_736941(i); } \\
& \text { tetacz_nli_753863_cut(j)=tetacz_nli_753863(i); } \\
& \text { tetacz_nli_793962_cut(j)=tetacz_nli_793962(i); } \\
& \text { tetacz_nli_863006_cut(j)=tetacz_nli_863006(i); } \\
& \\
& \text { acl_tetacz_nli_736941_cut(j)=acl_tetacz_nli_736941(i); } \\
& \text { acl_tetacz_nli7753863_cut(j)=acl_tetacz_nli_753863(i); } \\
& \text { ac_ttetacz_nli_793962_cut(j)=acl_tetacz_nli_793962(i); } \\
& \text { acl_tetacz_nli_863006_cut(j)=acl_tetacz_nli_863006(i); }
\end{aligned}
$$

end

max_tetacz_nli_736941_cut=max(tetacz_nli_736941_cut);

max_tetacz_nli_753863_cut=max(tetacz_nli_753863_cut);

max_tetacz_nli_793962_cut=max(tetacz_nli_793962_cut);

max_tetacz_nli_863006_cut=max(tetacz_nli_863006_cut);

max_acl_tetacz_nli_736941_cut=max(acl_tetacz_nli_736941_cut);

max_acl_tetacz_nli_753863_cut=max(acl_tetacz_nli_753863_cut);

max_acl_tetacz_nli_793962_cut=max(acl_tetacz_nli_793962_cut);

max_acl_tetacz_nli_863006_cut=max(acl_tetacz_nli_863006_cut); 
rms_acl_tetacz_nli_736941=((inttrap(tcut, $((($ acl_tetacz_nli_736941_cut).^2) $))) /($ tfinal/2) $) \wedge 0.5$; //aceleraçao ponderada rms segundo a definicao $1 \S 6.1$ ISO2631

rms_acl_tetacz_nli_753863=((inttrap(tcut, $((($ acl_tetacz_nli_753863_cut).^2)) $)) /($ tfinal/2) $) \wedge 0.5$; //aceleraçao ponderada rms segundo a definicao 1§6.1 ISO2631

rms_acl_tetacz_nli_793962=((inttrap(tcut, $(((\text { acl_tetacz_nli_793962_cut).^2)) })) /(\text { tfinal/2) }))^{\wedge} 0.5$; //aceleraçao ponderada rms segundo a definicao $1 \S 6.1$ ISO2631

rms_acl_tetacz_nli_863006=((inttrap(tcut, $(((\text { acl_tetacz_nli_863006_cut).^2)) })) /(\text { tfinal/2) }))^{\wedge} 0.5$; //aceleraçao ponderada rms segundo a definicao $1 \S 6.1$ ISO2631

mat_max_acl_tetacz_nli=[

736941, max_tetacz_nli_736941_cut, max_acl_tetacz_nli_736941_cut,

rms_acl_tetacz_nli_736941;

753863, max_tetacz_nli_753863_cut, max_acl_tetacz_nli_753863_cut,

rms_acl_tetacz_nli_753863;

793962, max_tetacz_nli_793962_cut, max_acl_tetacz_nli_793962_cut, rms_acl_tetacz_nli_793962;

863006, max_tetacz_nli_863006_cut, max_acl_tetacz_nli_863006_cut, rms_acl_tetacz_nli_863006];

$/ 1$

fprintfMat('C:(Documentos de trabalholscicos\mat_max_acl_yc_li.txt',mat_max_acl_yc_li);

fprintfMat('C:IDocumentos de trabalholscicos\mat_max_acl_yc_nli.txt',mat_max_acl_yc_nli); fprintfMat('C:IDocumentos de

trabalholscicos\mat_max_acl_tetacx_li.txt',mat_max_acl_tetacx_li);

fprintfMat('C:IDocumentos de

trabalho\scicos\mat_max_acl_tetacx_nli.txt',mat_max_acl_tetacx_nli);

fprintfMat('C:IDocumentos de

trabalholscicos\mat_max_acl_tetacz_li.txt',mat_max_acl_tetacz_li);

fprintfMat('C: Documentos de

trabalholscicos\mat_max_acl_tetacz_nli.txt',mat_max_acl_tetacz_nli);

mat_max_acl=[mat_max_acl_yc_li;mat_max_acl_yc_nli;mat_max_acl_tetacx_li;mat_max_a cl_tetacx_nli;mat_max_acl_tetacz_li;mat_max_acl_tetacz_nli];

fprintfMat('C:IDocumentos de trabalholscicos\mat_max_acl.txt',mat_max_acl); 


\section{Apêndice I - Dados de entrada}

Este programa contém os dados de entrada utilizados pelos demais. Com excessão da do valor da rigidez da suspensão secundária todos os demais são comuns para todas as simulações realizadas.

clear

//Dados de entrada a partir de hipoteses assumidas

tfinal=17; $\quad$ //Tempo de execução do modelo SCICOS a velocidade constante(s) deltat $=0.01 ; \quad / /$ Intervalo de tempo entre duas iterações sucessivas (s) lambda=11.88; $\quad$ //Comprimento de onda da irregularidade do trilho (m) $\mathrm{rm}=0.01 ; \quad$ //Amplitude da inregularidade do trilho (m) $\mathrm{v}=11.88$; /Velocidade de deslocamento do veiculo $(\mathrm{m} / \mathrm{s})$ lm=10;//Distância do banco na posição extrema da caixa a linha de centro transversal do veículo - assumindo a instalação do banco a 0,5m além da linha da suspensão secundaria a partir da linha de centro transversal do veiculo (m)

bm=1; //Distância do banco na posição extrema da caixa a linha de centro longitudinal do veículo - assumindo a instalação do banco sobre o alinhamento das suspensões secundárias de um mesmo lado do veiculo (m)

// Dados de entrada fornecidos pelo Benchmark Manchester

//Massa e inércia

$\mathrm{mc}=32000 ; \quad$ //Massa da caixa $(\mathrm{kg})$

$\mathrm{mt}=2615$; $\quad$ //Massa da armação do truque $(\mathrm{kg})$

icx=56800; //Momento de inercia longitudinal da caixa $\left(\mathrm{kg} \cdot \mathrm{m}^{2}\right)$

icy=1970000; //Momento de inercia transversal da caixa (kg.m²)

icz=1970000; //Momento de inercia vertical da caixa $\left(\mathrm{kg} \cdot \mathrm{m}^{2}\right)$

itx=1722; //Momento de inercia longitudinal do truque $\left(\mathrm{kg} . \mathrm{m}^{2}\right)$

//Rigidez e amortecimento

$\mathrm{kpz}=2440000$; //2 vezes a rigidez vertical da suspensao primaria $(\mathrm{N} / \mathrm{m})$

ksy=160000; //Rigidez lateral da suspensao secundaria (N/m)

$\mathrm{ksz}=430000$; //Rigidez vertical da suspensao secundaria (N/m)

kbt=940000; //Rigidez rotacional da barra de torção (Nm/rad)

cay=32000; //Amortecimento lateral truque-caixa (Ns/m) - dois por truque

$\mathrm{caz}=20000$; //Amortecimento vertical truque-caixa $(\mathrm{Ns} / \mathrm{m})$ - dois por truque

$\mathrm{cpz}=8000 ; \quad / / 2$ vezes o amortecimento vertical da suspensão primaria

csy=0; //Amortecimento horizontal da suspensao secundaria

csz=0; //Amortecimento vertical da suspensao secundaria 
//Dimensional do veiculo (m) - as referências entre parêntesis concernem a nomenclatura adotada pelo artigo

baz=1.3; / /Semi-distância entre amortecedores verticais (y6)

bp=1; //Semi-distância entre suspensões primárias (y1)

bs=1; //Semi-distância entre suspensões secundárias (y3)

hay=1.1; //Altura entre o centro de gravidade da caixa e o amortecedor horizontal - nota 1

hayt $=0.1$; $\quad$ //Altura entre o centro de gravidade da armação e o amortecedor horizontal nota 2

hm=0.470; //Altura do centro de gravidade da caixa em relação ao piso - nota 3 hs=0.9725; //Altura entre o centro de gravidade da caixa e o centro de aplicação de esforço da suspensão secundária - nota 4

hst=0.2275; //Altura entre o centro da armação do truque e o centro de aplicação de esforço da suspensão secundária - nota 5

lct=9.5; //Semi-distância entre os pivots dos truques ("bogie semi pivot spacing"=9.5m)

- nota 6

bb=1.435; //Bitola do trilho 


\section{Apêndice $\mathrm{J}$ - Cálculo das curvas de suspensão não linear}

clear

//Dados de entrada

mcsi=32000; //massa da caixa em kg

delta=0.0127; //amplitude maxima de movimento da suspensão

$\mathrm{w}=4$;

$\mathrm{fdx}=[1,1,1,1]$

fdxcut=[1,1,1,1,1];

if $\mathrm{w}==1$ then, //Tipo 203

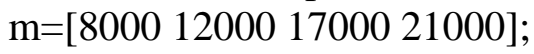

k=[2297 31894303 5195; 220330764168 5042; 209229624050 4920];

$\mathrm{h}=[8.59$ 10];

tipo='Suspensão S1';

end

if $\mathrm{w}==2$ then, //Tipo 29

$\mathrm{m}=\left[\begin{array}{lll}10000 & 160002100027000] \text {; }\end{array}\right.$

k=[2927 42595370 6702; 268539615024 6300; 262739074973 6253];

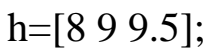

tipo='Suspensão S2';

end

if $\mathrm{w}==3$ then; //Tipo 218

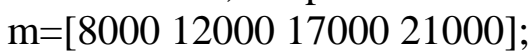

k=[2439 33824561 5504; 232832494399 5320; 225831734318 5233];

$\mathrm{h}=\left[\begin{array}{lll}8 & 9 & 9.5\end{array}\right]$;

tipo='Suspensão S3';

end

if $\mathrm{w}==4$ then; //Tipo 222

$\mathrm{m}=\left[\begin{array}{ll}15000 & 225003000037500] \text {; }\end{array}\right.$

$\mathrm{k}=[455263068061$ 9816; 433060317733 9435; 417958587538 9218];

$\mathrm{h}=\left[\begin{array}{ll}8 & 8.5\end{array}\right]$;

tipo='Suspensão S4';

end

pa $=(\mathrm{h}(1)+\mathrm{h}(3)) / 2$; //ponto médio de operaçao da suspensão

mc=round((mcsi/4)/0.45359237); //massa da caixa sobre cada suspensão em libra

sk=size(k); //variaveis auxiliares para a interpolaçao "m" e "k" 


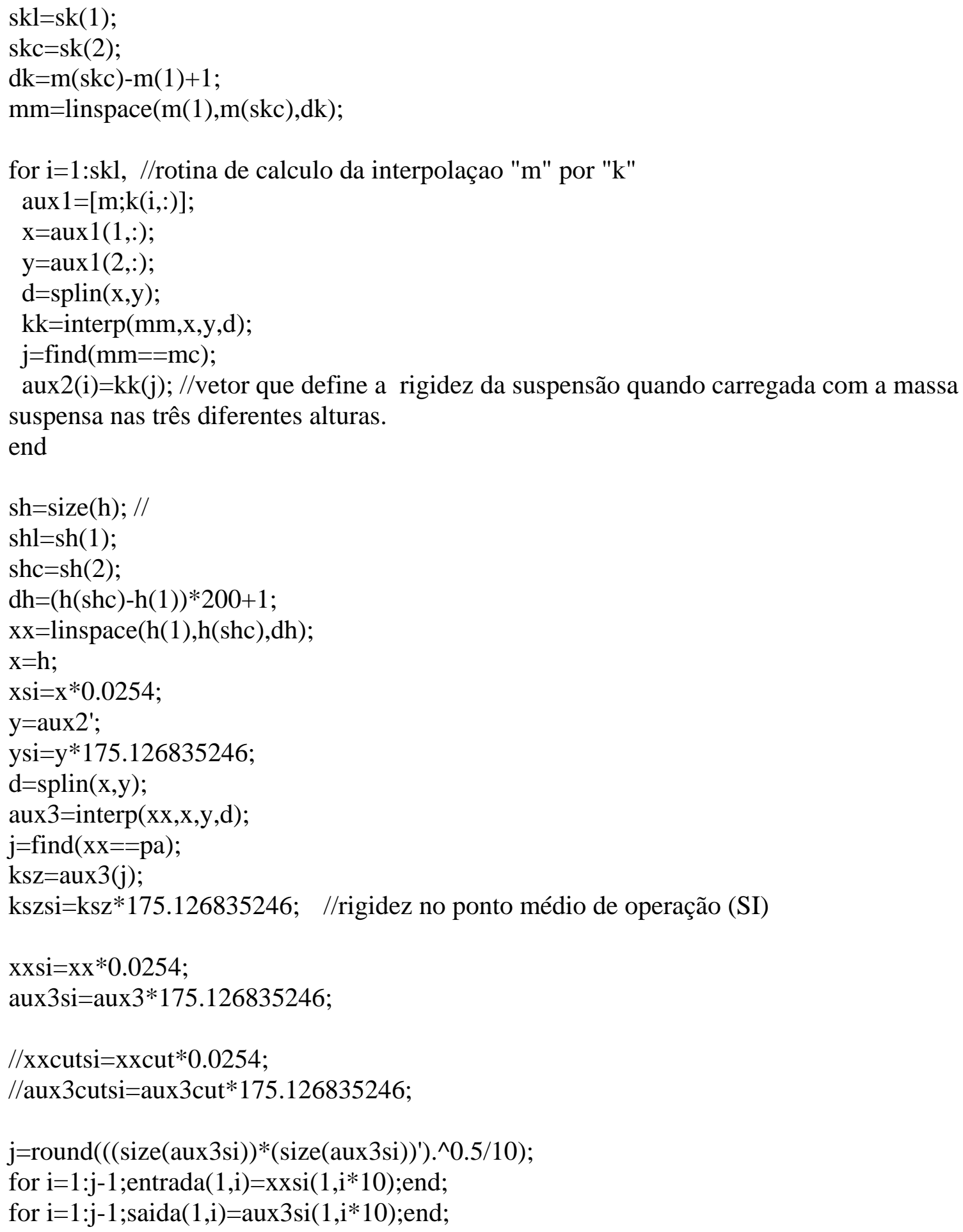

//Grafico entre alturas maxima e minima nominal (continuo) e curva na faixa de operação $\left(^{\circ}\right.$ ) e dos pontos

$\mathrm{f} 1=\operatorname{scf}(\mathrm{w})$;

//ajuste do titulo e identificação dos eixos $\mathrm{da}=\mathrm{gda}()$; da.title.font_size $=4$; //ajuste do tamanho da fonte do titulo do grafico da.title.font_style $=2$; //ajuste do tipo da fonte do titulo do grafico 
da.x_label.font_size = 3; //ajuste do tamanho do titulo do eixo $\mathrm{x}$ da.x_label.font_style $=2$; //ajuste do tipo da fonte do eixo $\mathrm{x}$ da.y_label.font_size $=3$; //ajuste do tamanho do titulo do eixo y da.y_label.font_style $=2$; //ajuste do tipo da fonte do eixo y //geraçao do grafico

plot2d(xxsi,aux3si); //curva entre alturas maxima e minima nominal //plot2d(xxcutsi,aux3cutsi,style=-2); //curva na faixa de operação plot2d(entrada,saida,style=-2); plot2d(xsi(1),ysi(1),style=-4); plot2d(xsi(2),ysi(2),style=-4); plot2d(xsi(3),ysi(3),style=-4); //Pontos de origem da curva entre alturas maxima e minima nominal xtitle([tipo],' Altura (m)','Rigidez (N/m)'); //titulos do grafico, eixo x e x //ajuste do grafico a=get("current_axes"); a.font size $=2$; //ajuste do tamanho da fonte da escala a.font_style = 2; $\quad$ //ajuste do tipo da fonte da escala a.grid $=[4,4] ; \quad$ //ajuste das cores dos eixos secundarios a.figure_size $=[800,333]$; limiteixo=a.data_bounds;

entrada $=$ string(entrada); entrada $=$ strcat(entrada,';'); print('C:IDocumentos de trabalholsuspensaolentrada.txt',entrada); saida=string(saida); saida=strcat(saida,';'); print('C: $\mid$ Documentos de trabalholsuspensaolsaida.txt',saida);

Tabela I.1 - Coordenadas dos pontos que definem as curves "Rigidez x Altura" das suspensões pneumáticas

\begin{tabular}{cccccccc}
\hline \multicolumn{2}{c}{ Suspensão S1 } & \multicolumn{2}{c}{ Suspensão S2 } & \multicolumn{2}{c}{ Suspensão S3 } & \multicolumn{2}{c}{ Suspensão S4 } \\
\hline $\begin{array}{c}\text { Altura } \\
(m)\end{array}$ & $\begin{array}{c}\text { Rigidez } \\
(\mathrm{N} / \mathrm{m})\end{array}$ & $\begin{array}{c}\text { Altura } \\
(m)\end{array}$ & $\begin{array}{c}\text { Rigidez } \\
(\mathrm{N} / \mathrm{m})\end{array}$ & $\begin{array}{c}\text { Altura } \\
(m)\end{array}$ & $\begin{array}{c}\text { Rigidez } \\
(\mathrm{N} / \mathrm{m})\end{array}$ & $\begin{array}{c}\text { Altura } \\
(m)\end{array}$ & $\begin{array}{c}\text { Rigidez } \\
(\mathrm{N} / \mathrm{m})\end{array}$ \\
\hline 0,217043 & 766945,45 & 0,204343 & 795737,55 & 0,204343 & 814275,48 & 0,204343 & 900768,18 \\
0,218313 & 764224,27 & 0,205613 & 791984,68 & 0,205613 & 812829,46 & 0,205613 & 896037,68 \\
0,219583 & 761593,66 & 0,206883 & 788351,36 & 0,206883 & 811384,27 & 0,206883 & 891450,6 \\
0,220853 & 759053,61 & 0,208153 & 784837,61 & 0,208153 & 809939,9 & 0,208153 & 887006,96 \\
0,222123 & 756604,13 & 0,209423 & 781443,41 & 0,209423 & 808496,35 & 0,209423 & 882706,74 \\
0,223393 & 754245,22 & 0,210693 & 778168,77 & 0,210693 & 807053,63 & 0,210693 & 878549,95 \\
0,224663 & 751976,88 & 0,211963 & 775013,69 & 0,211963 & 805611,72 & 0,211963 & 874536,59 \\
0,225933 & 749799,1 & 0,213233 & 771978,17 & 0,213233 & 804170,64 & 0,213233 & 870666,65 \\
0,227203 & 747711,9 & 0,214503 & 769062,2 & 0,214503 & 802730,39 & 0,214503 & 866940,15 \\
0,228473 & 745715,26 & 0,215773 & 766265,8 & 0,215773 & 801290,95 & 0,215773 & 863357,07 \\
0,229743 & 743809,19 & 0,217043 & 763588,95 & 0,217043 & 799852,34 & 0,217043 & 859917,42 \\
0,231013 & 741993,68 & 0,218313 & 761031,66 & 0,218313 & 798414,55 & 0,218313 & 856621,2 \\
0,232283 & 740268,75 & 0,219583 & 758593,93 & 0,219583 & 796977,59 & 0,219583 & 853468,41 \\
0,233553 & 738634,38 & 0,220853 & 756275,76 & 0,220853 & 795541,45 & 0,220853 & 850459,04 \\
0,234823 & 737090,59 & 0,222123 & 754077,15 & 0,222123 & 794106,13 & 0,222123 & 847593,11 \\
0,236093 & 735637,36 & 0,223393 & 751998,09 & 0,223393 & 792671,63 & 0,223393 & 844870,6 \\
0,237363 & 734274,69 & 0,224663 & 750038,6 & 0,224663 & 791237,96 & 0,224663 & 842291,52 \\
0,238633 & 733002,6 & 0,225933 & 748198,66 & 0,225933 & 789805,11 & 0,225933 & 839855,87 \\
\hline
\end{tabular}


Continuação

\begin{tabular}{|c|c|c|c|c|c|c|c|}
\hline \multicolumn{2}{|c|}{ Suspensão S1 } & \multicolumn{2}{|c|}{ Suspensão S2 } & \multicolumn{2}{|c|}{ Suspensão S3 } & \multicolumn{2}{|c|}{ Suspensão S4 } \\
\hline $\begin{array}{c}\text { Altura } \\
(\mathrm{m})\end{array}$ & $\begin{array}{c}\text { Rigidez } \\
(\mathrm{N} / \mathrm{m})\end{array}$ & $\begin{array}{c}\text { Altura } \\
(m)\end{array}$ & $\begin{array}{c}\text { Rigidez } \\
(\mathrm{N} / \mathrm{m})\end{array}$ & $\begin{array}{c}\text { Altura } \\
(m)\end{array}$ & $\begin{array}{c}\text { Rigidez } \\
(\mathrm{N} / \mathrm{m})\end{array}$ & $\begin{array}{c}\text { Altura } \\
(m)\end{array}$ & $\begin{array}{c}\text { Rigidez } \\
(\mathrm{N} / \mathrm{m})\end{array}$ \\
\hline 0,239903 & 731821,07 & 0,227203 & 746478,28 & 0,227203 & 788373,08 & 0,227203 & 837563,65 \\
\hline 0,241173 & 730730,12 & 0,228473 & 744877,46 & 0,228473 & 786941,88 & & \\
\hline 0,242443 & 729729,73 & 0,229743 & 743396,2 & 0,229743 & 785511,5 & & \\
\hline 0,243713 & 728819,9 & 0,231013 & 742034,5 & 0,231013 & 784081,94 & & \\
\hline 0,244983 & 728000,65 & 0,232283 & 740792,35 & 0,232283 & 782653,2 & & \\
\hline 0,246253 & 727271,96 & 0,233553 & 739669,76 & 0,233553 & 781225,29 & & \\
\hline 0,247523 & 726633,85 & 0,234823 & 738666,74 & 0,234823 & 779798,2 & & \\
\hline 0,248793 & 726086,3 & 0,236093 & 737783,27 & 0,236093 & 778371,94 & & \\
\hline 0,250063 & 725629,31 & 0,237363 & 737019,36 & 0,237363 & 776946,49 & & \\
\hline 0,251333 & 725262,9 & 0,238633 & 736375 & 0,238633 & 775521,87 & & \\
\hline
\end{tabular}

